Historic, Archive Document

Do not assume content reflects current scientific knowledge, policies, or practices. 


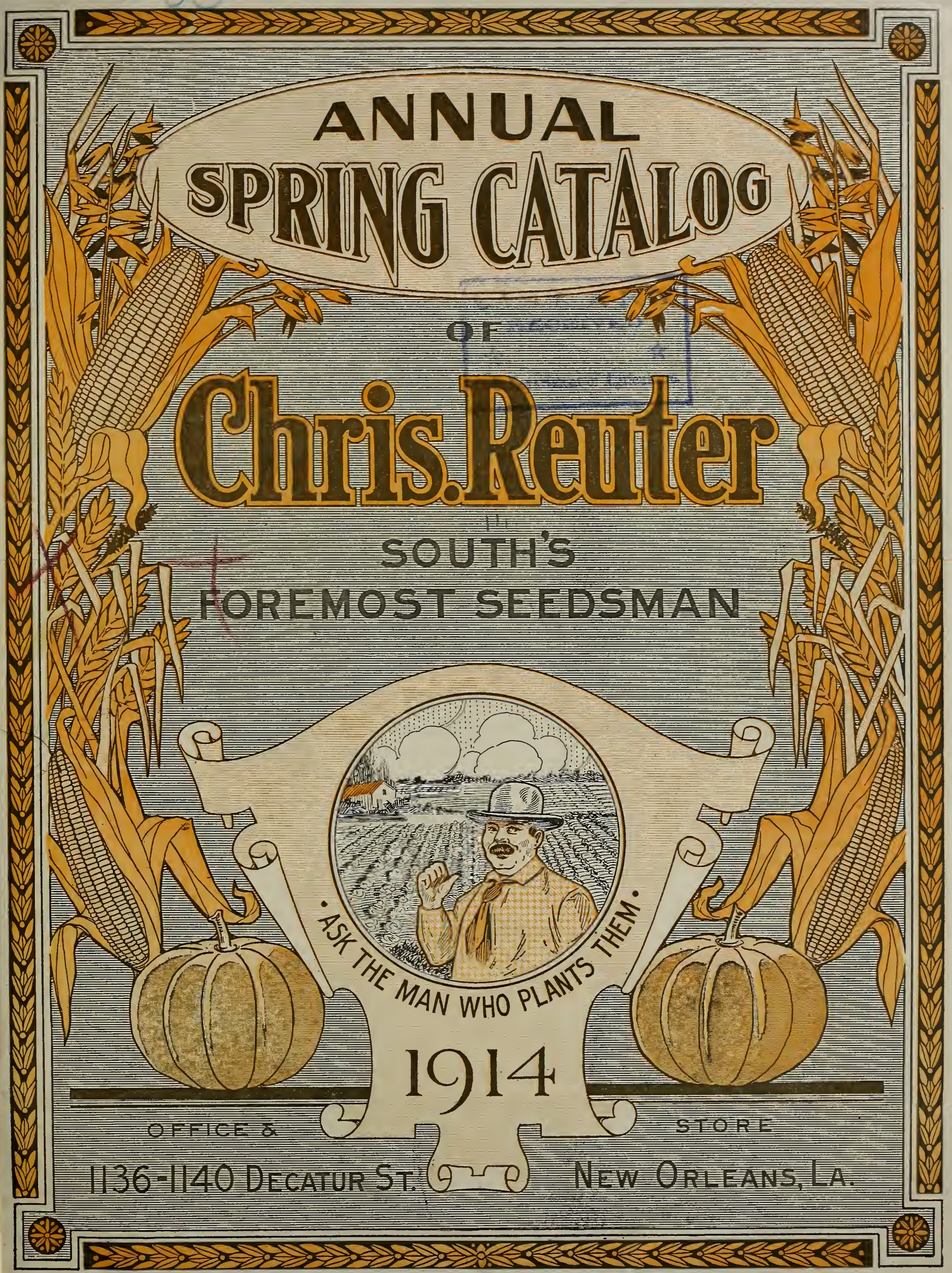




\section{THIS IS} MY

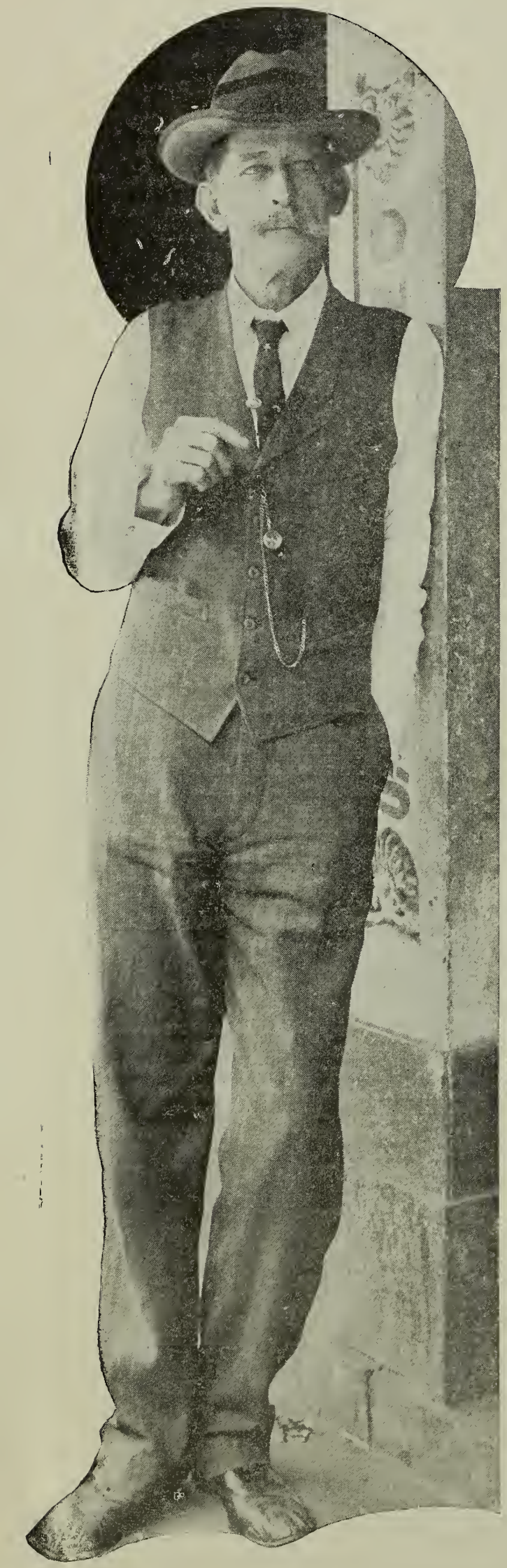

I believe it is by far the best and finest book that I have ever issued. I certainly have worked mighty hard to make it so. And I hope that you will like it; that you will find it serviceable; that it will start you on the road to planting better seeds and that you'll find within these pages ideas and information that will prove helpful in your struggle with the elements to make a living plus a generous profit from the soil.

I'd like to have you compare this new catalogue of mine with others that may come to you. Not in the fancy printing or highfalutin' art work that some of them are frequently decorated with; not in "we-claim-the-world" phrases; nor in the number of pages or the fanciest covers. But I'd like you to compare the straight-from-the-shoulder talk that $I$ have endeavored to put into this book; the kind of talk that can only come from a down-deep belief in a product that has been carefully watched from the time it was first conceived to the day it is sent on its way to the real consumer-or planter. Fancy art work and high priced printing can't make seeds germinate or come true to type; nor can they have the slightest effect on the honesty and integrity of the seedsman who uses them in his sales work. High priced books are of great help to the good seed man just as they are a snare and a blind when used by the unscrupulous. I can't afford to use high-priced catalogues for I spend too much money in every known method to supply my friends with genuine seed-and, believe me, it takes some money to make sure that you are handling the quality kind.

While I haven't spent a fortune to place this book in your hands I certainly have had to go down deep in my jeans to issue even as creditable a catalog as I believe this book to be. The valuable part of this book, to my notion, is the direct, frank, and Honest-to-God talk that I have put into it. And, back of it all is the many years that $I$ have been gaining experience from my own farming and gardening, from those practical planters and market gardeners whom $I$ am privileged to call my friends, and from every other available source that $I$ have been able to discover. The result of all these years' efforts, the best knowledge and methods in the planting, harvesting and marketing of quality seeds, is brought to you within the covers of this annual book of mine.

$I$ say to you again that $I$ hope you will find it serviceable and that from it you will get something that you can take out into the field with you and cash in on. If you find, after reading it through, that something is missing that you think ought to be in the book; something that had it been there would have helped and aided you and the thousands of other gardeners and farmers who will receive it, I certainly would thank you to sit right down and tell me what it is. If there is one thing that $I$ do enjoy and welcome it is suggestions from my friends and customers. And I'll promise you that every suggestion you send will receive the utmost consideration and courtesy.

If you are one who received my catalogue a year ago you will find many new things worth reading. One thing in particular I want to call to your attention-my new Service Bureau. I can't tell you on this page about the good that I hope will come from the establishment of this helpful bureau, but I ask you to read all about it on another page. AND BE SURE TO MAKE USE OF ITS SERVICE.

$I$ have probably written more for this page than the printer can put into it, but as a last and parting word, I ask you to read my new book, and if $I$ can help you in any way, at any time, in making your farm or garden work happier, more profitable, and more worth-while from every standpoint, you let me know how I can do it. Use the mails, the telephone, the telegraph, or the railroads-anyway just so you let me know.

YOUR FRIEND IN NEW ORLEANS,

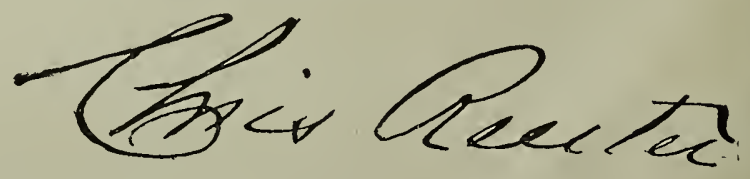


OFFICE AND STORE: 1136=1140 DECATUR STREET, NEW ORLEANS, LA.

New Order Blanks will be sent on request. Always write letters on a separate sheet from your order.

If you want information about any kind of crop, address my Free Service Bureau. Don't ask questions on this Order Sheet.

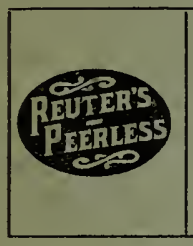

\section{THE REUTER=GUARANTEE}

I WILL REFUND to you the full price paid for any seed purchased from me should they prove defective in germination or purity when properly planted and cultivated. Of course, I cannot warrant the crop, because it is dependent on many conditions that are beyond my control. No honorable seedsman can do more, and I am only able to make this guarantee because I know that there are no better seeds in the world than REUTER'S PEERLESS SEEDS.

MY RESPONSIBILITY-Complaints sometimes made that seeds are not good may quite as often be attributed to other causes as to the quality of the

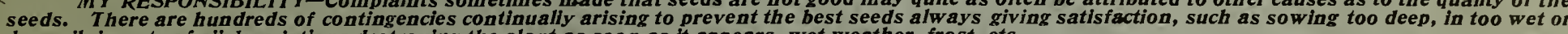
Ury soil, insects of all descriptions destroying the plant as soon as it appears, wet weather, frost, etc.

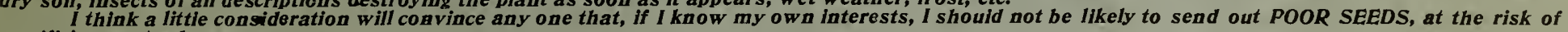
sacrificing my trade. accept the Seeds on these terms and conditions, they must be returned at once, and the money that has been paid for same will be refunded.

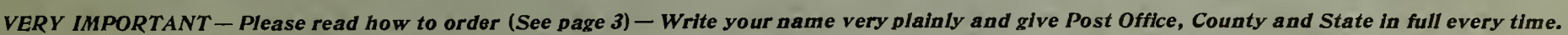

FORWARD BY $\left\{\begin{array}{c}\text { State on this line whether wanted } \\ \text { by Mall, Express or Freight }\end{array}\right\}$

YOUR NAME

POSTOFFICE

COUNTY

STATE

STREET, P. O. BOX OR RURAL DELIVERY

EXPRESS OR

FREIGHT OFFICE

\begin{tabular}{|c|c|}
\hline 1914 & ORDER NC \\
\hline AMOUNT ENCLOSED & Amt. Enc \\
\hline Money Order...\$ & Date Rc'd \\
\hline Draft or Check.\$ & Checked $t$ \\
\hline Postage Stamps $\$$ & Packed by \\
\hline Cash ... & Date Sc \\
\hline Total........ & Shipp \\
\hline
\end{tabular}

Have I your permission to substitute equal or better in nearest variety I can supply if out of variety ordered?

If I can give you better service by shipping prepaid express instead of price postpaid, may I do so?

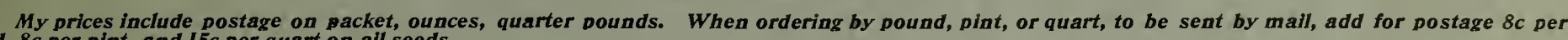
pound, $8 \mathrm{c}$ per pint, and $I 5 \mathrm{c}$ per quart on all seeds.

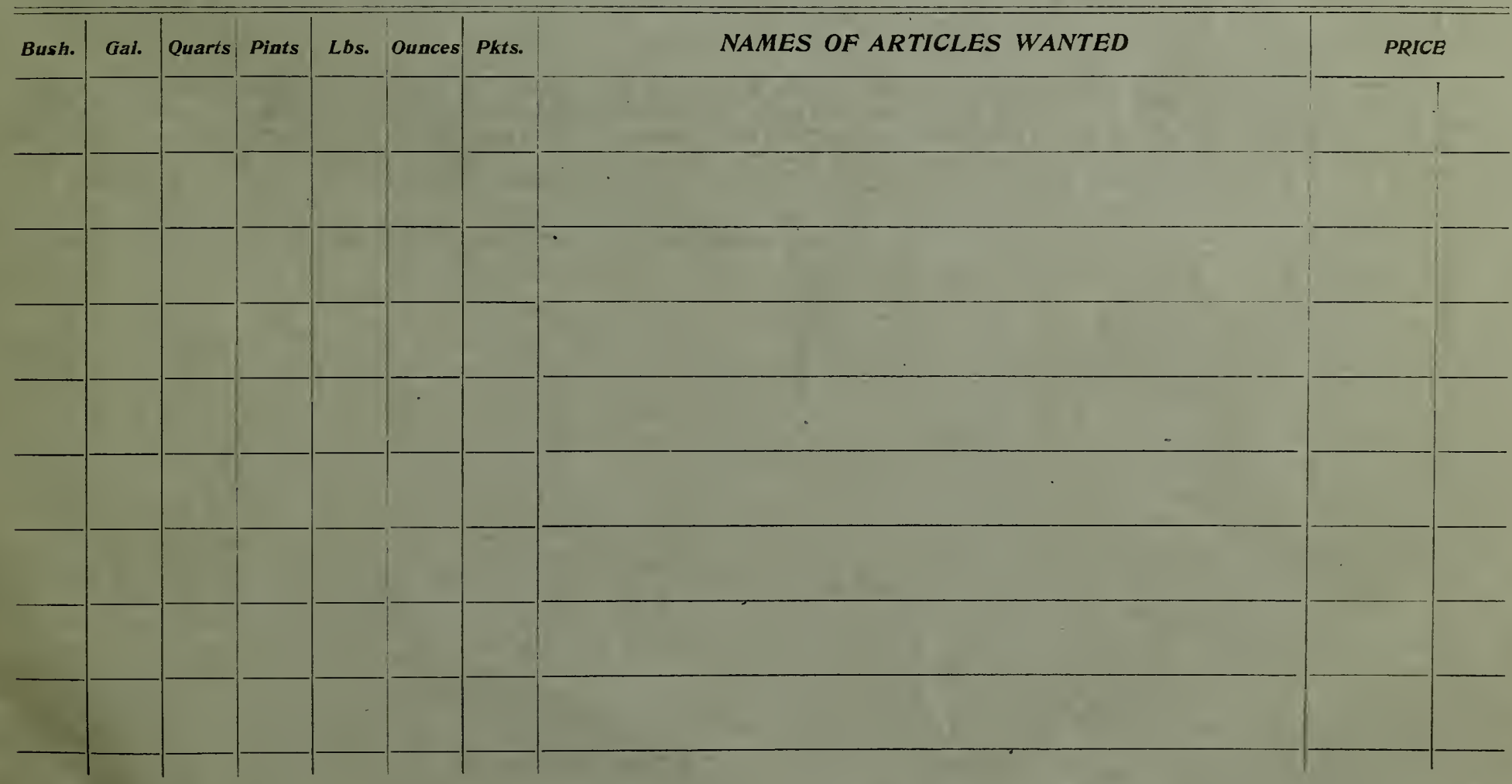

BERMUDA ONION GROWERS, see page 75 before ordering. 


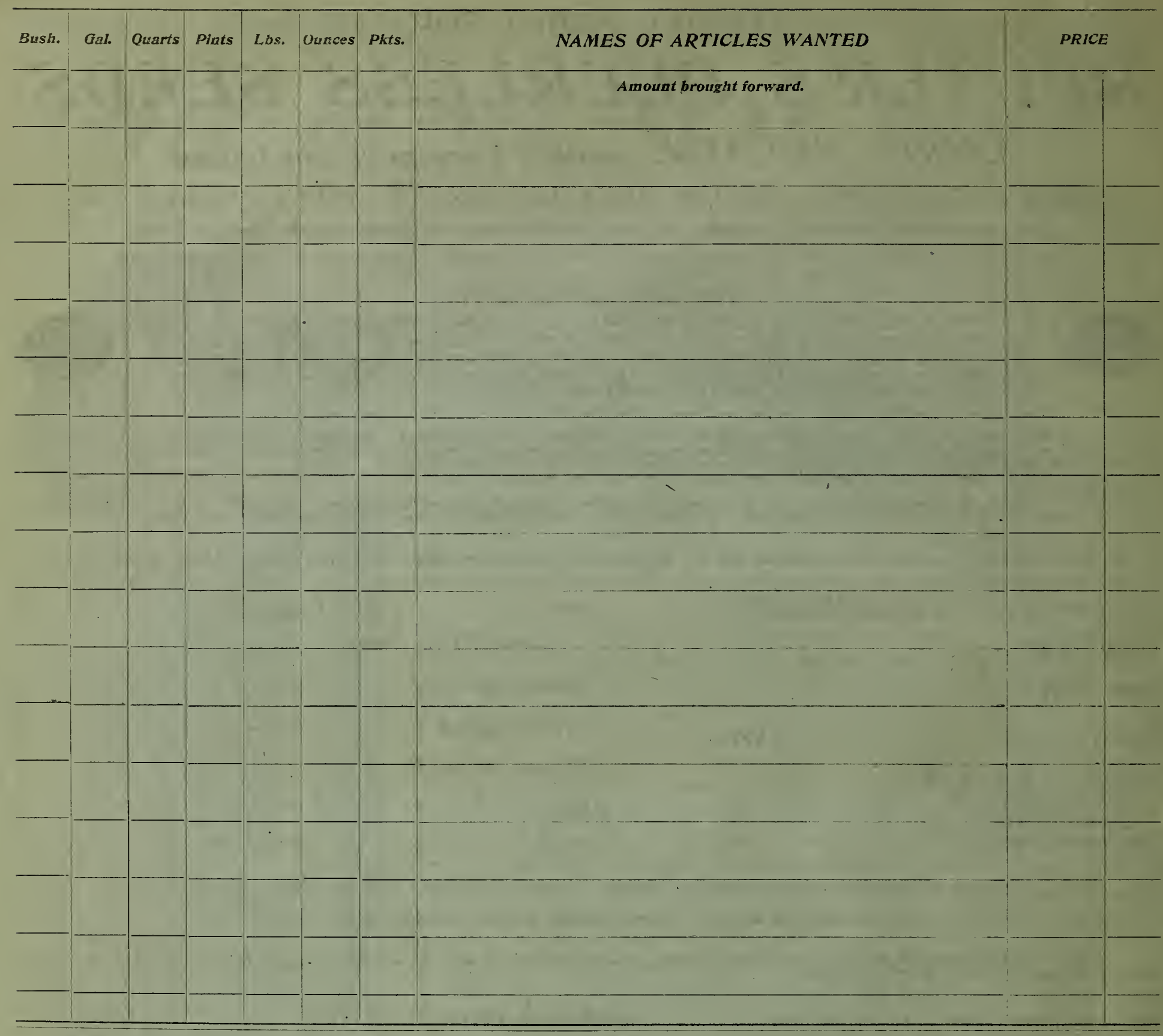

I ang anxious to obtain the rames and correct post office addresses of a number of your friends and acquaintances who are farmers and gardeners whom you think would be interested in receiving my Catalogue. I am extremely anxious that this list be made absolutely correct so far as post office, name and rural route is concerned, and in order that you may use care in compiling same, I will give you FREE an assortment of SIX of my choice strains of PEERLESS VEGETABLE SEEDS for gar: den use, if you will fill out the blank below and send it with an order for Seed or other articles selected from my Catalogue.

NAMES

\begin{tabular}{|c|c|c|c|c}
\hline POST-OFFICE & R. F. D. & COUNTY & STATE \\
\hline & & & & \\
\hline & & & \\
\hline & & & \\
\hline & & & \\
\hline & & & \\
\hline
\end{tabular}

To CHRIS. REUTER, Seedsman, New Orleans, La. - The above list of names are correct.

Please sign your name and address here: 


\section{The REUTER=GUARANTEE}

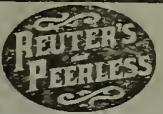

I CAREFULLY TEST all of my seeds before sending them out. Every lot of seed's must show a rigid germ= ination test, both in the soil and artificially, before it is sold. I believe that KNOWING the quality of my stock is just as important as SELLING them, and no expense or effort is ever spared to furnish my customers with seeds of UNQUESTIONED PURITY AND RELIABILITY.

I CANNOT AFFORD to knowingly sell seeds doubtful as to the quality and purity, as the bulk of my local sales are made to gardeners whose products I handle the season through.

I WILL REFUND to you the full price paid for any seed purchased from me should they prove defective in germination or purity when properly planted and cultivated. Of course, I cannot warrant the crop, becarrse it is dependent on many conditions that are beyond my control. No honest seedisman can do more, and I am only able to make this guarantee because I know that there are no better seeds in the world than REUTER'S PEERLESS SEEDS.

\section{LOOK FOR THE BLUE LABEL!}

This label, printed in blue, is attached to all packages of quarter=pounds, half=pounds, pounds, pints and quarts, and is your protection in securing genuine REUTER'S PEERLESS SEEDS.

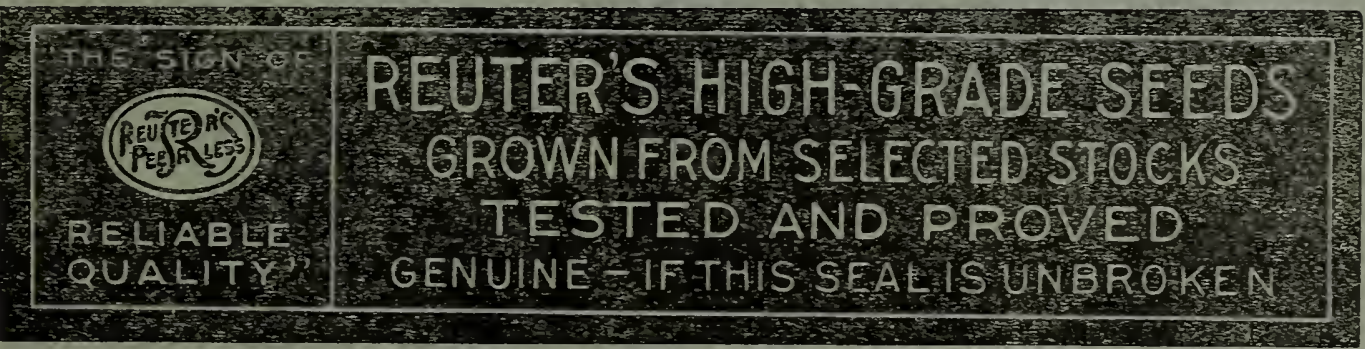

\section{GENERAL DIRECTIONS TO CUSTOMERS}

ORDER EARLY - It will greatly facilitate shipments if orders are sent in early. We aim to ship all orders the same day they are recelved, but sometimes it is impossible during the rush seagon. You may order your geeds whenever you desire, and Fe will reserve the stociss for you and shlp whenever you

ORDERs FRoM NEW CUSTOMER.-Persons unknown to us, to avoid delay, will please send remittance or satisfactory city us, to avold delay, will ples.
reference with their orders. CASF WITH orDER-Customers will please remit when or-
deting. If goods are wanted C. O. D., twenty-tive per eent, or one-fourth of the amount, must sccompany the order.

HOW TO SEND MONEY.-Remittances should be made by Post Office Money Orders, Express Money Orders, Drafts or Checks on New Orleans or New York. Where it is not possible to obtain found convenient for remitting small amounts, and can be used to advantage. Coin should not be sent iy mall.

HOJv TO ORDER,-Please be careful to sign your name, Post Office, Rural Route, and State on every order. Be sure to tell us your nearest express office, should you desire the seeds forwarded by express; or, if by freight, your railroad station; or, if by boat. our landing.

CARTAGE AND PACKIYG.-We make no charge for boxes, baskets, barrels or bags. We make no charge for cartage or delivery to any railroad station, or express office in New Orleans. nd auarter-pounds ordered at list prices will be - Packets, ounce or express. When larger quantities. sil as pount free by mail are wanted by mall or express, prepaid, customers are requested to remit elght cents per pound snd fisteen cents per quart extra. When not ordered by mail or ezpress, prepaid, as aiove dirested, we ship by express or freight at burers expense.

LARGE ORDERS, - Any Market Gardener, Association, or individual requiring large quantities of seeds, are invited to write for special prices. Although we have made our prices in this catalogue very low, yet when a considerable quantity in pounds or bushels are wanted. We a re frequently in position to supply at be distinctly understood, however, that we will not sacrifice quality in so dolng. Mall us a list of your wants, and we will submit to you our lowest cash price for the lot.

All offers and quotations are made for immediate acceptance; prices subject to change without notice and being unsold on re-

SAFE ARRIVAL OF SEEDS. - I guarantee that all seeds sold shall reach my customers in gocd condition. I earnestly urge my anything proves otherwise than on the arrival of their order if friends of all my customers, and want you to know that mail orders receive the very same careful attention that customers do over my counters. Of course, my clerks will make errors, as they are but human. When mistakes do occur. I am always anxious to rectify and make good.
MY PKICES.-My prices will compare responsible firm in this country. Better seeds cannot I guarantee every seed I sell to grow and give satisfactio

FALL CATALOGUE.-My fall catalogue will be ready

July 1st. It is brimful of seasonable seeds to plant during aut summer and autumn months. It will mean a saving to you when you are ready to buy your Onion Seed

ORDERS WITHOU' NAME OL ADDHESS. -

get hundreds of orders from my customeis

amounts, which I am unable to send out

to Iorward them. Every day or so

seeds promptly. Then I get real busy iv: th thi
to locate the order. Often it is a hard pr.

to locate the order. Often it is a hard p

you mail your order, send me a duplicate

enclosed, and in what form. I want to
want you to complain about my service-if

BUREAU SERTICE BULLETINS.- I am

as Alfalfa, Lespedeza Oats, Onions, Cabbar,

impossible for me to include all of this information in

logue, so if you are interested in any crops, I will gladl

modate you with full information regarding same, i

personally through my Service Burea

you.

FREE SAmPLES. - I am always too glad to send you free samples of Corn, Grass Seed, Garden Seeds, etc., for testing pui: me to send you these samples, for I know the quality of the sample will bring me your big order.

NON-WARRANTY. - While we exercise the greatest care to have all Seeds PURE and RELIABLE, we do not give any warranty on these terms and Ir the purchaser does not accept and the money that has been pald will be refunded.

Complaints sometimes made that seeds are not good. may quite as often be attributed to other causes as to the quality of the seeds. There are hundreds of contingencies continually arising to prevent the best seeds always giving satisfaction, such as sowing. too deep, in too wet or dry soil, insects of all descripfrost, destroying the plant as soon as it appears, wet weather,

DON'T FAIL to occasionally send us the names and addresses of jour neighbors who appreciate the vital importance of planting

\section{AND REMEMBER OUR FREE SERVICE BUREAU.}




\section{A Free Service Bureau for Your Benefit!}

I have organized and equipped at considerable expense a Service Bureau that is here for your benefit. This bureau will answer any question that you ask of it if the problem is connected with your farm or garden work. It is prepared to answer questions that arise on every Southern farm probably better than any other institution operating for the farmer's benefit, because it is not only in direct touch with every experiment station and agricultural college in the South, and the various efforts of the distribution Department of Agriculture, but it has, in addition, my thirty-four years of practical experience in gardening, farming, every word of advice that is sent you.

Although the service of this Bureau is absolutely free to my customers, do not think that you are under obligation to me when you make use of it, or that it is organized with philanthropic motives. The fewer problems you have, the more successful your crops in yield and quality, and the more profitable your farm operations, the better customer you will be for my seeds. Suppose, for instance, someone told you that Sweet Clover would be a good crop for you to plant, and suppose you knew nothing
whatever about it. If you ask this Service Bureau of mine, it will tell you ALI about Sweet Clover, and how it would fit in as a whatever about it. If you ask this Service Bureau of mine, it will tell you ALL about Sweet Clover, and how it would fit in as a
crop with your other farming efforts. It would also tell you if Sweet Clover was not the crop for You to plant. The information crop with your other farming efforts. It would also tell you if Sweet Clover was not the crop for you to plant. The information
furnished by my Service Bureau will be absolutely truthful and disinterested from my standpoint. I can't afford to have you planting some crop that will not be a success and one of profit to you. Neither wy your wour forget me if I tell you through my Service Bureau of a way to save money or labor, or some method to increase the productiveness of your soil. Now this Sweet Clover instance is but one question. I want you to ask any question, and as many questions as you like on any matter pertainindependent of the sales department of my Seed Store. That is, if you were to ask me for advice about sowing Sweet Clover. and I suggested that you do so, we would not hound you to death by trying to sell you MY Sweet Clover Seed, although I believe

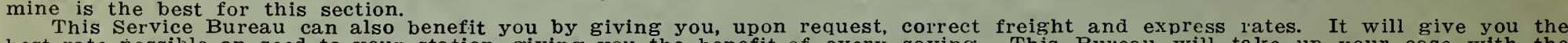
best rate possible on seed to your station, giving you the benefit of every saving. This Buleau will take up your case with the railroad or express company any time that you are overcharged, and will offer its services in obtaining a refune for you. This I personally request that you make free use of this New Department. Don't hesitate to ask questions and tell me freely
bout your problems. I will answer you frankly and specifically. This Bureau is open for business RIGHT NOW, and you can commence to fire in questions at once. Fire away!

\section{BEST SPRAYING METHODS FOR THE VEGETABLE GARDEN.}

My farmer friends in the Southern States are realizing more and more that spraying is absolutely necessary. In sections where truck crops are grown to any great extent, insect enemies and fungous diseases are more apt to cause great losses to the truckers, by damage done to the crops; it is therefore absolutley essential that the trucker use some poison to combat these enemies.

In believe in spraying, because I have tried it on my own seed farms, and have induced hundreds of the truckers in my section to do the same thing. I know that it is a necessity. I speak from experience, not from

successful gardening. It is just as important to spray properly as it is to buy good seeds. beoin to think of spraying. It will then Don't wait until the plants are half dead from the rave make your mixtures at home. Get a thorough understanding of the best methods of mixing and the proper time to spray.

Rotation of Crops is of the utmost importance in the control of insect and fungous diseases.

Fertilizers, applied liberally, will often stimulate plants attacked by insects and disease to outgrow the injury.

they first feed in the spring, is a leading principle in the control of these insect pests.

Protect the Birds-they are best friends of the farmer and gardener.

Leaf-eating insects should be killed by the use of stom
Sucking insects can only be killed by contact poisons.

Cut ing ins and grasshoppers may be destroyea by using a poisoned bran mash. I generally use about a quart of molasses or half pound of sugar per gallon of water and use enough to dampen 50 pounds of bran. Add $1 / 2$ to 1 pound of Parish Green, sprink-

\section{A FEW GOOD FORMULAS FOR INSECTICIDES AND FUNGICIDES.}

BORDEAUX MIXTURE.

Copper Sulphate (blue vitriol) $\ldots \ldots \ldots \ldots$ pounds

Water to make 50 galions.

Dissolve the sulphate in hot water, using wood or earthen vessel. Slack lime in tub, using only enough water to insure stir. Pour milk of lime thus made into sulphate solution. Then add water to make fifty gallons. Strain, stir thoroughly
apply. Mixture should always be made fresh before using.

AMMONIACAL COPPER CARBONATE.

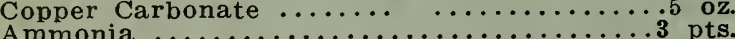

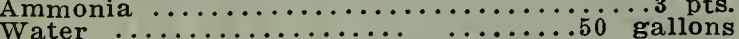

Dissolve carbonate in ammonia, and keep in glass, stoppered bottle. Dilute to required strength. Solution loses strength on
standing. For use where Bordeaux will spot fruits late in standin
season.

\section{CORROSIVE SUBLIMATE.}

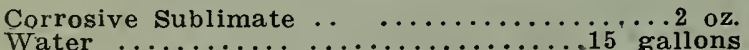

Dissolve corrosive sublimate in 2 gallons of hot water; then dilute to 15 gallons and let stand 5 to 6 hours. Place Seed Potatoes in sack and immerse for $11 / 2$ hours. Dry before planting. Caution-Corrosive Subl
should be used in handling.
Forma

FORMALIN.

Used for the same purpose as corrosive sublimate but not poisonous. Immerse potatoes 2 hours; dry before planting. For soil dren.

\section{REUTER'S TOBACCO DUST.}

Every market gardener and trucker who grows vegetables to any great extent has to fight bugs and worms continuously. I have found that Tobacco Dust is an excellent remedy, and it is used quite extensively by the gardeners in New Orleans and vicinity with good results. They like it better than Paris Green because it is not as dangerous and really seems to drive the worms away. At the same time, Tobacco Dust does not injure the plant or its growth as does other insecticides that contain arsenic in one form or another. I send quite a lot of Tobacco Dust down to my farm every year to dust the Cauliflowers, Cabbage, etc. Then it is an excellent fertilizer also, and the more we apply the better it is.

I want you to order some Tobacco Dust this year with your Seeds. I don't want you to wait until the plants are full grown and the insects are eating them all up, and then hasten to write me, saying, "Friend Reuter. ship me a hundred pounds of Tobacco

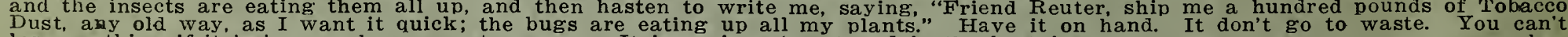
lose anything if it is in your barn ore store-room. It is an investment and is the best insurance you can carry on your crop when the bugs begin to get real hungry. It is just the kind of insecticide you want-easy to use not poisonous. a safe, sure bug destroyer. The cabbage worm will be looking for a new home when you begin to dust some of this tobacco around your plants.

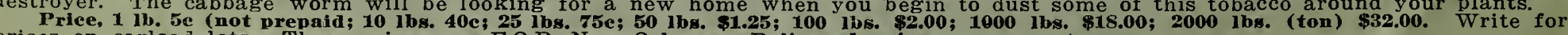
prices on carload lots. These prices are F.O.B. New Orleans. Delivered prices on request. 


\section{JUST WANT TO SAY THIS TO YOU!}

No doubt you have received plenty of catalogues from other seedsmen, praising their stocks to the highest, and claiming that no one else sells seed as good as they. do. You gave one of these houses an order, and when you received the seeds they proved no better than the kind you have been buying from your town merchant. You were disgusted, of course, with the seeds and service, and don't want to believe anything you see in the present seed catalogues. I am in sympathy with you and agree fully with you. You have lost faith in their descriptions of various vegetables and realize that the beautiful words written by seedsmen to describe some vegetables are false and without foundation. The seeds you bought produced something far away from the product you thought you were buying. To tell you,the truth, more than half of the seed dealers don't know what they are talking about when they write up a description on some vegetable and farm products. They are absolutely ignorant of the growth, culture, and habits of the plant. They are unfamiliar with the seeds themselves, and only sell them to make a profit. Whether the seed produces as they say or not is of little interest to them. The profit of the sale more than pleases them, and they let you worry.

Then again, there are other seedsmen who do business in big cities remote from growing sections. Some of them have never seen a seed crop grow and cannot tell you the difference between Japan Clover and Alfalfa, or a beet and a carrot. They are not at all acquainted with the numerous

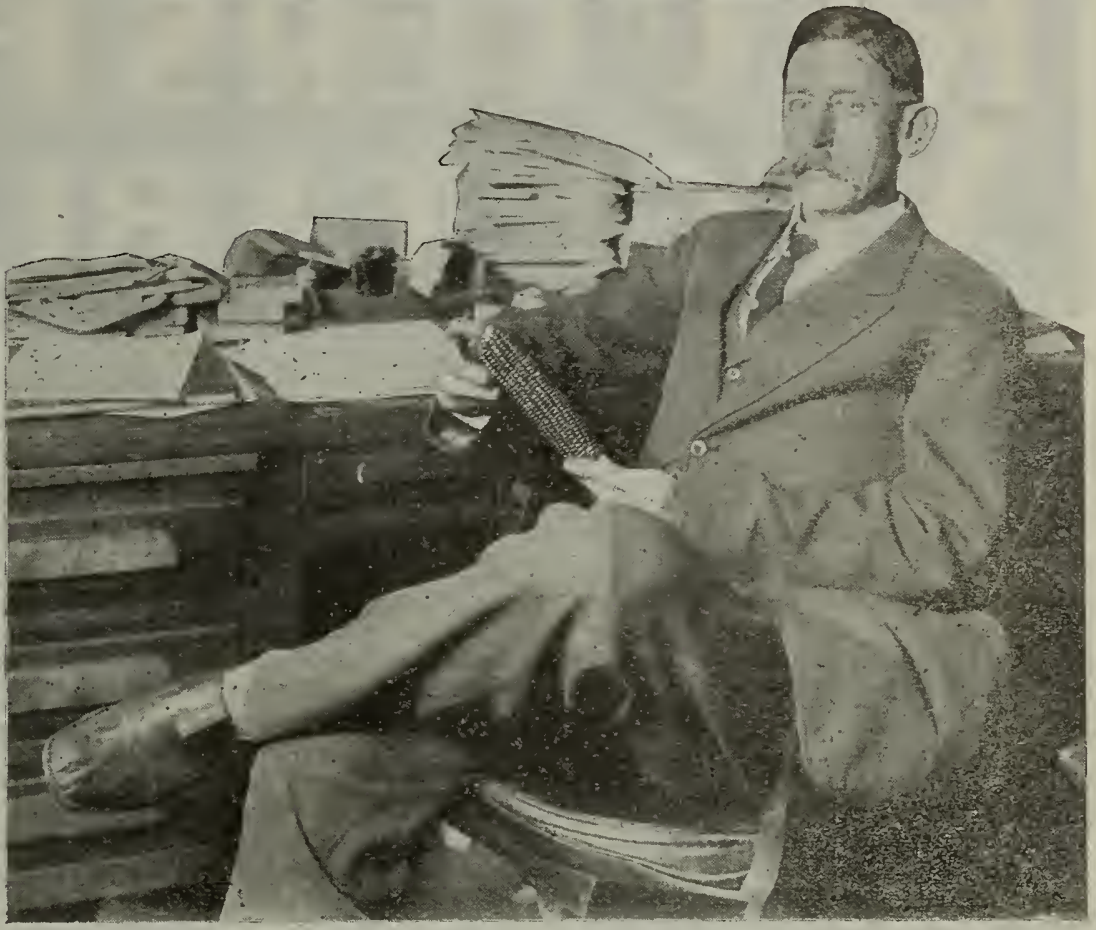

CHRIS. REUTER

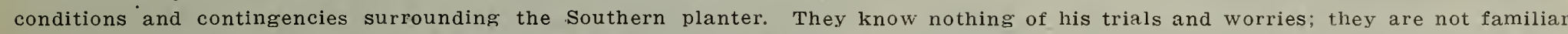

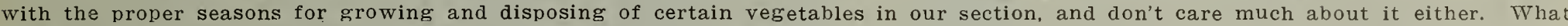

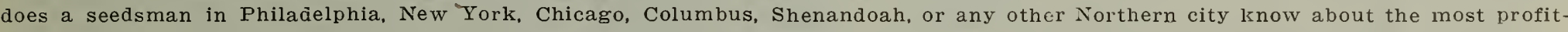

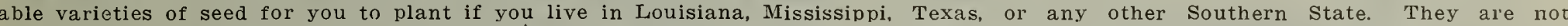

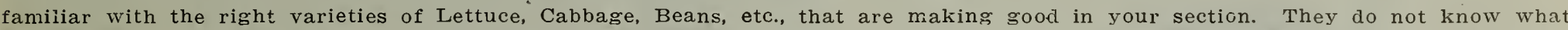

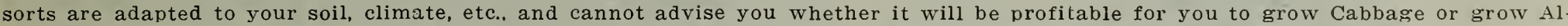

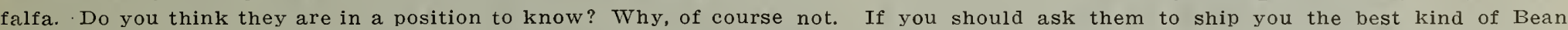

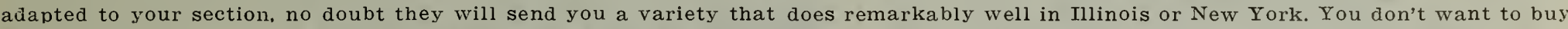

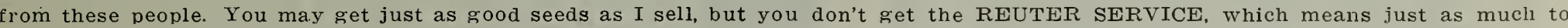

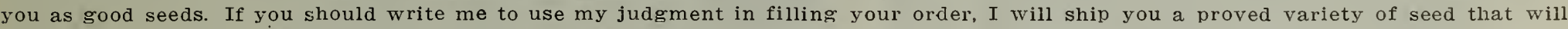

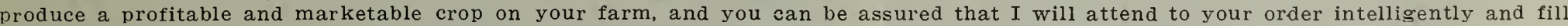

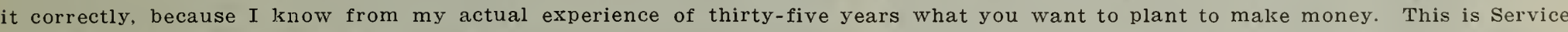
-plus good seeds and reasonable prices.

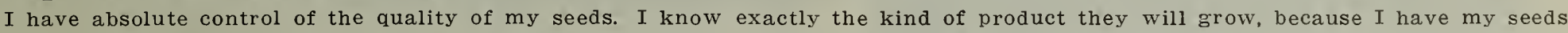

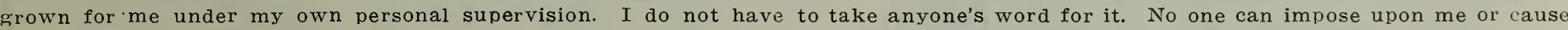

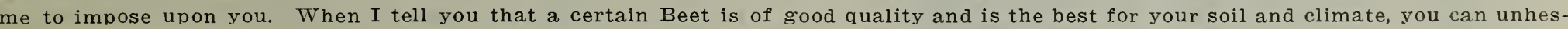

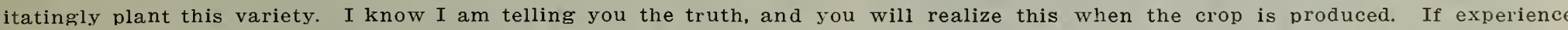

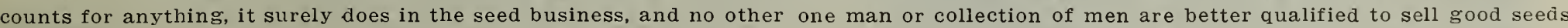
than I am.

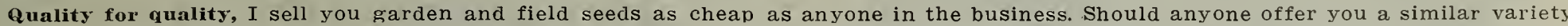

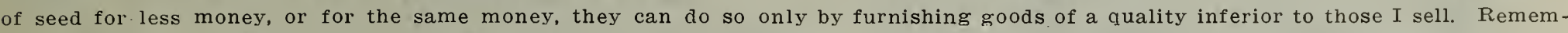

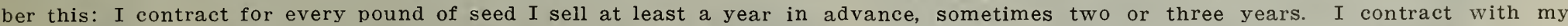

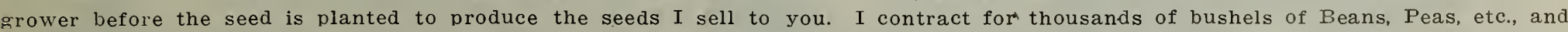

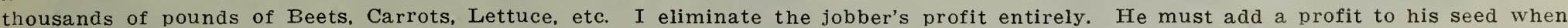

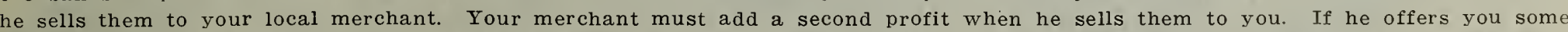

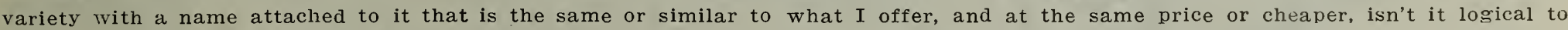
think that something is lacking?

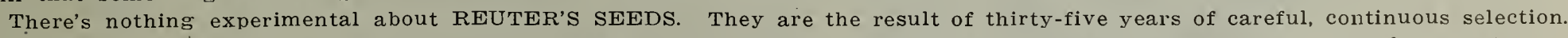

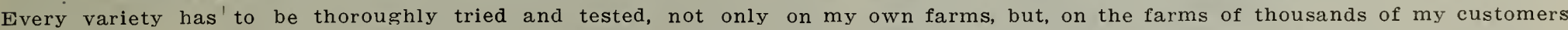

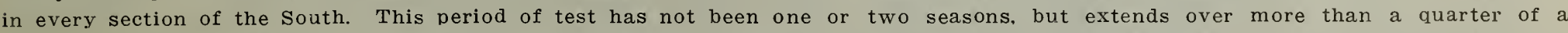

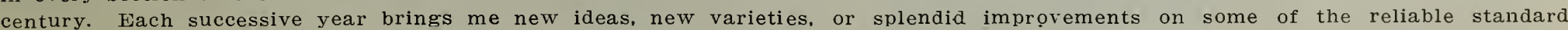

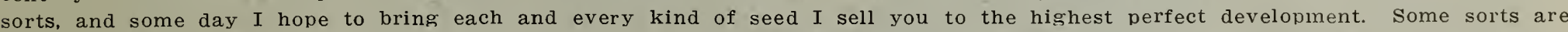

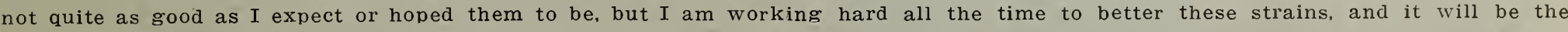
work of years, not days.

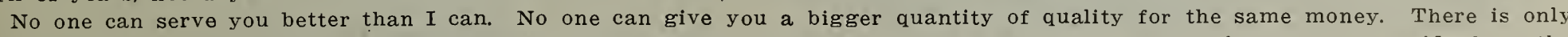

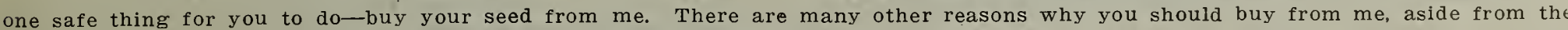

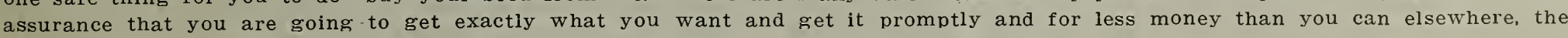
unequaled liberality of my Guarantee on the other page should be the final deciding factor. No other seed house in the South offers you such protection. You simply can't lose a cent when you deal with me. Read my GUARANTEE. Plant my Seeds, and if they don't grow, test this Guarantee, which corresponds to the STERLING MARK ON SILVER. I will give you nothing but quality, plenty of good value, and sound helpful advice and service, such as you have never as yet experienced. Your final verdict should be: "I will plant Reuter's Seeds this spring, and continue
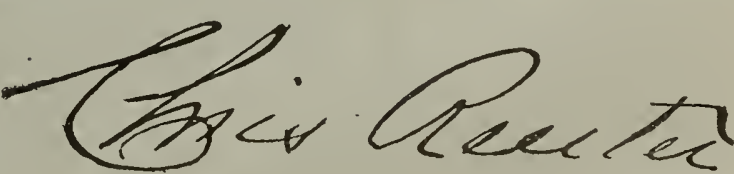
to plant them as long as I live." 

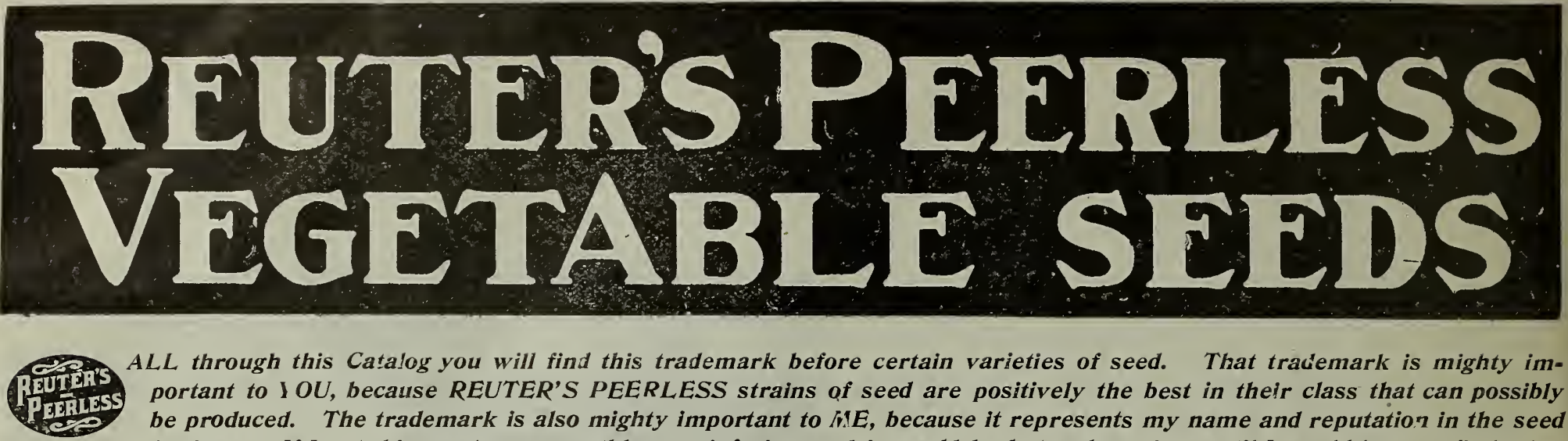

ALL through this Catalog you will find this trademark before certain varieties of seed. That tracemark is mighty important to IOU, because REUTER'S PEERLESS strains of seed are positively the best in their class that can possibly be produced. The trademark is also mighty important to $I E$, because it represents my name and reputation in the seed business. If I put this mark on a worthless or inferior seed it would be but a short time until I would have to find other patrons to maintain my business and I would eventually have to quil the trade entirely.

I will personally stand back of every strain and variety that bears this trademark. I develop, test out for several seasons, and carefully inspect the seed crops that supply my stocks. I know without a doubt that the seeds I offer with this mark are first=class in every particular and the very best for the purpose and climate and marketing requirements.

I have had remarkable opportunities to seek out and find the most suitable variety for every purpose, for I have bought and shipped vegetables and farm produce for many years and I have never overlooked the wonderful opportunities for gathering from the growers themselves the strong points, the weak ones, and the various qualifications of the many strains and varieties.

Of course, it is impossible for me to grow all of the seed that my extensive trade calls for, but wherever my seed stocks are grown for me, I personally select the growers and make my contracts accordingly, and I constantly. keep in close touch with the crops from the time the seed is planted until iny seeds are gathered. And then the seed comes to me and I thoroughly and rigidly test it for germination and purity. No seedsman could be more careful in selecting his stocks. No seedsman values his reputation higher than I do the good name I have built up among the market gardeners and farmers of the South. This is well shown by the reputation I enjoy right at home, for THREE OUT OF EVERY FOUR of the New Orleans market gardeners plant my seed exclusively, and do so year after year. No finer vegetables are sold in any market in the world than those grown and shipped out of New Orleans. And the great majority of the vegetables bought by the housewives of New Orleans are produced from REUTER'S PEERLESS VEGETABLE SEEDS.

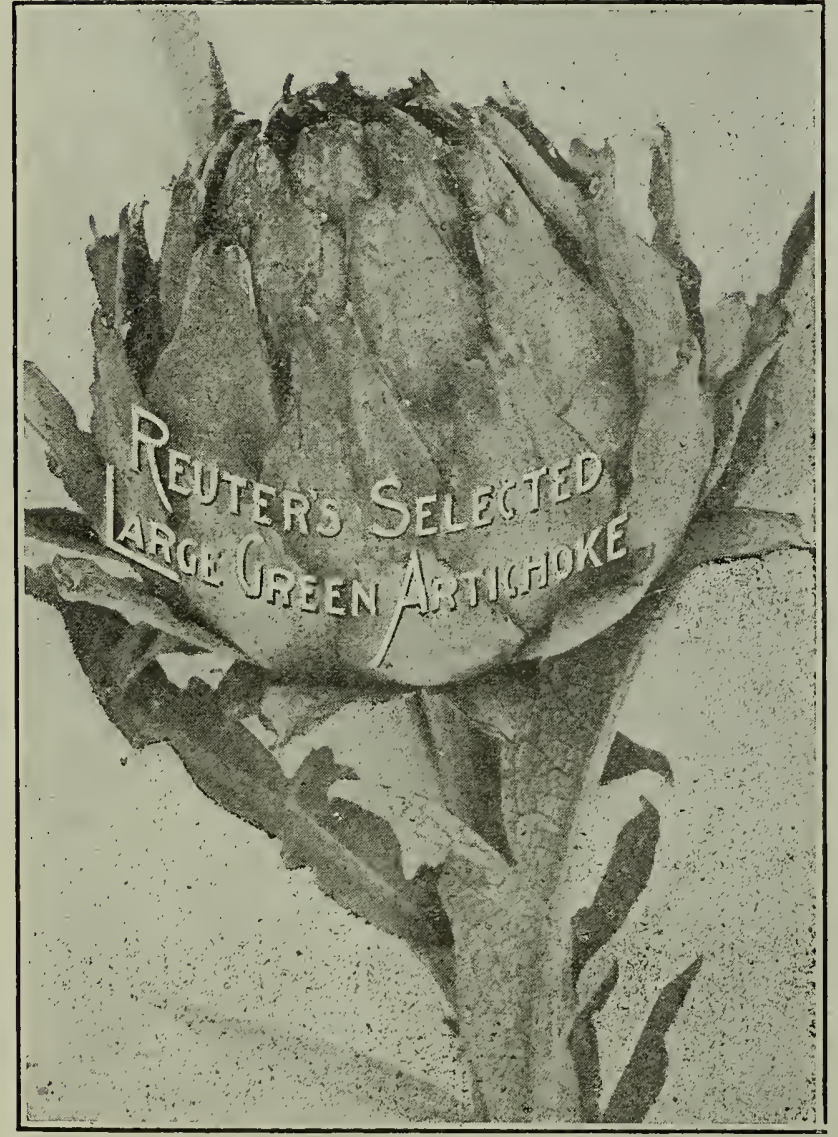

So I ask you to remember this trademark. Whenever you see it before a variety you can bank on that variety being the finest strain that you, or I, or any other person can produce.

\section{Artichoke Seed and Roots}

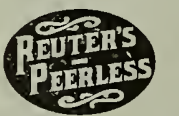

Green Globe-The best sort for general use and extensively cultivated in the vicinity of New Orleans. The best method is to have them propagated from suckers, which the fall and early winter and plant them four feet apart the fall and early winter and plant them four feet apart and spaded or plowed between them, at the same time the suckers and spaded or plowed between them, at the same time the suckers should be taken of. Can also. be sown from seed. Sow in drills about one foot from row to row, cover with about one-half inch of about one foot from row to row, cover with about one-half inch of earth. The follo

Green Globe Artichoke Plants, per-100, $\$ 2.00$; per 1,000, \$15.00; per $10,000, \$ 125,00$.

Seed, per oz. 35e; 1/4 lb. \$1.00; $1 \mathrm{~b}$. \$3.50.

\section{Jerusalem Artichokes}

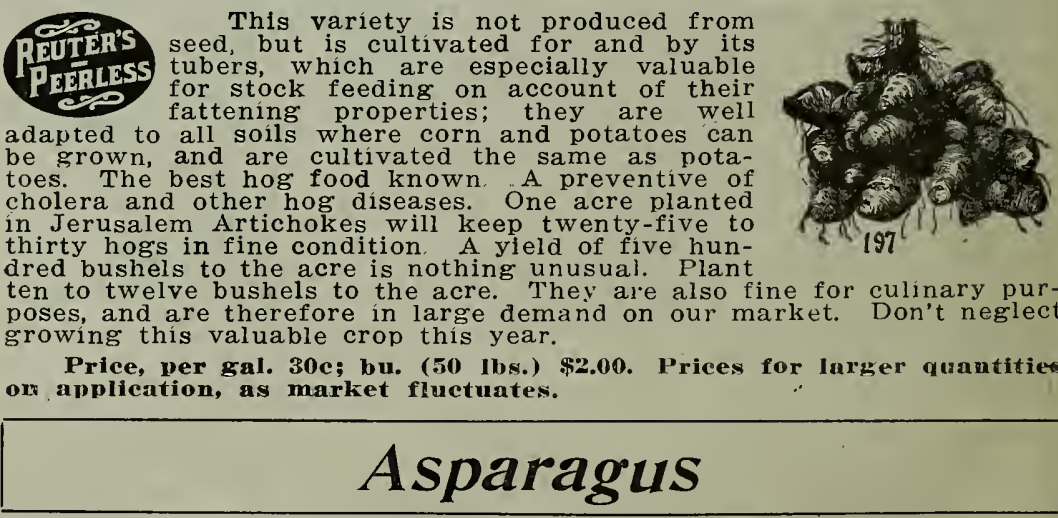

Culture-Sow the seeds early in the spring and give good When two years old, transplant into permanen d be well and deeply manured, trenched about in the rows, spreading out the roots and coveront inches. On the paproach of winter, cover composit, fork the beds early in the spring and or composit, fork the beds early in the spring and sh brine will answer the same purhave had a frost. If cut before,
up young shoots, which will weak-

\section{REUTER'S GIANT ARGENTEUIL-French Grown}

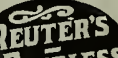
we have found this sort to excel, both from a poin of productiveness, tenderness, earliness, and resistshoot or spear is often two inches in diameter and twelve inches long, of which every part when boiled is tender and delicious. It succeeds well in nearly all soils anc

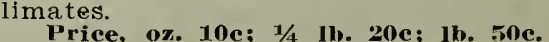

Price, oz. 10c; $1 / 4,1 \mathrm{l} .20 \mathrm{2} ;$ lb. 50e.
Roots: 100, $\$ 1.00 ; 1,000, \$ 7.00$ (two years old). 
Grown in Sections Immune

From Disease

\section{Northern Grown BEANS}

Varieties

Selected

for Profit

My stocks of Bean Seeds are grown for me under special contract by the most critical growers of this famous Vegetable for seed purposes in the world. These growers are fortunately situated in sections where the soil and climate have proved to be per fectly adapted to the supreme growth and development of Bean Seeds. The stock seeds are bred each year on these seed farms-not purchased from haphazard dealers to be planted with little or no care. They are TRUE=TO=TYPE, every field being carefully rogued and cleared of all off types; the chances of mixture are practically eliminated; the types are improved year after year by the most careful, painstaking and systematic efforts on the part of my growers. They are all VIGOROUS, HEALTHY, PROLIFIC SORTS, as the seed is almost free from blight or anthracnose, the latter the most serious disease that wroughts havoc upon your crop. The United States Department of Agriculture urges you to obtain your seed from seedsmen who can offer you disease=resistant strains, which only come from careful growing and breeding of typer in restricted sections that are POSITIVELY IMMUNE FROM THIS DIS= ASTROUS DISEASE. This process of development offers less immediate profit to the grower of good bean seed, but you and I real= ize that the gardener who grows beans for profit in the South must be careful of the source of his seed supply. That is why I sell thousands of bushels of the finest bred stocks to the most discriminating gardeners in the South. You might be paying me twenty= five to fifty cents more per bushel than you can buy from your local dealer, but the difference in the price is insignificant when you carefully consider the range in quality and the resulting profits. Culture-For the earliest crop they should be planted after all danger of frost is past. Fur a succession they should be planted
about every two weeks in rows eighteen inches apart; drop a bean every two or three inches; hoe irequently, always, however, when the vines are dry-drawing the soil up towards the plants. Bush Beans planted in this latitude during the months of June and July will not produce very much. abundantly until killed by the frost.

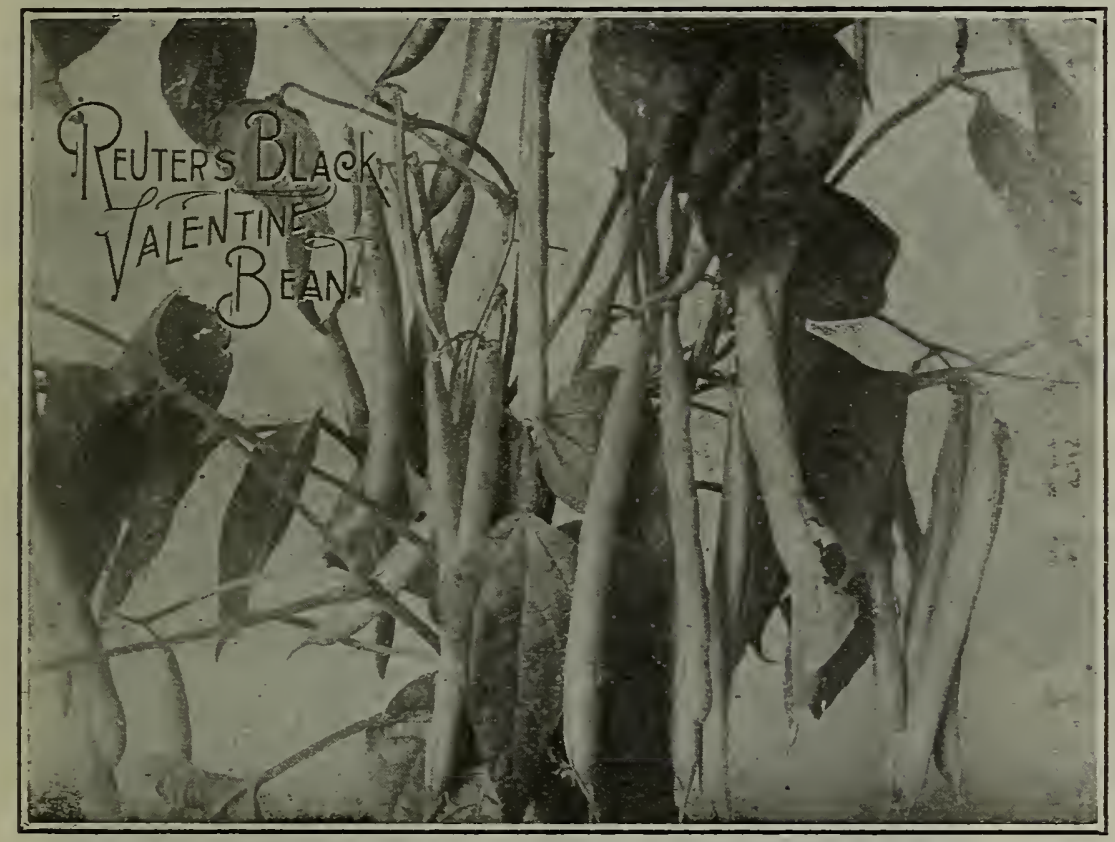

\section{BEANS, Leading Sorts}

Bush or Snap Green=Pod Varieties

REUTER'S BLACK VALENTINE

\section{Unsurpassed for Market}

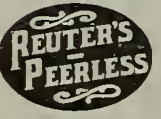

Ready for picking in 45 days from planting. A prolific and continuous cropper. A roundpodded Bush Bean of extra fine quality.

The finest bush variety in cultivation. A extremely popular with the market gardeners in the South. owing to its hardiness, rust resistance and prolificness. The pods are perfectly round and straight, of a beautiful green color. It is suited for both spring and fall planting. and is universally pronounced as the best for shipping, as well as for local

Price, pkt. 5c; pt. 20c; qt. 30c; gal. \$1.00; peck \$1.75; bu. $\$ 6.00 ; 5$ bu. and more at $\$ 5.75$ per bu.

REUTER'S GIANT STRINGLESS GREEN POD

REUTER'S EXTRA EARLY REFUGEE - Very Early

A green-podded bush bean that is widely known in this section. It is one of the best green-podded sorts for the market gardener, as it stands shipment
well. Vines are a little smaller, more upright, and leaves a little larger than those of the Late Refugee, or 1,000 to one. It is about ten days earlier than Fine for both early and late planting.

this variety. Price, pkt. Jc; $\$$. pt. 15
u. and more. $\$ 4.75$ bu.

\section{REFUGEE, OR THOUSAND \\ TO ONE-Round Pod}

A popular market gardener's variety. Similar to the Valentine but pods one-third larger, tapering. to a slender point. Pods are of attractive appearhardy. good for both early and late planting and an immense producer. Owing to its dense foliage it will immense producer. Owing to its dense foliage it will stand a light frost without injury to the pods. We highly It is also immune from bean diseases.

Price, pkt. 5c; pt. 20c; qt. 30c; gal. \$1.00; beck \$1.75; bu. \$6.00; 5 bu. or

REUTER'S FRENCH MARKET-Round Pod A Remarkably Early Bean, Exceedingly Prolific and of Fine

An extra round green-podded bush bean of exceptionally fine quality. It is extra early and a prodigious cropper. The plants are of robust. compact habit, and pronuce perfectly round straight, for home garden, and is a favorite with the New Orleans market gardeners.

Price, pkt. 5e; pt. 20e; qt. 30e; қal. \$1.00; peck $\$ 1.75 ;$ bu. $\$ 6.00$; 5 ตn. or more, $\$ 5.75$ bu.

Note-The prices, except for packetw, de not include postanc. A very productive, long round-podded variety, producing large
pods, measuring five to six inches in length; very tender and
absolutely strignless, and of the finest flavor.
Price, pkt. Jc; pt. 15c; qt. 25c; \$al. 90c; peck \$1.50; bu. \$5.00.

REUTER'S LONGFELLOW

The pods are productive. Ripens uniformly and of the finest quality.

Price, pkt. 5c; pt. 20c; qt. 30c; gal. \$1.00; peck $\$ 1.75 ;$ bu. $\$ 6.00$. BURPEE'S STRINGLESS GREEN POD
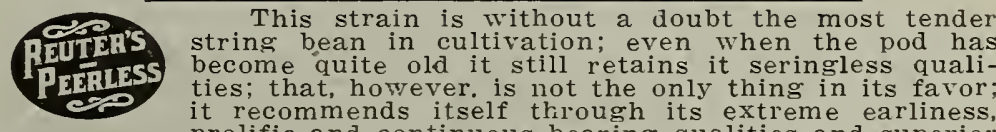

flavor. A leading sort for the home garden, and extensively cul-

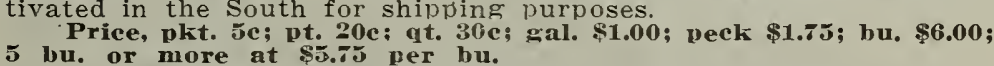

\section{REUTER'S EXTRA EARLY RED VALENTINE}

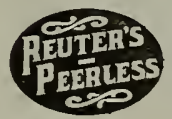
Dwarf Snap Bean in America. Very hardy and vigor-
ous in growth. Round. thick, solid pods; tender, and
of the very finest flavor. A first-class market variety
and extensively grown by truckers throughout the South for this purpose. Our strain is the earliest, hardiest and most uniform selection on the market, and the large number of orders for

Price, pkt. Jc; pt. 16e; at. 25e; gal. S0c; peek $\$ 1.40$; bu. \$5.00; 5 bu. or more $\$ 4.75$ bu.

\section{REUTER'S BEST OF ALL-FLAT PODS}

A highly desirable sort for private garden use. The hardy vigorous vines produce an aboundance of very straight, handsome pods, which, when fit for use as snaps, are very brittle and of a peculiar deep green color. A prime favorite with many

Price, pkt. Je; pt. 15c; qt. 25c; gal. 90c; peck \$1.50; bu. \$5.00. If by mail, add se per pint and tăe per quart to the price. 
Prices Do Not

Include Postage

\section{BUSH OR SNAP BEANS}

Green Pod

Varieties

\section{HODSON GREEN POD}

This variety is practically identical with the Hodson Waxwith the exception of the color, which is green instead of yellow. It is an exceptionally strong and robust grower. Many of the

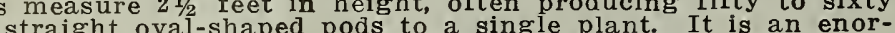
mous yielder, unaffected by rust or blight. The green pods, when packed young, are entirely stringless. It deserves a trial.

Price, pkt. 5e; pt. 15e; qt. 25e; gal. 90c; peck \$1.50; bu. \$5.00. ROUND YELLOW SIX WEEKS

Very similar to Long Yellow Six Weeks as to vine, with pods shorter and much more thick and fleshy, about one week later, being ready for table 57 days from planting. Seed round, yellowPrice, pkt. 5e; pt. 15e; qt. 25e; gal. 90e; peck \$1.50; bu. \$5.00. NEW BOUNTIFUL BEAN-A Flat, Green Podded Bush Bean Remarkably Prolific and Continuous Bearer. Absolutely Stringless This superior variety is a distinct improvement in green bush beans, and has become exceedingly popular wherever known. The plant is remarkably handsome and of thrifty growth, tremely practically rust and mildew proof. It is very hardy, exeeks; it is the first to give pods fit to pick in the spring, and last to yield edible pods in the Fall.

But the crowning merit of this grand Bush Bean is in the rich green pods, which are of immense size, thick, broad, extra long, very uniform in shape, solid, meaty, and of high quality, meltingly tender and having a delicious flavor exclusively their free from any tough, membranous lining, even when matured.

Price, pkt. Je; pt. 15e; qt. 25e; sal. 90c; peck \$1.50; bu. \$5.00.

\section{EARLY LONG YELLOW SIX WEEKS}

Early market sort; full, flat, green pods. A good yielder and vigorous grower.

Price, pkt. 5e; pt. 15e; qt. 25e; gal. 90c; peck \$1.50; bu. \$5.00.

\section{EARLY MOHAWK-Flat Pods}

A long. flat-podded, very productive variety, withstanding a greater degree of frost and cold weather than any other sort, and on that account is preferred for first planting.

Price, pkt. 5e; pt. 15e; qt. 25e; gal. 90c; peck $\$ 1.50$; bu. \$5.00.

\section{KEENEY'S STRINGLESS GREEN REFUGEE}

A remarkable new bean. The originator of this new strain of Green-Pod Refugee. Mr. Keeney, has been working for more than twenty years to get the string out of the old Thousand-toOne Refugee Beans, and has succeeded in eliminating it entirely. The plant grows to a large size and is enormously productive, one plant having borne 56 well-developed pods and 16 small ones, and had the earlier pods been picked as soon as suitable for use this plant would doubtless have produced more than 100 good pods. The shape is round, size medium to long, slightly curved, medium green in color, resembling the Late Refugee in this respect, also in the season, which is practically the same. The variety a thorough trial.

Price, pkt. 5e; pt. 20c; qt. 30c; gal. \$1.00; peck \$1.75; bu. \$6.00.

\section{BROAD WINDSOR}

Also known as Fava or Horse Bean. An English bean used in the dry state shelled. Plant in drills two or three feet apart every six inches one bean, during November. Will not produce as well if planted in the spring.

Price. pkt. 5e; pt. 10e; qt. 20e; gal. 65e; peck \$1.25; bu. \$4.75.

\section{WAX OR YELLOW=PODDED BEANS $\mid \begin{gathered}\text { Bush or Snap } \\ \text { Varieties }\end{gathered}$}

\section{WARDWELL'S KIDNEY WAX}

Market Gardener's' Favorite. The Standard, Flat, Wax-Podded Variety

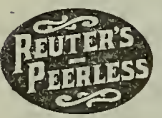
variety possessing exceptional merit. In many to the Louisiana and other Southern States enormous acreages are annually planted, with great profit most hardy of the wax varieties. The pods are long. ntirely stringless and brittle. It is enormously productvie.
Price, pkt. 5e; pt. 20c; qt. 30c; gal. \$1.00; peck \$1.75; bu. \$6.00. REUTER'S HODSON WAX

Unsurpassed for Shipping, Rust Resistant, Enormously Productive, Superb Flavor This superior variety has become very popular with the market gardeners throughout the South, especially in the Lower Coast section of Louisiana. of this splendid sort is exceptionally fine. The pods are straight and average about seven inches in length; absolutely rustless and freer from blight. The vines are the pods from the hot sun, and renders them exceptionally tender, brittle, and of very fine quality. It is not an extra early
sort, but for a main crop it cannot be equaled. SURE CROP STRINGLESS WAX BEANS

This is a grand new variety of Dwarf Wax Beans originated by Mr. Keeney of New York State, and introduced into the Southput it is entirely different in quality. It certainly deserves a trial. The plant grows to a medium size, and, having a strong, thick stem, stands up well even during a long season of stormy weather, thus protecting the pods from less at all stages of development. It is extremely productive, bearing extra large pods, measuring 7 to $7 \frac{1 / 2}{2}$ inches long, more than one-half inch wide and nearly one-half inch thick. Its account we predict an enormous demand from, the critical will stand more adverse weather conditions than any other wax this feature alone sufficient to war-

Price, pkt. 5e; pt. 25c; qt. 40e; gal. \$1.50; peck \$2.25; bu. \$7.00. REUTER'S WEBBER WAX

Wax Bean of distinct character. This bean is quite Tangipahoa Parish, La., grown extensively by many of gardeners who claim that it resists disease and drouth effectively, and, in addition, is immensely prolufic and a splendid shipper. I have secured a small lot which I can offer The pods are of an exceedingly bright yelow color, handsomer in this respect than any other wax bean; 政 Price, pkt. 5e; pt. $20 \mathrm{c}$; qt. 30c; gal. $\$ 1.00$; peck $\$ 1.75$; bu. $\$ 6.00$
bu. or more at $\$ 5.75$ per bu.

The price on beans, except for packets. do not include postage.

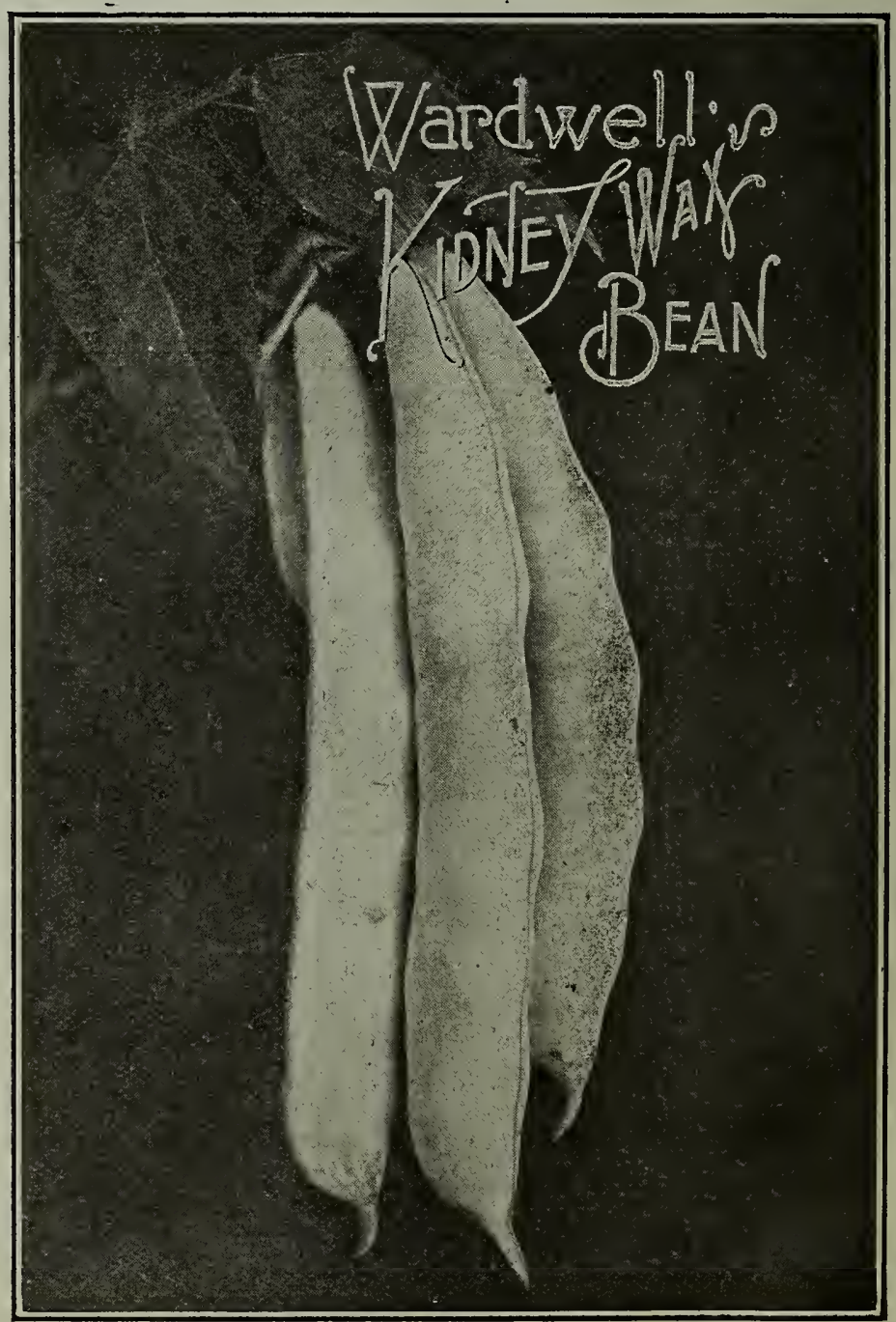




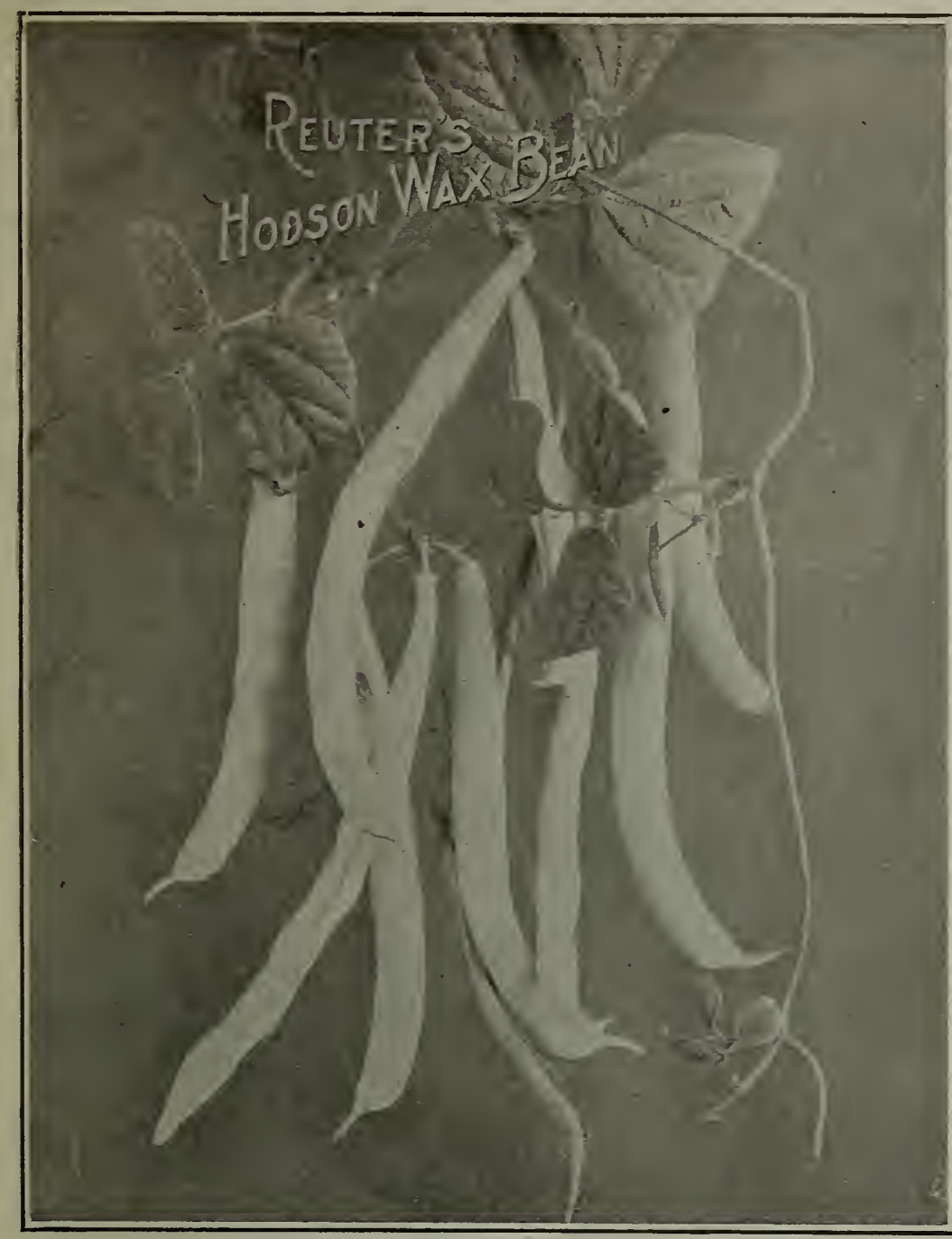

BEANS, Wax=Podded Bush Varieties

\section{DAVIS KIDNEY WHITE WAX}

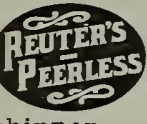

An excellent bean in every respect. The shipper. pods are long. straight, waxy yellow, and of good quality. The vine is rustless, bearing its
pods near the center in clusters. An excellent $\$ \% .00$.

Price, pkt. 5e; pt. 25e; qt. 35e; gal. \$1.25; peck \$2.00; br.

\section{CURRIES RUST=PROOF WAX}

The Earliest and Most Prolific of All Wax Beans

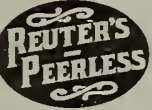

A superior variety for the market; very early and productive. Tender and absolutely stringfor many years with other Wax Beans, nearly all of them more or less affected by rust, this bean remained entirely free from rust. Pods are long. flat, and of fine quality. We highly recommend this splendid market gardener's variety, as it is especially adapted to long-distance shipments. \$5.00.

Price, pkt. 5e; pt. 25е; qt. 35e; sal. \$1.25; peck \$2.00; br.

\section{KEENEY'S RUSTLESS GOLDEN WAX}

grade beins Large, flat golden yellow and very fleshy pods. It has an excellent flavor and is less likely to be stringly than any other rust-proof beans. A strong grower Price, pkt. 5e; pt. 20e; qt. 30e; gal, $\$ 1.00$; peck $\$ 1.75$; bu. $\$ 6.00$.

\section{GERMAN PROLIFIC BLACK WAX}

An improved strain of the old Black Wax. The earliest of all wax beans. Dwarf Bush growth; very productive. Its handsome, yellow, fleshy, stringless pods commend it for both home and markei garden purposes. $\$ 6.00$.

Price, pkt. 5c; pt. 20c; qt. 30c; gal, \$1.00; peck \$1.75; bu,

\section{VIOLET FLAGEOLET WAX}

This sort is also known as Perfection Wax. The pods are very large and flat, often twelve inches long. When well grown it is one of the most showy of the wax beans. The seed is very large, flat, dark violet. $\$ 7.00$.

Price, pkt. 5e; pt. 20e; qt. 35e; gal. \$1.25; peck \$2.00; bu

Two Money=

Making Sorts

BUSH LIMA BEANS

Both Enormously

Productive

\section{HENDERSON'S IMPROVED BUSH LIMA}

The earliest of the bush limas; two weeks earlier than any of the climbing limas. It is small in size, but enormously productive, a reliable cropper, and of extra fine quality. The New Orleans market gardeners plant no other bush lima, which is the best argument in its favor we can offer.
pkt 5e; pt. 25 ; qt. 35e; gal. \$1.25; peck \$2.00; bu. \$7.00.

\section{IMPROVED BURPEE'S BUSH LIMA}

A true form of the large White Lima. The bushes are of five to eight. It is far superior to any other large lima bean now existing, and has the same good eating qualities as the best large pole limas, while the plants are more productive.

The bushes stand very erect and hold their pods well off the soil.

Price, pkt. Je; pt. 20c; qt. 35c; gal. $\$ 1.25$; peck $\$ 2.00 ;$ bu. $\$ 7.00$.

\section{POLE OR RUNNING BEANS.}

Pole Beans are later and more productive than Bush Beans. Set the poles four to six feet apart, and the ground well drawn around them before the seeds are planted. Don't cover the seeds more than one or two inches.

\section{REUTER'S CREASEBACK POLE BEANS}

A Perfectly Round, Green=Podded Pole Bean. A Prolific and Continuous Bearer Superior Quality.

For the Southern market gardener the best pole
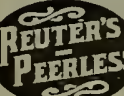
bean in cultivation. This variety is raised almost exsands of hampers of beans raised from our special stocks are annually shipped to the Northern markets. stocks are annualy shipped to the Northern markets. pers This bean is given the preference over all other sorts on any market in the United States. The pods average five to six inches in length, perfectly round, solidly fleshy, and of the finest quality. It is the earliest pole bean grown.

Price, pkt. 5c; pt. 25c; qt. 40c; sal. \$1.50; peck \$2.75; bu. \$7.50.

\section{SOUTHERN PROLIFIC}

Very productive and popular here, owing to the fact that it commences to bear when scarcely higher than the average bush and keeps on producing until killed by the frost. Largely raised here for a fall crop on this account.

Price, pkt. Jc; pt. 20c; qt. 35c; gal. \$1.25; peck $\$ 2.00 ;$ bu. \$7.00.

\section{KENTUCKY WONDER, or OLD HOMESTEAD}

An early, very prolific sort, with showy pods, which are of most excellent quality. The vines are vigorous, climbing well and very productive, bearing pods in large clusters. The pods are medium light green. very long, often reaching nine or ten inches, nearly round and very crisp, when young, becoming very irregular and spongy as the beans ripen.

Price, pkt. 5c; pt. 25e; qt. 40e; gal. \$1.40; peck \$2.25; bu. \$7.00.

\section{KENTUCKY WONDER WAX}

A novelty of recent introduction possessing all the qualities of its green-pod namesake. The long pods are a little broader, lery fleshy and quite stringless as snaps. The mature pods are fon eight to nine inches in length. Its earliness and hardin latitudes. Its very large, golden yellow pods are certainly handsome in appearance, and are unexcelled in quality by any wax podded Price, pkt. 5e; pt. 20c; ot. 35e; gal. \$1.25; peck \$2.00; bu. \$7.00. REUTER'S EARLY GOLDEN CLUSTER WAX

The grandest rellow-podded Pole Bean in cultivation. Pods are produced in clusters of from 4 to 6 the entire length of the vine, and are fit for use a long time aft $\$$ reaching maturice, pkt. 5e; pt. 20e; qt. 30e; gal. $\$ 1.00 ;$ peck $\$ 1.75 ;$ bu. \$6.50.
Price,

The culture of pole limas is the same as for other pole beans, except that on account of being more tender, the seed is usually planted one to two weeks later. If planted too early, they are apt to rot in the ground.

\section{REUTER'S SIEVA, or SMALL LIMA}

The Best Pole Lima Bean for the South. It is the earliest of all Pole Limas. Grows quickly, immensely productive and bears continuously through-

Price, pkt. 5e; pt. 20e; qt. 30e; gal. \$1.00; peek \$1.75; bu. \$6.50.
KING OF THE GARDEN LIMA

Price, pkt. 5e; pt. 20e; qt. 30e; gal. \$1.00; peck \$1.75; bu. \$6.50.
KING OF THE GARDEN LIMA

A vigorous grower and very prolific. Pods are from five to ight inches long. On account of its immense pods, it is a favor ite with many of the market gardeners.

Price, pkt. Jc; pt. 20c; qt. 30e; gal. \$1.00; peck \$1.75; bu. \$6.50. 
My stocks are grown for me in France, as that country excels the world for the production of the finest quality of Beet Seed. They are all grown from carefully-selected full-grown roots, uniform as to size, shape and color, and I believe my strains are unsurpassed. During 1913 I sold more than 20,000 pounds of Beet Seed to the New Orleans Market Gardeners. Sow 10 Ibs to the acre.

Culture-The ground for Beets should be rich and well cultivated. Sow in drills twelve inches apart and about one inch deep. When the plants are well up, thin to from four to six inches. In this latitude Beets are sown from January until the end of April, and from

\section{REUTER'S CRESCENT CITY BEET-The Best of the Early Beets}

A strain of Beets similar to Crosby, but of darker color and finer form. It is the best red turnip in cultivation and is grown extensively by the local market gardeners, who consider it the earliest and best bunching beet ever introduced. In quality and color it is without an equal. very fine grained, tender and sweet, and free from stringy and woody character. The color is deep red, almost black; tops are not too small, thus making it an ideal bunching sort. Our stock is grown expressly for us by a most famous French Seed Grower, and our carefully selected stock will produce a crop more uniform pressly for us by a most other strain obtainable. Mr. Peter Campere, a leading New Orleans market gardener, states: In shape, color and quality than any other strain obtainable. $I$ have ever planted. I have never seen a crop more uniform in shape, "Reuter's Crescent City Beet is without a doubt the f."

size and color, and intend to plant no other variety."

\section{REUTER'S CROSBY EGYPTIAN}

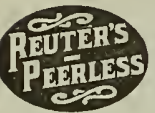

A highly selected strain of a most famous Beet. This superfine stock is eagerly sought after by the New Orleans market gardeners and we have hundreds of testimonials on file giving this grand selection first place among early market Beets. In this particular strain we believe there is embodied every good feature required to make a grand early market beet. Mr. Reuter recommends it to all his critical gardener friends with the assurance that no money can buy better. Our strain is kept top notch by our responsible foreign growers, who exert the utmost care in growing in order to retain in equal proportion, earliness, shape and color. No matter how much you think of the strain you have been planting, plant this and compare results. Many customers

Price, pkt. 5e; oz. 10c; 1/4 lb. 20c; lb. 65e; 5 lbs. \$3.00.

\section{REUTER'S CRIMSON GLOBE BEET}

\section{Second Early and Main Crop}

This splendid variety has been grown quite extensively in many sections of the country and the tremendous inin many sections of the country and the tremendous intion. Color is deep blood red fine grained, and of unsurpassed quality. The foliage is small-leaves all grow from a very small crown in the top of the bulb. The Beet is entirely free from fibrous rootlets, having only a slender this root. No up-to-date gror can afford to be without this excellent new sort. For home use it is of equal quality earlier in maturing.

Priec, pkt. 5e; oz. 10c; 1/4 lb. 25e; lb. 65e; 5 lbs. $\$ 3.00$.

\section{REUTER'S SELECTED EDMANDS BEET}

Good for bunching, and is a standard winter

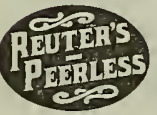
ath, largely cultivated by the local truckers. Its ing sort. Roots make it a very desirable bunchflesh is a deep red color, and always sweet and

Price, pkt. 5e; oz. 10c; 1/4 lb. 20c; lb. 60c; 5 lbs. $\$ 2.75$.

\section{REUTER'S IMPROVED EARLY BLOOD TURNIP}

A superior selection of Blood Turnip Beet, dark red,
fine flavor. It forms medium-sized, sound, half-flattened fine flavor. It forms medium-sized, sour
bulbs. Good for late or early planting.

Price, pkt. 5e; oz. 10c; 1/4 lb. 20c; 1b. 60c; 5 lbs. $\$ 2.75$.

\section{REUTER'S CHICAGO MARKET}

The most perfect dark blood-red kind. Even the leaves of every beet are of the darkest glossy red, almost black color. It is turnip-shaped, medium in size, tops of good size, which make it an exceptional good bunching sort

Price, pkt. 5e; oz. 10c; 1/4 lb. 20c; lb. 60c; 5 lbs. $\$ 2.75$.

\section{DETROIT DARK RED TURNIP $=$ MAIN CROP}

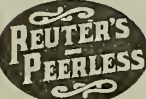

A very fine strain of turnip-shaped beet. Top Color of skin dark blood red; flesh bright red. Quality is of the very best. sweet, tender and lasting. It is a great favorite on many markets, and we have

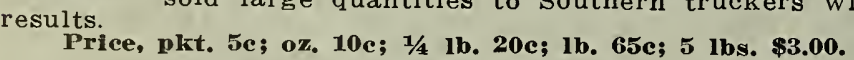

\section{REUTER'S EXTRA EARLY ECLIPSE}

This is the best extra early variety grown for this

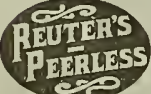

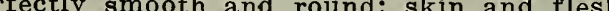
of a bright red color. It does not grow to a large size, and is therefore preferred by the large truckers in this section for shipping purposes. Our strain has a reat reputation among the New orleans gardeners, and hundreds reputation among the New orleans

Price. pkt. 5e; oz. 10e; $1 / 4$ 1b. 20c; 1b. 55e; 5 lbs. 82.50.

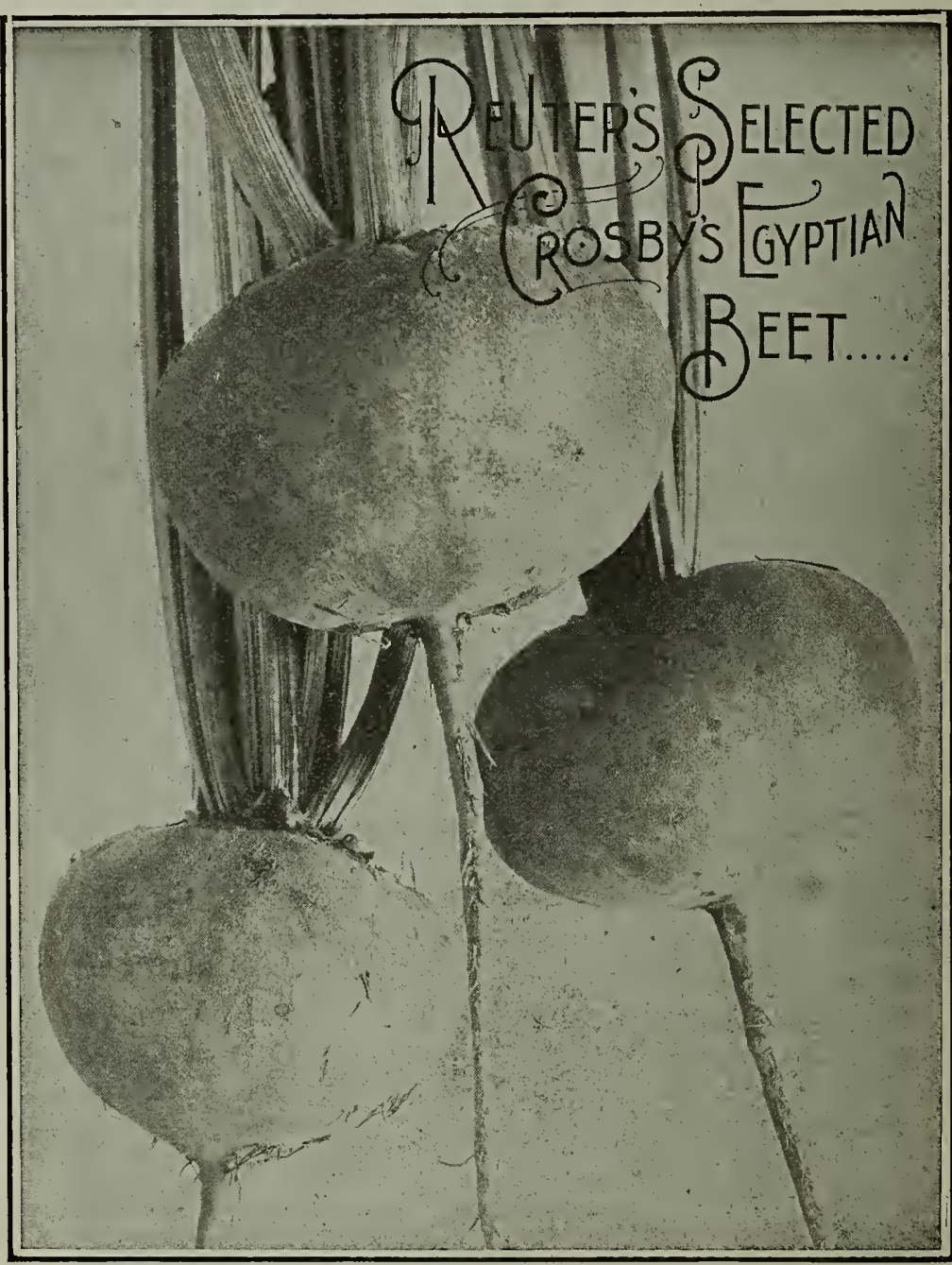

\section{NEW BEET! REUTER'S FIREBALL}

$A$ new and distinct extra early perfectly globe-shaped Beet. It is not only the handsomest beet on the market, but is also of superlative quality and a sure market winner. The flesh is a brilliant fiery red, fine grained, very solid, crisp and sweet. st has a very small tap root, slender leaf stalks and a smooth to a fancy trade. The very small tops, which do not permit as great rapidity in bunching as the larger tops of some other kinds, have the advantage of taking less room in a bed. Seed is in very limited supply.

Price, pkt. 5e; oz. 10c; 1/4 lb. 20c; lb. 65e; 5 lbs. \$3.00.

\section{SWISS CHARD (Spinach Beet)}

This variety is grown exclusively for its leaf stalks, which are used the same as Spinach. It is a great favorite in this market, where it is found in every garden. The culture is the same as Beets. We will be quickly appreciated by all critical growers.

Price, oz. 10e; $1 / 4$ lb. 20c; $1 \mathrm{~b}$. 50e; $10 \mathrm{lbs}$. $\$ 4.00$

American Grown Beet Seed does not do well in the South. Don't be deceived and buy elsewhere because the price is lower. The same critical dealers and growers buy in large quantities from us year after year. 


\section{Mangels and Sugar BEETS for Stock Feeding}

Root Crops are highly valuable to the Southern Farmer. The value of these for stock feeding cannot be overestimated. The results from their use are wonderful, as they are very nutritious and fattening, and improve the health and condition of the stock, and also the quality and quantity of the milk. They yield enormously, and can be grown at a trifling cost from our highly reselected imported seed. Mangels and Sugar Beets are a necessity, and the tremendous increasing demand from all sections of the South is the best evidence that these people are awakening to the vital importance of planting Root Crops for cattle feed. Everyone who keeps even one cow should grow a patch of either Mangels or Sugar Beets. A trial will prove to you the phenomenal yields which they produce.

Live stock on the farm means wealth. Cattle, hogs and sheep are the farmers' greatest assets. Live stock raising makes prosperity. With the advent of the boll-weevil, and the present three-year tariff on sugar, it is essential that the planter divert his attention to raising something that is more lucrative than either of these staples. To wait until he is financially broke before
making the change is folly. We must begin now to start a small stock of cows and hogs to insure a monthly cash income. A cow is good for at least ten years and gives a calf each year, which will soon total a nice herd. Begin as soon as possible with a few cattle. Take good care of them. Feed them properly. Give them plenty of good nourishing feed, such as sugar beets, good hay, with the proper care and attention. We are in a natural cattle country. Our mild winters afford us pasture the year through. Cattle require little attention in the summer time. But, in the winter, they must be given more care, more nutritious feed, such as corn silage, stock beets, oats, etc.

Cattle-raising offers the greatest opportunity for the improvement of existing conditions on your farm. There is no reason why you should not have a herd of cattle, which will be a constant source of cash income. With the present one-crop the Southern farmer is usually short of cash during the growing seasons. He must wait until his crop is harvested before he can

Successful cultivation depends largely upon the well-prepared seed bed, ploughed deep and a rich, friable sand, or clayey loam. Rich. mucky soils will of ten give an immense yield of roots, which though excellent for feed, are of little value for sugar-making. Sow in the fall and winter in rows two feet apart, and thin to nine inches in the rows. Youn plants may be transplanted to fill up vacancies. The seed
Cultivate frequently. Sow six to eight pounds to the acre.

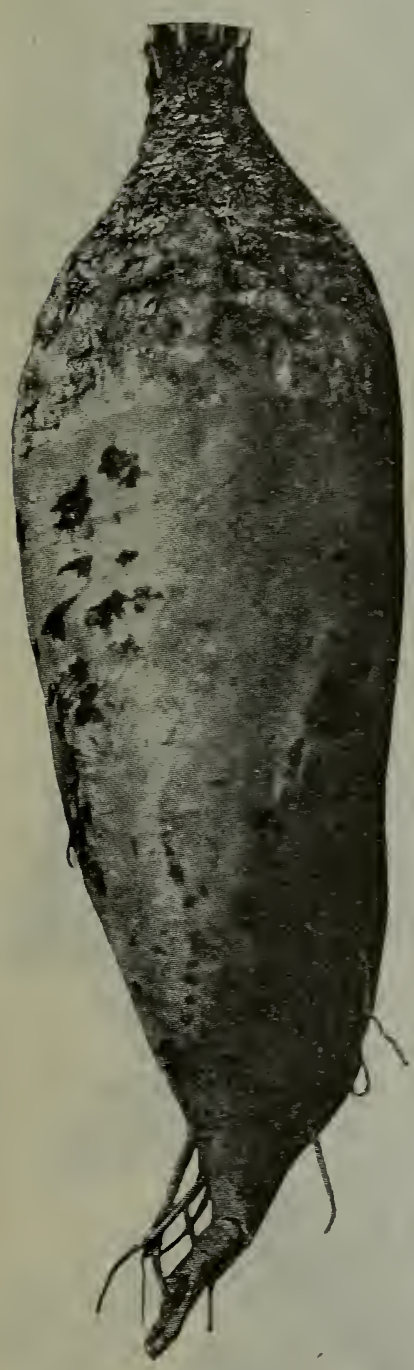

Reuter's Mammoth Long Red MangeI

\section{MANGELS \\ REUTER'S MAMMOTH LONG RED \\ A Wonderful Yielder.}

One of the best mangels ever offered to the grower. It produces large roots, uniformly straight and well formed, weighing from thirty to forty pounds each, of a beautiful red color, wonderfully productive. average 1,200 to 1,600 bushels to the acre. Its keeping qualities cannot be excelled. The roots grow from one-half to two-thirds above the surface and are frequently two or more feet in length by six inches in diameter. My seed stocks are carefully selected for heavy yielding qualifications.

Price, oz. 10c; $1 / 4$ lb. 15c; 1b. 40e; 10 lbs. \$3.50; 100 lbs. $\$ 30.00$.

\section{GIANT ECKENDORF MANGEL}

It is a popular German variety, and is more largely planted in that country than any other sort. The roots are cylindrical in shape and grow mostly above the surface. The weights of the roots differ from fifteen to twenty pounds. This variety is especially valuable, not only of yields. Awarded first-class certificate by Danish Government, where

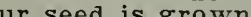

Price, oz. 10c; $1 / 4$ lb. 15e; lb. 40c; 10 lbs. $\$ 3.50 ; 100$ lbs. $\$ 30.0 \theta$.

\section{SLUDSTRUP MANGEL}

An exceptionally large-growing variety, and of the finest quality grown from a selection that has been bred year after year from the most perfect and largest specimens. The root is large. It is a remarkable yielder and contains a very high percentage of dry matter. Our seed is Danish grown. First-class certificate awarded.

Price, oz. 10e; $1 / 4$ lb. 15e; lb. 40e; 10 lbs. $\$ 3.50 ; 100$ 1bs. $\$ 30.00$.

\section{GOLDEN TANKARD}

One of the best Iong yellow mangels in cultivation. Tops comparatively small, with yellow stems and midribs; neck very small. light gray above ground, deep orange below. Flesh yellow. Matures earlier than other large sorts. It yields an enormous bulk on good land and

Price, oz. 10e; 1/4 1b. 15c; 1b. 40c; $10 \mathrm{lbs}$. \$3.50; 100 lbs. \$30.00.

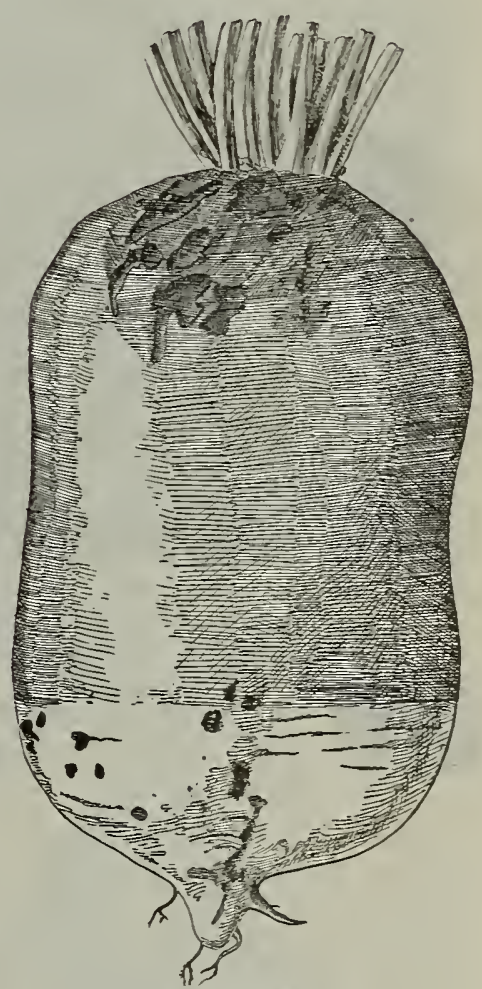

Mangel Eckendorf

\section{French Seed Oraly}

\section{SUGAR BEETS}

Germinated Before Sold

The growing of Sugar Beets offers a great opportunity for the profitable extension and diversification of agricultural industries in the South. The sugar beet is proving a profitable crop for the farmer. Its influence in developing stock breeding feeding, and dairy industries is attracting the favorable attention of farmers interested in these pursuits. The rapid growth in our sales of sugar beet seed within the past year shows that the value of this important crop is gaining recognition. The two
best sorts are mentioned below. I obtain the seed from France. These two sorts contain the highest percentage of sugar. Yields of fifteen to twenty tons to the acre have been frequently made in the South, and from these beets 13 to 18 per cent of sugar can be obtained.

My good growers in France are specialists, and every care is exercised to improve the stocks by selecting the most important types and heaviest yielders, and those that contain a very large percentage of dry matter. It is essential that the grower purchase the best seed, carefully test the vitality before planting, and be SURE of its source.

\section{KLEIN WANZLEBEN}

This is the variety so extensively planted for sugar factories. Roots are a little larger than Vilmorin's Improved, and a little hardier and easier grown. Tops rather large; leaves slightly waved. Yields from twelve to eighteen tons per acre.

Price, oz. 5e; $1 / 4$ lb. 15c; 1 b. 40e; 10 lbs. \$3.50.

Note-Write for prices on larger quantities. Remember that all root crops are profitable and nutritious for stock feeding. than with Mangels and Sugar Beets. Include a few pounds in your order this spring. My stocks are large and extra fine.

\section{VILIMORIN'S IMPROVED}

One of the richest in sugar content of the sorts in cultivation. It will do better on new lands than any other, suffers less from the excess of nitrogen, and will keep the best. Tops are of

Price, oz. 5e; 1/4 lb. 15e; 1b. 40e; 10 lbs. \$3.50. medium size, with smooth, bright green leaves. Grows entirely under the ground, and yields 
One Ounce Will

Produce 3000 Plants
CAULIFLOWER
Cheap Cauliflower Seed

Cannot Be Good

All the Cauliflower Seed I offer is produced by the most famous growers in Denmark, in such localities that are best adapted to their perfect development. The seed is saved from heads especially selected for seed purposes and can be absolutely depended upon for best possible crops.

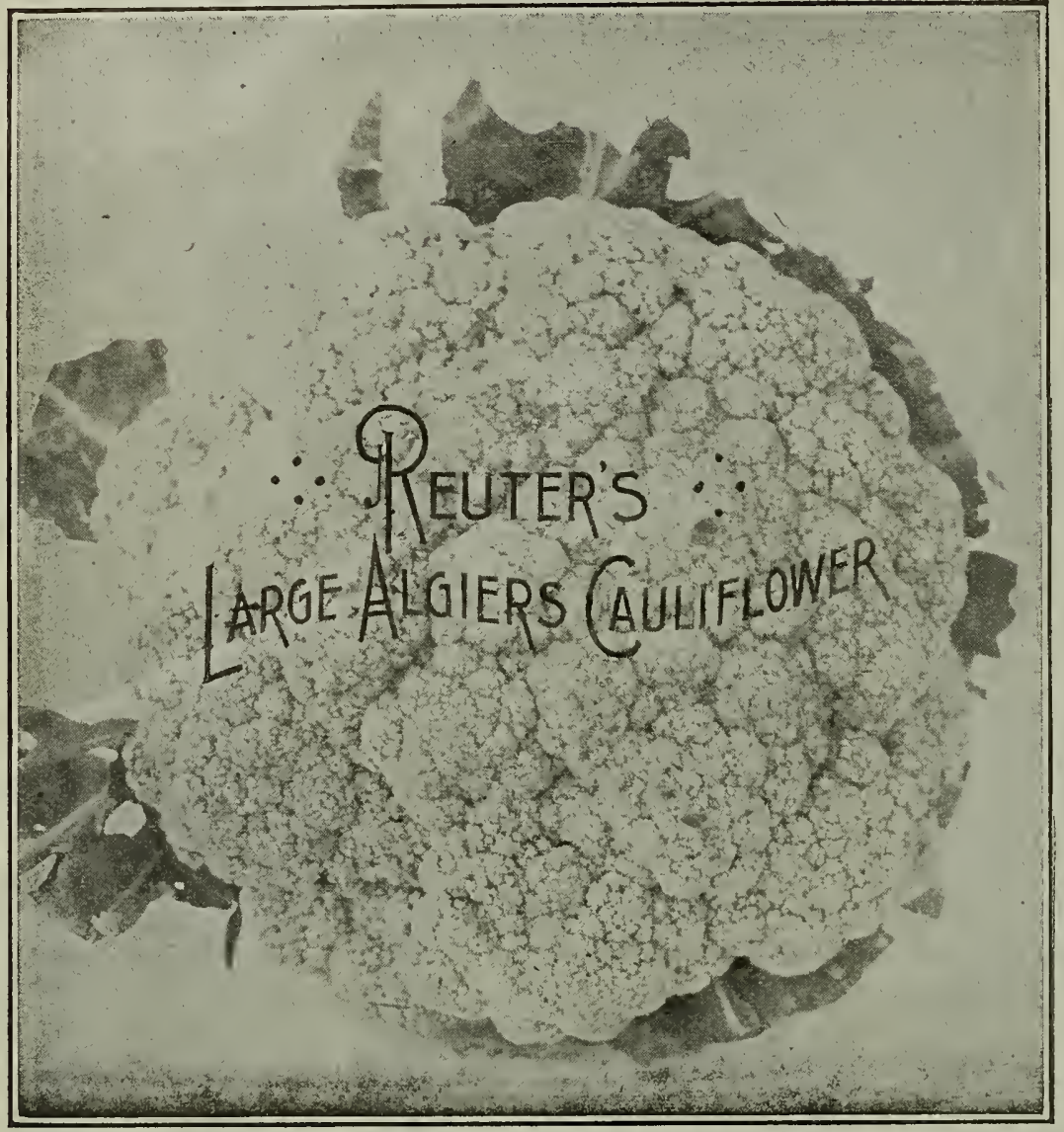

\section{ALL PACKETS 10 CENTS POSTPAID}

Culture-Cauliflower succeeds well in any soil where cabbage will grow. It therefore thrives best in deep, rich, sandy soil, and requires plenty of moisture during the formation of the head. The Late Italian and Large Algiers should be planted from April to July. The latter month and June is the best time for sowing the Early Giant Italian is the in June July, August, September. October and November the Algiers can be sown. The Algiers is considered the finest in this section. The Early Snowball can be sown from August to February, and oftentimes as late as March, if the season is favorable, although the fall sowing is the most preferable. Dusting with Hammond's Slug Shot and Tobacco Dust are goed and safe remedies for some of the insect

\section{REUTER'S PEERLESS LARGE}

\section{ALGIERS CAULIFLOWER}

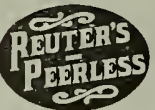

Unsurpassed variety. Beyond a doubt the finest cauliflower to plant in the South. It will head where others fail.

It is a magnificent variety and proIt is or dwarf habit and vigorous growth, quite early. The leaves protect the heads so that they will endure uninjured a frost that would perhaps ruin other sorts. We have made careful and continuous tests of this strain, and grown with the stocks offered by

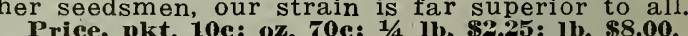

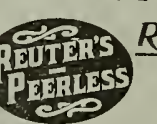

REUTER'S EARLY ITALIAN GIANT

A magnificent sort extensively cultiis pure. Southern truckers. Our strain

One of the finest varieties, of vigorous growth, heads very large, white and compact, and thoroughly able from a noted foreign grower, and is largely in demand throughout the South

\section{REUTER'S EARLY SNOWBALL}

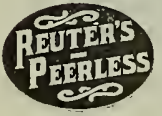
in Louisiana and other Southern States enormous proportions, and it is indeed etting to be a profitable industry. This prices as $\$ 2.50$ per dozen in Chicago, $\$ 3.00$ per dozen in New York, and $\$ 4.50$ per dozen in Boston were most encouraging for the Louisiana planters during has increased to such an extent that it has developed a new truck crop for our section-winter cauliflower. I handle only the finest selection of pure Danish Seed. Cheap Cauliflower Seed cannot be good, whether you buy it here or import it yourself direct. The price should never be questioned, and a good grower of Cauliflower never hesitates to pay twenty dollars a pound for the best seed procurable. My strain of this famous variety produces round heads, pure white, of medium size, and perfectly solid. The plants are compact, with short outside leaves, and therefore althe most exacting. If you are interested in the growing of winter cauliflower, write to the Louisiana La, for their Bulletin No. 140, "Preliminary Report Cauliflower." It is a leaflet well written Mr. Tiebout, an able horticulturist of this state.
Price, pkt. 10e; oz. \$1.50; 1/4 lb. \$5.50; lb. $\$ \mathbf{2 0 . 0 0}$

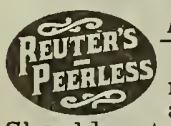

REUTER'S LATE ITALIAN GIANT rather extensively in the South. The heads Should not be uniformly large, white and compact. to nine months before it heads. 86.00.

\section{REUTER'S EARLY DWARF ERFURT}

A very early, very distinct and really valuable varlety, but difficult to keep true to name. Our thoroughbred strain is a very popular one. Of dwarf close and white. Where extreme earliness is not the greatest consideration, we recommend the strain.
Price, kkt. 10c; oz. $\$ 1.50 ; 1 / 4 \mathbf{1 b}$ \$5.50; 1b. \$20.00.

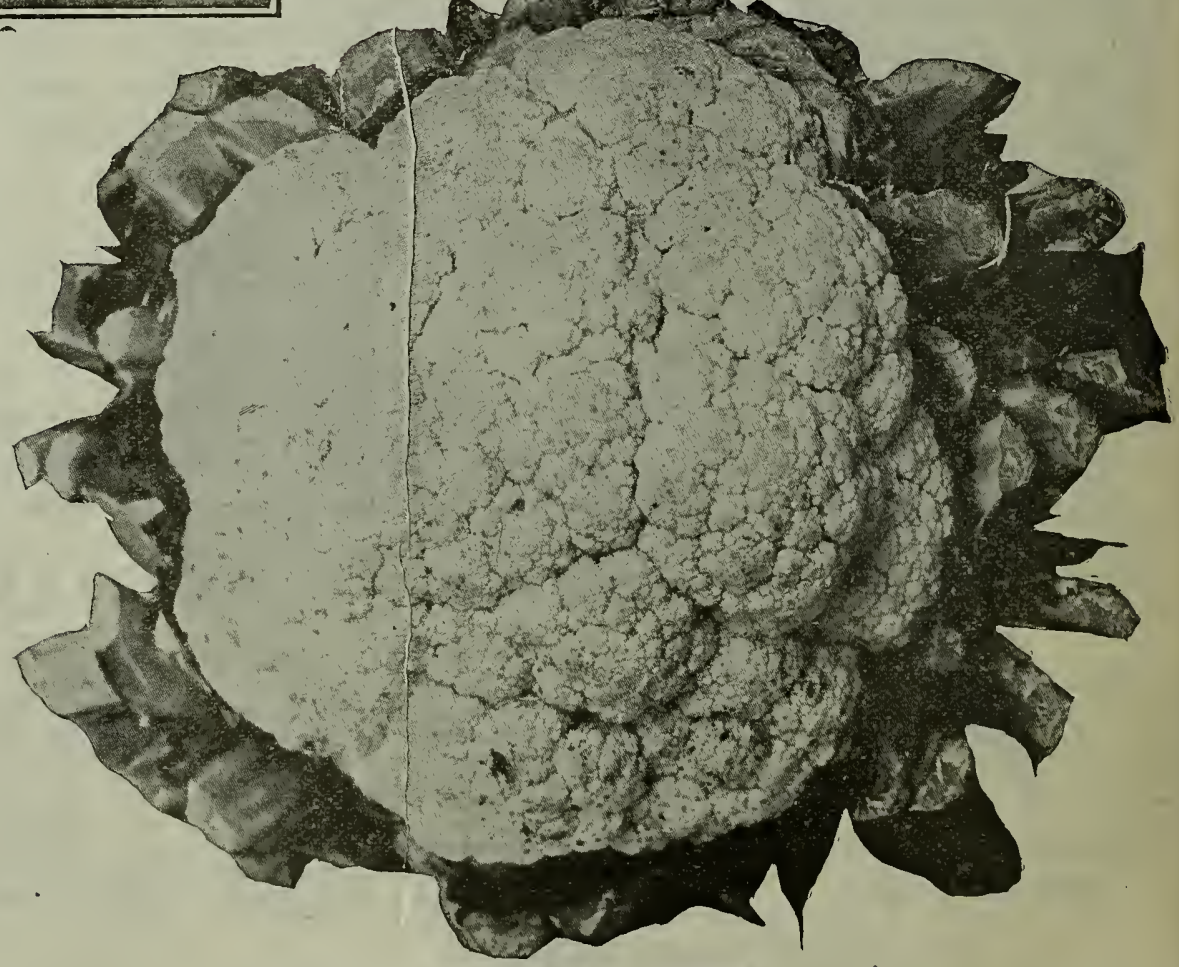

Reuter's Early Snowball

\section{DRY WEATHER, OR. DANISH GIANT}

This new strain is originated in Denmark, and we earnestly ecommend it to all market gardeners for a trial. Especially adapted for sections subject to long dry seasons, as it will grow and produce the finest heads in spite of lack of moisture. Heads finest flavor. Valuable for growing in the Southern States. We import our stock direct from the originator.

Price, oz. \$1.50; 1/1/1b. \$5.00; 1b. \$18.00. 


\section{Biggest Growers in the South Plant My Celery Seed}

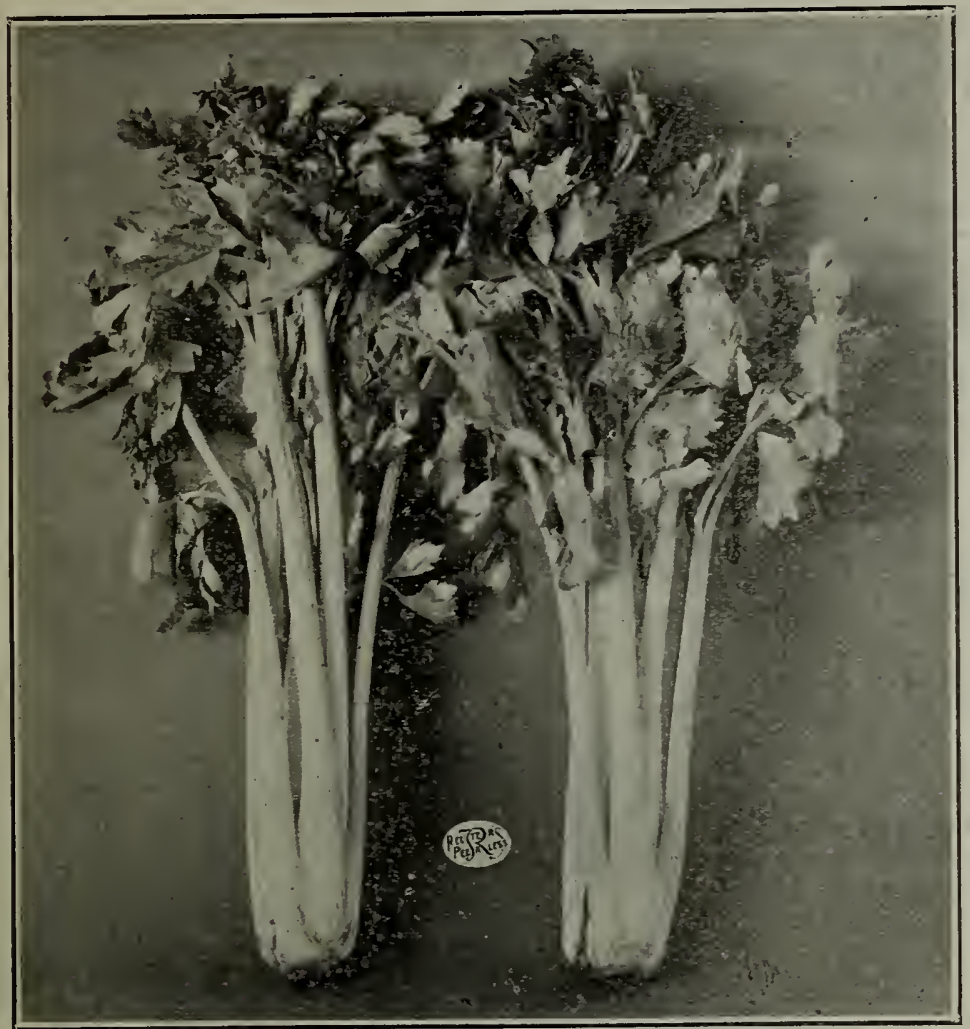

I Import this Seed

Direct from France
CELERY

Culture-Sow in May and June for early transplanting, and during August and September for a late crop. Sow in shallow boxes indoors, or in a finely prepared seed bed out-doors. See to it that the seeds are not covered too deep, and that the bed is kept moist, almost wet, until the seeds germinate, as plenty of moisture is essential to a satisfactory growth. When the plants are about two inches high, thin out and transplant so that they may stand three inches apart. When the plants are about six inches high, transplant into trenches about four inches deep. nine or ten inches wide and about two feet apart, made very rich with thoroughly decomposed manure. Plants should be from six to eight inches apart. When planted out during the hot summer months. the trenches should be shaded. Celery requires plenty of moisture, and watering with soapsuds or liquid manure will benefit the plants a great deal. When tall enough, it should be banked up with earth from both sides to bleach it for the market.

\section{REUTER'S GOLDEN}

\section{$\underline{S E L F=B L A N C H I N G \quad C E L E R Y}$}

This is the strain that is so popular throughout this entire big country. Extensively cultivated throughout the South, and the demand for my superfine French Seed the past year has been tremendous. No other strain can give you the same satisfaction. No matter how much other seedsmen will try to get your order for Celery Seed, always be sure that you are obtaining stock grown in France by Vilmorin. This is the only kind I handle. It is compact in growth and the stalks are large, solid, and of a remarkably beautiful rich golden yellow, very crisp and tender, and free from stringiness. Don't buy American Grown Golden Self Blanching Celery Seed. It does not do well in the South.

Price, pkt. 25e; oz. \$1.00; $1 / 4$ 1b. $\$ 4.00 ;$ ub. $\$ 15.00$.

\section{PERFECTION WHITE PLUME-REUTTER'S SELECTED STOCK}

$A$ very early sort, but not compared in quality or apearance with our superior strain of Golden Self-Blanching. The plant is a very rapid grower, and the leaves are light green, with tips almost white. Our strain is extra select.

Price, oz. 25e; $1 / 4$ 1b. 75e; 1 b. \$2.50.

\section{GIANT PASCAL}

One of the best varieties for fall or winter use. It is a vigorous grower, producing very large, broad, thick stalks, which are of excellent quality and entirely stringless. A very good market sort.

\section{CUTTING, OR SOUP CELERY}

This variety is sown in the early spring in rows, and the tops are cut when three or four inches high for use as soup flavoring. Grows very rapidly and will furnish a succession of cuttings throug
Price. oz. 10c; $1 / 4$ lb. 30c; 1b. \$1.00.

\section{CELERIAC-Turnip=Rooted Celery}

A popular German vegetable that is worthy of more extensive cultivation. Grown exclusively for the roots, which are used in salads or boiled like Parsnips or Turnips. Flavor very similar to Celery.

\section{GIANT PRAGUE}

Best of the class, very large and smooth roots. A desirable sort for market.

Price, pkt. 5c; oz. 20c; $1 / 1 / 1$ lb. 60c; 1 b. $\$ 2.60$.

\section{Sometimes Called} Chicory

\section{ENDIVE}

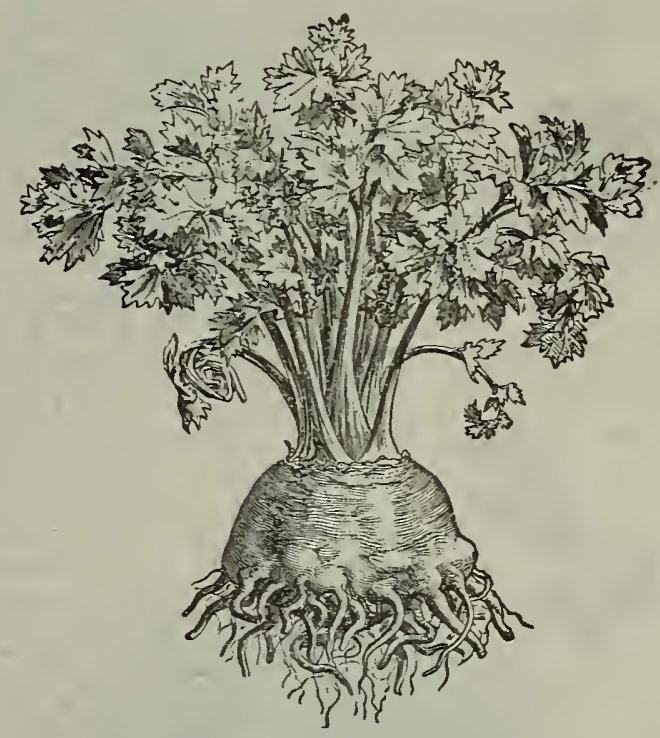

Celeriac

\section{Best Standard} Varieties

\section{REUTER'S MARKET GARDENERS' GREEN CURLED}

The standard sort for fall and winter crop. Very hardy, leaves beautifully curled, very tender. Our strain is the long-standing type, easily blanched and of an attractive appearance. Hundreds of carloads of this variety are shipped to the Northern markets
Orleans during the winter. Our strain is far superior

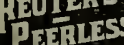
ese to the cheaper California grown stock, as we import our seed direct from France.

Price, pkt. 5c; oz. 10c; 1/4 1b. 30c; 1 b. \$1.00; 5 1bs. \$4.50.

\section{BROAD LEA VED BATA VIAN (ESCAROLLE)}

A variety having large, thick broad leaves, slightly curled and light green in color. The Inner leaves form a large heart, which blanches nearly white, and is crisp, tender and of a very fine flavor. Raised extensively by the local gardeners. Our strain is unexcelled.

Price, pkt. 5c; oz. 10c; 1/1 lb. 30c; 1b. $\$ 1.00 ; 5$ lbs. \$4.50.
This variety of the Cabbage tribe is known as Curly Greens, or Kale. Well known and extensively planted by foreigners, but little used by others. Sow in the spring and transplant with the late cabbage in early summer. For fall crop, sow early in which can be used during the winter months; if slightly covered which can be used during the winter months; if slightly covered with manure or litter will continue to grow until spring. The
leaves are fit to use as soon as they get a touch of frost. To preserve them during early winter, treat them the same as Cabbage.

\section{DWARF GREEN CURLED SCOTCH}

A dwarf, very hard and popular with all market gardeners. The leaves are as curley as Parsley. tender and of fine flavor. We have secured a very fine strain.

Price, pkt. 5e; oz, 10c; $1 / 41 \mathrm{lb}$. 20c; $\cdot 1 \mathrm{~b}$. 50c. 


\section{VARIOUS USEFUL AND MARKETABLE VEGETABLES}

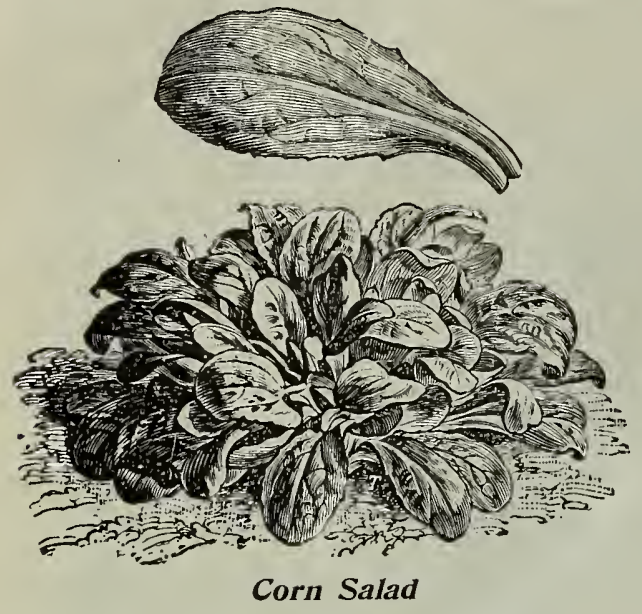

\section{CHERVIL (Cerfeuil)}

An annual with aromatic leaves resembling Parsley in appearance, and is used extensively in this section for flavoring soups, stews, etc. Also used for garnishing purposes. Should be sown in the fall and spring.

Price. pkt. 5e; ox. 10e; $1 / 4$ lb. 35e; 1b. \$1.00.

\section{BROCCOLI}

A vegetable similar to Cauliflower, of less delicate flavor, but much hardier. Further north than New Orleans it is cultivated extensively, as it does better than Cauliflower, bein ${ }^{\circ}$ hardier. Cultivate the same as Cauliflower.

PURPLE CAPE-The leading sort. Heads are purplish, and resembles the Algiers Price, pkt. 10c; oz. $30 c ; 1 / 4$
(1)

\section{COLLARDS}

Our Collard seed is grown in the South from the finest stocks and our strain cannot be excelled for purity and quality.

\section{GEORGIA, OR SOUTHERN}

A variety of Cabbage that does not form a head, but produces a mass

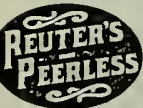
of leaves Very hardy and con tinuous frower Fire but produces a mass but rather imploves its quality. Sow thick in drills in rather rich ground. ransplanting when about four inches high, ol sow in drills where the plants are to remain, and thin out to two or three feet apart in the row when of proper size. In this latitude it can be sown from January to May, and August to October.

\section{BRUSSELS SPROUTS}

family, which produces miniature heads on the side

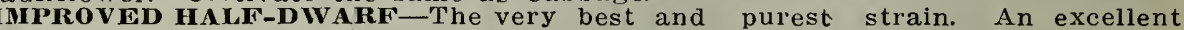

\section{GARDEN CRESS}

the ested as a salad, also for garnishing purposes. This

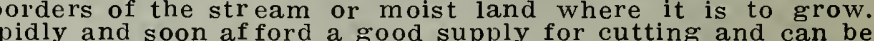

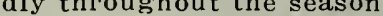

CURLED OR PEPPER GRASS-A popular salad which should be sown early in

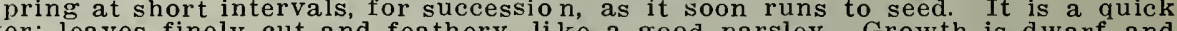

Price, pkt. 5c; 0z. 10c; $1 / 4$ lb. 20c; 1b. 60c.

\section{CORN SALAD (Doucet)}

This is a hardy, quick-growing plant; the leaves furnish a good substitute for the during the winter. Sow the seed broadcast, or in drills nine inches part Price, pkt. 5e; oz. 10c; $1 / 4$ 1b. 20c; 1b. 60e.

\section{SWEET, POT AND MEDICINAL HERBS}

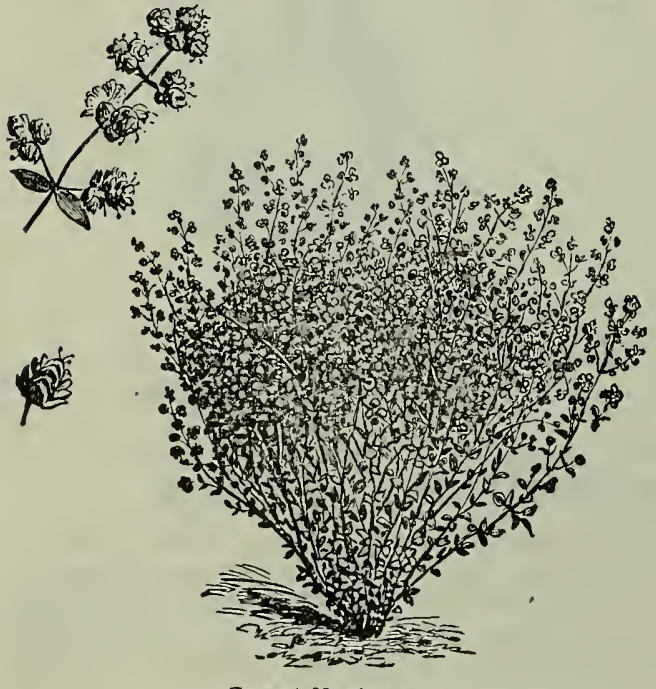

Sweet Marjoram

Every garden should contain a few herbs, as they are useful in many ways; some possess culinary as well as medicinal properties.

Most of the varicties thrive best in rich. mellow soil. In all cases the soil should be carefully prepared and well cultivated, as the young plants are for the most part delicate and easily choken out by weeds. Sow early in the spring in very shallow spade. Most of them should be cut when in full bloom, wilted in the sun and thoroughly dried in the shade.

ANISE. For garnishing and flavoring. Pkt. Je; oz. 10c. 5c; oz. 15e.

BASIL, SWEET. Used in soups. Stews, and sauces.

CARAWAY. For confectionery, medicine and flavering Pkt. sc; oz. 10e.

CASTOR OIL BEAN. Used for medicine and ornamental bedding plants. Pkt. 5e:

CATNIP. For medicinal purposes. I'kt. 10c; oz. 40c.

CORIANDER. Seeds are aromatic. Pkt. se; ox. ioc.

DILL. Seeds used for scasoning. For Dill pickles. Pkt. 5e; oz. 10c.

LAVENDER. Aromatic. Plst. 5e; oz. 20e.

MAJORAM, SWEET. Used for seasoning. Pkt. sc; oz. 15c.

ROSMARY. Used for seasoning. Pkt. 10e: oz, 40e.

SAGE. Leaves used for seasoning purposes. Pkt. 5c; ox. 15e.

SAVORY. SUMMER. Used for flavoring. jkt. 5e; oz. 15c.

THYME, FRENCH. For seasoning. Pkt. I0r; ox. 40e.
WORMWOOD. Used medicinally and beneficial to poultry. I'kt. 5e; ox. 25e.

\section{ROQUETTE}

Is used as a salad, which it resembles very much. Sow from Septeniber to March. Price. pkt. 5e; 0\%. 15e; $1 / 4$ 11). 30e; 1b. \$1.00.

\section{SORREL}

Planted in drills a foot apart durin fall of the year and thinned out from three to four inches in the drills. It is used for various purposes in the kitchen also in soup and salad. Cooked like Spinach. kt. 5e; ox. 15e; 1/4 1b. 35e; 1b. 81.25 .

READ WHAT THE PEOPLE SAY ABOUT MY SEEDS!

Big Wells, Texas, Oct. 3rd, 1913.

I am putting out a crop of your seed and I want to show the growers what good strains you have. My onion seed is Cabbage, Onions, etc., have no equal, also other seeds and all growers who have purchased from you are well satisfied.
Hempstead, Texas, Aug. 27th, 1913.

Allow me to compliment your seed. All seed that I ordered from you gave perfect satisfaction. I secured a good crop with good success, so please send me a copy of your catalogue next

\section{Cheneyville, La., Aug. 25th, 1913.}

I am proud to state that all seed I ordered in the spring has proved to be better than recommended. I will always buy my seeds from you. 


\section{Reuter's High=Bred Tested CABBAGE SEED}

\section{PEERLESS STRAINS OF UNEXCELLED QUALITY AND PURITY}

There is no regetable cultivated more extensively in the South than Cablhage. Thousands of

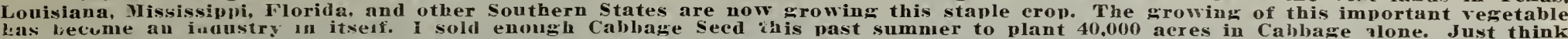
of it: Jore than 8,000 pounds of the purest Lons Island Grown Cabbage Seed left my store in less than four months: This is surely a manificent tribute to my honest efforts to give niy customers the hest seed that can be orown The truckers that buy this Cah-

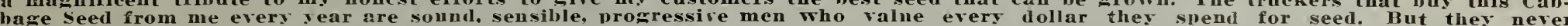
question puy prices. The kuow from actual experience that I am givisa them one hundred cents' worth of aualits for evers dol-

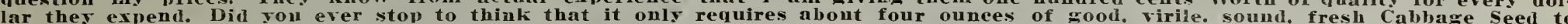

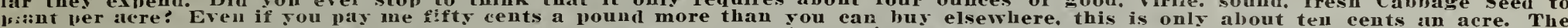

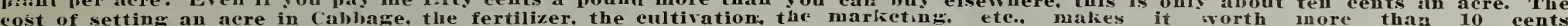
cost or setting an acre in Cabliage. the ferom an acre to insure your cron by minting good seed? fien sou realize how important a crop it is. and how much is debendent upo think for cne single moment that all Cabloge Seed is the same. Because a seedsman attaches a name to a calbige similar to the kind I offer you does not necessarily mean that the seed is the same. All of my Cablage Seed, with the exception of a few sorts I cannot afford to do it, and risk losing your trade. and you losing your crop through

selling Cabbage Seed than in any other line 1 know of. Irresponsible firms, witl little

cheab mongrel forein Cablage Seed at considerably less than I bay my good growers on Long island. are planting dependable seed. sire to broduce a cropo nnform in growth. headiegharacteristies. and maturity. When you plant of your eathaye erop by miving ron the finest seed in the world, so it is up to sou to make arood, by tilizc. this grourd to the highest, but if the seed you plant is mongrel stocks, sou cant produce a good crop, and alsolute failure will lie the result of one sear's work. Suppose your erop should vield fifteen tons per acre and Cabloge is selling for $\$ 30.00$ per ton, or a profit to sou of $\$ 450.00$ per acre. don't you think it false economy to try to sare about trents-five or fifty cents a poun

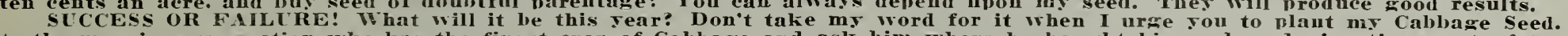
to the man in your section who has the finest crop of Cabbage and ask him where he bought his seed, and nine times out of ten. he will say Reuter. I sel! more Calbare Seed during the summer months than any seed honse in the south sells in twelve months. Why? I give you nothing but wality all the time. I give sou pedigree seed from extra re-selected stock seeds. I sell you seed at a reason-

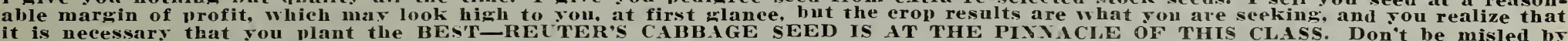

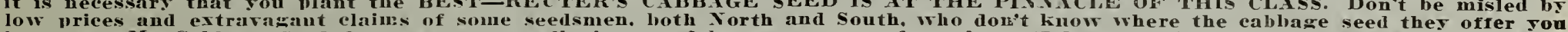

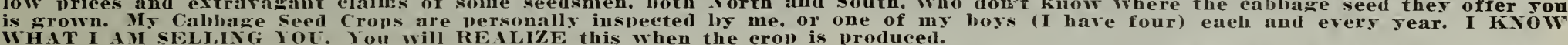

R. \& G. Riess, two of our most prominent market=gardeners, say: "We pronounce your Cabbage Seed the best ever planted." Write my Free Service Bureau for Directions for Cultivating Cabbage in YOUR Section.

\section{FOUR GREAT AND GRAND SORTS FOR TEXAS, GROWERS}

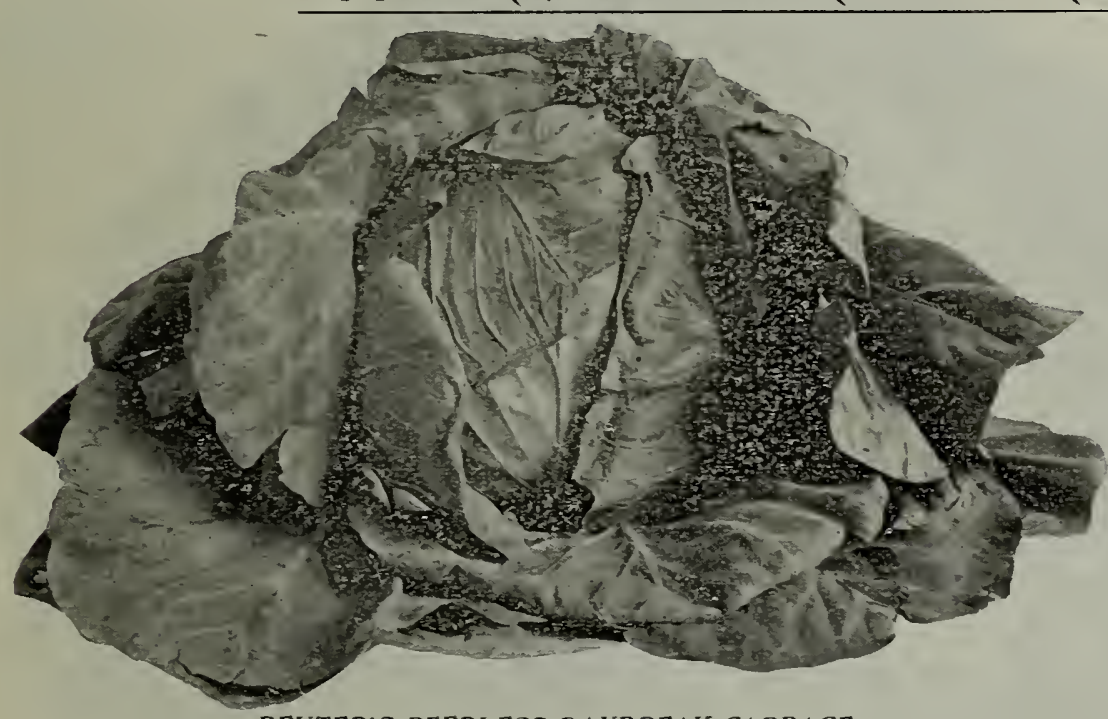

REUTER'S PEERLESS DAYBREAK CABBAGE REUTER'S GENUINE MONSTER SUREHEAD

Proved Trustworthy Needs no Introduction to Texas Growers

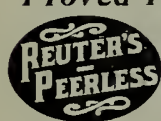

This is the Cabbage you have heard so much about. Thousands of acres are annually sown with this one sort. It is the finest type of second early esteem among the most discriminating growers in pounds annually. I am very particular about my stock of this variety, and have had my growers pay extra critical attention to the elimination of all "off-types" in my seed crops-the resul buy anywhere, no matter how much you may pay. It is popular The heads are uniform in size. very solid, ranging from fifteen to twenty-five pounds. Being a strong and vigorous grower
it will withstand lots of inclement weather without rotting. A favorite. because it has made good in every sense of the word.

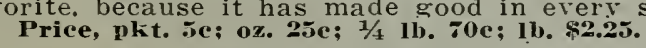

\section{REUTER'S ST. LOUIS LATE MARKET}

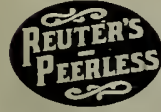
Last year I had more orders for this strain than I was able to handle, and the result was that many of
my best customers were disappointed. My grower on Long Island only delivered me nine hundred pounds on my contract order. and this was not nearly enough to go better than most other sorts. The heads are extra large, round, mattened on top. fine grained and keep exceptionally well. In what different in growth. My seed stock is good-cannot be Price, pkt. 5e; 1/4 1b. 70c; Ib. \$2.25.
REUTER'S PEERLESS DAY $=$ BREAK

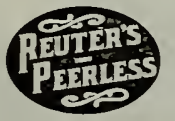

in loal lots. I have carefully studied its growth, time of maturits, shipping qualifieations, and usually like the idea of breaking away fron the usual path and offer something distinet. I would rather iniprove the mood, old. standard, reliable sorts that liave always made good. But this is a dandy cabbage. You will eventually want it. Taken from every angle REUTER's CBBC is a winuer for the market mardeuer who blants money-making rarieties to rivaled by the Faned Surehead. Its growth is particularly strons and rigorous. its color dark bluislt creen, indieating ust constitution and healthy develonment. The leave are broad and well filied out to their juncture with the tamers alnost to a point where it enters the oround. head is thick and flat. with the outer leaves covering it well across the center. It is very large. solid and of the most the eablage is well developed. It will eventually supersede many of the old well-established standard sorts that are fivorite in the trucking centers. If you lave had trouble in getting sour cabbage to head this year, change sour seed. Plant Das-Break. There was scarcely a single failure pounds each. Remember that this is not a novelty, but a rlant. This is a profltable sugrestion.

\section{REUTER'S TEXAS VOLGA-TRUE STOCK}

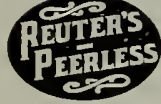

TEXAS VOLGA $T R$ UE STOCK greater variety of beautiful words, so that I could vegetables orown from my seeds. This ls one of them. Here is one cabbage that has made good, an ererybody in Texas that wrows Cabbage to any extent will bear out nis sted within the last few sears and found to be profitable and especially adapted to the climate and soil In Southwest Texas. where it now leads all others. It is a quick grower, maturing alout the same time, or possibly a little earller, than ably solid and white. It will outsell all otler crbbage at slyht. Grows close to the around and produces heads that are exceptionally uniform in size. shape. and maturits. I want to eall sour special attention, if sou are interested in qualits. to this straln. as its excellent qualits, flavor. tenderuess, and erispness is unequaled. I offer only Lons lsiand seed-bred up to the acme of perfection by growers who have devoted their 


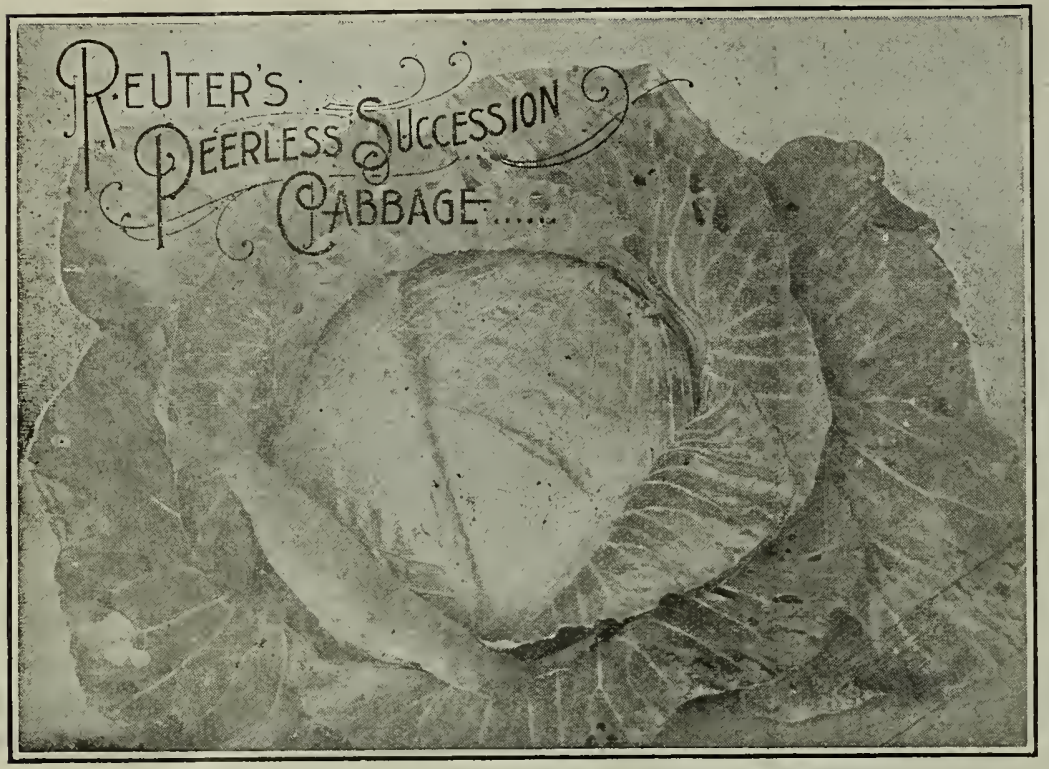

\section{REUTER'S PEERLESS SUCCESSION}

\section{Best Second Early Cabbage in Existence}

This grand variety comes in a few days later than our Early Summer, but is nearly double the size of that variety. Our strain is the result of many years of continuous care and critical selection, and we have at last secured a perfectly true stock of seed. We have on file today more than two hundred unsolicited letters from prominent truckers throughout the South in regard to its great excellence. It is the best bred variety in America, and it is doubtful if we have a Cabbage that possesses more uniform heading characteristics. Under favorable conditions every plant will produce a head, and they run remarkably uniform in shape, size and markings. We believe it to be the most reliable cabbage ever introduced. The heads are medium size, very firm and solid, averaging 10 to 12 inches in diameter, but are frequently larger. Average twelve to fifteen pounds, but many weigh more.

Price (sealed packages), pkt. 5c; oz. $25 \mathrm{c} ; 1 / 4$ 1b. 70c; 1 b. \$2.25; 5 1bs. \$10.75 (prepaid).

Note-We only sell the seed of this magnificent variety in Sealed Packages. The enormous demand for it last season requires us to protect ourselves and our customers in this manner. Be sure to get our critically Grown-Reselected Long Island Stock, which is procurable only direct from us.

Seeds are different from other merchandise. The true value of seeds can onIy be established after weeks or months of labor. Why buy from haphazard, non-experienced seedsmen and take a chance? Sceds of the highest grade and purest strain can only be obtained from practical trained seedsmen, with an honorable reputation that has been made and must be maintained.

\section{REUTER'S PEERLESS LATE \\ FLAT DUTCH CABBAGE}

The Finest Late Flat Dutch Cabbage in the World.

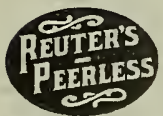

The most magnificent strain of Late Flat vutch Cabbage ever introduced, and pronounced by the most experienced ciubage growers throughout the South as the Iinest type on the market. 'The heads are tlat, grow very large and solid and of the finest quality. often weighing fifteen to forty pounds. The plant has a short stem, rather large oute leaves and color bluish green. The remarkable success obtained from this Cabbage by the New Orleans marke gardeners and hundreds of other critical growers throughout the South con vinces us that the demand will bo greater than ever, and on account of the short crop of seed the past season, we would advise early ordering in order to avoid disappointment. Remember that the genuine oz. 20c; $1 / 4$ lb. 60c; lb. $\$ 2.00$; 5 lbs. $\$ 8.75$ (prepaid).

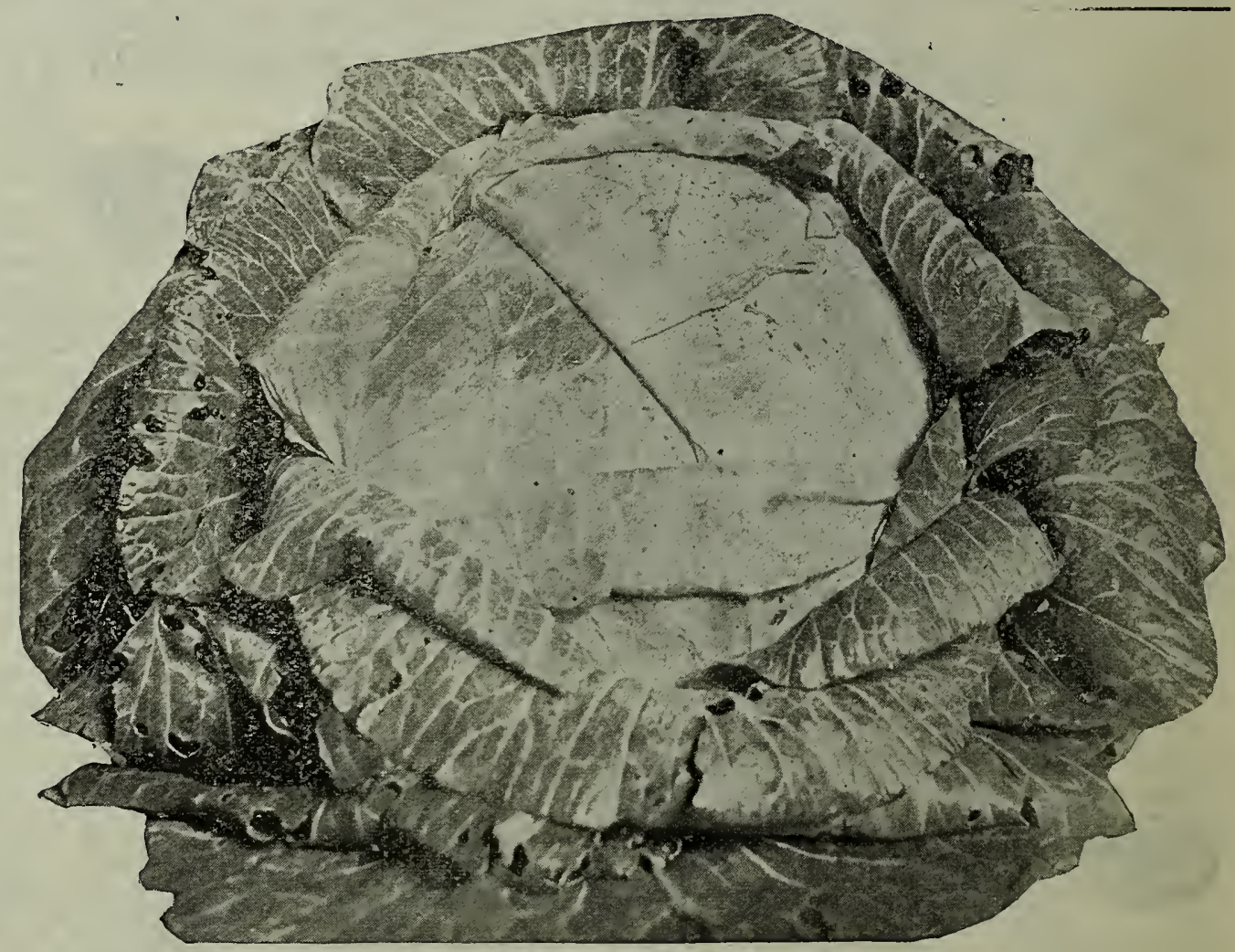

Reuter's Peerless Large Late Flat Dutch

\section{REUTER'S IMPROVED'AMERICAN DRUMHEAD}

A standard winter cabbage for main crop. A sure header and very regular in growth. It forms large, hard, solid, flattened heads, uniform in shape and color, and of handsome appearance. Our strain is carefully bred, and will always produce a head from fifteen to thirty pounds.

Price, pkt. 5e; oz. 20c; $1 / 4$ lb. 60c; $1 \mathrm{~b}$. $\$ 2.00$.

\section{LOUISVILLE DRUMHEAD}

A fine, short-stemmed strain of Late Drumhead, highly esteemed hy the market gardeners of the Southwest, where it is said to stand warm weather better than most other sorts. The heads are of good size, round, flattened on the top, fine grain and keep well.

Price, pkt. 5e; oz. 20c; 1/4 lb. 60c; lb. $\$ 2.00$.

\section{LARGE CHARLESTON WAKEFIELD}

Resembles the Early Jersey Wakefield in form, but much larger; heads often averaging about ten pounds. It has become the foremost variety in all sections where Cabbage is grown extensively for market. My strain is pure.

Price, pkt. 5c; oz: 25c; $1 / 4$ lb. 70c; 1 b. $\$ 2.25$.

\section{REUTER'S EARLY JERSEY WAKEFIELD}

The quality of our select stock of this well-known variety has created considerable comment throughout the South. and we can assure our customers that our seed this season will be the same, grown on Long. Island, where the variety originated, and where the soil and climate are best suited to produce the purest and most vigorous stock. Heads solid, erect, and conical in form, very uniform in size. Our stock has few

Price. pkt. 5c: oz. 20e; $1 / 4$ lb. 60c; 1 b. $\$ 2.00$. 


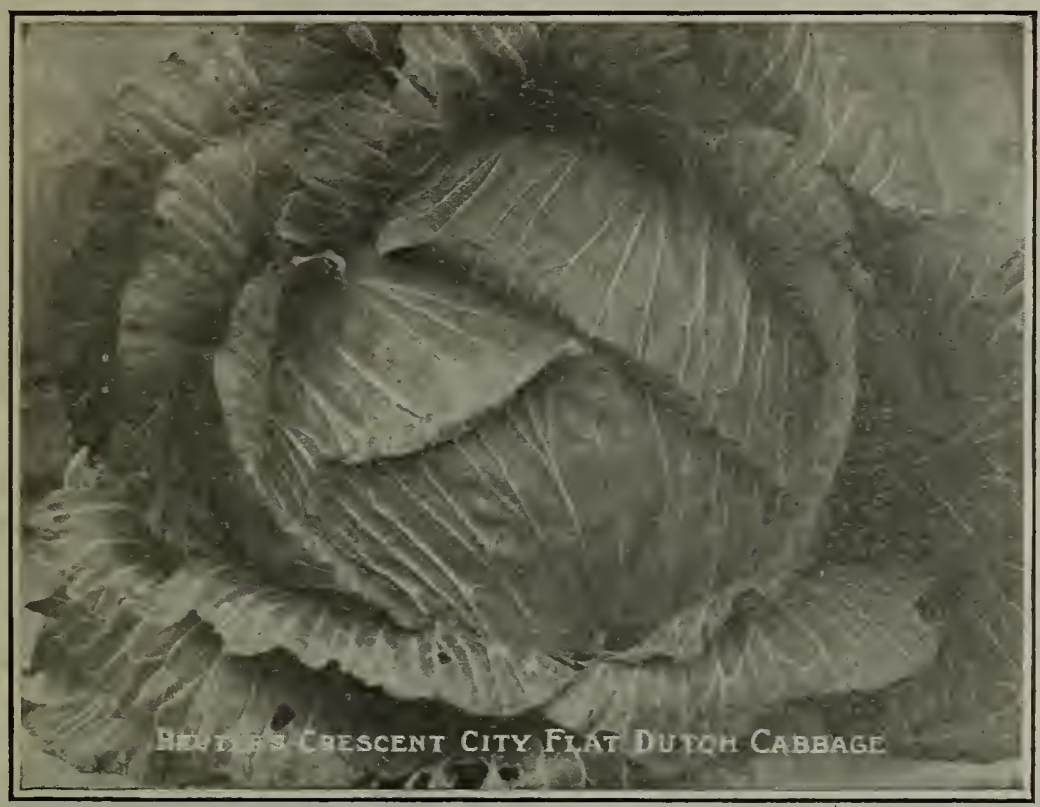

\section{STEIN'S EARLY FLAT DUTCH CABBAGE}

The most popular of all Early Flat Dutch varieties grown

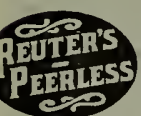

by the local market gardeners, and the very large quantities we have sold in Texas, Louisiana and Mississippi the past two years, show that it is an extremely valuable sort to all truckheader, very uniform in growth and of fine quality. It is a dwarf and compact grower, allowing close planting. We have taken great pains to secure a fine strain of this cabbage and we think our reselected seed is without a superior. We do not handle the cheap imported English seed of this variety, but obtain our stock from a most reliable grower on Long Island.

Price, pkt. 5e; oz. 25c; 1/4 lb. 70c; lb. \$2.25 (prepaid).

\section{REUTER'S IMPROVED EARLY SUMMER}

This valuable variety is widely known and largely grown. It forms large, flat, round, solid heads, weighing eight to ten pounds each. though with rich cultivation it often gives ten to twelve-pound heads. The heads are very compact and solid. The quality is most excellent. It matures about ten days later

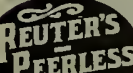
The quality is most excellent. It matures about ten days later
than the Early Jersey Wakefield, but is much larger in size. It is one of
the best early cabbages. Our seed is strictly Long Island Grown.

best early cabbages. Our seed is strictly Lon
Price, pkt. 5c; oz. 20c; 1/4 lb. 60c; 1b. \$2.00.

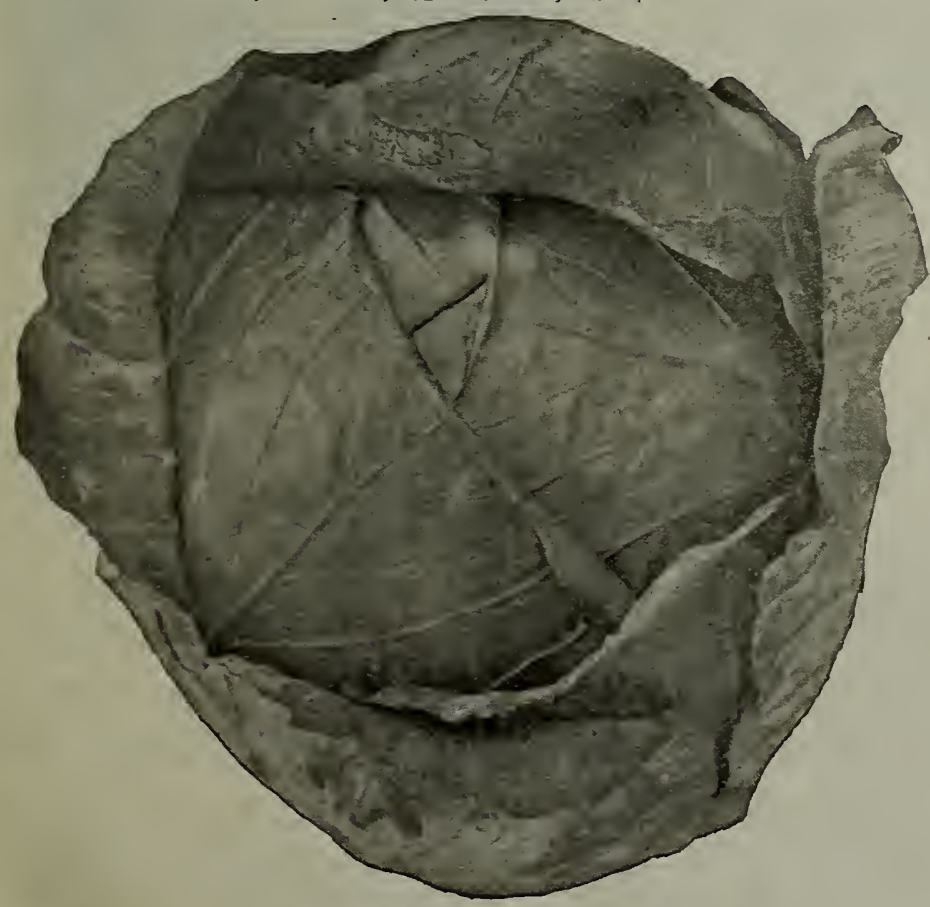

Reuter's Red Zenith (New)

\section{REUTER'S EXTRA EARLY FLAT DUTCH}

The best of the Extra Early Flat Dutch varieties. The plants are compact, with round thick leaves that form an oval head, which is very large for the size of the plant.

Price, pkt. 5e; oz. 25c; 1/4 lb. 70c; 1b. \$2.25.

\section{REUTER'S CRESCENT CITY FLAT. DUTCH} $A$ Grand Leading Main Crop Variety

This excellent variety is one of the finest strains of the Late Flat Dutch Cabbage on the market. In growth it is particularly strong and vigorous. Its color is a dark bluish green, indicating robust constitution and healthy development. The leaves are broad and well filled out to their juncture with the stem. The head is thick and flat, with outer leaves covering it well across the center. It is very of coarseness, the veins and ribs being well developed, but not prominent. Very popular with the leading truckers in St. Bernard Parish, Louisiana. $\$ 2.20$; 5 1bs. $\$ 10.7 \%$.

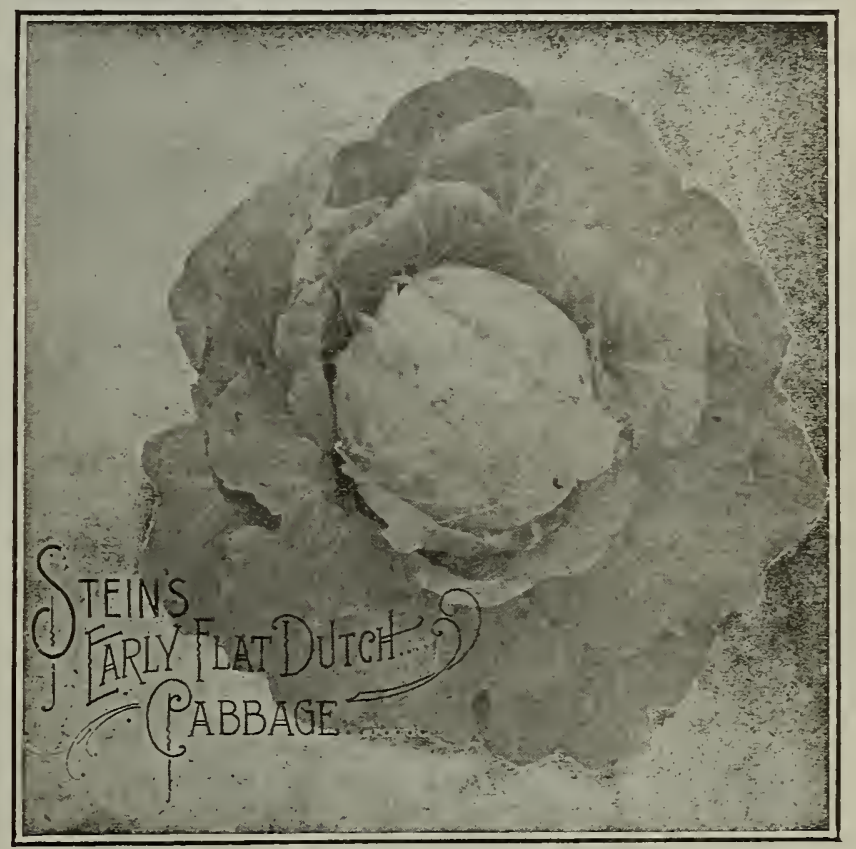

\section{MAMMOTH RED ROCK}

The largest and best-heading Red Cabbage. Produces heads averaging from fifteen to twenty pounds each. It keeps longer than most varieties, and never fails to head, and is of close, compact growth.

Price, pkt. 5c; oz. 25c; $1 / 4$ 1b. 70c; 1b. \$2.50.

\section{REUTER'S RED ZENITH (New)}

This grand new Red Cabbage is a vigorous grower nd quite hardy. The heads are of dark red color, and are extremely firm and heavy. The quality is superfine, and we cannot too highly recommend it. rom all sections

Price, pkt. 5c; oz. 30c; $1 / 4$ 1b. $\$ 1.00 ; 1 b . \$ 3.50$.

\section{ALL HEAD EARLY (FAULTLESS)}

The earliest of all large Cabbages. The heads are large and remarkably solid; flat, and very compact. The hard heads grow so free from spreading leaves that fully one thousand more heads than usual can be cultivated on an acre.

Reuter's Selected Stock, oz. 20c; 1/4 1b. 70c; 1b. \$2.25; 5 lbs. $\$ 10.75$ (prepaid).

\section{ALL SEASON, OR VANDERGA W}

A very good all-season sort. It is almost as early as the Early Summer, but a great deal larger. A sure heading variety at any season of the year, and is all that the name ilent quality. Suffers very little from excessive drouth or heat.

Reuter's Selected Stock, oz. 20c; $1 / 4$ 1b. 70c; 1 b. $\$ 2.25$.

\section{EARLY WINNINGSTADT}

One of the best second early varieties, being very hard and sure to head. Heads are medium size, conical in shape, and quality very ity

Reuter's Selected Imported Stock, oz. 15c; 1/4 1b. 40c; 1b. \$1.50: 


\section{Money=Making Kinds $\quad C A B B A G E$}

Selected for You if

You Live in the South

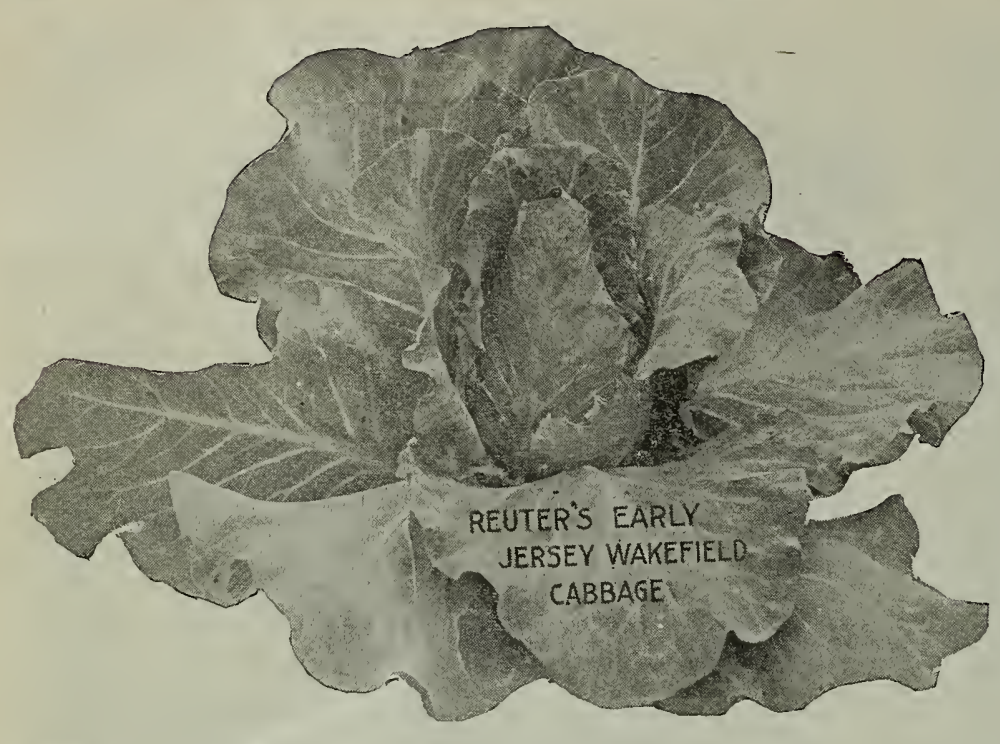

\section{REUTER'S IMPROVED AMERICAN SAVOY}

The best cabbage for quality and flavor, and is far superior to the ordinary Savoy varieties on the market. Leaves are beautifully curled, and when touched by frost becomes very tender and delicious. A good header and vigorous grower.

Price, pkt. 5e; oz. 20e; $1 / 4$ lb. 60e; lb. $\$ 2.00$.

\section{REUTER'S PREMIUM FLAT DUTCH}

One of the oldest varieties in existence and more largely planted than any other sort, producing large, solid heads of bluish green, with a broad and flat surface. When touched with frost, the outer leaves and tender. Our strain is without an equal, and trial will convince you of its remarkable purity.

Price, pkt. 5e; ox. 20c; $1 / 41$ lb. 60c; 1b. $\$ 2.00$.

\section{FOTTLER'S IMPROVED BRUNSWICK-Short Stemmed} A very fine second early variety, and is the earliest DUTDS of the large-heading varieties of Drumbead Cabbage. anjuss Every head is uniform and remarkably solid even Wead resting almost directly on the soil. Its uniformity in shape, solidity and large yield per acre makes it especially valuable for market gardeners. With good cultivation the heads average about fifteen pounds.

Price, pkt. 5e; or. 20e; $1 / 1 / 1$ lb. 60e; 1b. $\$ 2.00$.

\section{Reuter's Danish Grown Cabbage Seed}

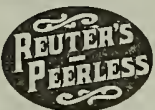

\section{Imported Direct From Denmark!}

The Cabbage seed listed below are strictly Danish Grown from the stocks, and there are no higher bred seed than the strains we offer.

\section{DANISH BALL HEAD-Tall Stemmed}

The most popular winter variety. One of the hardiest Cabbages in cultivation, and resists both cold and ary weather equally well. Heads are round, very hard and solid. A compact and vigorous grower. Quality is unexcelled and is very popular on account of its well-known lkeeping qualities.

Price, oz. 25e; $1 / 4$ lb. 70c; 1 b. $\$ 2.50$.

\section{DWARF AMAGER - Short Stemmed Danish Ball Head}

The heads are round and large, very solid and about two weeks earlier than the Tall Stemmed variety.

Price, oz, 25e; $1 / 4$ lb. 70c; 1 b. $\$ 2.50$.

\section{DANISH ROUND HEAD}

The heads average larger and mature fully two or three weeks earlier than the Danish Ball Head. It is very hardy. resisting heat and disease well. The plants are very strong and compact in growth, producing round solid heads of finest quality.

Price, oz. 25e; 1/4 lb. 70c; 1b. \$2.50.

\section{COPENHAGEN MARKET}

The heads of this Cabbage are of a splendid shape and ready early in the season. It is not only early, but is very large, firm, Winter Ball Head very closely, except that it is smaller and slightly flat on top.

Priee, oz. 25e; 1/4 1b. 70e; 1b. \$2.50.

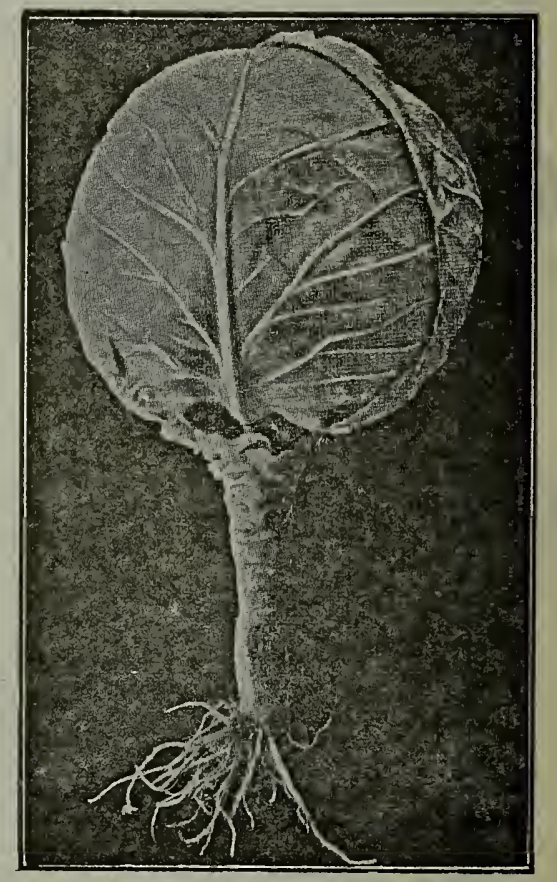

COPENHAGEN MARKET

\section{EVENTUALLY YOU WILL BUY MY SEEDS!}

I am a farmer and gardenex. I am a suecessful farmer, because $I$ apply myself to my work in the right kind of way. Kxperience on my own farms has taught me that there is such a thing as deception. I have found that this dishonest field is larger than even you or $I$ think it is. There are hundreds of new and old secd houses in this grand old land who seem to devote all their time and energy to furnishing their small list of customers with good-for-nothing seeds. They don't lonk for repeat orders. They seem to think that if they stick you once it is enough. They don'tgo any further, beeause the field is so large, so mall fall for their line of talk, and bite, that they are generally satisfied with but one order from some of the most gullible. selling them to right now that $I$ am selling goodsceds, and I am selling them in the finest section of this whole eountry. I am them the truth. The theory of to-day that buying seeds is atrietly a dollar and eent proposition is false. It is wrong, and $I$ stand ready to prove it to you that this statement is radical and without foundation. When you buy seeds fro mme, it is a dollar and QUALITY proposition all he tine.

The Seed Question has you guessing. You no longer contend that all seeds are the same. Big, prosperons, progressive, farmers like John Meyer, A. H. Ahten, S. W. Hostetter, A. B. Blakemore, Frank Fordano, R. \& G. Riess, and thousands of others in Texas, Louisiana, Alabama, etc., most eertainly have induced you to wit up and take notice. I am not trying to advocate myself as the only reliable seedsman in the South. No doubt, you ean buy just as good elsewhere, but you are assured of a bigger nct brofit on your farm in the long run when you buy my seeds.

For thirty-four years I have devoted every bit of my time and energy to the gardener and farmer. I know the requirements of a good seedsman from their standpoint. I am trying to live up to this standard, and sell them seels that are always trustworthy, pure, reliable, and producers of big, profitable crops. I seleet only the kinds of seed that I know will brillg profit to the grower. the not deal in untried, worthless novelties.. I have eliminated them entirely from my catalogue, although many seedsmen derive after year on my own farms, or on farms under my own personal supervision. My seed crops in the North are personally inspeeted each year by myself or one of my sons. I have four sons. They are four good ones, too, bint am not going to talk about my family here. Sometimes $I$ contract for the entire seed output of some of these farms. I am a erank on quality, and sometimes $I$ find it $n$ hard proposition to get sone one to grow my seeds. I must, of eourse, pay more, because I deerease the yield of good seeds by enstant rosueing and eliminating the off-types. This costs lots of money, but in the end it vill be my most profitable venture, and will terd to always increase my trade and reputation. I don't buy from dealers at all. I buy DIRECT from growers. I know what $I$ am getting all the time, and $\mathrm{know}$ what $\mathrm{I}$ sell you, too. This means a great deal to me, and less worry to you. 
Four Pounds

Plant an Acre French=Grown CARROTS

Write for Prices on

Large Quantities

Carrot Seed is a leading specialty with me, and all of my stocks are hand rubbed, and are grown for me by critical and experi. enced growers who know the vital importance of careful selection and isolation. My seed is of the highest class and should satisfy any Market Gardener, no matter how discriminating. Our Market Gardeners planted 9,000 pounds of my Carrot Seed during 1913.

Culture-Requires a well-enriched sandy soil, well manured. If the ground is not of this quality, it should be dug deep and well broken the year previous. Sow in drills one foot apart, covering the seed half an inch deep. Thin out the plants from three to five inches apart, according to the variety. Our local gardeners sow them broadcast, and very often the roots are small from being crowied ton much together.

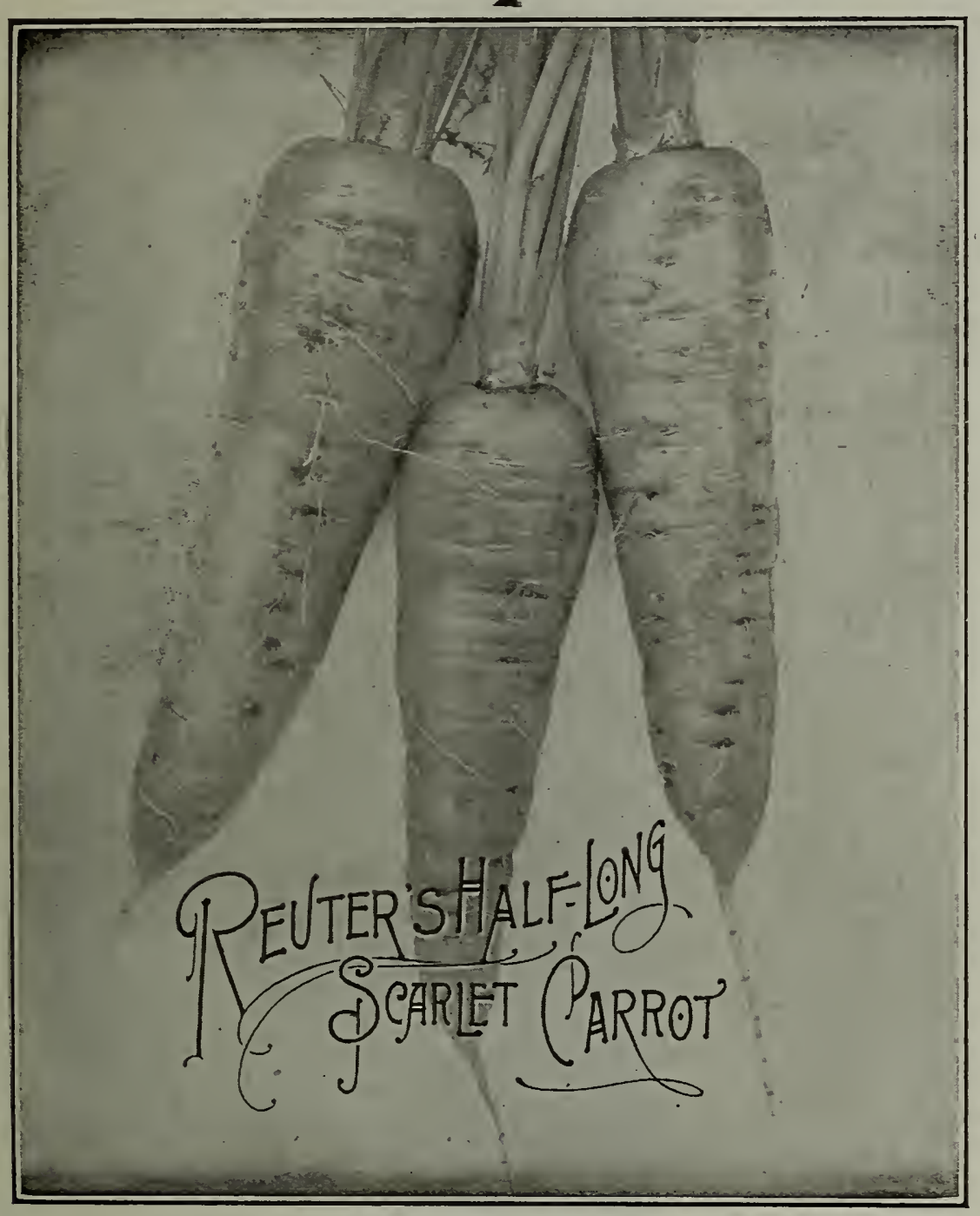

\section{EARLY OXHEART, OR GUERANDE}

A very short, thick carrot, often attaining a diameter of five to slx inches. terminating abruptly in a small tap root. Especially edapted to hard, stiff soil where a longer variety will not thrive.

Price. pkt. 5e; oz. 15e; 1/4 1b. 40c; 1 b. \$1.50.

\section{REUTER'S IMPROVED LONG ORANGE}

A well-known variety. The roots are of large size, and are smooth, fine grained and in all respects superior. It is a good keeper. Enormous crops can be grown under good culture, particularly in deep. light soil. Grown extensively for stock feeding.

Price, pkt. 5e; oz. 10e; 1/4 1b. 25e; lb. 80c.
REUTER'S IMPROVED EARLY HALF $=L O N G$

\section{SCARLET}

The Most Profitable Market Variety

This is the best early Carrot of its

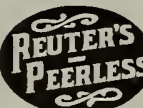
kind in existence, and is largely raised in gardeners for their main early crop. Roots are medium size, thickest near the crown, rapering regularly to a point. It is remarkably even in shape and size, and we know of no sort that equals it in this respect. It is a heavy cropper, and, owing to its beautiful appearanee and extreme earliness, it is more extensively cultivated for market than all other varieties. Those desiring an excel.

Price, pkt. 5c; oz. 10e; $1 / 4$ lb. 25e; 1b. 80e.

\section{REUTER'S EARLY CHANTENAY}

\section{Best Bunching Variety}

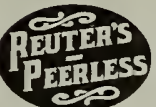
A handsome, stump-rooted sort, growing six inches long. very uniform and mously, productive. It is largely grown mously productive. It is largely grown by the local market gardeners for bunching, and we regard it as one of the most profita Price, pkt. 5c; oz. 10c; 1/: lb. 25e; 1b. S0c.

\section{REUTER'S ST. VALERY}

Early and Main Crop Variety

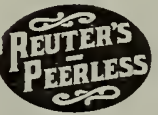

A long handsome variety. The root,
which is very straight, very smooth, and which is very straight, very smooth, and bright red, is very broad at the neck, when it is frequently two and three inches in may be ten to twelve inches, is only about four and cultivated extensively for the market.

\section{REUTER'S SELECTED DANVERS}

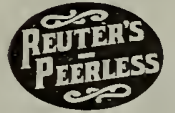

The finest Carrot ever introduced. It is superior to all others for a main crop, and is very popular with the market gardeners throughout America on account of its productiveness and adaptability to all Roots medium in length and taper uniformly to a blunt point. My strain is the most uniform in size, highly recommend it to all gardeners and truckers. Price, pkt. óc; oz. 10c; 1/4 1b. 25e; lb 90c; 10 lbs.

\section{REUTER'S MAMMOTH WHITE BELGIAN}

The best stock carrot in existence, and is being extensively cultivated throughout the South for this purpose. It is an extra heavy yielding variety, of splendid quality, often 16 inches in length, yielding as high as ten tons and over of roots per acre. There is no better stock feed in the world than carrots, and you should plant a few acres this year. All you have to do is to cut them up, sprinkle with salt and feed with meal. The yields are enormous.

Price, pkt. 5c; oz. 10c; $1 / 4$ lb. 20c; 1b. 65c; 10 lbs. $\$ 6.00$ SALSIFY, OR OYSTERPLAN7

Culture-Succeeds best in light, well enriched soil. Sow in drills, about ten to twelve inches apart and thin to three to four inches in the rows. Should be sown in the fall of the year, not Iater than December. Like Parsnips. Salsify is improved by a touch of frost.

\section{REUTER'S MAMMOTH}

\section{SANDWICH ISLAND}

Very large in size, roots of the finest quality and most delicate flavor. A popular snrt with al' raninnino

Price, pkt. 5c; oz. 15́c; 1/4 $1 b$. 50c; 1b. \$1.50.

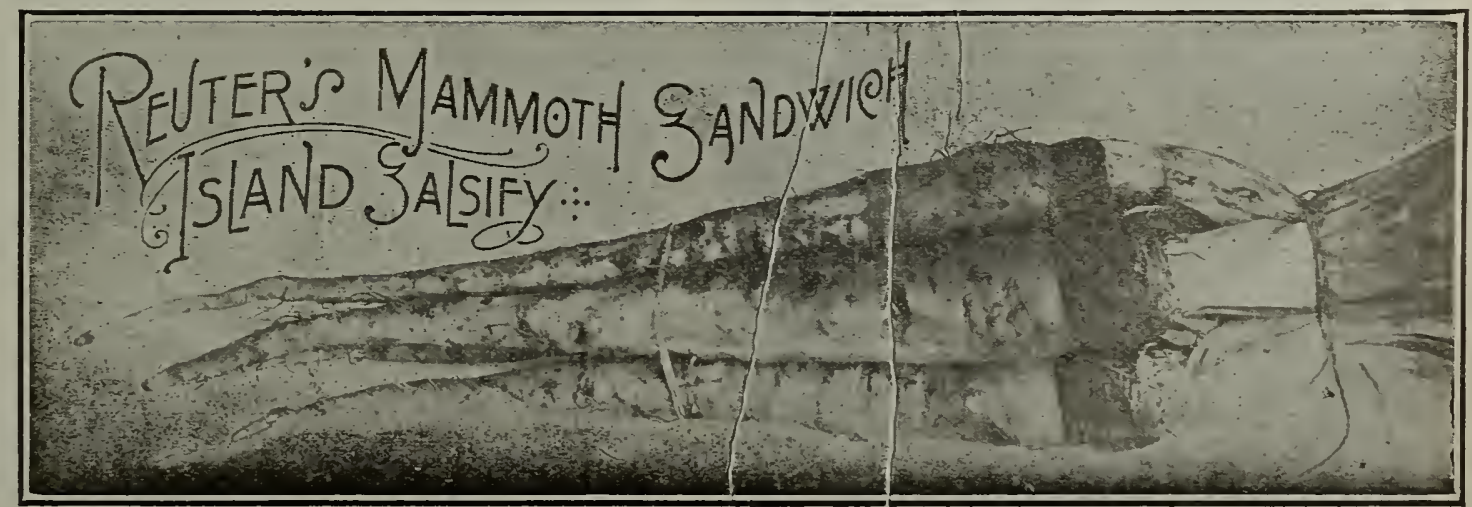



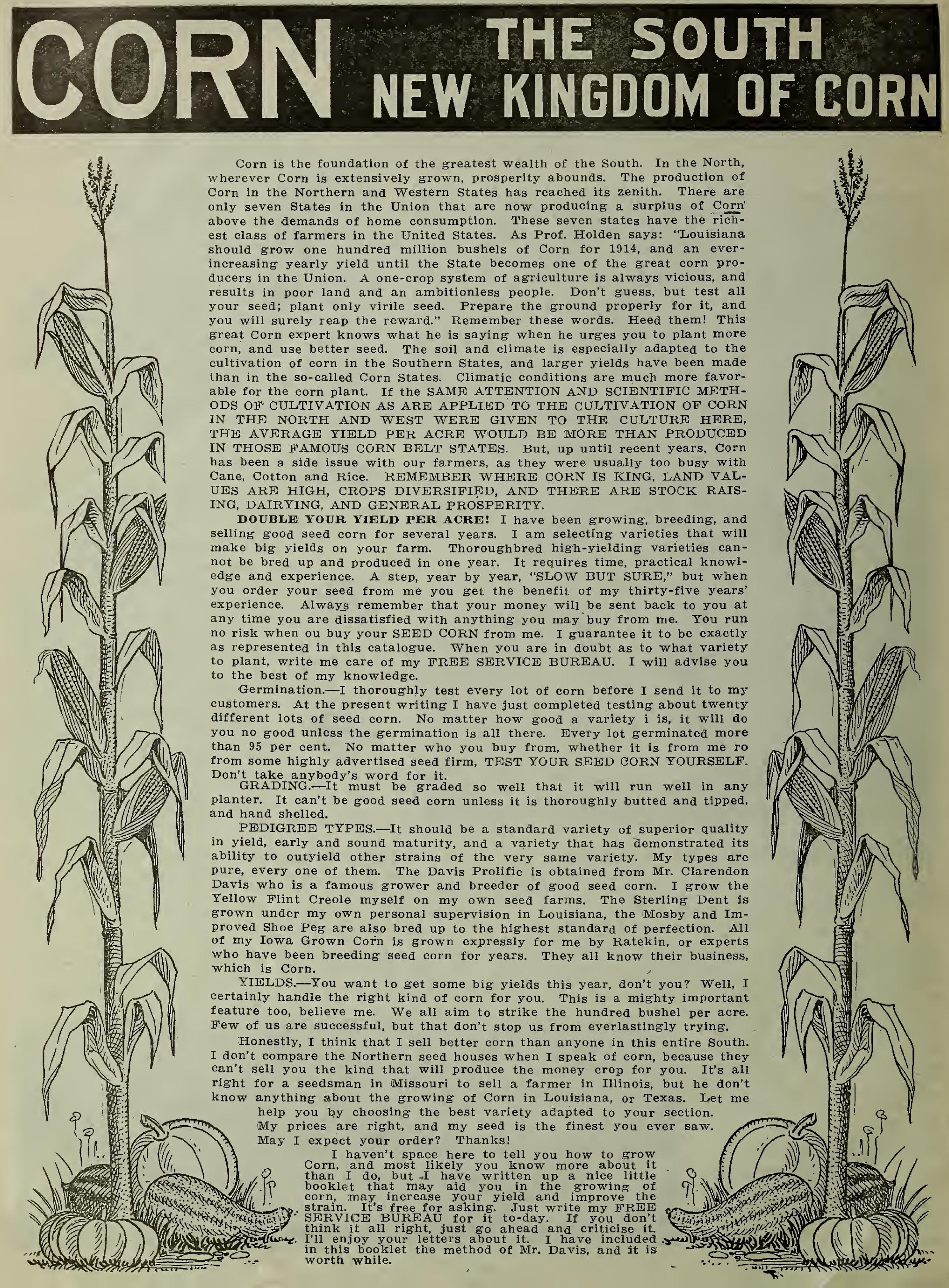


\section{REUTER'S PEDIGIEF SEED CORN}

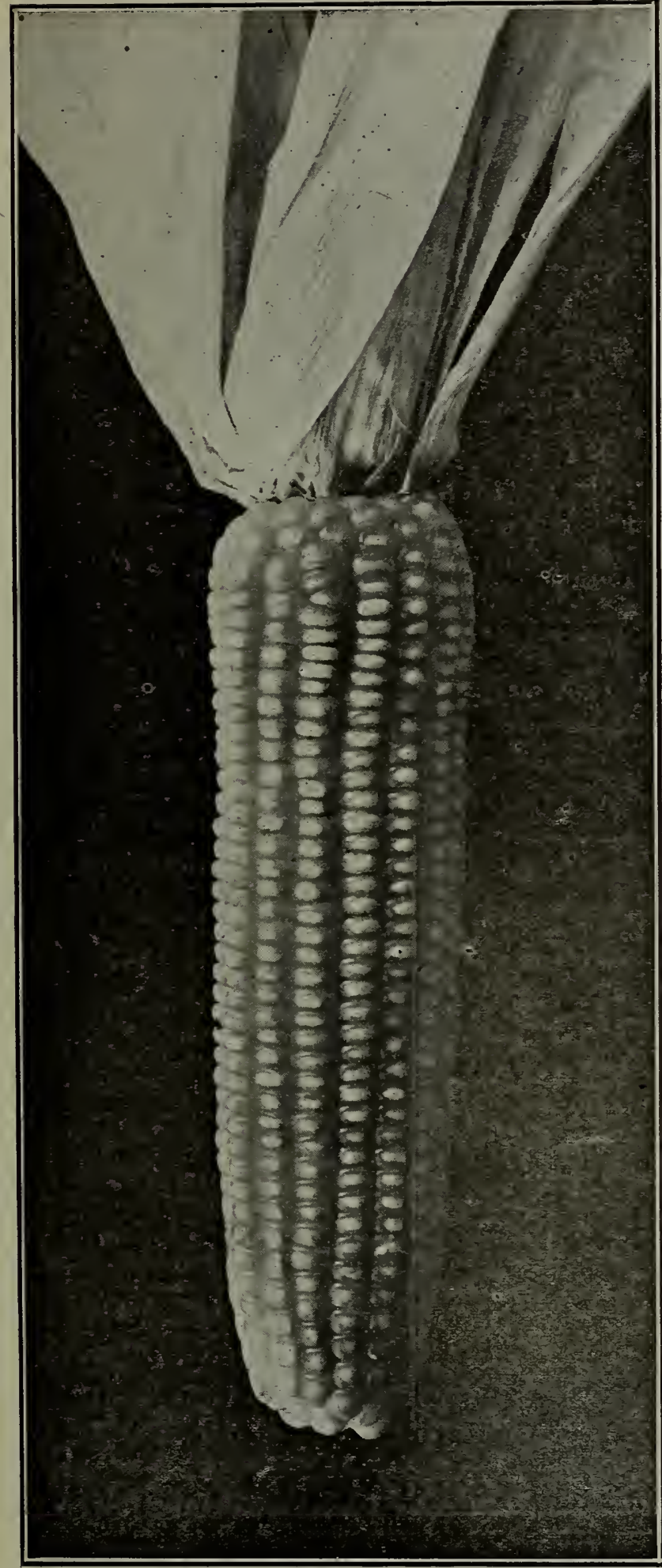

REUTER'S GENUINE YELLOW CREOLE

\section{REUTER'S YELLOW FLINT CREOLE}

Weevil Proof-Bird Proof-Drouth Proof-Rain Proof-Failure Proof

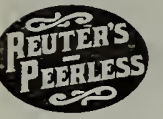

This is MY Corn. While I

ties ot corn as any seedsman in this country, yet $I$ devote more time to this one variety than I do to any other part
of my seed business. I grow it myself on my own farm, which is situated about fifty miles below New Orleans. I have of this seed corn, also Sorghums, and some vegetables, principally Letear with oranges selling more than $\$ 2.00$ per box, I will have lots of Christmas money. Did you ever eat a Louisiana Orange? Try one once. proposition, and want to say all I can about this splendid sort, which I grow EXCLUSIVELY on my farm. I do not orow any other sort. I devote every bit of my attention to the culture of this Yellow Flint Corn. Why? Because I believe that it is the finest Corn you can grow. It is the This corn was "born" in Louisiana. It was not introduced by anyone. I did not introduce it. It was growing here long before I was born, and oping it all the time improving it breeding. it up to the highest until oping it all the time, moproving it, breeding it up to the highest, until Of course, I can't do all this at once, as it takes time to develop a type, and requires lots of hard work and patience. lots talk like me before, and have tried their corn, and it proved to be anything but bug proof. Or perhaps it was weevil-proof, and lacked every other element to make it a desirable sort. But this corn is an all-around
good corn, and is splendid for your farm. It is the hardest grained yellow corn I know of that is adapted to the South. It resists drouth better than any variety, and will withstand more wet weather than anything HUSK covers the ear of the corn so completely and tightly that it is impossible for any bird or weevil to get to the corn. The husk is big and heavy and closes like a vice over each ear of corn. This feature only fashioned corns planted in the South plant this sort. Most of the oldin the crib by the grain weevil, this pest often making it unfit for feed. If you want to keep your corn the entire year and have feed twelve any soft corn you have ever planted, and is absolutely weevil proof, because the weevils simply can't eat it. The cattle on my farm relish it, for the Northern Feed Corn as well. This Corn contains only TWELVE PER CENT OF MOISTURE at husking time and is so dry when picked that it is ready for immediate export to any European market or South Africa. Liverpool buyers prefer it to all other kinds of corn they receive, condition, whereas other corns will usually heat and get musty. The progressive Sugar Planters in Louisiana always plant this Corn. They growing in this state for a century, but no attempt has ever been made to improve or develop it until I planted some on my farm. In a year or so, grown under the "HOLDEN SYSTEM." You all know Prof. Holden, the great corn expert. If you don't try to 'get acquainted with him next time he gets in your town. as he will aid you in your crop of corn. He has forty bushels to the acre, and as you well know the forty bushels to the acre, and as you well know the sho was a very creased the yield somewhat. Produces two good ears on every stalk, and sometimes three. I suggest that you plant this seed in February or early advance of the corn movement from the Northern and W'estern States. in Louisiana and produces excellent results, as it will even then mature STOP PAYING FOR NORTHERN CORN GROWERS' AUTOMOBILES! Do you know that thousands of carloads of corn are shipped into Texas, Louisiana, Mississippi, and other Southern States every year from Missouri, Nebraska, Iowa and other Northern states? Do you know that richest in the entire countr. you can't pay train fare
to take your family to the city once a year. in line with them and in line with them and CREASE THE YIELD! MORE AND BET is what we want now. Corn never fails and other Southern States. During 1913 the drouth was fierce, and thousands of acres of corn in the North and West were burned out. During this year in Louisiana., Mississippi, and other Southern States raised 50 to 100 bushels an acre. Corn never fails in the South. The average rainfall is from 42 to 55 inches. The heavy rainfall comes durng season. There is never a failure from drouth if you plant the right seed. The growing season is eight months. Corn is never damaged by frost. With all these favorable conditions helping you, why can't you buy an automobile and enjoy life. Why can't you get richer bv growing corn? You ought to be tired of paying your local grain dealer feed bills. Make up your mind to quit- this year by growing Reuter's Yellow Creole Seed Corn. It will fill your crib or fill your silo. It will corn, the feed man would go out of businss so far as selling feed to the planters is concerned.

Reuter's Yellow Creole will grow weli on the poorest kind of land, but, of course, will do much better on rich ground. The stalks average eight to twelve feet in height. Has very long, deep roots, making it an excellent storm-proof and

drouth-resistant variety.
PRICE, PACKET 10e; quart (not prepaid) 20c; gal. 60c; peck 85e; bu. \$3.00; 10
bu. \$27.50. Write for prices on Orieans. Samples gladly furnished.

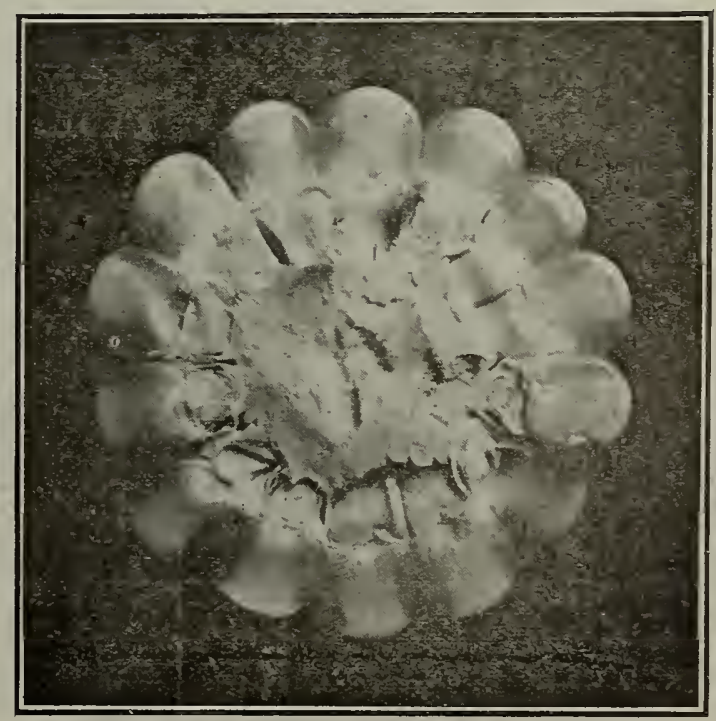




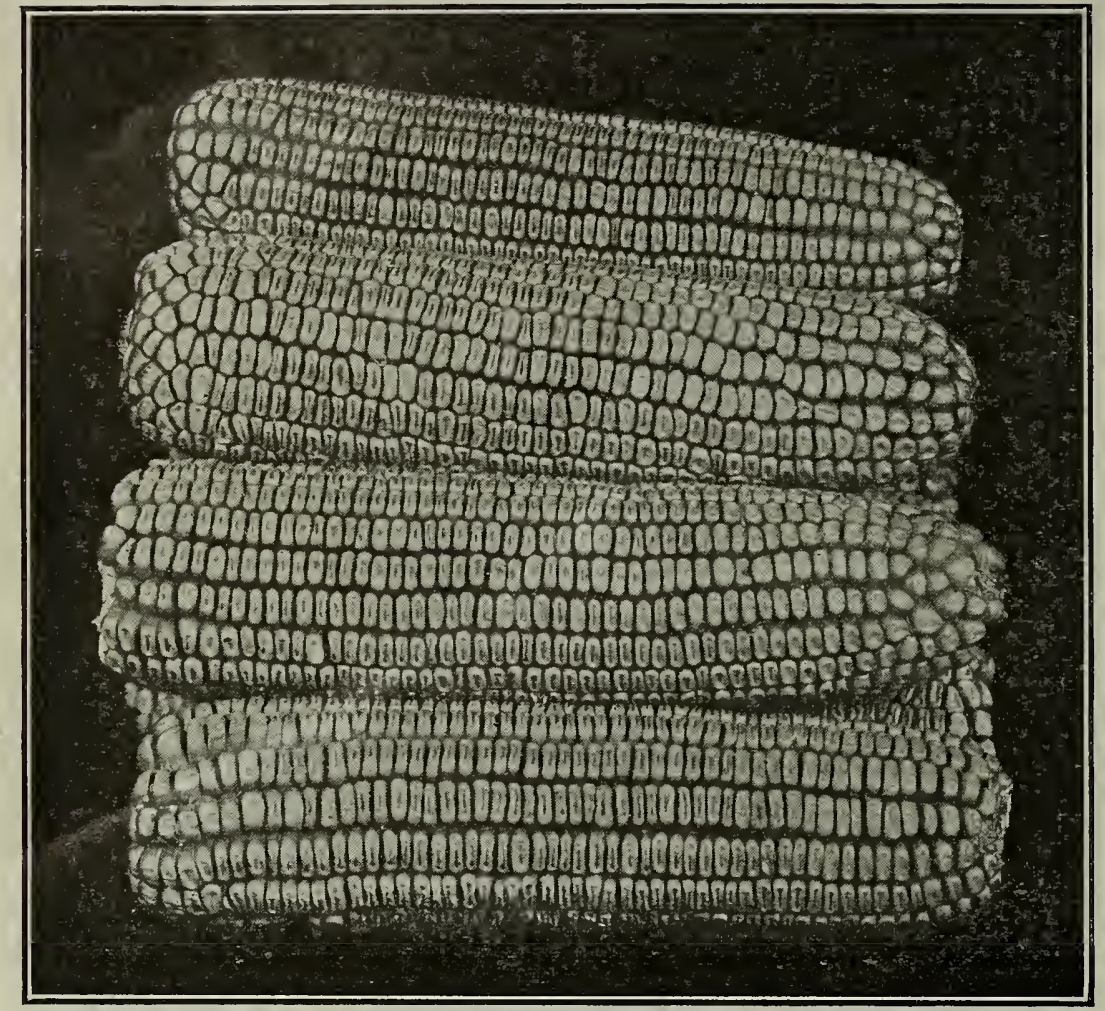

REUTER'S STERLING WHITE DENT, GROWN IN LOUISIANA

\section{REUTER'S STERLING WHITE DENT}

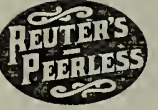

This is another grand corr, that deserves more attention and more extensive cultivation. New to you, but I have folseveral years, and made sure that it is all I claim for it. GROWN IN LOUISIANA under my own personal supervision, because I have contracted for the entire output of my grower, who has grow Corn for me but lots of Oats. Lespedeza. etc. lil fact. I oenerally look upon his farm as my own, and see to it that the crops are cultivated according to you own crank me but this crop does this corn look to and outyielded anything in the community. Everybody. for miles around would drive up to the farm on Sunday experts came along also and everybody praised it. I experts came along also and everybody praised it. I want you to get thoroughly acquainted with this grand, take my grower's word for it when he first told me about this variety. I told him I was from Missouri, and he showed me more than I expected.

\section{PEDIGREE SEED CORN}

Pedigreed seed corn, like pedigreed horses, must have a record behind them, showing their ability to produce larger yields than other leading varieties under
precisely the same conditions and same treatment, also
their vitality to resist extremes of seasons and weather to the utmost degree.

For years and years my growers have been improving this variety, devoting every bit of their time to the breeding of this superfine corn. The possibilities of my grower to develop a superior type from this stock appealed to me several years ago, so I urged him to grow his ideal. This has had type ear which came nearest uniform type of the corn much to do with the present tion to yield, yet he never overlooked selecting only good size ears, deep kernels and comparatively small cob, and the rows. A rather rough rugged type was developed without giving much attention to most of the fancy show characteristics. A tendency
to select ears with well-filled tips probably had something to do with the fact that the Sterling Dent has a tendency to produce a
considerable proportion of ears large in circumference as compared with their length. The indentation is noticeably rough, but not harsh to the hand. The butt is rather fine for white corn, the kernels rounding out well around a shank.

In order to get a good yield my grower attempetd to get a corn which would grow few or no stalks that either were barren or which bore small nubbins. He did not consider more than two ears per stalk objectionable provided. the ears were well developed. So when this corn is planted on good soil its tendency to prolific production is very noticeable, many hills with three stalks
producing four to five good ears. Even six ears have been found in such hills. They usually produce two good ears however, which any good corn grower will say is enough.

It is grown in Louisiana, and is thoroughly acclimated in every respect. Anyhow, to-day a man is not judied by what nis father is, but by his own ability to do good and .

flint variety. The birds can't harm my Sterling Dent, however, because the this kind in the right manner after you have harvested it, you won't have ans set completely in straight rows. It is a very strong growor, early enough f the least affected by drouth or rain, and produces an abundance of fodder. There is a big demand for well-bred acclimated Seed Corn. The climat to produce good yields, combined with good growth and good big ears. Wh early for main crop. Grows a rather robust stalk from eight to ten feet high mend this corn too highly, and urge you to plant it. It will make good on
your farm, just as it is making good on hundreds of farms ni the south.

HELP YOUR FARM TO BE A SUCCESS! Buy a bushel or so of this corn this spring and plant it. It will astonish you in yield and weevil resistance. want a field of the finest white dent corn for feeding and marketing, you will do well to try ten or twenty acres of it. It can be planted until June and will was mighty good considering the inclement weather conditions.

\section{BEWARE OF MONGREL "SEED CORN" GROWN IN THE NORTH AND SOUTH}

You don't realize just how much of this scrub stock is being sold to un suspecting farmers every year. Some dealers go out and buy up corn that looks good, but has never been bred or developed, and will never produce then go ahead and buy your seed. Pay a little more, for good corn see REUTER'S STERLING WHITE DENT is the best White Corn for you, while REUTER'S YELLOW FLINT CREOLE is the best yellow corn in the world. on better land will outyield anything in your field. Urge your friends to plant your two grand sorts. Plant liberally this year if you want to increase at least one of these two grand varieties? My word, they will prove trust-

Price, packet 10c; quart (not prepaid) 20c; mal. 60c; peck 80c; bu. \$2.75; 10 bu. \$25.00. Write for prices on larger quantities, either F.O.B. New Orleans or your station. Samples gladly furnished.

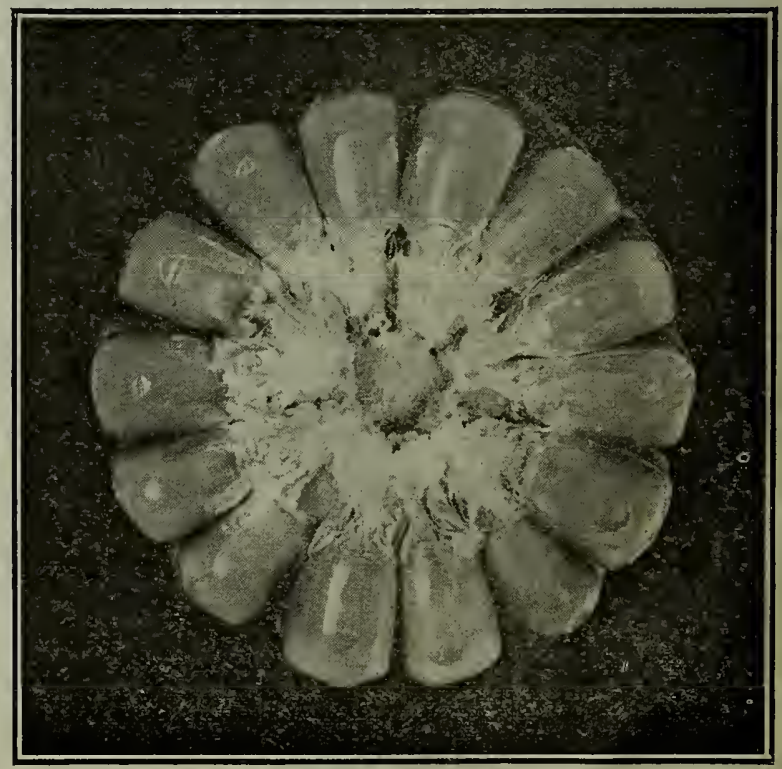




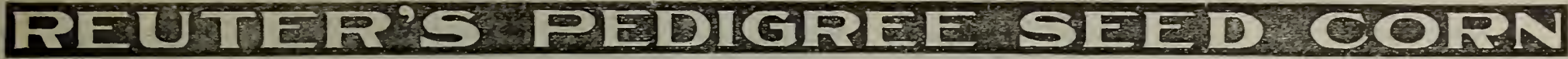

\section{DAVIS' PROLIFIC CORN}

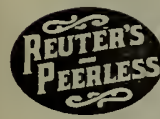

Davis Prolific Corn is the product of years of selection and breeding, the object being the producing of a high yielding corn suitable to the average soils of the South, and one that was hard
enough to resist the weevil, and at the same time not too hard for stock to eat, and one that would produce two ears to the stalk where the soil's fertility was sufficient to produce them. This we have aecomplished and are now supplying the most critical farmers
in Texas, Louisiana, Mississippi, North Carolina and Tennessee with this corn. This corn is well known as DAVIS POOR LAND CORN because of its ability to make good yields on land that ordinarily would not produce a fair crop of the usual Southern varieties. Any corn that will produce well on thin soil will, of course, make heavy rields on good lands. deep, wedge-shaped grain, with small cob. The ears are
medium in size, filling close in the rows and well out at medium in size, filling close in the rows and well out at the tip and butt. It is not a flinty grain, but one of the soundest corn grown. It is fine stock corn and makes most excellent meal and is in great demand for milling purposes. shell out 60 to 62 pounds of grain, or 86 per cent. Ordinarily ear corn will shell out 56 pounds to the bushel, or eighty per cent

The demand for this corn has grown until Mr. Davis was unable to supply it. He grows only one corn on his big farm in Alabama, and this one corn is DAVIS'PROLIFIC. In 1910 he raised 6,626 bushels, and in 1911 he raised 5,164 aged 65 bushels to the acre. The 1911 commercial seed field of 80 acres averaged 54 bushels to the acre. The 1912 commercial seed field of 50 acres averaged 64.2 bushels to the acre.

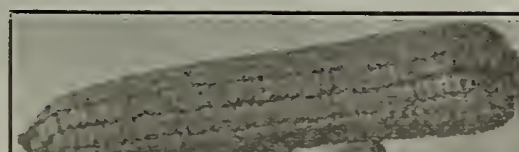

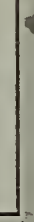
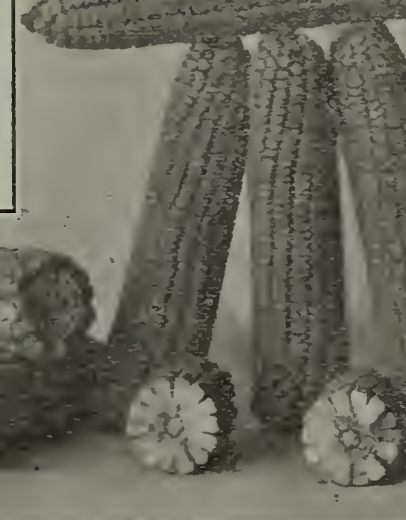

DAVIS' PROLIFIC CORN

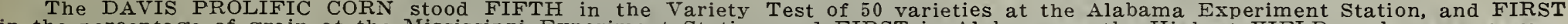

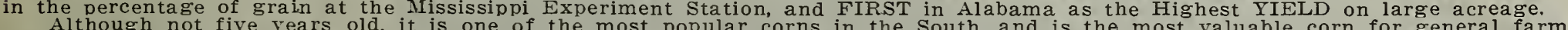

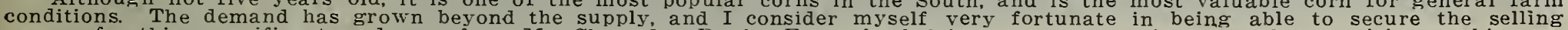

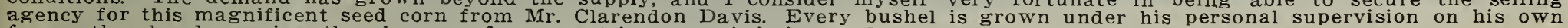
farms, thereby decreasing the chances of your getting poor inferior seed.

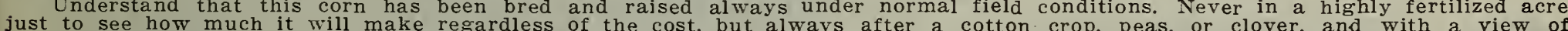
after a cotton crop, peas, or clover, and with a view of

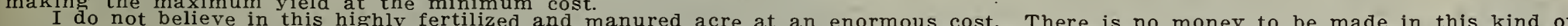

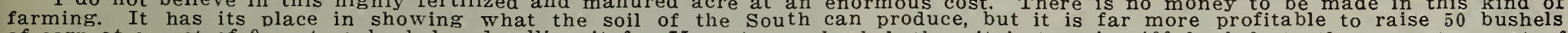

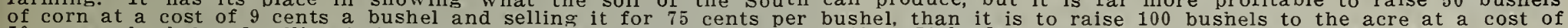

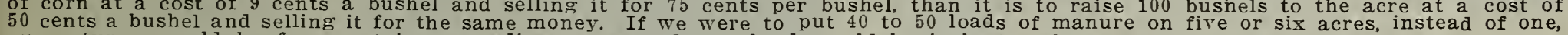

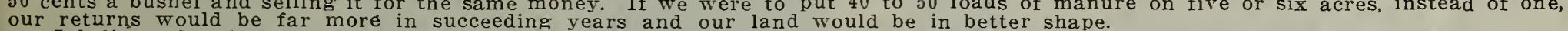

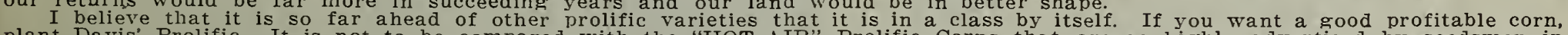

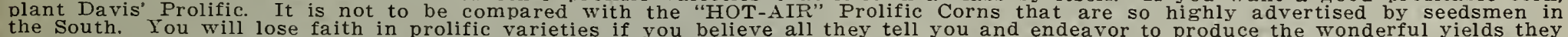

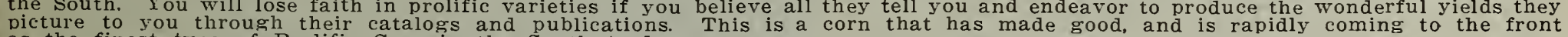
as the finest type of Prolific Corn in the South to-day.

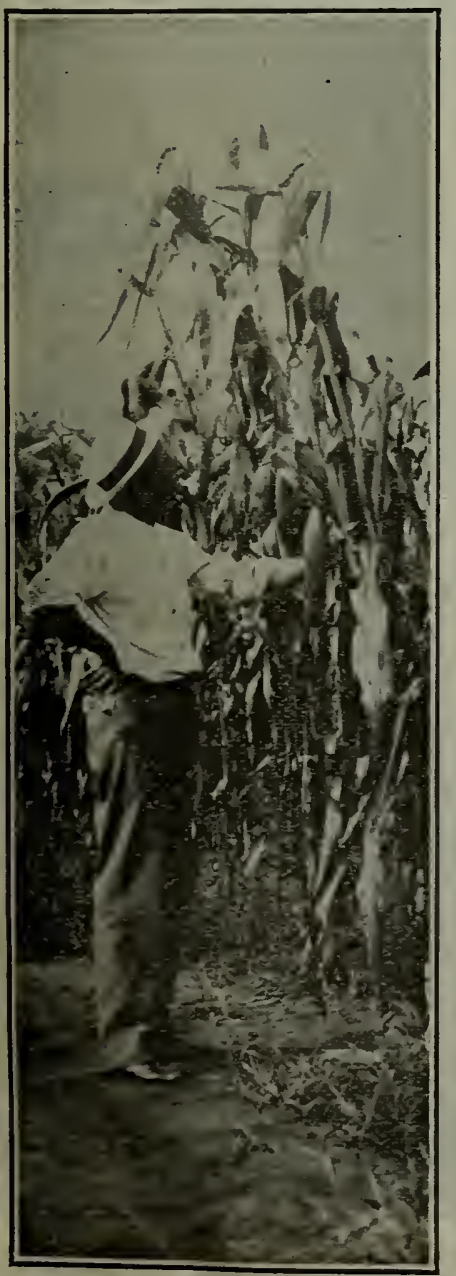

Mr. Davis and Some Corn

It has been bred to exactly two ears to the stalk so as to develop size and avoid four or five nubbins, characteristic of some prolific sorts. Ears average eight to ten inches long, rows twelve
to sixteen grains long, pointed, medium hard, medium size, evenly lined and irmly set on small to sixteen grains long, pointed, medium hard, medium size, evenly lined and irmly set on small
white cob. This variety fills out well both tips and butts; in fact, the ear, owing to the smallness of the cob, is practically all Corn.

who who is one of the most progressive farmers in our Southern country. He has bred up by careful selection a variety of corn that has given wonderfully good results over the South. He has Jour seed from me. South many varieties of Prolific Corn are sold to the farmers. When planted they usually produce four or five small ears that are practically worthless for feed or grain purposes. These "Hot-Air Prolific Corns" are a curse to the Southern farmer. The seed irregular, the strain is not pure, the yield is lessened, the germination is impaired; in fact, the corn produces the poorest kind of crop. You then lose faith entirely in Prolific Corns. I don't ly evaded by the farmer who is growing corn for profit. With the Davis' Prolific you have the about it, but just a pure, reliable, pedigree Prolific Corn that is being grown in Alabama by Ir. Clarendon Davis. He don't say that it is the finest corn in the world, but he does state that it is a Prolific Variety that has come to stay, and will eventually supersede every Prolific Mr. Davis' farm. He plants no other kind. Will you do the same? farm, the same as it has on

DAVIS PROLIFIC CORN is a wonderful producer of both grajn and forage. It is the finest type of Prolific Corn I have ever seen. It is the best ALL-AROUND CORN you can plant.

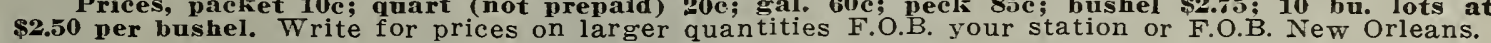

\section{TESTIMONIALS}

Dear Sir-In reply to yours of Nov. $27 \mathrm{th}$, will say that I was more than pleased with your corn. I have saved all my seed for another year from the corn I ordered from you. It averaged 50 bushels per acre. It is all you claim.

Wishing you much success, I am.

\author{
Respectfully yours, MEARS.
}

Malesus, Tenn., Nov. 30th, 1911.

Mr. Clarendon Davis. Huntsville, Ala.

Dear Sir-Replying to your favor of the 21 st inst.. would say that the seed corn (The Davis Poor Land Corn) that I purchased of you last spring. Was planted from April 28th to May 10 th. Came up unusually well-I think at least $98 \mathrm{per}$ cent came up vigorous and strong, and grew corn on the road from Medon to Jackson. I regard the Davis Poor Land Corn very prolific and corn on the road from Medon to Jackson. I regard the Davis Poor Land Corn very prolific
exceptionally free from rot.

Oak Park Plantation, Olive Branch, Miss., Dec. 10th, 1911.

Mr. Clarendon Davis. Huntsville, Ala. been in cotton since it was cleared. It made 45 bu. per acre without fertilizer. The yịeld would been in cotton since it was cleared. It made 45 bu. per acre without fertilizer. The yield would with the result and shall continue to raise your corn. 


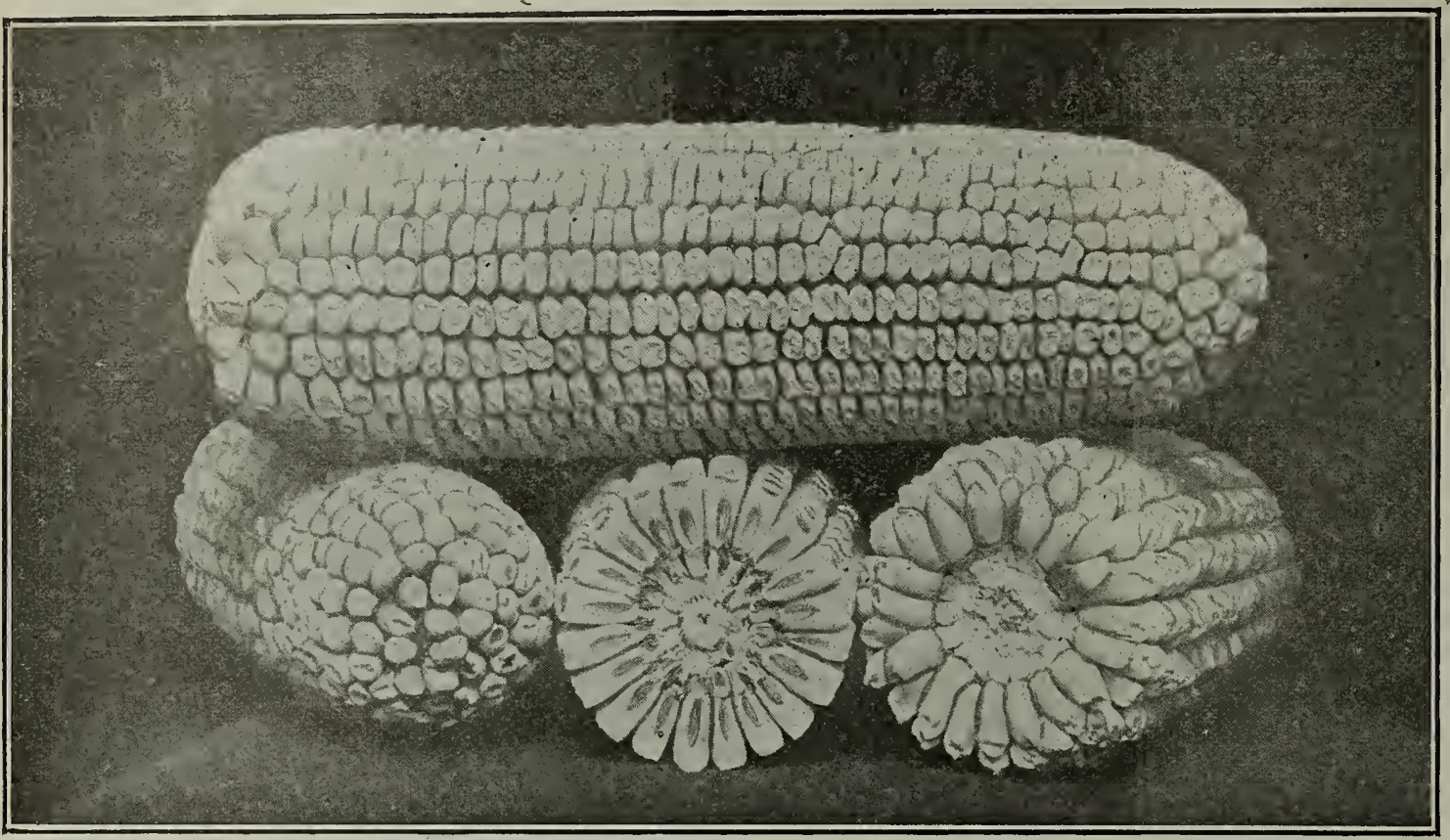

TEN REASONS why you should plant IMPROVED SHOE PEG SEED CORN!

It is adapted to your section. It is drouth and rain-proof It is weevil and bird proof.

It is a tremendous producer of grain.

It matures in 120 days.

It is flinty, but not a hard corn.

It can be planted as late as June.

It yields two good ears to the stalk.

It is grown in the South for you.

It has been thoroughly tried and tested.

\section{IMPROVED SHOE PEG CORN}

Shoe Peg Corn is by no means a new breed or variety of corn. There's scarcely an old farmer in the entire South, for this is STRICTLY A SOUTHERN CORN, who has not planted Shoe Peg during his life, and they all invariably prefer this variety for general planting. Being a native Southern Corn, it is perfectly adapted to. Southern conditions, such bad elements every time. We have known it to make a fairly good crop without any rain at all after crop was three

Whe ears of this variety turn down on stalk at maturity, causing them to shed water, while if they remain standing as many
The has weevils, but they are much worse on corn that runs out past the shuck. The shoe Peg has shuek that not only covers the end. but extends beyoud; practically a weevil-proof corn. Seventy pounds of Shoe Peg Corn will shell less than fifty-eight pounds, but no tests have ever been made showing such a low average. I offer you only the finest Shoe Peg Corn Seed obtainable Selected under personal direction of the breeder himself. I do not clairn that this is a world-beater variety, but $I$ do claim that it is one of the best ALL AROUND SOUTHERN CORNS you or anyone else can plant.

The cob is medium in size, carries from sixteen to twenty-four rows of corn. Cob is red in color. This is a flinty variety, however, it is not as hard as some corn. Color of grain is white with yellowish tinge. While it contains some strawberry blood, this corn is not as dark as the strawberry corn. I can truthfully say it is a milling corn of the HIGHEST QUALITY, and most excellent flavor.

\section{BEWARE OF DOUBTFUL 'SEED CORN!}

Many planters go to their nearest dealer when the planting season is upon them and procure a few bushels of cheap Northern Seed Corn to plant. When the crop is produced they begin to lose faith in the growing of corn in the South. Don't go near your general store when you anticipate planting seed corn. Tear the order sheet out of this catalogue and attach a money order on your

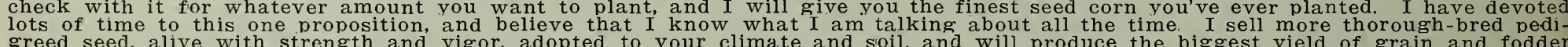
greed seed, alive with strength and vigor, adopted to your climate and soil, and will produce the biggest yield of grain and fodder

I'll tell you all about it on another page. I want you to plant some shoe Peg Corn this year. It averages two fine ears to than 60 bushels to the more properly cultivated. Plant durng February, March, April and Planted as late as June with good results. BY AN EXPERT. PLANT NO OTHER. BE SURE OF YOUI MEMBERED LONG AFTER THF PRICE IS FORGOTTEN. ORDER DIRECT FROM ME.

I have hundreds of testimonials on file about this corn. They are from good, honest, reliable farmers who value their cpinion believe me. They would not Write me such nice letters, if the Corn did not make good with Every old farmer in the South knows the good qualifications o Improved Shoe Peg Corn, and it is immensely popular wherever Prices of Improved Shoe Peg Corn Packet 10c; quart (not prepaid) 20e; sal. 60e; peck $\$ 1.00$ bu. \$3.00; $21 / 2$ bu. lots nt $\$ 2.75$ ner bushel. 10 bu, lots at paso

quantities F.O.B. New Orleans or F.O.B. your station. Samples giadly furnished.

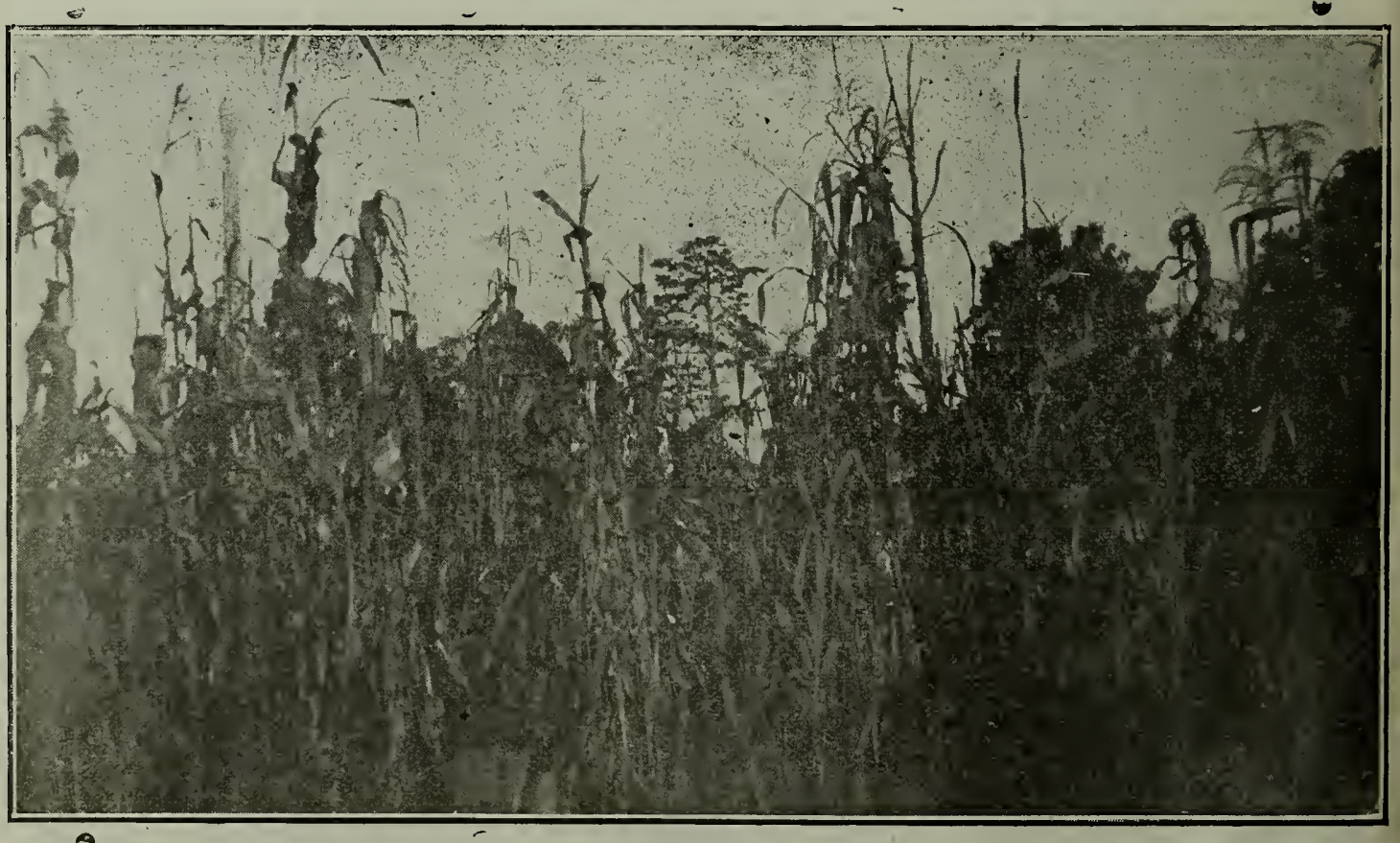

This picture shows the detasseled rows in the seed patch of our grower, the originator of this strain of corn, one acre of this corn gathered by actual welght showed a yield of 100 barrels to acre; 1 barrel of this corn will shell over 1 bushel. 


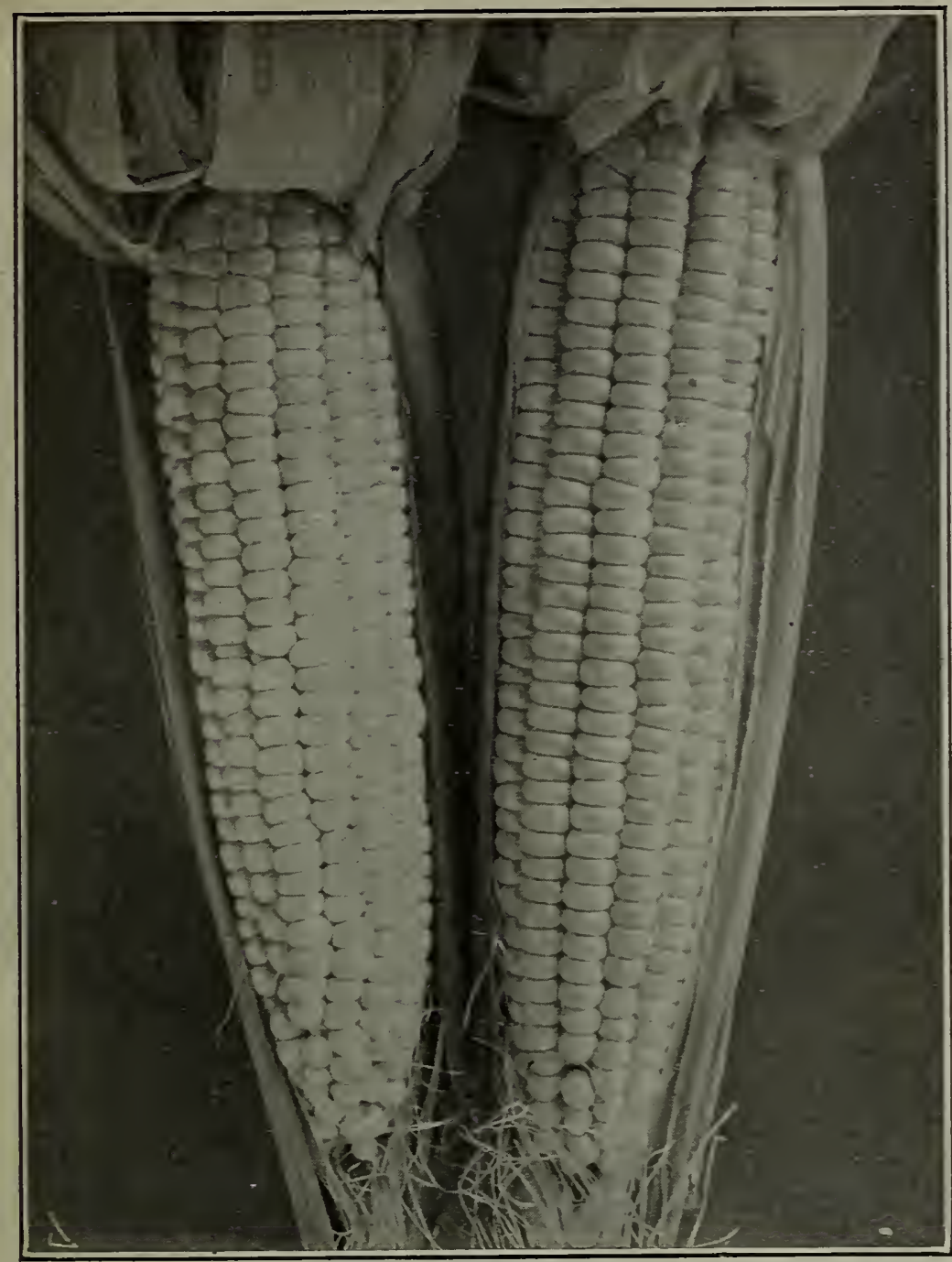

STOWELL'S EVERǴREEN SUGA R:COR.V REUTER'S WHITE SNOWFLAKE

A very fine field sort, especially adapted to the South because of its earliness, productiveness and fine quality. Its growth is from seven to eight feet producing two ears to the stalk. Which are ver
large, the cob which is rers thin and grains deep. Excellent for Roasting Ears, and is well liked by the New Orleans Market Gardeners for this purpose.

\section{REUTER'S MOSBY PROLIFIC CORN}

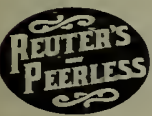

This is one of the finest Southern Prolific Corns planted in the South. It is a pure white corn on a small cob, deep full grains. Ears are of medium size. Stands drouth remarkably mell. Produces from two to four well formed ears to the stalk. This from two to four well formed ears to the stalk. This ton Belt and more widely and favorably known than any other White Dent Corn. It is a sure-cropper. middling early deep grained. pure white, and a good corn in every way. On old, thin it seems to be able to adapt itself to hard, unfavorable conditions. This is also true of the Davis' Prolific. On rich lands it has made The that there is no better all-around enormous rields, and I think that there is no better all-around seed. however, and sometimes you may obtain some of the Ilosby from a dealer who is selling you scrub, mongrel seed. My growers have been selecting the Irosby for several years With a riek of getting a better strain, and I don't think that my strain is excelled by anyone. I have a big supply of it this year, and will pleased to quote you special prices on large quantities.

Prices. packet 10c; quart (not prepaid) 20e; ral. 50e; peck 75c: bu. \$2. 10 bu. or more at $\$ 2.50$ per bu. Write for price delivered your station. Samples free.

\section{TRUCKER'S FAVORITE}

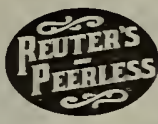

\section{A grand rariety maturin}

long. symmetrical it is a large.

Price, qt. 20e; sal. 50c; neck $90 \mathrm{c} ;$ bu. $\$ 3.00 ; 10$ bu. $\$ 27.50$.

\section{STOWELL'S EVERGREEN SUGAR CORN}

This is not only the most celebrated. lar of all varieties; although not an ea

though quite late. Some mat observe

and have not had the pure stock.

so quickly Without the פrower

seed establishments as Stomell's

ricinity of other sorts.

Price, qt. 20c; gal. 50c; peck $90 \mathrm{c}$; bu. $\$ 3.25$; 10 bu. $\$ 30.00$.

\section{COUNTRY GENTLEMAN}

The ears average

is small this

Price, qt. 25c; gal. 60c; peck \$1.10; )n. \$4.00.

\section{ADAMS EXTRA EARLY}

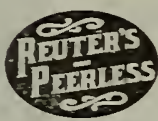

\begin{abstract}
Price, qt. 25c; gal. 60c; peck $\$ 1.00 ; \mathrm{bu} . \$ 3.50 ; 10 \mathrm{bu} . \$ 32.50$.
\end{abstract}

\section{CHAMPION WHITE PEARL}

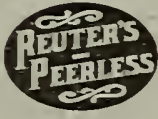

uniform well filed ears,
grains. A very fine field
tensively for market. Our
Ratekin in the right way.
to the ordinary commercial

seedsmen.

Planted largels for market oy

Price, qt. 15c; gal. 40c; peck 75c: bu. $\$ 2.50 ; 10$ bu. \$22.50.

\section{REUTER'S ADAMS EARLY LARGE}

One of our leading rarie priceraging seren feet in height and well bladed. REUTER'S IMPROVED FRENCH MARKET

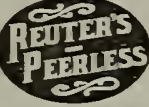

time as the Large Adams. Produces large ears and large grains. It is raised extensively- for have not as yet been able to supply the great demand sold hele. 4 t. 15e; gal. 0c: peck $75 \mathrm{c} ;$ bu. $\$ 2.50 ; 10$ bu. $\$ 22.50$.

\section{IMPROVED SQUAW CORN}

The demand for this splendid corn from the Southern States Than ever, and it certainly has

natural drought resisting dry weather Cor

Iexican June, and should be planted

stock or roasting ears. The ears grow

long, and carry from ten to twenty-four ron

The grains are peculiar, some being red. blue, speckled an

white; more blue than any other color.

Iexican purposes it is just as good as the Mexican June, but is inferior to this splendid rariety for the other in Ohlahoma. We sell each variety for what

it really is, and nothing more. 10 bu. or more at \$2.50 per bu.

\section{THE QUESTION OF ACCLIMATED SEED CORN!}

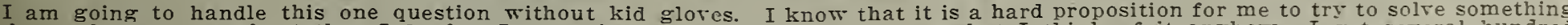

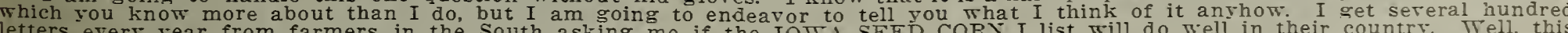
Tell, this corn usually does well all over the South. It all depends on the rariety. I really think that the acelimated or ho

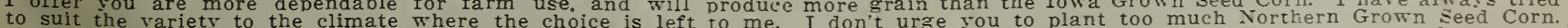

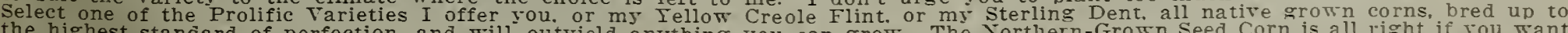

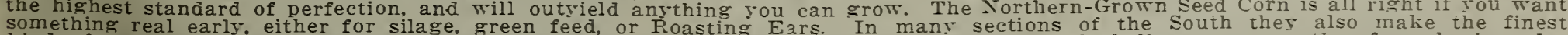

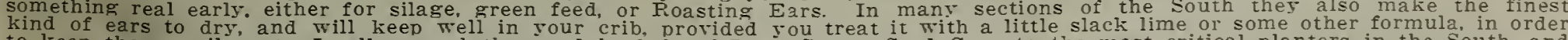

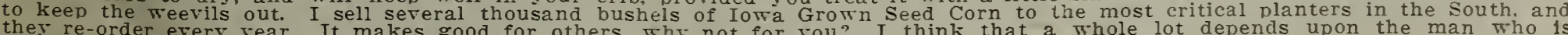

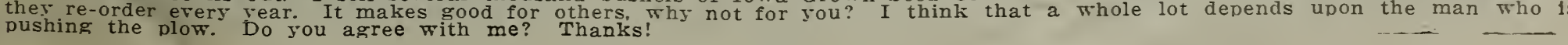




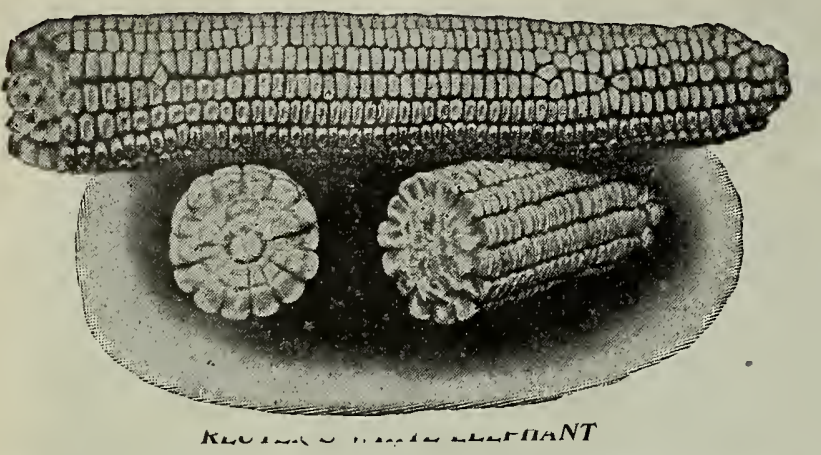

\section{REUTER'S WHITE ELEPHANT}

\section{Largest Corn Grown}

This is the enormous white corn you have read so much

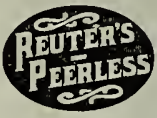
作 entire south. There is not a Corn grown anywhere near its size that is so early, It matures about the same time as the Iowa Silver Mine, but is nearly half longer, and in fact bigger than any White Corn I handle. It is truly a winner in the sulich, and made ears like stove wood in Louisiana last year. This is my tirst attempt to catalogue this great big banner corn, but I do so unhesitatinaly, as hundreds of other farms in the South. Description-It is a pure white corn of unusual size and length. On good
land ears will rull from 11 to 14 inches, with occasional specimens 15 inohes long. Grains medium deep (five-eighths inch), very wide and thick. Chalky white on top and clearer below. The germ is extra large. Rows fourteen to sixteen, straight and close together. True Dent Type. Cobs pure white, Stalks about medium height and very heavy up to the ear. which is generally set at about five feet or a little less. Stands uj uncommonly well, and there is practically no down corn. Breeder. You can't always procure the right strain, so I urge you to buy direct from me. It is a vigorous, healthy, rank-growing corn that will yield enormously. It ripens early too. It is the Bigans con

Prices, packet 10c; quart (not prepaid) 20c; gal. 50c; peck 80c; bu. \$2.75; 10 bushels or more at \$2.50 per bu. Write me for samand prices delivered your station.
Note-My seed is extra selected, butted and tipped by hand, and well graded. I test it before I sell it to you.

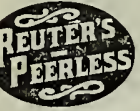

\section{IMPROVED BOONE COUNTY WHITE \\ Sometimes Called "Cornplanter"}

Niy seed comes direct from the Nishna Valley, Iowa, and canne bre improved upon. their lifetime to the breeding of pure, reliable types and strains. In this Improved Boone fine quality. It matures in 110 to 120 days. and is a splenclja yielder. It is similar to my Iowa Silver Mine, but matures a out at both ends, cylindrical and are 9 to 11 inches lon's, averaging 20 rows. some 18 to 22 . Grains are very deep, and a litpearl white and have a fine large germ. The variety grows a large stalk from 10 to 12 feet high with an abundarice of thin or poor soils. $10 \mathrm{c}$; quart (not prepaid) 20c; gal. 50e; peck 75e; bushel \$2.75; 10 bushels or more at $\$ 2.50$ per bushel.
Write me for samples and prices F.O.B. your station. Don't Write me for samples and prices F.O.B. your station. Don' ments.

\section{ATTENTION OF LARGE PLANTERS!}

We annually sell thousands of bushels of HIGH-GRADE PEDIGREE SEED CORN. We have hundreds of customers who buy ten, twenty, and even a few hundred bushels a year for their planting purposes. Our prices are cheap, considering the seeds, and compare the average yield resulting from our PEDIGREF SEED CORN and the ordinary corn grown by unexperienced and haphazard srowers for seed and feed purposes. Remember that whatsoever we sow that shall we reap. These sayings are just as true in corn growing as they are in any other to grow big crops of corn, yet all our labor put on the soil, and all our money invested, would be a loss without good, vigorous, pedigree seed corn. True, we might take our smallest ears of corn and by continuous cultivation on good soil and seed selection, develop in a few years seed that would produce good crops, but the process is too slow and expensive when we have seed obtainable at prices a little higher than is usauly asked your seed corn for this spring, and quote you special prices on large quantities, furnishing samples of our stock. All of our seed corn is shipped from our warehouses in original bags, guar-
anteed as represented, otherwise we return the money paid for

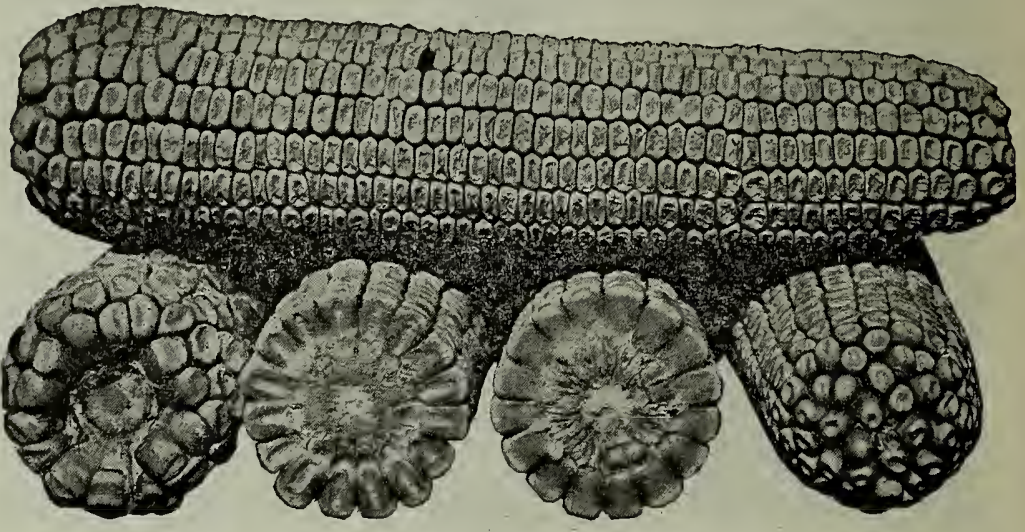

RATEKIN'S IMPERIAL WHITE-Red Cob

This is a pure white corn with a red cob-a sign within itself of great vitality: ears run down 9 to 12 inches long. measuring from 7 to 8 inches in circumference; 16 to 24 rows of very deep grains firnily set on a small red cob, as shown in the accomaging from 7 to 10 feet in height. with a large amount of foliage. This corn is well adapted to old, poor and thin lands, and will make a good crop where other sorts fail. It is extensively planted by the local gardent yor for asting Ears, and I sold sevshipper, and the milk is retained longer than in other varieties. It is very early, being ready for market in seventy or eighty days, or only a week or so later than the Extra Early Adams.

Price, packet 1nc; quart (not prepaid) 20c; æal. 50c: peck 75e; bushel \$2.75; $10 \mathrm{bu}$. or more at $\$ 2.50$ per bushel. Write for special prices F.O.B. your station. Samples on request.

\section{HICKORY.KING}

Hickory King is a white variety of field corn which has the laroest grains with smallest cob of any corn in existence. The grains are so large and cob so extremely small that when the ear is broken in two pieces a single grain. will cover completely the cob section. This corn is of very vigorous habits, is a splenthin and sure cropper, and is especially well suited to light or many sections of the Southern States. Ripens in 100 to 123 days. It husks and shells easily and produces much fodder.

Price: By freight or express at purchaser's expense, qt. 20c; gal. 50c; peck 75c; bu. \$2.75; $10 \mathrm{bu}$. \$25.00. Write for prices on arger quantities, also for samples of our superior stock.

\section{MAMMOTH IOWA WHITE}

This big early white corn has made rapid strides within the few years since being brought to perfection. Its strong

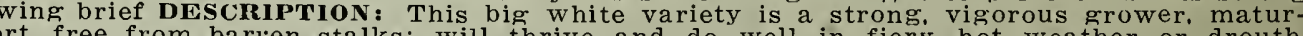
where other varieties fail. The ears are large, pure white, well filled out at butt and fip small weather or drouth, of deep wedge-shaped kernels full of starch and oil. Ears 8 to 12 inches long and 7 to 8 inches in circumference. Bred for yield and early maturity. In Iowa Mammoth White will mature in 100 to 110 days. In localities where this famous has been introduced its fame has spread from farm to farm and county to county, and wherever it has obtained a foothold Every farmer who intends to plant an early maturing white dent corn this spring should consider this one sort. It is a won-
derful grower. producing big ears and big stalks. It is really great for ensilage purposes. so I urge upon you to order a few bushels derful grower. producing big ears and big stalks. It is really great for ensilage purposes. so I urge upon you to order a few bushels
this vear. It is grown for me in Iowa, right in the Nishna Valley. where thousands of bushels of the finest corn in the world are
distributed and that it will be one of my biggest sellers, so I am putting in rather a large stock, and feel confident that my customers will respond

Prices. packet 10c; quart (not prepaid) 20c; gal. 50c; peck 80c; bushel $\$ 2.75 ; 10$ bushels or more at $\$ 2.50$ per bushel.

Prices are all F.O.B. New Orleans, Let me send you samples and quote you special prices delivered your station. How about 


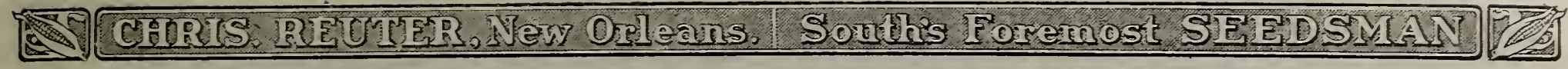

\section{Pedigree Stocks \\ IOWA=GROWN SEED CORN \\ Early to Mature}

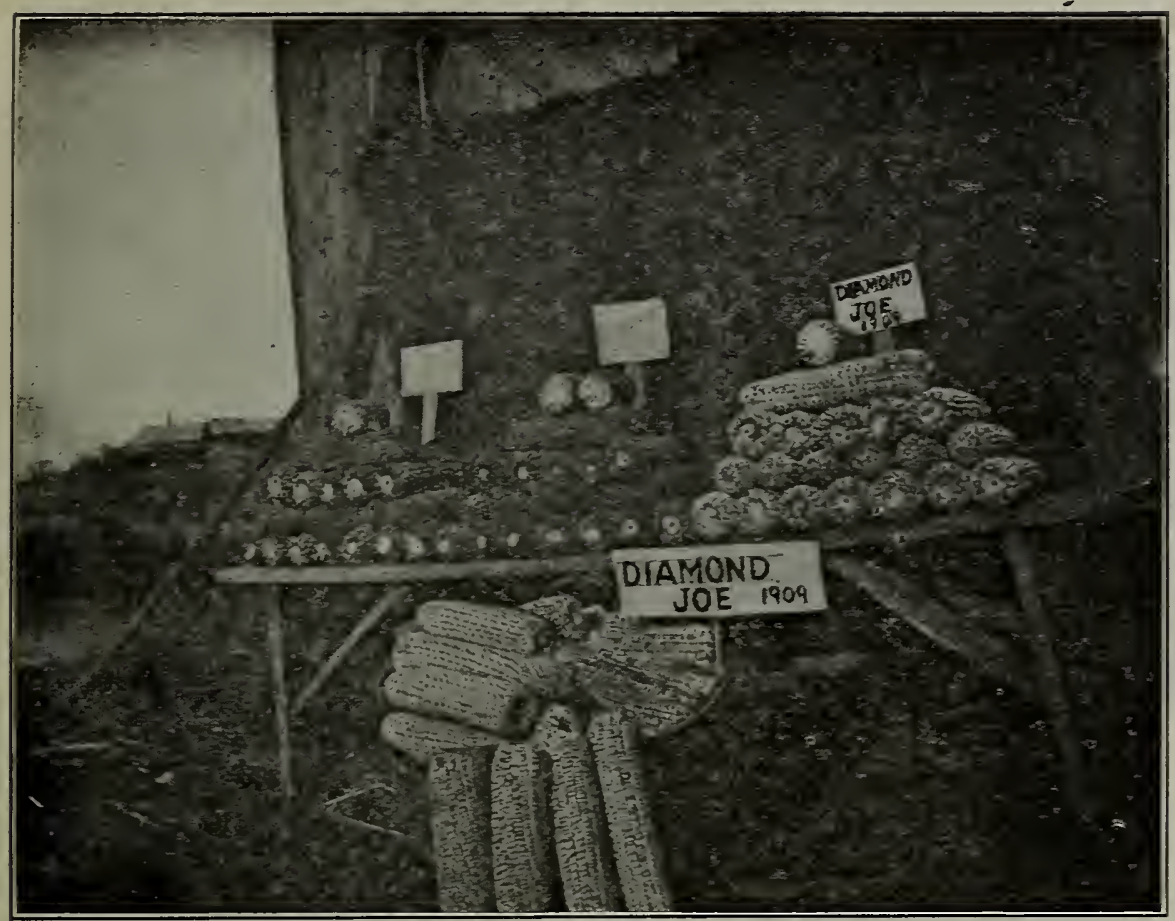

DIAMOND JOE'S BIG WHITE

Grown by Ratekin in the Right Way

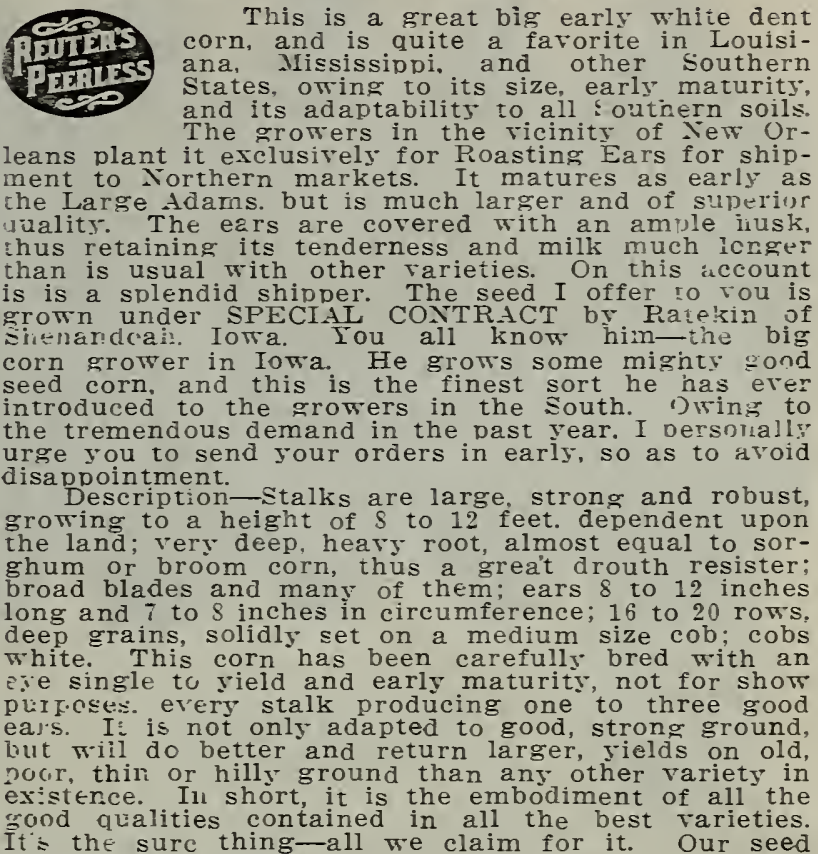

It : the sure thing-all we claim for it. Our seed
stock of this corn is exceptionally fine this vear (ex-

rra choice, haririg beeil grown from absolutely pure seed stock,

Prices, packet 10c: quart (not prepaid) 20e; gal. 50e; peck 75c; bushel \$2.75; 10 bu. and over at 52.50 per bu. Bags included. PEUTER'S IOWA SILVER MINE
REUTE

This corn is noted for its great vitality to withrtand and resist extreme conditions of weather, wet or dry. also very hot weather, and makes good crops when other sorts wither, burn up and perish under dry, hot winds and scorching sun. Each year our growers select and improre it in every way possible, not so much to increase the size of the ears, but to increase the uniformity of size and barren. weak. sickly stalks, and are pleased in the belief that they have brought this corn up to the highest standard of perfection, both in yield and early maturity.

We sell hundreds of bushels of this splendid sort to planters in every section of the South, and ereryone obtains splendid results from it. In view of this we do not deem it necessary. if space would permit, to print even a partial list of names and testimonials we have received pertaining to this wonderful corn, and especially in regard to our High-Bred Select Seed. Our stock is absolutely genuine an dhas been kept pure and bred up and improved year after year. This is not a new variety, but is one of the oldest and best known made, there are thousands of bushels of mongrel white corn offered and sold every year under the name of Iowa Silver Mine. White corn offered and Description-Stalks medium in height. ranging from 7 to 10 feet high, very leafy, broad blades, and a lot of them. The type of this corn is very even and leafy, broad blades, and a lot of them. The trpe of this corn is very even and kernels, solidly set on a medium small white cob, ears well filled out at butt and tip ends. The cob being medium small, it dries quickly and rapidy, while the corn is ripening. Matures in from 90 to 100 days.

Price, qt. 20c; gal. 50c; peck 75e; bu. \$2.75: $10 \mathrm{bu}$, at \$2.50 per bu. comparison of quality furnished on request.

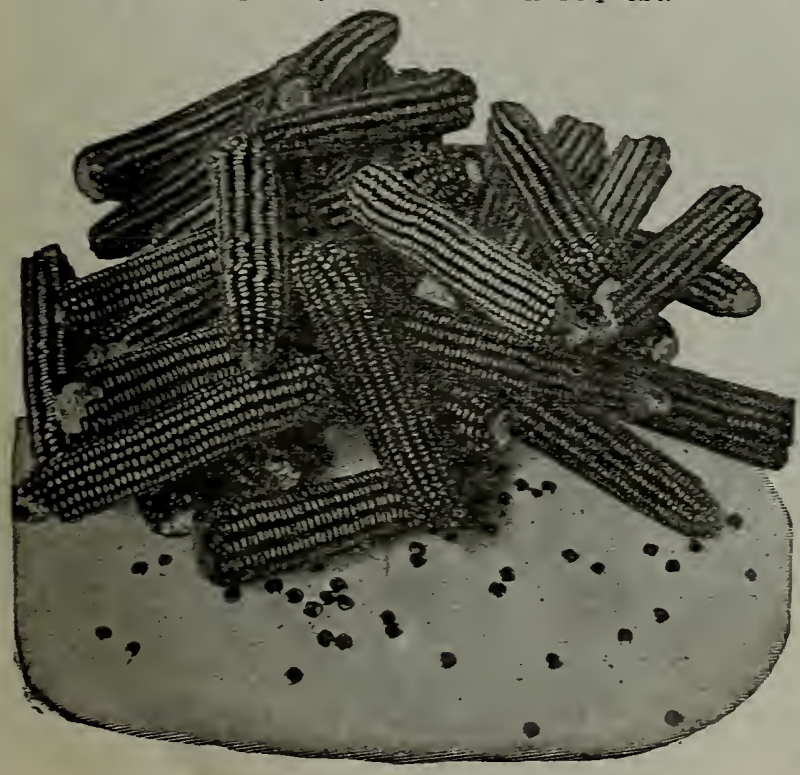

Write for samples and prices delivered your station.

\section{WHITE CAP}

RED BUTCHER, or

\section{BLOODY BUTCHER}

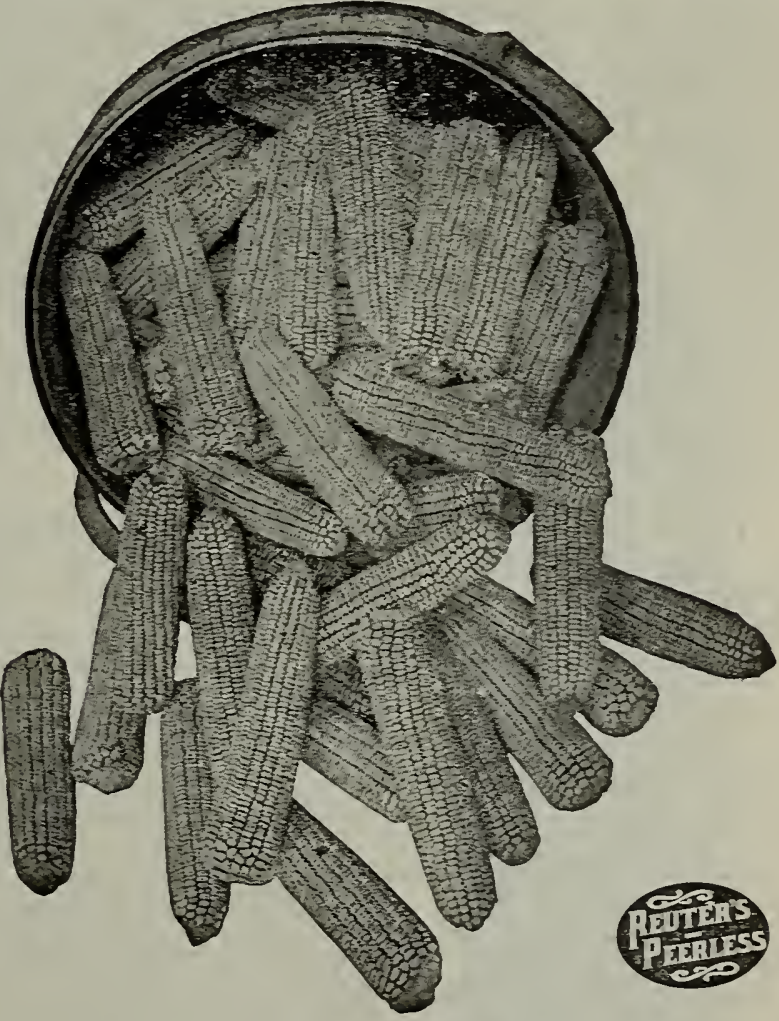

IOWA SILVER MINE

A most beautiful large-grained red corn It is an enormous yielder of arge, handsome ears, nue isurirg 8 tc 10 inches. Color deep cherro-red with White cap, generally 14 rows of pure red white cap corn on a small cob. Sough. Mratures in 90 rays. Popular ir Texas and Louisiana.

Price, quart 20c (not prepsid); gal. 50c; peck 75c; bu. \$2.75; 10 bu. at $\$ 2.50$ per bu. Write for rrices on larger quantities F.O.B. your station, or F.O.B. New Orleans. Samples free for asking.

\section{POP CORN}

White Rice-Widely cliltirated and used more than any other sort. Short Pht. sc; 1l. 20c pustpaid: hy freight or express, $1 \mathrm{~b}$. 10c; 20 lbs. $\$ 1.75 ; 100 \mathrm{lbs}$. \$7.50. 


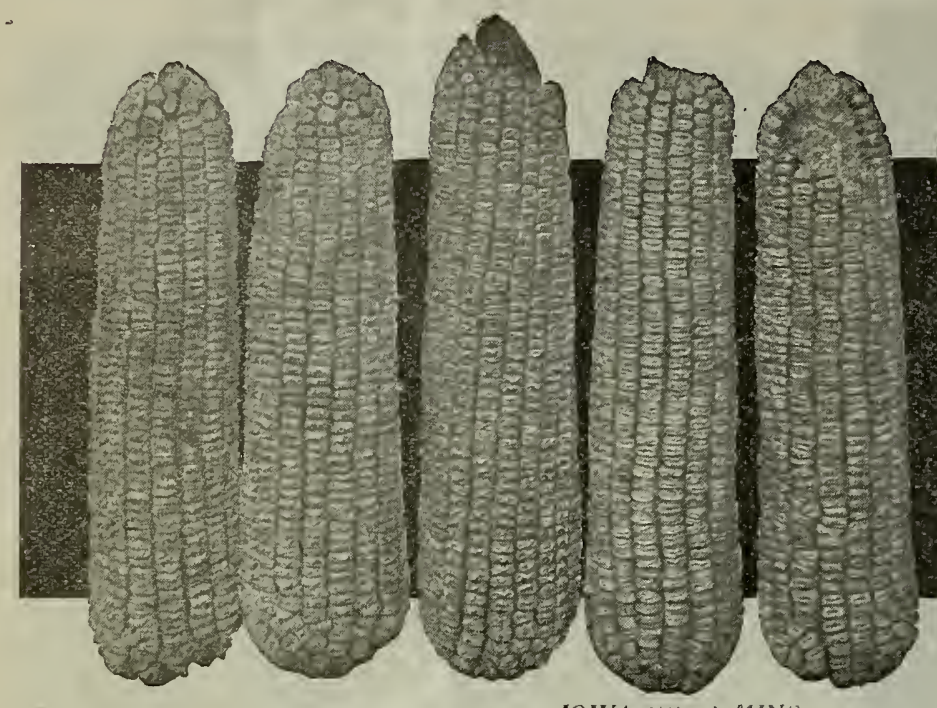

IOWA CUULD MINE

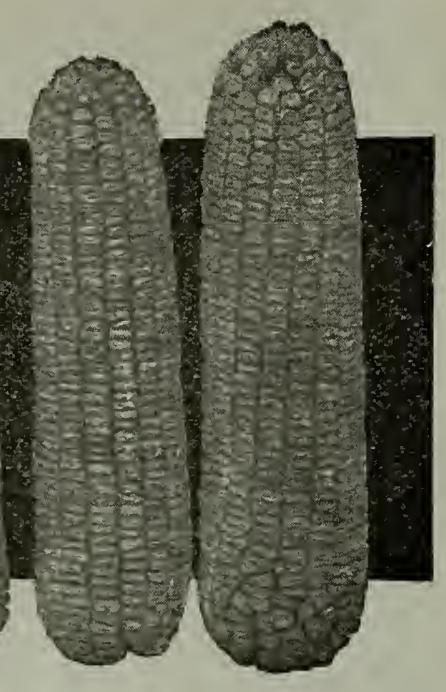

REUTER'S PERFECTED GOLDEN BEAUTY

It has become famcus throughout the South within recent years on account of its many excellent qualities. It is a superior strain of the well-known Golden Beauty, obtained by careful, critical selection. In the preparation of the corn for seed each ear is carefully selected and the end grains discarded. It is not to be compared with the original Golden Beauty.

Description-In Reuter's Perfected Golden Beauty Corn, our customers will find a high-bred pure variety of a beautiful golden yellow color, and on that will please you, contains ten to fourteen rows of extremely large, broad grains, deep and solidly set, makes the finest appearance when shelled, but equally beautiful in the ear. It is a vigorous grower, attaining a height of eight to ten feet, producing one to two large-sized ears to a stalk. The ears are set midway of the stalk, three and one-half to four feet from the ground. The cobs are unusually small; when broken in half the grains will always reach across. The
richness of color and fine quality of the grain make it very superior for grinding into meal. It cannot be recommended too highly.

Early Maturity-In breeding and propagating this splendíd improved sort, our growers have kept uppermost in mind a LargeEared Early Maturitg Variety that would make itse
to one hundred days, producing the maximum yield. $\$ 25.00$.

Price, packet 10c; quart (not prenaid) 20c; gal. 50c; peck 75e; bu. \$2.7.5; 10 bushels or more at $\$ 2.50$ per loushel. Write for spe-
cial prices F'O.B. your station. Samples free.

\section{MAMMOTH IOWA YELLOW DENT}

This is a great, big yellow corn that is making good everywhere in this big South. It is indeed worthy of more extensive cultivation, and should be grown by nearly every planter in the State of Louisiana, to say nothing of other Southern States. The Department of Agriculture at Washington, through its experimental stations in various states, has demonstrated beyond question that by proper crosses of valieties and strains superior types of corn can be produced. With this strong government backing seed corn growers and breeders present their claims and prove it by Uncle sam. In brumging MAMMCTH IOWA YELLOW DENT CORN to rerféction, my growers have produced, I believe, the best Large Warec Early Maturing Yellow Dent Corn in the United States, with the possible exception of RATEKIN'S FAMOUS PRIDE OF NISHNA, the latter winning distinct favor in our state.

Description-Grows a rugged stalk of medium height and proaucing ears 9 to 12 inches in length, often as large as 7 to $71 / 2$ inches in circumference. Mostly 18 rows, but sometimes 16 to 20 . Matures in 90 to 110 days. Ears are well filled out with solidiy set deep kernels, rich in oil, and of a beautiful golden yellow color. The germ is extra large, and the rows run generally straight. The stalks are thick-jointed and the leaves are noticeably close together, wide and deep green. Grows about 10 feet high. It roots very deep, and seems to stand extremes of weather very good. If you want of foliage and fine grain. It is a big yielder on the poorest kind of

Prices, procket 10c; quart (not prepaid) 20c; gal. 50c; peck r5e; liu. \$2.75; 10 bu. or more at \$2.50 per bushel. Write for prices on larger quantities F. O.B. New Orleans or your station. Shipp
original sacks branded by my famous Iowa Corn Breeders.

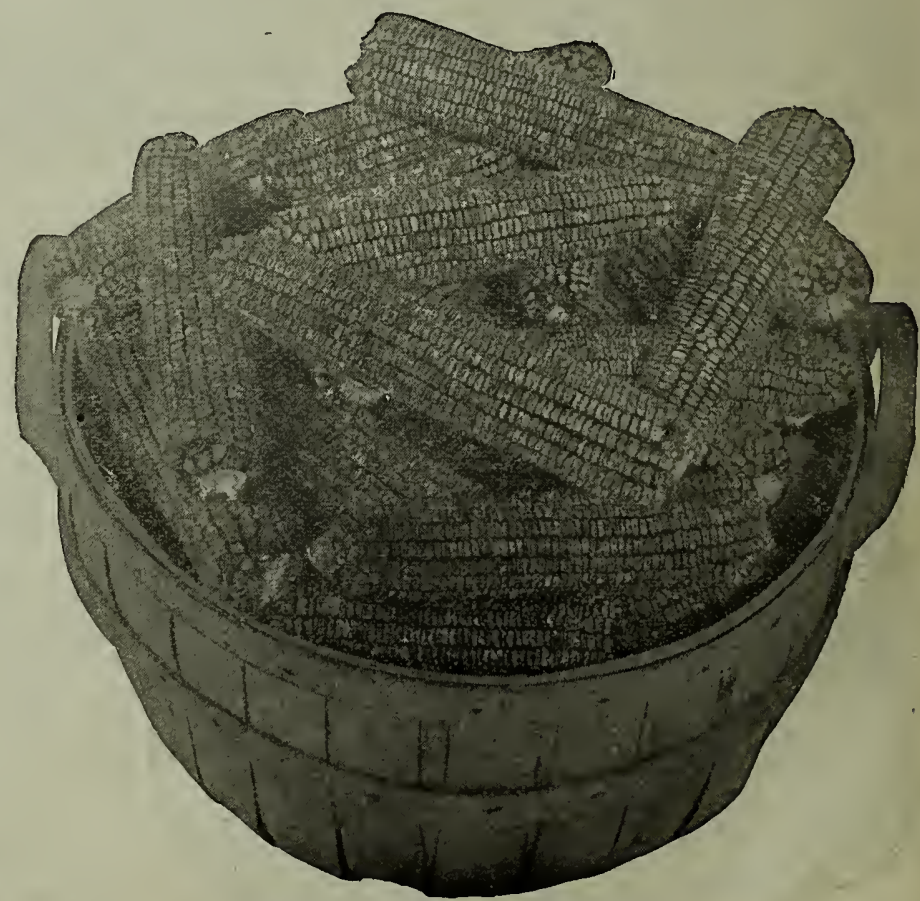




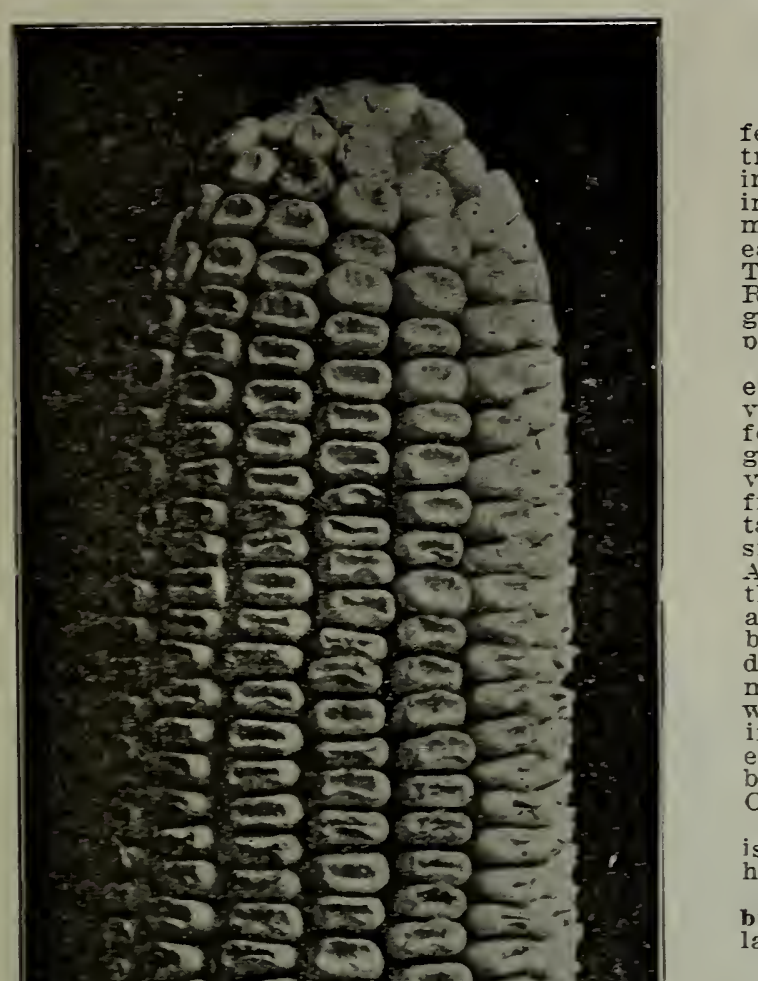

\section{RATEKIN'S PRIDE OF NISHNA \\ Direct from Nishna Valley}

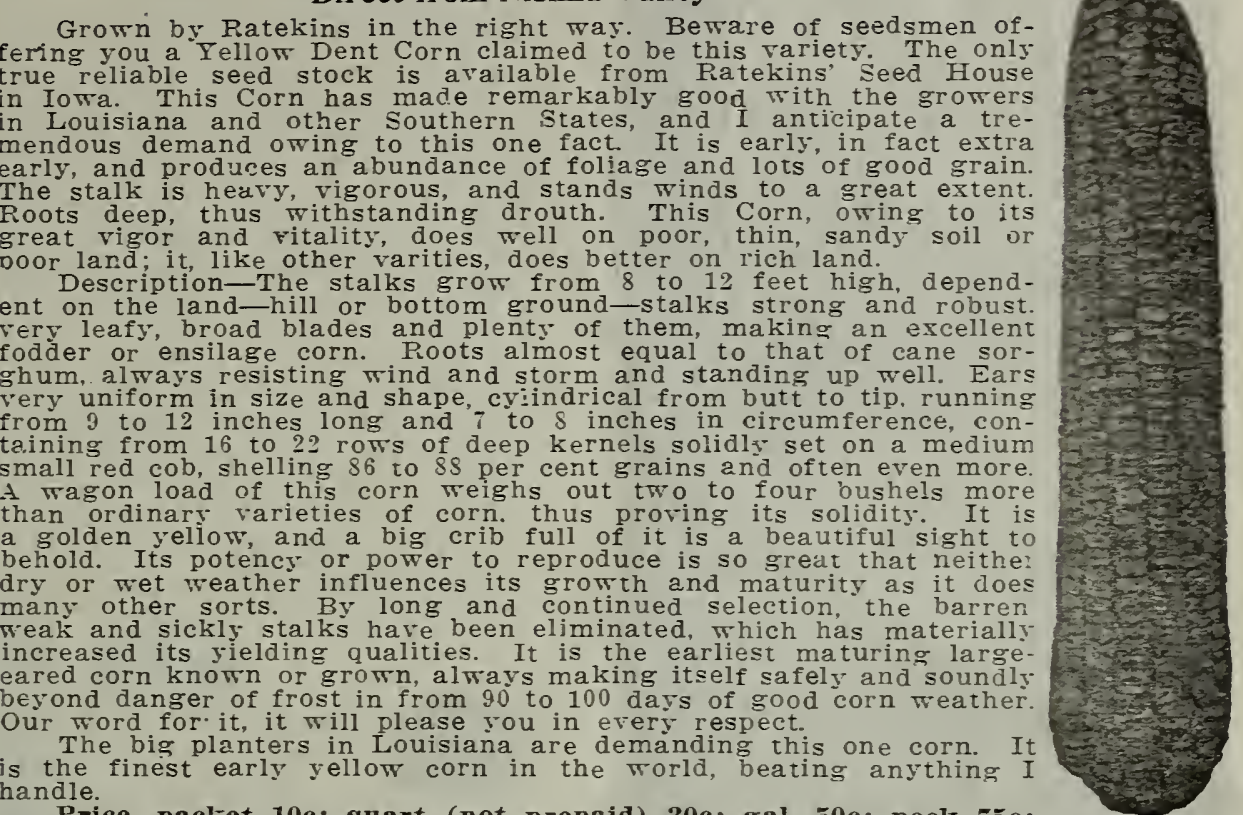

Price, packet 10c; quart (not prepaid) 20c; gal. 50c; peck 75c; bu. \$2.75; 10 bu. or more at \$2.50 per bushel. Trite me for prices on CALICO CORNI CALICO, or STRA WBERRY

Old=Fashioned Red, White and Yellow

This corn is the old-fashioned kind, and always rery popular

and for many years we have had a great demand for
great as beer the demand for this excellent feeding

greater attention to it the pas
Tround a superior type of this
from whom we obtained seed,

contradiction we can say we have the highest and best strai cob, thus insuring early maturity. The ears run from ni It is a combination in color of red, white and yellow stripes. in preference to other corn. To all those in want of one position to supply you with the very best of seed are in Very popular in Louisiana with some of our biggest sugar planters.

Price, packet 10e; quart (not prepaid) 20c; gal. 50c; peck $75 \mathrm{c}$; bushel $\$ 2.50 ; 10$ bushels or more at $\$ 2.25$ per bushel.

\section{REID'S YELLOW DENT \\ Universal Yellow Corn}

In answer to the question, "What is the most popular variety of yellow corn in the United States," we should be
compelled to say Reid's Yellow Dent. This corn was originated by Mr. James L. Reid, of Illinois, many years ago, and in fixing the type he made a good job of it, for the highest skill of experts have failed to change it for the better. It certainly is a thoroughbred. We offer the pure
type of this leading standard variety, which stands among the best all around purpose Yellow Dent Corn grown.

Description-Color deep yellow, with lighter cap. Grain very deep, closely packed; butts and tips almost entirely covered over. Slightly rough, with grains dented on top.
Leaves and stalks of Reid's Yellow Dent make the finest ensilage and fodder. Matures in 110 days.

Price, packet 10c; quart (not prepaid) 20c; gal. 50c: peck $75 \mathrm{c} ; \mathrm{bu}$. \$2.75; $10 \mathrm{bu}$. Or more at $\$ 2.50$ per bu.

PKIDE OF NISHNA REUTER'S ST. CHARLES WHITE The St. Charles White is a very handsome pure variety of white corn set on a red cob. and
Nivins this corn appears to make a finer and better grade for milling purposes and for corn meal Pत्र:11055 kernels. the upper corners of the kernels being round. The stalk grows from 8 to 10 and 12
feet high, dependent upon the land upon which it is planted, the lowlands and bottom producfeet high, dependent upon the land upon which it is planted, the lowlands and bottom produccorn for general crop purposes; for grain, fodder or for ensilage purposes. Our customers in the South, crop, East and West are greatly in favor with this excellent variety of corn. In the south for the grain confuse Ptock is far superior to the ordinary seed

Price, packet 5c; quart (not prepaid) 15c; gal. 40e; peck 70c; bushel \$250; 10 bu. or more at \$2.25 per bu. 


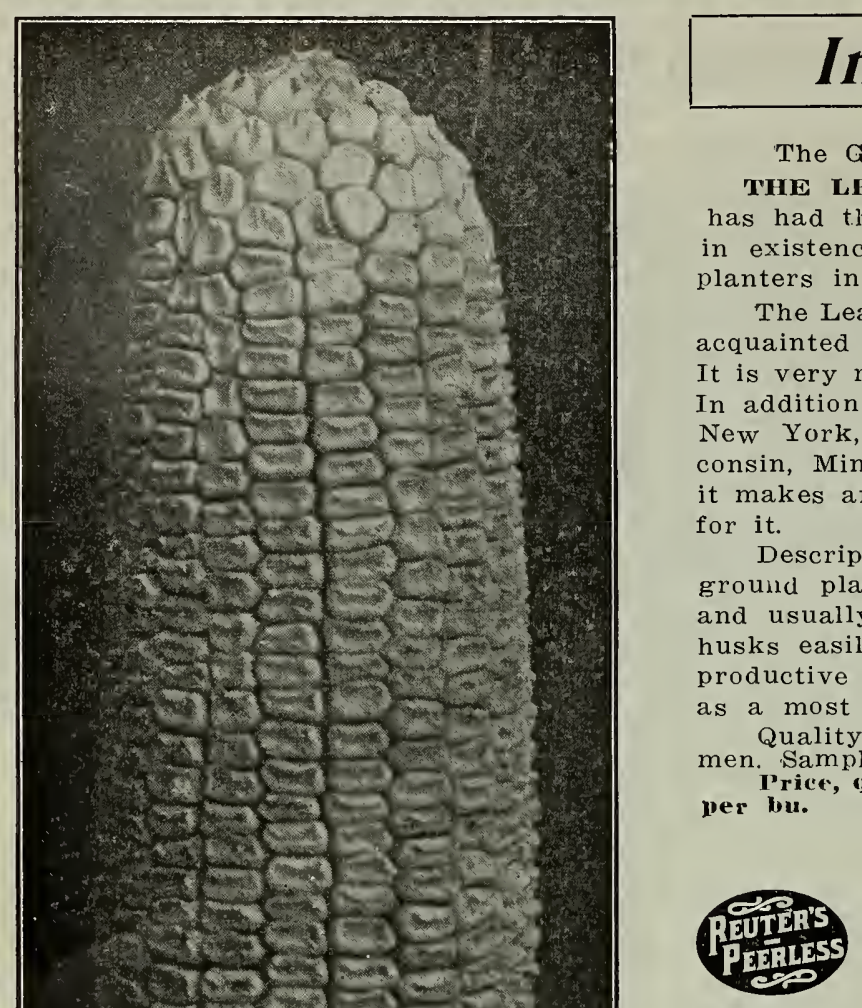

\section{Improved Early Leaming Corn}

The Greatest Yellow Corn for the South. Thousands of bushels sold annually. IE LEAMING CORN was first originated by Mr. J. S. Leaming, of Ohio, and Very popular in the South, and extensively cultivated by the large Loujsiana, Mississippi and other Southern States.

he Leaming Corn is known everywhere and by all who have ever tried or become ' rich in protein and oil, and thus becomes ideal from a feeder's standpoint. to this, it is grown very extensively in the East, New England States, Minnesota and the Dakotas, for its ensilage and fodder purposes of which or it.

Description-It grows to medium height, from 8 to 12 feet, dependent upon planted on, hill or bottom land. The ears are uniform and of good size, four feet from the ground, medium small red wob, roductive and an ideal corn. We can fully recommend it to farmers and feeders excellent variety of corn.

Dality-Our stock is far superior to the ordinary Leaming sold by many seeds-

rice, quart (not prepaid) $15 \mathrm{e}$; gal. 40e; peck 70c; bu. $\$ 2.50 ; 10$ bu. or more at 32.25

\section{REUTER'S IMPROVED WHITE WONDER}

King of all Corn. Grown in Oklahoma under scientific methods of cultivation. Will grow anywhere! Resists drought and scorching heat good as the Mexican June.

in in Oklahoma. Will grow uncier conditions that kill all other varieties. fields have been ruined by the continuous drought and hot sun killing the tassel and pollen this past season than ever before. This great Corn went forty-eight days of growing. weather without a drop of rain, and the heat the most severe ever known in the section where our seed is grown. All fields of other varieties burned up by the hot sun. It ripens the same time as the early varieties, and is the only largeeared corn for late planting that we know of that ripens so soon. Known to make one hundred bushels to the acre when other varieties made but thirty to forty bushels. The stalks grow from ten
thick, with short and heavy joints.

Our reliable Oklahoma grower describes this extraordinary sort as follows:

"Reuter's Improved White Wonder Corn will grow anywhere between the North and South Pole and make good. It is the King of all corns, will grow under conditions that kill all other varieties, and will grow when all other varieties rot in the ground. It resisted the excessively dry weather and withering heat of last season, and without a drop of water for forty-eight days. I made more Corn last season Price, quart (not prepaid) 15e; gal. 50c; peck $85 \mathrm{e}$; bu. $\$ 3.00 ; 10$ bu. or more at $\$ 2.75$ per hu.

\section{BRAZILIAN FLOUR CORN}

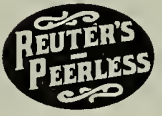

One of the grandest plants ever introduced. It originated in Brazil, where it constitutes the principal food for the inhabitants. The Corn is especially adapted to the wants of our Southern States. It withstands drouth, makes better Roasting. Ears than does any of the Sugar Corns. in early and remains late. This is a better corn to grow than the Mexican June. May be planted on stubble after grain crops are harvested and will, under such treatment, make a big crop of both grain and fodder.

The grain makes most excellent flour, as well as hominy. The ears are from four to eight inches long, and contain from eight to twelve rows of pearly white grain. The grain may be ground at any grist mill and the flour made from it makes as fine breakfast cakes as buckwheat. Owing to its heavy stooling habit it produces an enormous crop of fodder. Each stalk bears two or three ears, sometimes more. Our Southern farmer can make big money by growing Brazilian Flour Corn early and shipping in car lots to Northern markets.

Price, quart (not prepaid) 20c; gai. 60e; peck $\$ 1.00 ;$ bu. \$3.so.

IMPROVED EARLY LEAMING

\section{REUTER'S GENUINE MEXICAN JUNE}

The genuine Mexican June Corn is growll only in one part of Mexico, and we do not hesitate to say that it is the best and purest strain obtainable. The variety is more popular than ever, and we were unable to fill all our orciers last season owing to the tremendous demand. Our stock has established for itself a splendid reputation in many parts of Louisiana, Mississippi and other Southern States.

It is a White Corn of excellent quality and flavor; the ear is medium size, with a husk so closely adhering as to be practically worm and weevil proof. The stalk is short, seldom growing more than seven to eight feet high. The roots run deen and spread, so that it is a splendid drouth resister. Can be planted any time from April 1st until the end of August. Can be planted after an oat crop, or when other crops have failed, and mature before stant. Its germinating power is great, and consequently it will White Wonder for late planting.

Price, quart (not prepaid) 15e; gal. 50c; peek $\$ 5 \mathrm{e} ;$ bu. $\$ 3.00 ; 10$

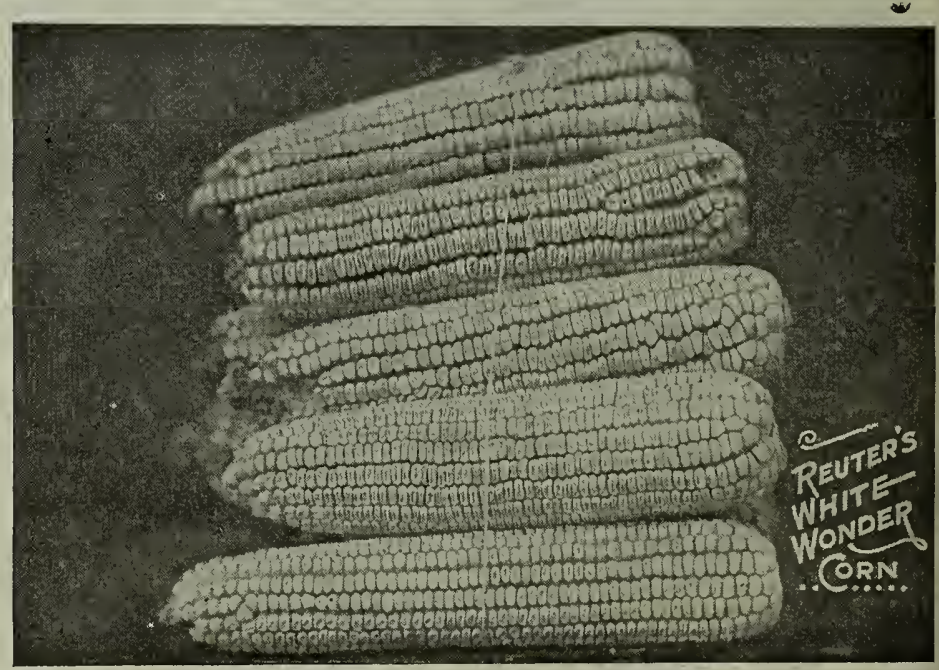




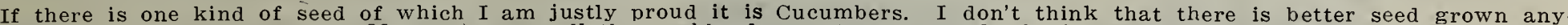

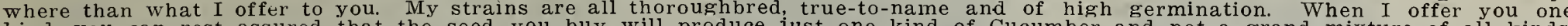

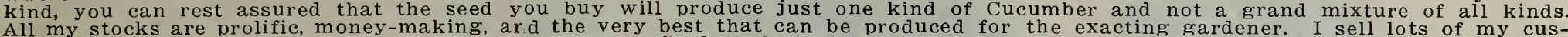

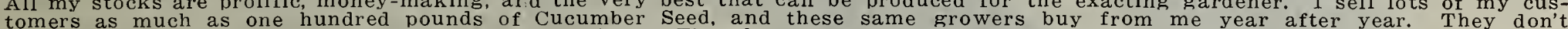

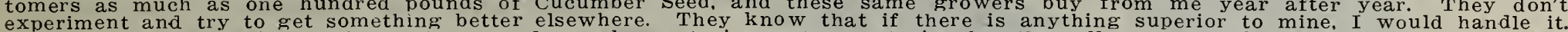

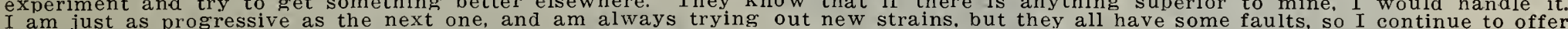

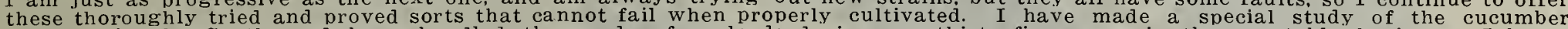

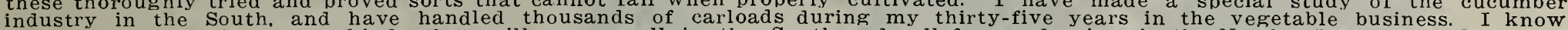

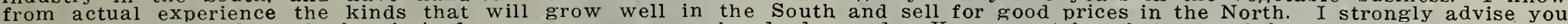

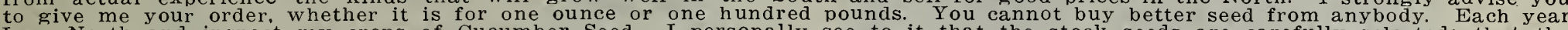

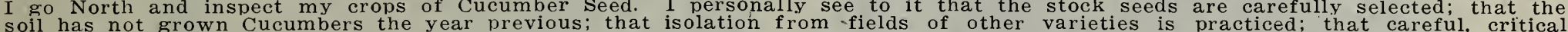

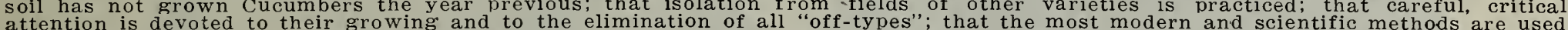

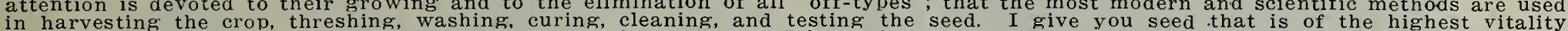

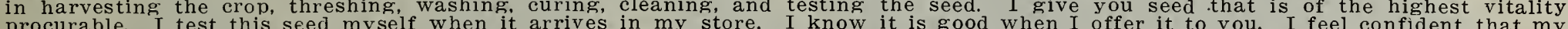

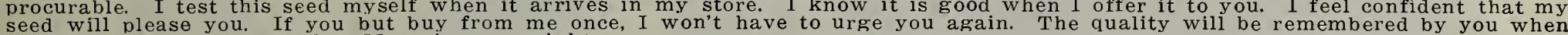
you think of planting again. My prices are right.

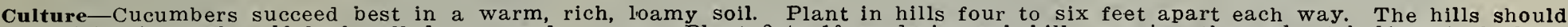

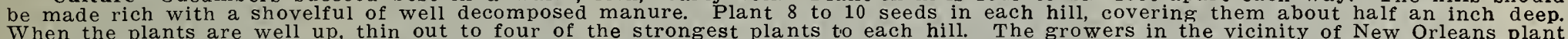

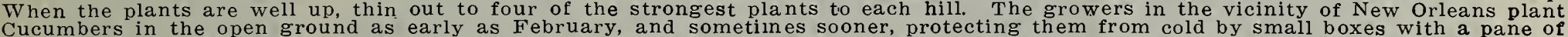

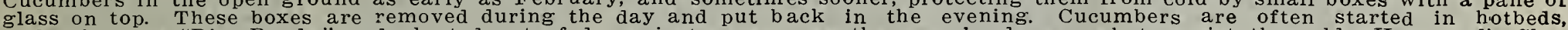

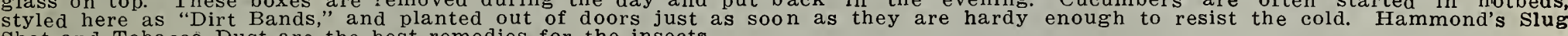
Shot and Tobacco Dust are the best remedies for the insects.

\section{REUTER'S PERFECTED DAVIS PERFECT CUCUMBER}

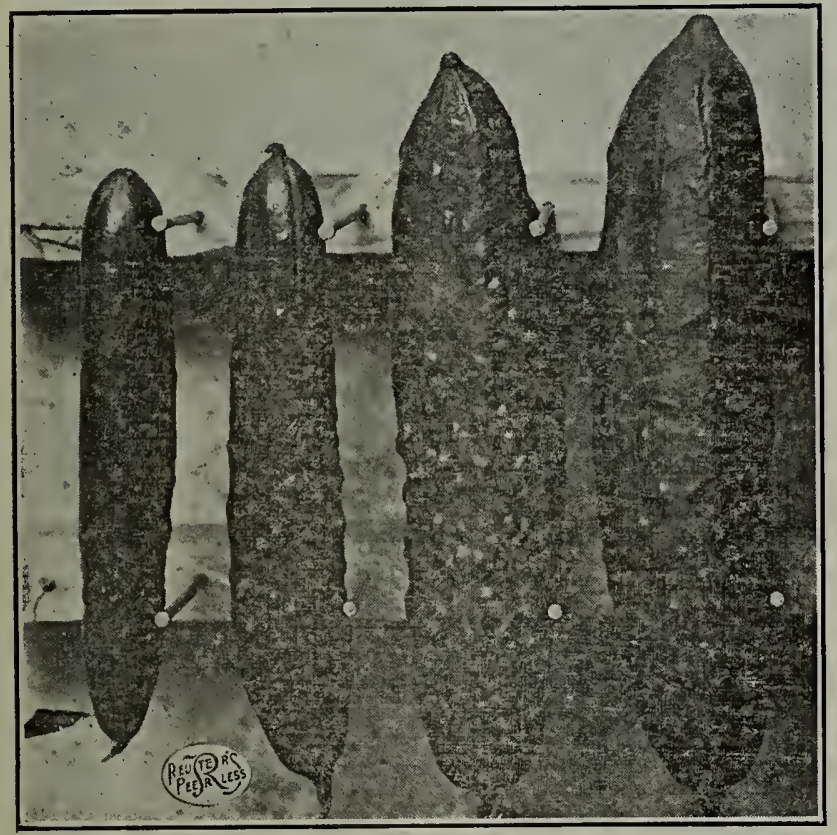

REUTER'S PERFECTED DAVIS PERFECT

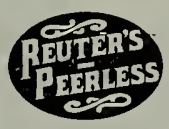
to breed up all the strains that are lacking, and try to retain the good qualities of those that are perfect. Possibly I have have, it was not my fault. I simply could not help it. For years I have been growing all kinds of Cucumbers on my farm in an endeavor to get one variety that would answer all purposes. I have found it when
planted this strain. It cannot be excelled in any way. It is far ahead of anything. I offer you, or anyone else can offer to you. I have a strain that required more than five years of careful, continuous selection to bring is the to its present standard of perfection. I can truthfully say that this other kinds you grow, plant a few acres of this sort. If possible, put your experiment. It is not a novelty that I am trying to get big prices for, but it is a vast improvement on the finest cucumber ever introduced. It deserves first consideration when you think of cucumber seed. Notice caregrowth, the splendid shape, fine color, and other good points too numerous to mention.

When the original Davis Perfect was introduced to the Cucumber growers in this country, it created a furore. But it had many faults, like all other strains that are produced too quickly. My growers. who, by the way, have particular strain was worthy of lots of attention. and began to work in particular strain was worthy of lots of attention. and began to work in There were many cucumbers in the original strain that had too much neck and showed many sports. The best specimens showed these faults. cucumber by going over the fields and staking specimens which were perfect at their slicing stage. This continued for four years and resulted in this "perfected strain, which I introduced to my customers three years ago. the neck has been bred out so that every fruit is shapely and holds its fine can be produced out-doors which can hardly be distinguished from green-
house stock. Mr. John Meyer, of Dalcour, La., operating the Promised Land
Plantation, who is, without a doubt, the biggest grower of Cucumbers in the , and has recently written me the following unsolicited letter: "Your in the

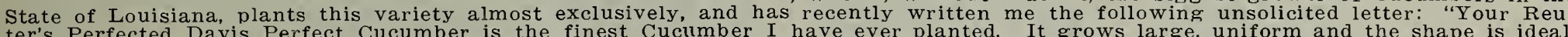

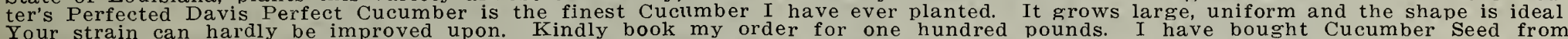

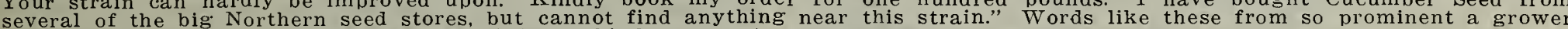
should be sufficient evidence that this stock is the kind you want. This man knows what nood cucumber seed is, and he has about four hundred acres under cultivation, principally lettuce and cucumbers, and buys every bit of his seed from me, although his account is solicited by nearly every big seed house in this country. The price of my Perfected is reasonable, and $I$ can sell it to you as follows:

Pkt. 5c; oz. 15e; $1 / 4$ 1b. 50c; 1b. $\$ 1.50 ; 10$ lbs. $\$ 14.00$, prepaid.

\section{REUTER'S EARLIEST OF ALL}

This Cucumber has proved to be the biggest money-maker ever planted by the Florida growers. I sell several thousand pounds in that State alone every year. The same growers purchase this strain from me all the time. They know what they are getting, so they don't experiment with other kinds so highly boosted by unreliable seedsmen or merchants who do not know what good cucumbers are, and live thousands of miles away from where they are grown. I have traveled Florida several times, and have made a study of this one crop. I know the kind of cucumbers the gardeners in that State require, and I offer this stock to them unhesitatingly. It will please you if you try it. If you Want to grow early cucumbers for profit, order a few pounds of White Spine Cucumber of handsome shape. which it holds a all stages of its growth. The color is a beautiful dark green, with lighter spines running from the blossom end. It is smooth, tender and crisp. Remains green on the vine, and after picking it never turns yellow. It is a very hardy, robust, prolific grower, and is free from disease. I have never seen an early cucumber grow more uniform in size, color, and evenness than this one sort able Cucumber on the market. I sell it only in sealed packages. Be sure you get my genuine stock.

Price, pkt. 5c; oz 10c; $1 / 4$ lb. 35c; 1 b. $\$ 1.00 ; 10$ lbs. $\$ 9.00$, prepaid.

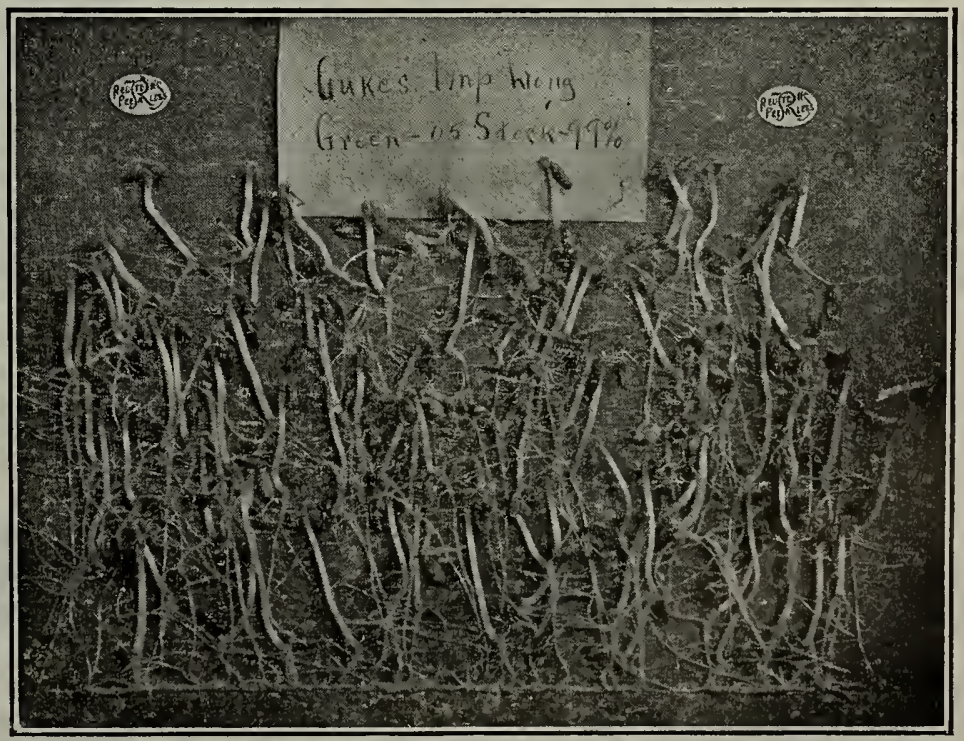

This shows you how I test my Cucumber Seed. I test all my seeds the same 31 


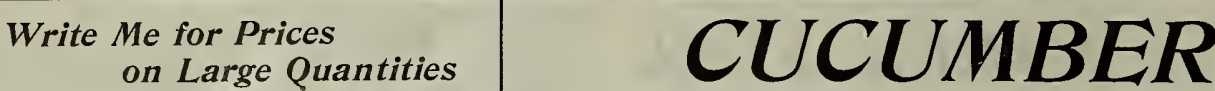

Isolation is Practised

Selection is Necessary Testing is Good Growth

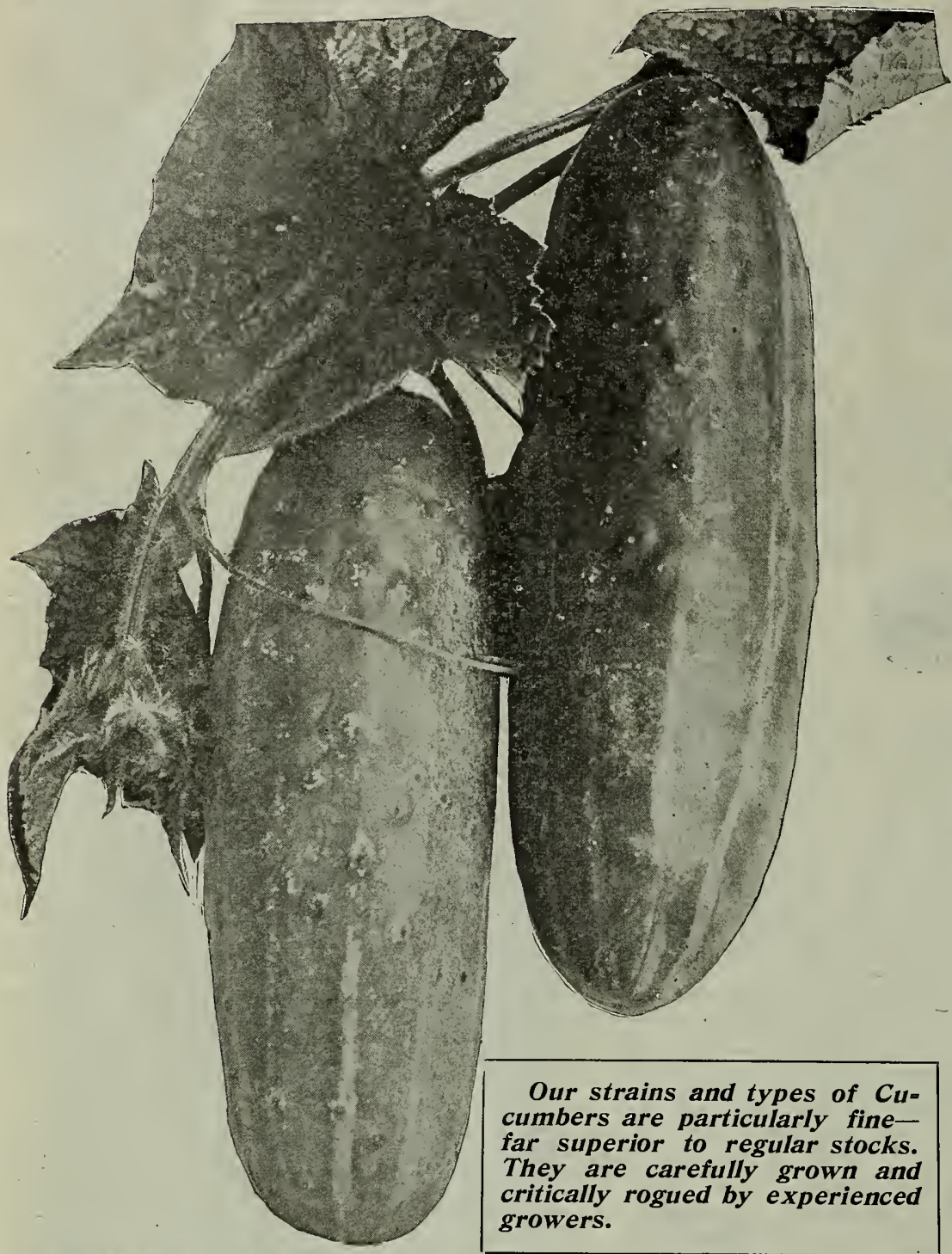

Reuter's Peerless New Orleans Market

\section{REUTER'S EARLY FORTUNE}

This is a fine selection of White Spine of recent introduction and is creating a furore among the many large truckers through out the south on account of its earliness, handsome shape, medium size, dark, glossy green color, and prolificness. A very fine va-

Price, pkt. 5e; oz. 10c; $1 / 4$ 1b. 30c; 1b. \$1.00; 10 lbs. $\$ 9.00$.

\section{FORDHOOK FAMOUS}

A new extra long White Spine Cucumber producing perfectly smooth, very dark green handsome straight fruits, measuring 12 to 17 inches long. They are always straight-never turn yellow,

and extra solid. It certainly deserves a trial.

\section{REUTER'S IMPROVED LONG GREEN}

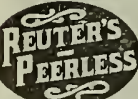

Vines very vigorous and productive. The frujts are long, often twelve to sixteen inches; slen of uniformly dark green color. Furnished some fruits early, but matures the bulk of its crop late. Price, plat.

\section{JAPANESE}

The strong vines throwing out numerous tendrils can be trained up a trellis or poles, which well insure earlier ripening and a straight handsome form in large fruits. Flesh is pur hite, crisp, tender and of mild flavor.

Price, pkt. 5e; oz. 15c; 1/4 1b. 40c; lb. \$1.50.

\section{REUTER'S NEW GRAND FORCING CUCUMBER}

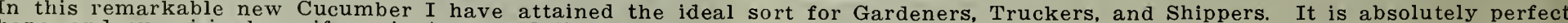

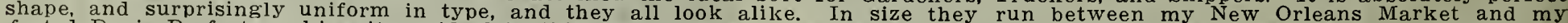

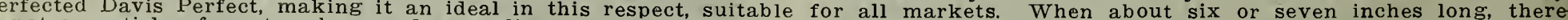
not a particle of waste when used as a slicer, and the seeds at last stage are hardly noticeable

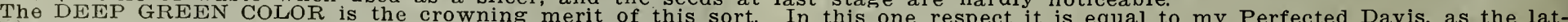

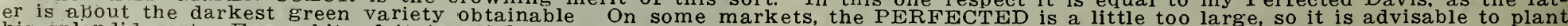
splendid sort. Every bit of it is edible.

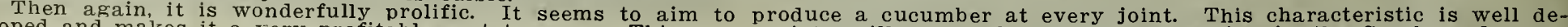

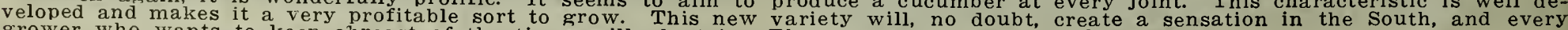
grower who wants to keep abreast of the times will plant it. The seed supply is short this year.

Price, pkt. 5e; oz. 15c; $1 / 4$ 1b. 40c; 1b. \$1.50; 10 lbs. \$14.00, prepaid.
REUTER'S PEERLESS NEW ORLEANS MARKET

For forcing or open ground this sort is eight to ten inches. Average length is froin is retained much longer and less affected by the its size and shape make it a splendid shipping sort. Last Truckers. They claim it beyond question the earliest and productive variety grown. We have hundreds of testimonial letters on file most prominent growers in this section, praising

\section{HENDERSON'S PERFECTED WHITE SPINE}

A variety that has been largely cultivated in this secorleans latter variety is far more prolific than this sort. Neverthelific, and bears uniformly It is quite early, enormously proored fruits, faintly marked with a slight yellowish shading Price. pkt. 5c; oz. 10c; 1/4 1b. 30c; 1b. \$1.00; 10 los. \$9.00.

\section{REUTER'S EXTRA EARLY WHITE SPINE} and length. fine dark green color We have a rather large trade for this sort in Florida and parts of Texas where

Price, plot.

\section{TAILBY'S HYBRID}

A variety hybridized with the White Spine and English rame, combining the hardiness of the fornier and the
beauty of the latter. Very long and superior for outdoor ture.

\section{KLONDYKE}

A fine strain of White Spine. Average six inches and of unexcelled quality. Vines are very hardy and provery fine sort. Its points of superiority are ex$t$ to hold its dark green color and crispness for a very Price,

\section{REUTER'S IMPROVED WHITE SPINE}

selected strain of the well-known White Spine Cucumber. handsome fruits of the most desirable qualities. A vigorous

Reuter's Selected Stock, oz. 10c; 1/4 lb. 25c; 1b. 90c; 10 lbs. $\$ 8.00$. REUTER'S EXTRA LONG EVERGREEN WHITE SPINE quality Hardy, early, and very productive. The fruit is long, cylindrical, very dark green, with very distinct strain developed through the most careful Price, pkt. 5e; oz. 10c; $1 / 4$ lb. 25e: 1b. 90c; 10 lbs. $\$ 8.00$.

\section{DA VIS PERFECT}

for forcing and for out-doors. The fruit is long and A strong grower, and on this account is a better blight resister

\section{ARLINGTON WHITE SPINE}

A medium size cucumber; color dark green, with very litAf the white spine showing. An excellent sort.

Price, pkt. 5e; oz. 10c; $1 / 4$ lb. 25e; lb. 90c; 10 ibs. $\$ 8.00$. Variety Raised in the Vicinity of New Orleans sun than other varieties. It is very uniform;

The demand for this sort is growing rapidly. It is dark glossy green. Grows very uniform and is a shy seeder. Price, pkt. 5e; oz. 10e; $1 / 4$ lb. 25e; lb. 90c; 10 lbs. \$8.00. 


\section{Finest New Jersey}

Grown Seed

\section{EGGPLANT}

Seed Grown from

Stock=Seeds Furnished by me

Culture-Seed should be sown in hot bed in the early part of January and February. When the plants are two inches high they should be transplanted into another frame, so that the plants may become strong and healthy. When warm enough, generally during March, transplant to the open ground in rich soil, two to three feet apart. For a fall crop, the
May, June ard July. Should the plants be attacked by insects, use Tobacco Dust or Hammond's Slug Shot.
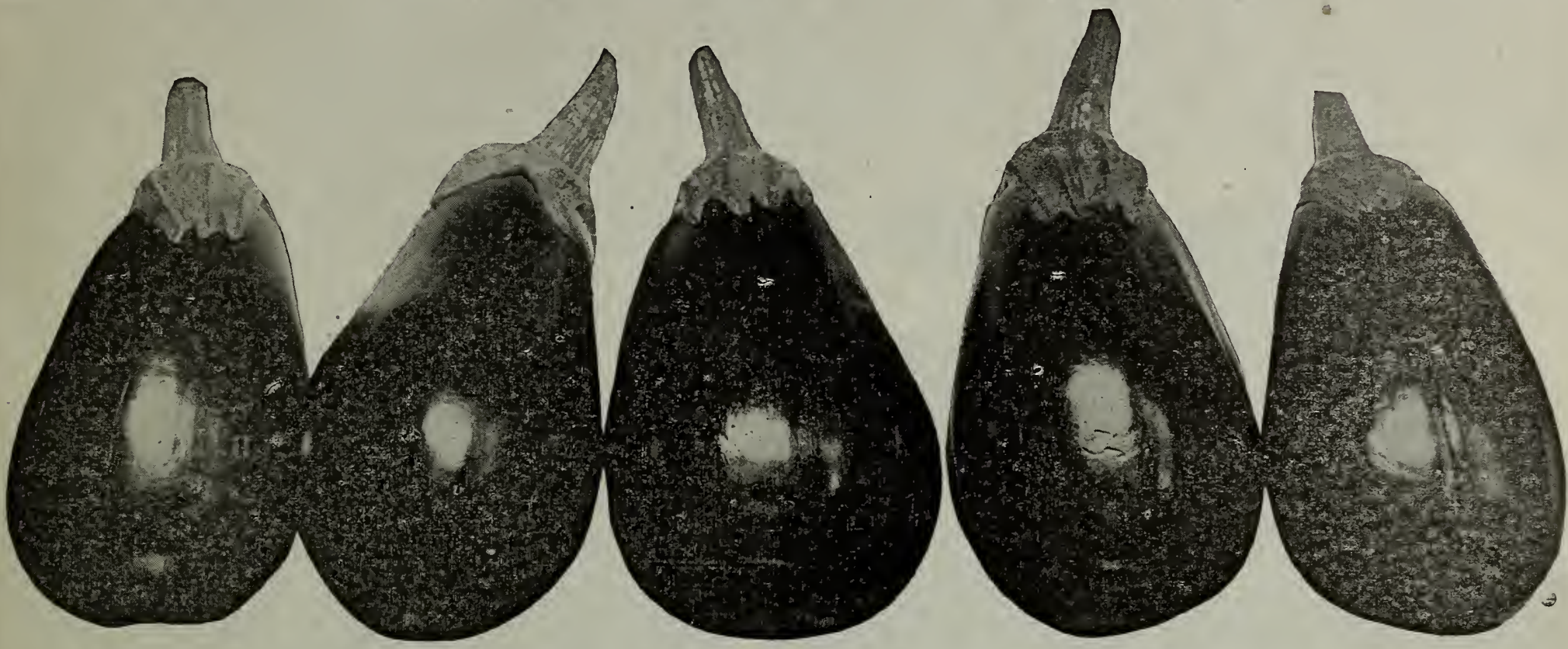

REUTER'S NEW ORLEANS MARKET EGGPLANT-THE WORLD'S FINEST

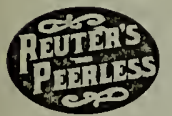

A distinct variety, absolutely different from any other. It is not a sort given this name to mislead anyone, but is the finest strain of this vegetable on the market. I sell several hundred pounds of it every year to the most critical gardeners in the South. It is perfectly adapted to the South, and in this respect is the superior of the New York Market, which is the standard variety in the North. No other seed store in this country can offer you this
particular strain of Eggplant. I handle it exclusively. The seed is grown for me from my own stock seed, which I particular strain of Eggplant. I handle it exclusively. The seed is grown for me from my own stock seed, which I

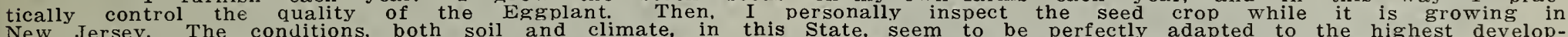

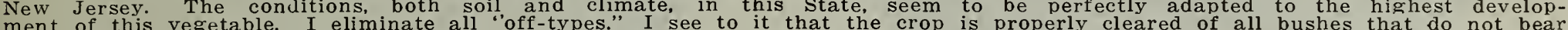

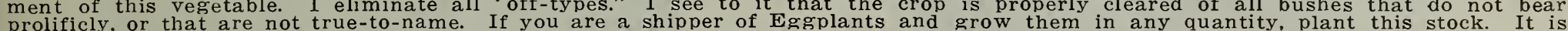

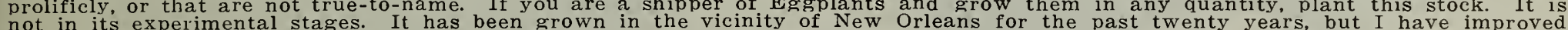

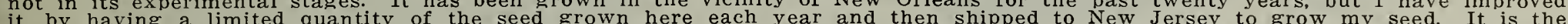

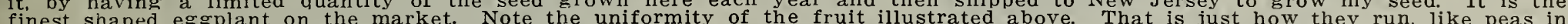

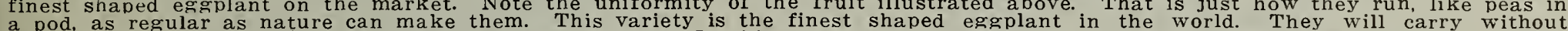

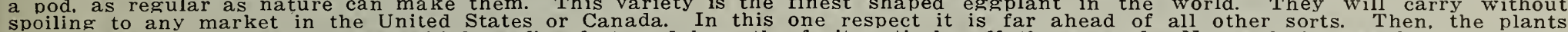

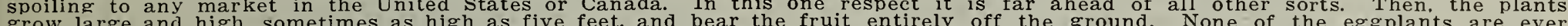

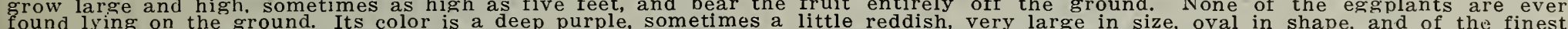

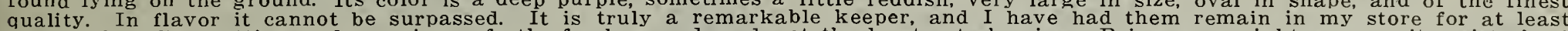

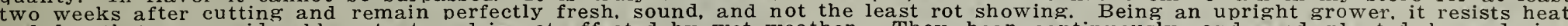

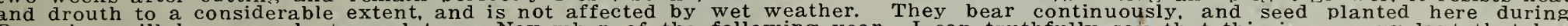

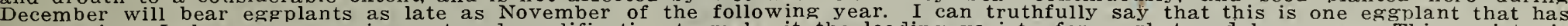

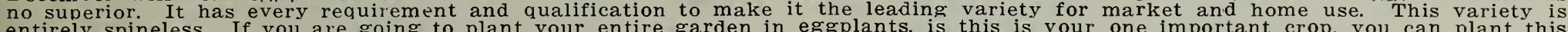

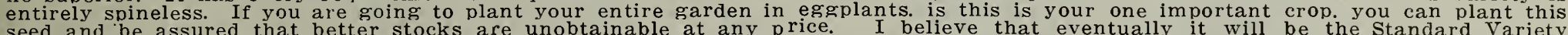

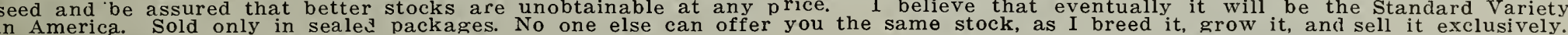

Price, pkt. 10c; $1 / 4$ lb. \$1.2.; 1b. \$4.00.

\section{NEW YORK IMPROVED LARGE PURPLE}

This variety is a general favorite for both market and home use. Fruits large, good shape, slightly rounder than the New Orleans Market, and of a dark purple color. Very prolific and spineless.

Price, oz. 10c; $1 / 4$ 1b. $\$ 1.10 ; 1 b . \$ 3.75$.

\section{KOHLRABI}

Culture-For fall or winter it should be sown from the end of July until the midale of October; for spring crop during January and February. When well started, the plants can be set out in rows about ten to twelve inches apart, and about the same distance in the rows. They can also be sown broadcast and thinned out afterwards.

\section{REUTER'S EARLY WHITE VIENNA}

This variety is one of the best, being extremely early with small tops. thus allowing close planting. Flesh white and tender. Our seed is French grown, and is of the highest quality procurable.

Price, pkt. 5e; oz. 15e; 1/4 1b. 35c; lb. \$1.25; 5 lbs. \$5.75.

\section{MAMMOTH ITALIAN FENNEL (Finnocchio)}

A very delicious vegetable largely grown by the Italians. In flavor it resembles Celery, but has a the fall and and of a very delicate odor. Sow during the fall and $\$ \mathbf{\$ 4 . 5 0}$.

$$
\text { Price, pkt. 5e; oz. 10e; 1/4 lb. 30c; lb. \$1.00; 5 lbs. }
$$

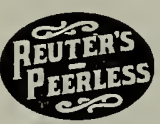

\section{FLORIDA HIGH BUSH}

Plants are large and high, usually bearing the ruits off the ground. The sun does not blight the blossoms, as in the case of the other varieties. Very popular with the growers throughout Florida and other Southern States, and we especially recommend cal growers. \$17.50.

\section{LEEKS}

Imported

Culture- Should be sown broadcast and transplanted when about seven inches high into rows twelve inches apart, and five or six inches apart in rows. Should be planted at least five inches deep. Sow in September and October for winter and spring use, and in January and February for summer.

\section{REUTER'S LONDON FLAG-SELECTED STRAIN}
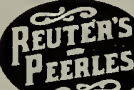

ixilixs
A very hardy variety and one of the best for fall and winter planting. A strong, quick grower, pro-
ducing long stems of uniform shape and size. We supply the best imported seed. $\$ 4.50$.

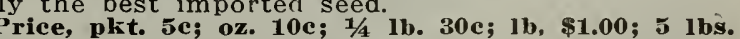

\section{MONSTROUS CARENTAN}

A very large grower, stems often three inches in diameter, becoming very white and tender. A very sort.

Price, oz. 15c; $1 / 4$ lb. 40c; 1b. \$1.50; 5 lbs. $\$ 7.00$. 


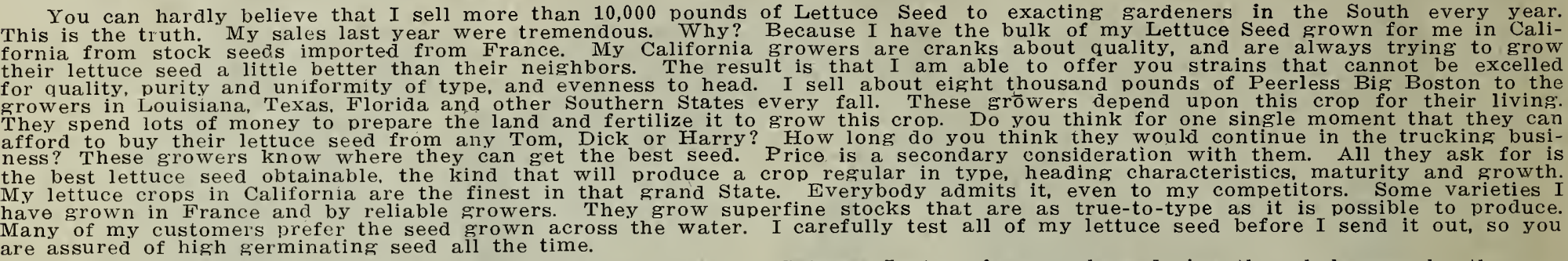

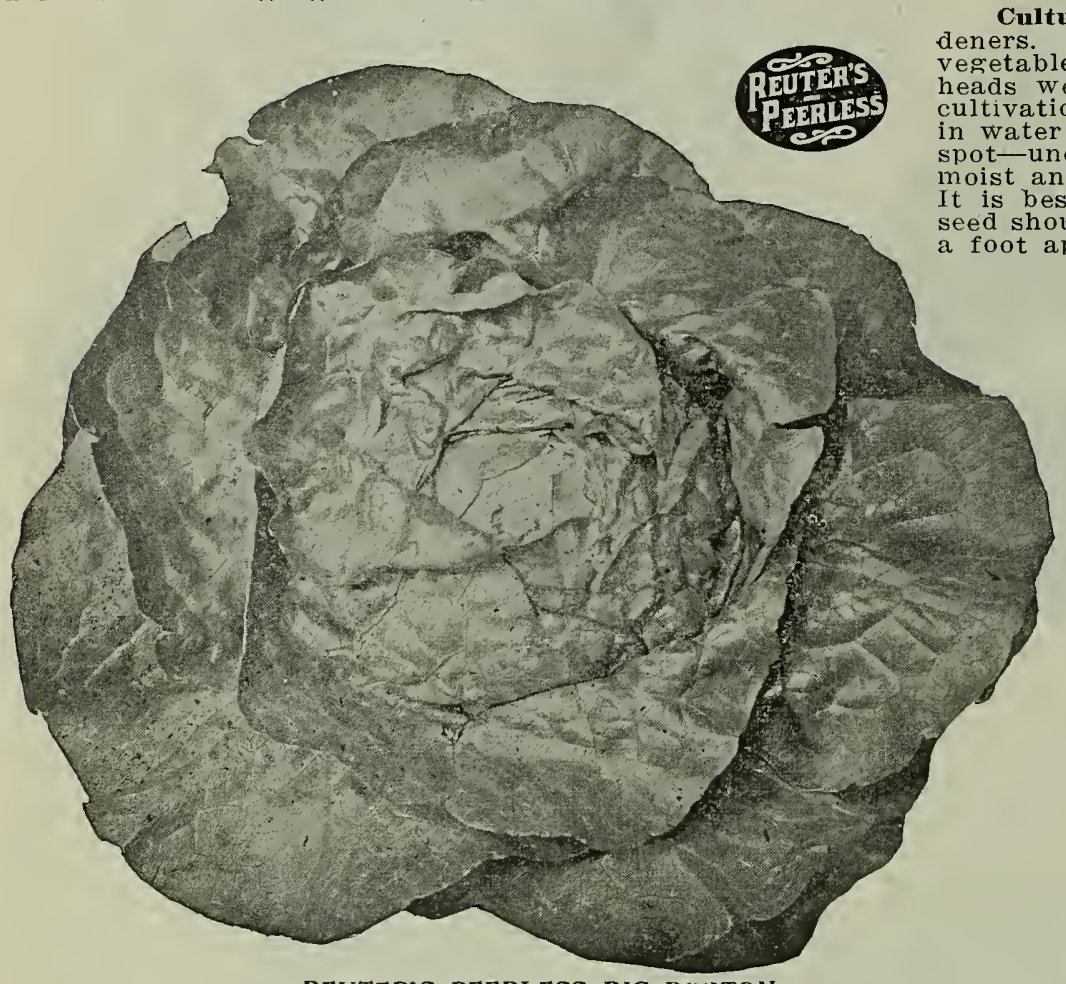

REUTER'S PEERLESS BIG BUSTON REUTER'S IMPROVED ROYAL CABBAGE

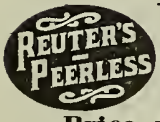

A desirable sort for summer or fall use, forming good-size heads of fine quality. Stands the heat remarkably well. Extensively planted by our
truckers during June and July for first market.

Price, pkt. 5e; oz. 10e; $1 / 4$ lb. 30e; $1 \mathrm{~b}$. $\$ 1.00 ; 5$ lbs. $\$ 4.50$ (prepaid). CALIFORNIA CREAM BUTTER

Very large, solid heads, slow to shoot to seed. Heads are Price, pkt. 5c; oz. 10c; $1 / 4$ 1b. 30c; 1 b. $\$ 1.00 ; 5$ 1bs. $\$ 4.50$ (prepaid). REUTER'S NEW ORLEANS IMPROVED PASSION

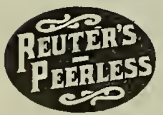
large extent by our Southern gardeners during the winter for shipment to the North. A good shipper, winter for shipment to the North. A good shipper,
very hardy to cold, and especially good for summer.
Our strain is unsurpassed. Price, pkt. 5e; oz. 10e; $1 / 4$ lb. 30c; 1b. \$1.00; 5 lbs.

\section{REUTER'S EARLY MARKET}

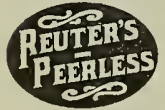

low to bolt to seed. A splendid Price, pkt. 5e; oz. 10c; $1 / 4$ lb. 30c; lb. \$1.00; 5 lbs.
$\$ 4.50$ (prepaid).

\section{IMPROVED LARGE SALAMANDER}

An excellent summer or fall variety, producing fine, compact heads. It is not affected by the hottest weather. We highly recommend it as one of the best summer sorts in cultivation. paid).

\section{REUTER'S FAMOUS TROCADERO-French Grown}

The cultivation of this large heading variety,

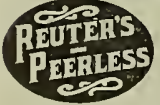

which for many years has been limited to the New Orleans Market Gardeners, is gaining popular favor the standard winter variety. The heads are very large and compact, light green in color, and of excellent quality. It wil stand more cold than any heading variety known. Our strain is a very fine one; runs wonderfully even and

Price, oz. 10c; $1 / 4$ 1b. 40c; 1b. $\$ 1.50 ; 5$ lbs. $\$ 7.00$ (prepaid).
Culture-Lettuce is sown here during the whole year by the gar-

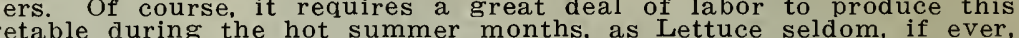
ads well in hot weather. We have found the following method of

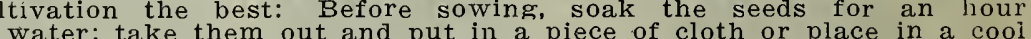
t-under a cistern, or if convenient in an ice-box. Keep the cloth oist and in two or three days the seed will sprout. Then sow thenl. sos
s. oot apart, and from eight to ten inches apart in rows.

\section{REUTER'S PEERLESS BIG-BOSTON}

My strain of this famous variety has won the favor of thousands of the most discriminating gardeners in the South. Every year I check up the orders on this stock, and the same growers buy from me year after year, truly a tribute to my efforts to furnish them with a strain that ter how much they may pay. It is the best heading variety in cultivation, and so well known that an extended description is not at all necessary. It is a splendid shipper, hardy, and thoroughly reliable. The heads are large and solid. My stock is sure to head. It never fails to produce extra large solid heavy heads. I plant about twenty-five acres every year on my own farm at Bohemia, and they surely look good this year, and the prospects are that I will make good profit off the crop. I planted the seed during september. I offer you both the French and California Grown impossible to the former is a linte better, but it is almost grown in California. I have planted both strains on my farms, and cannot detect any difference between them. If you don't mention what kind you want when you order, I
always give you the California stock. Remember that you cannot buy better lettuce seed than this in any part of the world.

California Seed-Pkt. 5e; oz. 10c; $1 / 4$ 1b. 35e; 1b. \$1.25; 10 lbs. $\$ 11,00$.

French Seed-Pkt. 5c; oz. 10e; $1 / 4$ 1b. 40e; 1b. $\$ 1.50 ; 10$ lbs $\$ 14.00$.

(These prices are prepaid.)

\section{REUTER'S FRENCH BLACK-SEEDED BIG BOSTON}

A grand acquisition that is creating a furore among our leading truckers. Similar to our White Seeded Big Boston, but much hardier and of finer
quality. Its usefulness and value are identically the quality. Its usefulness and value are identically the same as our Peerless Big Boston, but is preferred by
some market gardeners, because of its ability to head during the most unfavorable weather, and being slower to run to seed. Our stock is grown expressly for us in France, and our famous seed growers claim that it cannot be excelled as a heading variety. We have carefully investigated the merits of this magnificent strain, and thoroughly agree with our mor

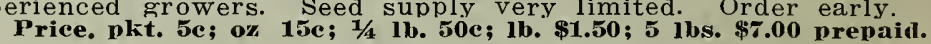
HUBBARD MARKET

A celebrated variety of the Salamander type, forming large compact heads. Fine for forcing or open ground.
Price, pkt. 5c; oz. 10c; $1 / 4$ lb. 30c; lb. $\$ 1.00 ; 5$ (bs. $\$ 4.50$ (prepaid). REUTER'S LARGE LATE SOUTHERN

This is by far the most popular sort among the New Orleans gardeners. It forms large solid heads that resist the sun for a to seed. It matures somewhat earlier than either the Big Boston or our famous Trocadero. It is a positive header under the most trying conditions, and
type for hot weather; also desirable for autumn use. a valuable type for hot weather; also desirable for autumn use. It may be sown at any season of the year, but seems to do best originator in France. $10 c ; 1 / 4$ lb. 30e; 1b. \$1.00; 5 1bs. \$4.50 (prepaid).

\section{ROMAINE COS, OR CELERY LETTUCE}

\section{REUTER'S PARIS WHITE COS}

The most popular of all Cos varieties, and is really the only Cos sort planted to any extent in this section. Forms large, upright heads, eight to twelve inches in height, and of the finest quality. (prepaid).

\section{TRIANON COS} paid).

Similar to the above, but grows whiter and matures ear-

Price, pkt. 5e; oz. 10c; $1 / 4$ lb. 35e; lb. \$1.25; 5 lbs. $\$ 5.50$ (pre- 


\section{\begin{tabular}{|c|c|c|c|c|c|}
\hline Grown in Colorado & Critical Selection
\end{tabular} No Melons Shipped From the Field MLOK \\ From Ideal Types}

I did not think it necessary to say anything about the quality of my Cantaloupe Seed until someone told me just how cheap he could buy some Rockyford Cantaloupe Seed direct from a grower in Colorado. This man started things. I was so confident that he seed he had reference to was serub stock that $I$ gave him ten pounds of my best seed for nothing, requesting him to sow it alonghe seed he had reference to was scrub stock that gave him ten pounds of my best seed for nothing, requesting him to sow it along-
ide of the stock he purchased out of Rockford, and to advise me of results. He is to-day one of my best customers, and erery year ibe of the stock he purchased out of Rockerd, a fom me and never mentions price. He gets superfine seed and the price is right. buys about a hundred pouns of Cantaloupe seed from me and never mentions price. He gets superfine seed and the price is right. If you crow easively for this purpose and selected for quality, not profits. Without the best seed from perfectly developed specimens, you clusively for this purpose and selected for qualis, not profits. Without the best seed from perfectly developed specimens, you can only reap one harvest- failure. Don't experinent. You can't afford to. Do you think 1 would huy s0 to 100 pounds of Rockyout if the seed they offered me was strictly A1, saved from selected melons grown for this purpose only. It would surprise you to know the amount of deception that is practiced in this seed business. Some seedsmen buy up the culi melons when the shipping season is over and endearor to sell this kind of stuff to you as Genuine Rockyford Seed. They clean up the field after the good
melons have been marketed. Just think of it! This, no donbt. surprises you. Well, it did surprise me when my attention was ealled to it. I did not think it possible for any man to practice such dishonest methods to make a living. For goodness sake, be careful from whom you buy your seed. It is a dollar proposition svith you entirely. You leave the question of good seed with the man from whom sou buy, but you must pay more attention to your purchases than ever before. It is indeed a ticklish proposition to know real good. Big growers and little ones, all say that my seed is the finest they have ever planted. Seed selection means quality. Quality means profits to you. I give you all that you can expect both in quality and selection.

Culture-Melons thrive best in a light rich soll. Rich earth for the young plants is far better than manure, but if the latter must Plant the seed in hills six feet apart each way dropping ten to twelve seeds in a hill. When up and all danger of insects has passed, pull
the ground, and pinch the ends of the growing shoots to induce early fruiting.

TWO BIG MONEY=MAKERS FOR TEXAS, LOUISIANA AND FLORIDA GROWERS!

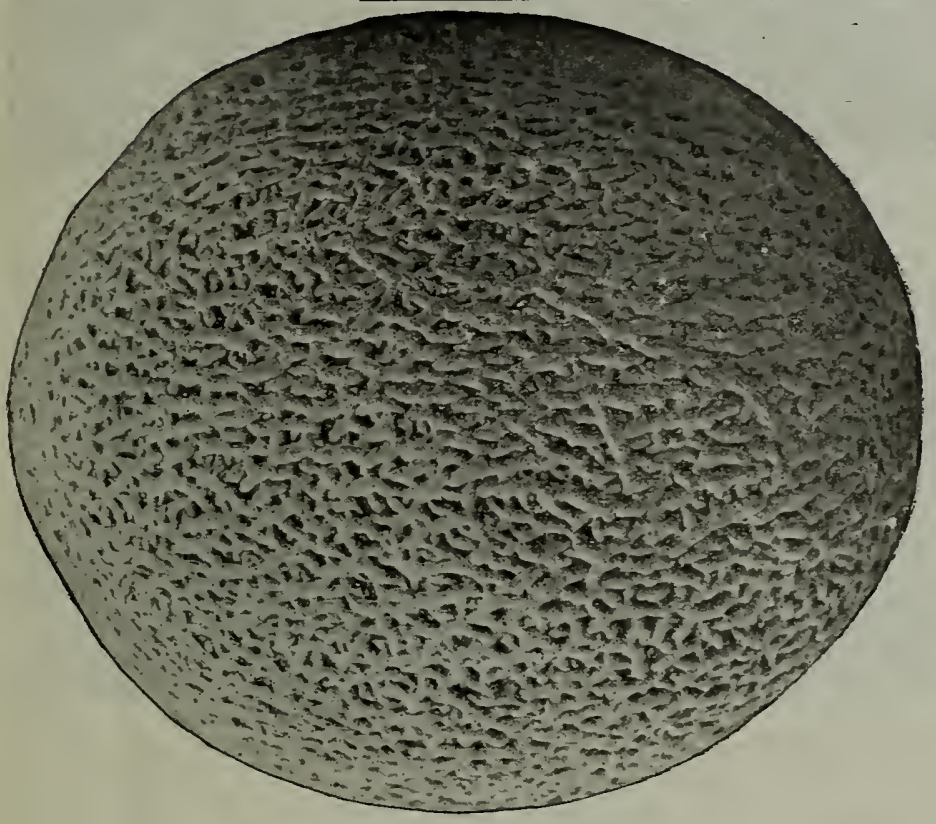

REUTER'S GENUINE ROCKYFORD CANTALOUPE

\section{REUTER'S GENUINE ROCKYFORD CANTALOUPE}

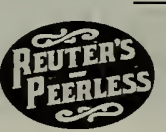

Far away in the "Land of Abundant Harvests" I have this melon seed grown. It is grown by farmers who sell seed, not melons. They get paid well for growing this extra fine seed for me, and don't have to worry about disposing of their crop of melons. The market prices don't interest them at all. All that they are worried about is the quality of the seed they grow, endeavoring at all times to improve the type, flavor, and growti. The strain 1 offer to you is better than qualities. A money-maker for the large grower of Cantaloupes in the quath, who expect to profit by growing this one bio crop. I have more than 5,000 pounds sold for January shipment, a tribute to my strain, the results of many years' careful breeding and selecting.

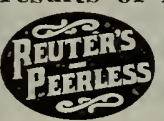
This is the highest development yet attained in the
Rockyford Cantaloupe both in netting and rust-resistant qualities. The melons appear as shown in cut, solid net. the heavy gray netting being closely laced and interlaced over the entire surface of the melon from the stem to the
well-developed blossom button. The length and thickness as our seed crop runs this past year was ideal, fully ninety per cent of
the melons being choice standard size. The meat is light green and very deep; its flavor is not excelled by any of the green meat sorts resistant. Under favorable conditions, when other strains rust badly the vines of this strain remain green and thrifty continuing to blosin many localities rust often destroys the crop, and when other strains have lost their quality on account of rust this continues to ripen melons of the highest quality. Our seed is carefully selected, and only the finest standard size, solid netted melons cut, in this lot
Irice, o\%. 10c; 1/4 lb. 25e; lb. 90e; 10 lbs. \$S.50, prepaid.

\section{BURRELL'S GEM-SELECT}

The tendency in

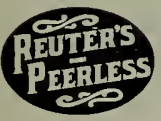

to produce something for big profits. That is one reason why this melon degenerated by lack of proper care and attention. It is a tremendous money making variety, however, and hundreds of the best truckers in Texas, Florida, Louisiana, Mississippi, and other sections have realized big juicy profits from planting this one sort. I do like to talk about $r y$ strain of this one variety, but I really think it is the finest in the world. It is grown by an old seed-grower friend of mine in Colorado. He don't grow for everybody. He is not one of these big commercial growers who have too much to handle and are unable to devote proper attention to selections. This man grows for me only, and only grows this one variety. I handle quite a few thousand pounds of it every spring. Then he is not ambitious to get rich quick and is satisfied with the good price I pay him for the seed. No matter from whom you may contemplate buying this stock in the spring, at least purchase a few pounds from me and compare it with the stock you are growing from seed purchased from others.

It is an abundant yielder, often producing 15 to 25 melons to the hill. The meat is rich golden color, very thick, and fine grained. The flavor cannot be surpassed. The seed is closely held in place in three lobes and do not easily shake loose. The rind is covered with a closely packed gray netting, except the narrow strip between the ribs, which is not netted. The blossom end is well protected. Note the photo which is an excellent reproduction of one melon produced from my seed. The shape is ideal, averaging six inches long and tapering at the end. A splendid shipper, a good producer, and naturally a profitable sort. Buy your seed from me this year. You will then be one of my $\tilde{5} 0,000$ regular customers.

Price, pkt. 5c; oz. 10c; $1 / 4$ lb. 25e; 1b. 90c; 10 lbs. \$8.50, prepaid.

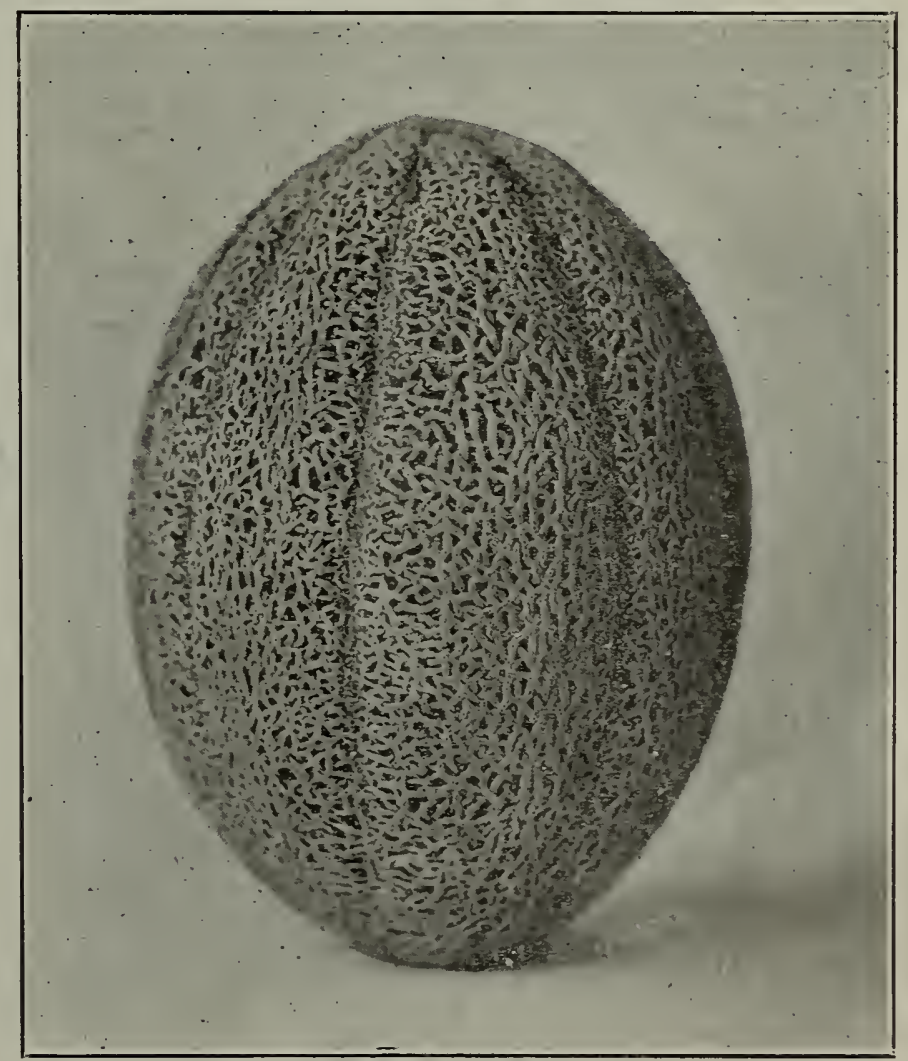

BURRELL'S GEM--FINEST SEED SELECTED 
You Pay for Quality But You Get th MUSKMELONS

Quality is the Foreword. I Can Think of Nothing Else

\section{REUTER'S SELECT EDEN GEM}

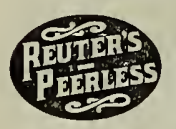

would like to take a few of my best customers out to Colorado and show them the wonderful work I ani having done out in that worious state in the way of breeding and selecting and I know that you would be interested very much in the methods, and the process of elimination, the latter discards all melons that are not strictly up to grade and quality. If there is one single fault about the melon, whether it is in the size, flavor, shape, or growth, it is discarded. My growers never take a chance on quality. They can't afford to and hope to supply me year after year. They are just as critical in their fields, as I am about testing $\mathrm{my}$ seeds in my store. That is one reason why I get alons so well vith my growers and my customers

In my strain of Eden Gem you have a melou that is of the highest development that is possible at present. In a few years I might be able to offer you an improvement on this strain, but to offer you an improvement on this strain, but much you may pay or from whom you are going much you may pay or from whom you are going to obtain your seed. It belongs to the famous yielder, nearly all melons heavily netted, like the photo, which is a few put aside for my seed. The meat is dcep and of excellent quality. My seed is carefully grown from selected melons ony, and I sell several thousand pounds anuually to the most critical trade in the South. Price, pkt. 5c; oz. 10c; $1 / 1$ lb. 30c; lb. $\$ 1.00$
10 lbs. $\$ 9.00$, prepaid.

REUTER'S NETTED ROCK

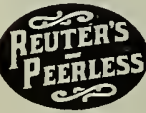

Cantoupe that retains The seed I offer you is the best that money and brains can produce. This melon very closely resembles the Edem Gem in shape, color, and growth. Practically the meat is very deep. They are fine shippers; running a large per cent standard size. It is very popular in many sections of the South, and the growers seem to think favorably of my strain. last year the demand was tremendous, and possibly it will be paic:

Price, plet. 5e; oz. 10c; $1 / 4$ lb. 30c; 1b. $\$ 1.00$; 10 lbs. \$9.00, pre-

\section{REUTER'S NEW ORLEANS MARKET}

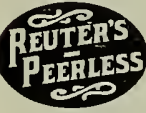

in melon largely grown by the market gardener ket. For two successive years these melons have been scarce on this market, and the growers obtained gardener has grown the seed I offer you, and I really think it is the finest seed leaving this section. Of course, very out. This is a very good melon for your local market, being of large size, well netted, of the finest flavor and quality.

\section{EXTRA EARLY HACKENSACK}

A very large, green fleshed melon. Very early. Melons weigh from four to ten pounds and are of excellent flavor. Vines hardy vigorous and productive.

Price, oz. 10c; $1 / 4$ lb. 30c; 1b. $\$ 1.00 ; ; 10$ lbs. \$9.00.

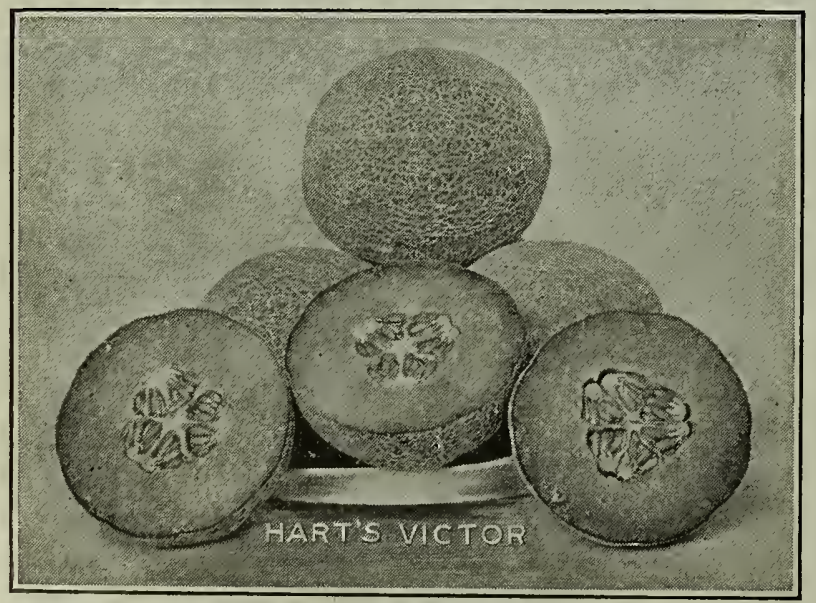

$O S A G E$

This is a very popular melon and one of the best, owing to its fine spicy flavor and good shipping qualities Skin darli green, slightly

Price, oz. 15e; 1/4 1b. 40e; 1b. \$1.50.

\section{$C A S A B A$}

An introduction that has proved a big success, and a melon that is getting immensely popular with the most critical trade in the country. It is oblong in shape, medium netted, buff-yellow. very thick, smooth, close-grained flesh, having a spicy aroma and a flavor bordering on a pineapple.

\section{TEXAS CANNON BALL}

A very popular melon in Texas, where it it cultivated to a state for home and nearby market use. It is not a good shipper, and I don't advise you to plant it if you want to grow melons for profit. It will do all right for the wide range of soils and climatic conditions, and will often grow when all others fail. Round, medium in size, heavily netted. Fles green, very solid, melting and of delicious flavor.

Price, pkt. 5c; ox. 15c; 1/4 lb. 40c; lb. \$1.50, postpaid.

\section{REUTER'S IMPROVED BANANA MUSKMELON}

Not a market variety. A long salmon-fleshed variety having the fragrance of the banana, and of fine flavor, growing about ifteen inches long.

Price, oz. 10c; $1 / 4$ lb. 30c; lb. \$1.00; 10 lbs. \$9.00.

PAUL ROSE

This is a very good melon. Fruit oval. Flesh rich orange red. Most delicate and delicious flavor.

Price, oz. 10c; $1 / 4$ lb. 30c; $1 \mathrm{~b}$. $\$ 1.00 ; 10$ lbs. $\$ 9.00$.

\section{HART'S VICTOR}

A strain that has become very popular throughout Texas, Colorado, and other States. I obtain my seed from the originator. He writes me as follows: "In breeding and selecting Cantaloupes for a new strain, the idea I had constantly in mind was to please the consumer. After many years of patient effort we achieved our aim, and produced a cantaloupe without a flaw or blemish, bred, perfected and tested, a thing of beauty. The coloring exquisite, finely textured, thick meat, blending from a rich deep green to pale pine and asain darkening into more pronounced pink in the center. With an exceedingly small seed cavity, a good mesh and thick button, wo have a perfect cantaloupe, with a flavor that is sweet, it easily took 1st prize at both our County and State Fairs, and repeated its supremacy at the State Fair in 1911 and 1912. It is bound to please flavor cannot go hy very thiek meat; its delicate aroma and its delicious maturing. also a great shipper, due to its thick meat and the normal development of its fruit from vigorous vines. These points make the Victor the ideal cantaloupe to plant for both private and commercial giowers.

Price, pkt. 10e; oz. 15e; $1 / 4$ lb. 60e; 1b. \$1.50, prepaid. 


\section{We are Glad to Quote Special Prices on Quantities \\ WATERMELONS}

Sandy land with clay sub-soil recently cleared, or land of same character that has been lying out sufficiently long to be tree from grass seed, is good for melons. If desired to plant other than the above a pea-sod is fine. March 1st harrow the land well: check the land ten feet each way, the way you expect to cultivate; run furrow with a 20 -inch solid sweep as deep as you can, then scatter about one-half poun of cottonseed meal about 18 inches or two feet in check. If barnyard manure is to be used scatter a peck as same as the meal in checks; list with four furrows; let stand till April 1st deep; plant with a hoe. It is a good plan to plant at intervals until June 1st; plant every two or three weeks. Cultivate lightly: as soon as plants are well up cultivate every 10 days or two weeks until rines are three or four feet long. I leave one vine
to each hill; do not plow very deep any time after planting. You can have the best melons that grow by July 1st.

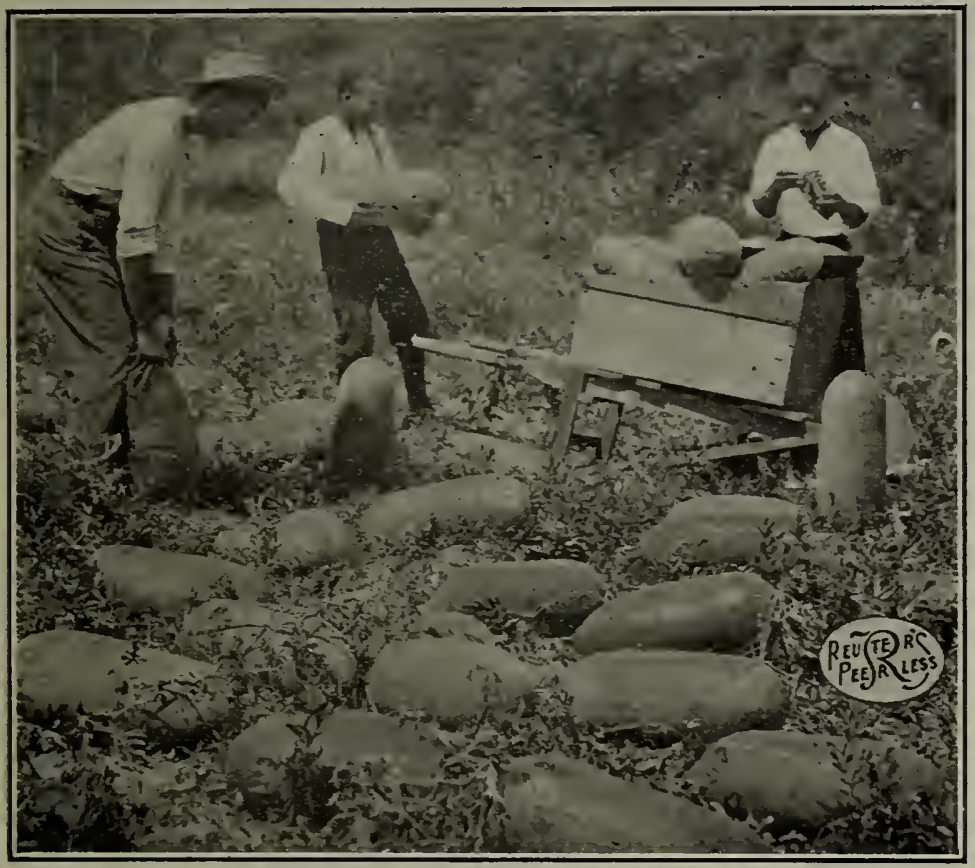

Selecting Tom Watsons for My Seed. All My Watermelon Seed is grown in the Sunny South

Every pound of my Watermelon Seed is grown expressly for me in the Sunny South. I do not buy a single ounce of seed in the North. I cannot afford to and hope to retain your trade if you grow melons for profit. When you plant my saved from melons selected for seed purposes exclusively. My growers are exacting-too much so, to grow melon seed for profit. They eliminate all under-sized, poorly shaped melons, and feed them to the hogs. Only the finest, choicest. most perfectly detention is also devoted to the breeding of the plant, clearing out all vines that do no bear prolificly.

Of course. lots of Northern and Southern Seedsmen claim to handle Southern Grown Melon Seed. There is just as much of this worthless seed grown in the South as in the North and West. I can buy all the $W$ atermelon Seed I want in Florida for $15 \mathrm{c}$ per pound. But can I get quality at this price? Would you grow melon seed for me at $15 \mathrm{c}$ per pound, and save the seed only from the finest melons, only on vines bearing prolificly? Why, of course not. You would want to charge me about fifty cents or more for this kind of seed, and I don't blame you. It is worth much attention to the melon seed they sell. Most of them sell so little that it does not pay them to lose any time about selection from pedigree stocks. I sell more than 20,000 pounds of Waterme under my own personal supervision in sections where each me under my own personal supervision in sections where each opment. I know growers in Florida who handle fifty different varieties of Watermelon Seed and supply the biggest seed houses in the South, East. North and West with this inferior grade of

Is it possible, Mr. Melon Grower for any seed grower to produce so many different varieties in his section and develop a seed that is absolutely true-to-type? Can all these varieties pollen of one variety not be transmitted to another? It isn't logical and it of one van't not be transmitted to another? It isn't logical and it simply can't be done. I have my Watson grown in one section of Georgia, my Kleckley Sweet in one section in Texas, my H. There is no mixture. I pay my growers a sufficient price

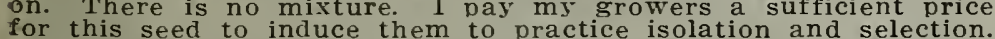
for this seed to induce them to practice isolation and selection. They must do it in order to keep my trade. and let me assure you that it is something worth having. In some instances with my big sellers I contract for the grower's entire crop. I see to of seed are grown in Kansas, Nebraska, and other States. The vines are rank in growth, the melons are rank in flavor and size.

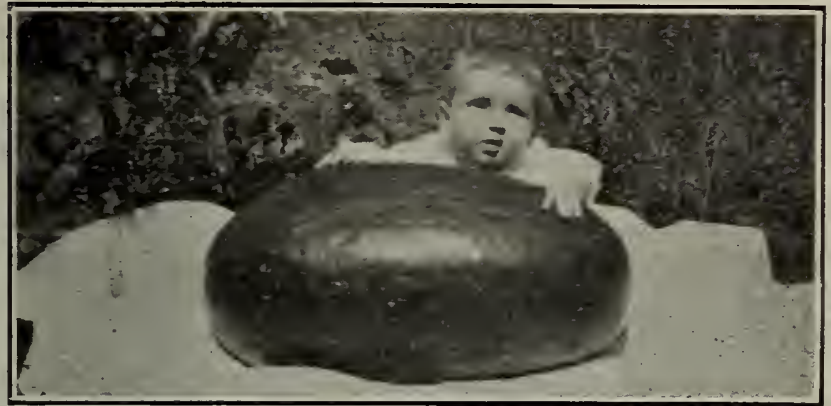

Million Dollars Worth of Baby and Ten Cents Worth of Melon

ones you will proauce from the seed I sell. I know some of the best houses in this country who purchase this grade of seed. and the grower of melons usually contends that good melon seed cannot be obtained from a seedsman and the only sure method is to grow the seed yourself. Don't deceive yourself into believyou will join the thousands of truckers who buy from me rear after year. not one pound. but hundreds, and never complain. Wate my seed I can unhesitatingly say Seed that cannot be excelled by any the seed will prove to the world. This is not an idle boast. but duced from my seed will be true-to-type, of uniform size. and of unsurpassed flavor. Cheap melon seed cannot be good. Don't Forget the price entirely, and buy where you know you can get 列 I stake my reputation on the quality of my melon seed. I think it is one of the most important items I handle. If you grow for
profit, and plant a large quantity of seed, write me for special prices. I will not, under any circumstances, sacrifice quality.

\section{RUBBER RIND WATERMELON}

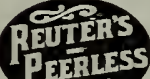

Narning! No one has the right to sell the seed rator. who has this name copyrighted.

The following description has been given to me "Knowing the defects as a shipper of the first melon I originated (the Halbert Honey) on account of its tender rind I went to work to produce a melon of equal beauty and as laod quality with a tough rind. After seven years of patient ago, and have it on the market this third year. It is decidedly the handsomest melon in shape and color of all shipring melons. Some will tell you it is as good in quality as the Halbert Honey. and eaten separately you might think so, but $\pi$ hen compared side by side, which is the proper way to compare melons, you will find the Halbert Honey the best in the world." very thin and exceedingly tough. almost as a piece of rubber, hence the name. pound in good seasons and nice size, weighing from 20 to 100 pounds in good seasons and nice soil. Flesh is dark red in color,
sweet and quite tender for a melon of so tough a rind. Seed, large, mostly mottled with black and white but some seed are white with darls rim around the edge. A cut shows their handand certificates from the best growers in the South praising this one variety. It is a wonderful shipper, withstanding all kinds

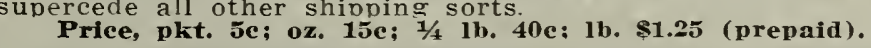

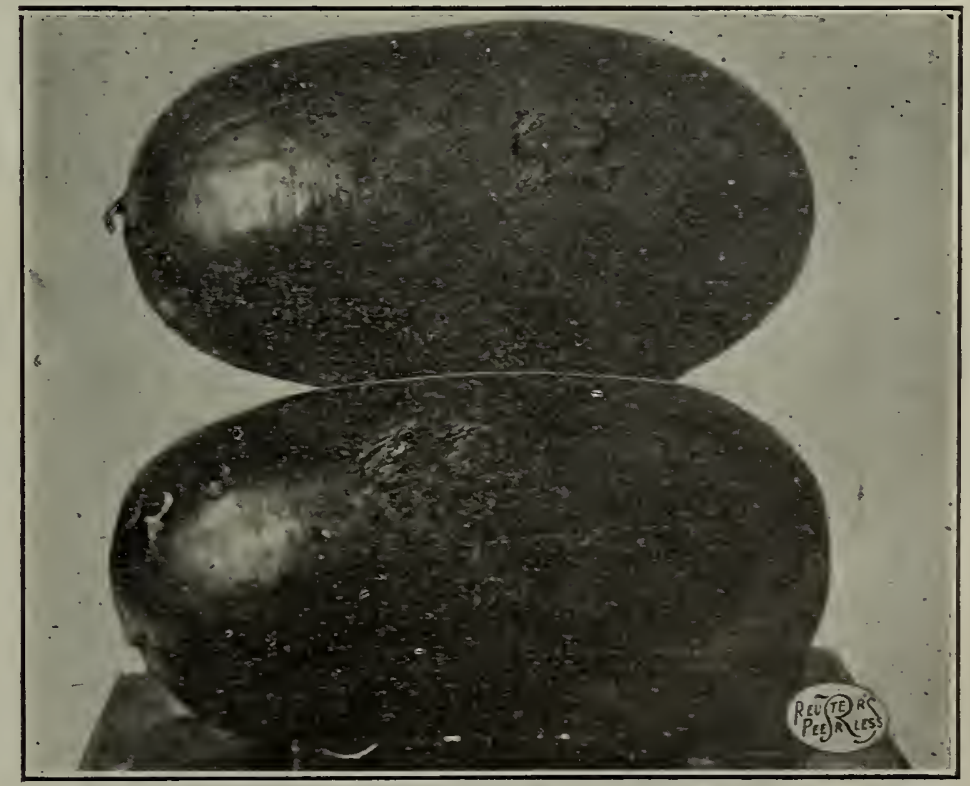

HALBERT'S RUBBER RIND-=A Good Shipper. Fifty and One-Hundred Pounders During a Good Season. 


\section{Watermelons Pure Strains}

\section{HALBERT HONEY=Grown by Halbert}

have

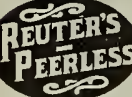

contended that the Kleckley

Sweet is the sweetest of all

melons. This was before I
got acquainted with Mr. Halgot acquainted with Mr. Halmerits of his Halbert Honey, which is just as sweet as the Kleckley Sweet and much more regular in form and more productive. In quality it is simply delicious, sugary, and of a rich fruity flavor, peculiar to stances, the sweet flesh melts away in the mouth like so much honey. The hardy vines are remarkably prolific. The crop covers the ground, and it is no uncommon sight to see four and five melons growing in a heap together, one on top of the The melon is long in shape and blunt at

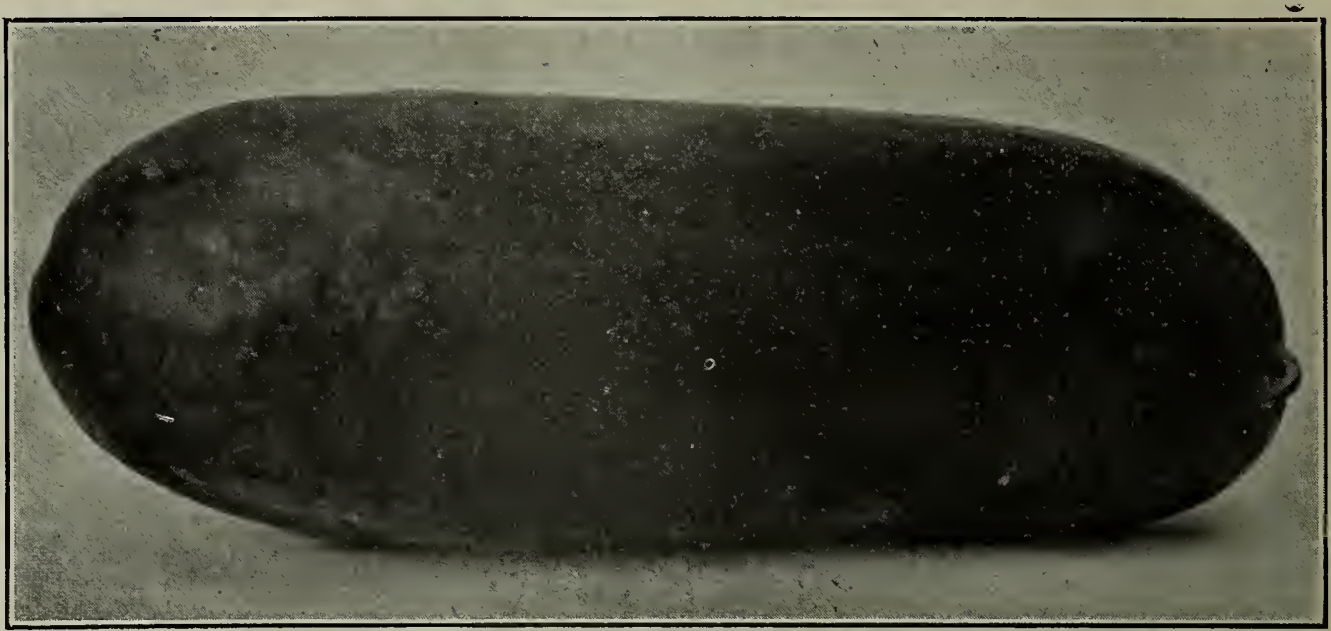

1 HALBERT'S HONEYmas Good as it Looks

each end. The rind is dark green in color, thin and brittle. Flesh tender and luscious, extra sweet, of blood red color, melting in side. Medium in size, but in good sandy soil and plenty of rain will grow to 75 pounds and more.

My grower has devoted great pains to bring this melon to a higher standard of perfection, if possible, during the last few years, and while other raisers for regular seedsmen have allowed the melon to run down and deteriorate. It is, therefore, to your interest to buy from the seedsman who handes th on his own farm. The high-class seed $I$ offer to you is of the

$$
\text { My prices are: Pkt. 5e; oz. 15e; 1/4 1b. 35e; lb. \$1.00 (prepaid). }
$$

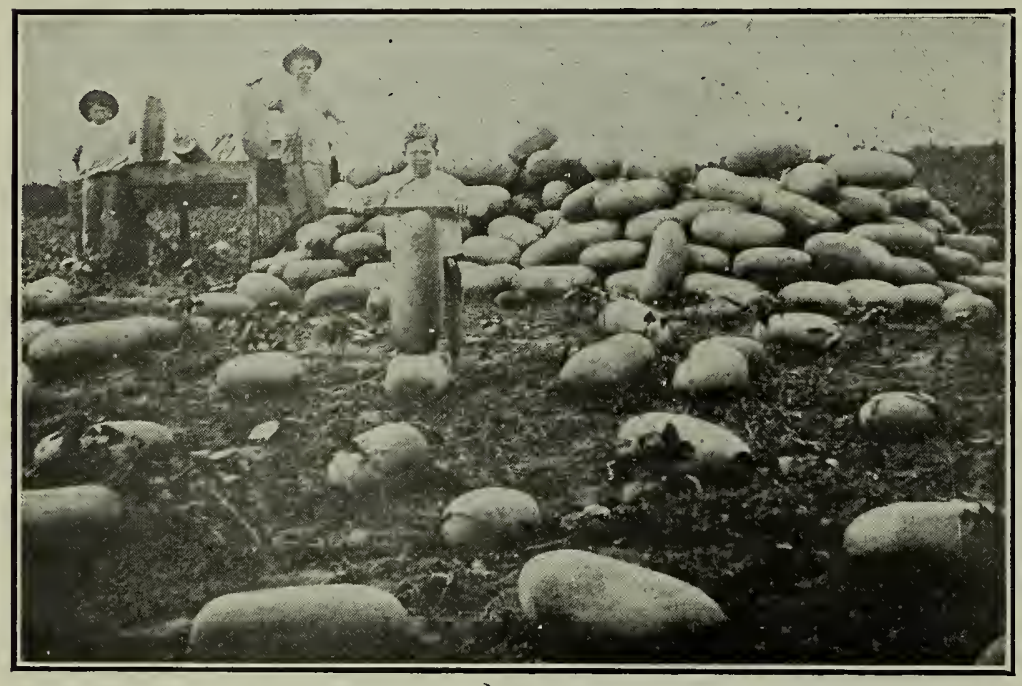

Portion of Our Seed Crop of Alabama Sweet Watermelon finest selections possible. Sold only in sealed packages. The very your order.

\section{REUTER'S ALABAMA SWEET (Grown in Texas)}

A grand variety. The rind is dark green marked with still deeper green mottled stripe, and while thin it is very tough, making the melon a first-class shipper. The flesh is bright red, fine grained, sweet and luscious, entirely stringless and very firm. The seeds are white, slightly tipped with brown, and are firmly set in small cavities near the rind. On September 29th our famous Texas Grower wrote us as follows: "I have your seed out and ready for shipment. My in many instances melons weighing considerably more."

Price, pkt. 5c; oz. 10e; lb. 60e; 10 lbs. $\$ 5.00$ (prepaid).

\section{KLECKLEY SWEET (Grown by Kleckley)}

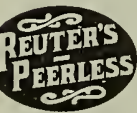

One of the most popular melons grown in the ment to neãrby markets. Vines are vigorous anment to nearby markets. Vines are vigorous and productive, fruits of medium size to large, often rind, flesh bright scarlet with broad solid heart, the seeds are nearly white and placed close to the rind. The flesh most crisp sugary and melting in the highest degree, entirely free from stringiness. They are being shippd from one to six hundred miles. Our stock is grown for us by Mr. Kleckley and, of course is of the highest quality obtainable.

Price, pkt, 5e; oz. 10c; $1 / 1$ 1b. 30c; 1b. 90c; 10 lbs. $\$ 8.00$ (prepaid).

\section{REUTER'S TRIUMPH}

Fruits large, nearly round; skin dark green, sometimes indistinctly striped with a lighter shade. The rind is thin but firm making it an excellent shipper. Flesh bright red and of finest quality. Our grower has improved this strain for a number of years. In 1904 there were ten melons shipped to the St. Louis won the Gold Medal on display. Melons often weigh over a hun-

dred pounds. Our strain is pure. paid).

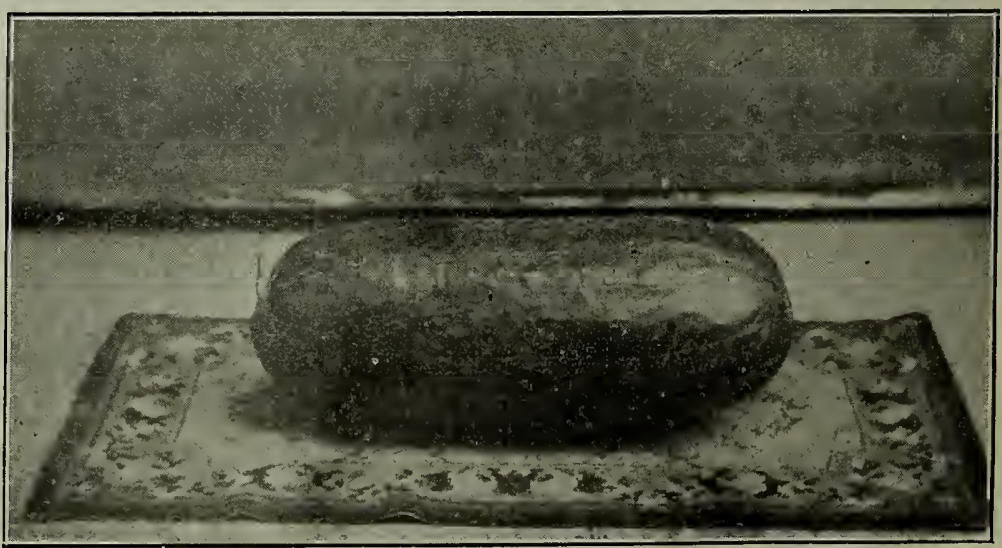

Kleckley Sweet (Grown by Kleckley) 
Write for Prices on Large Quantities$$
\text { WATERMELONS }
$$

Pure in Type

Uniform in Shape.

Sweet in Flavor

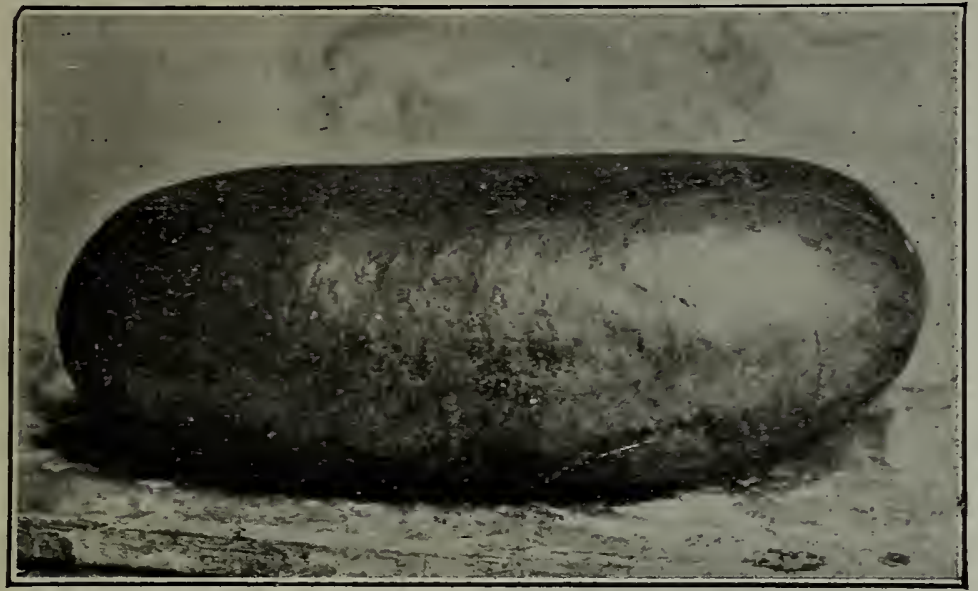

REUTER'S GENUINE WATSON (GeorgiaTGrown)

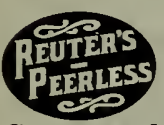

Also known as "Tom Watson" Watermelon. A long, dark green melon, growing to a good size, often weigling fifty pounds, as well as being a profour inches long by ten to twelve inches in diameter. Color is dark green, flesh crimson, quality fine, thin rind, and most excellent shipper. During the past four or five years this melon has had a remarkable popularity.

Our seed stock of this Melon is absolutely pure. Grown under the most critical system of cultivation and selection in a famous Melon section of Georgia expressly for our trade. We can unhesitatingly state that we are offering for sale seed of the highest grade and purest quality. We pay more than twice as much for this, stock than we can buy so-called "Selected Watkind of Melon Seed are annually shipped from that State. The keed is usually taken from the culls left after the shipping season is over. No selection is made as to type, no regard as to size or earliness. Our strain is kept pure. A trial will readily convince you that the price asked is low, considering the superior quality

Price, pkt. 5e; oz. 10e; $1 / 4$ lb. 30c; lb. 90c; 10 lbs. \$\$.00, prepaid.

\section{TRUE DARK ICING}

A nearly round Watermelon with very thin rind. The seeds are white. The flesh is solid and of delicious sweetness. An excellent market and home variety.

Price, pkt. 5c; oz. 10c; $1 / 4$ lb. 20e; lb. 50e; 10 lbs. \$4.00.

\section{NEW ANGEL KISS}

This variety originated in Texas, and its popularity has now extended throughout the entire country. It grows medium to very large in size, often weighing forty to sixty pounds, and twentyfive to thirty inches in length. The color is a silver-gray, handsome and attractive. It is a very strong and vigorous grower. red by the time the seeds are formed in it. often before the melon is really grown. It has few seeds, possibly less than any other watermelon. A splendid sort for home use.

Price, pkt. 5c; oz. 10c; 1/4 lb. 25e; lb. 75e; 10 lbs. $\$ 6.50$ (prepaid).

\section{MONTE CRISTO}

Very similar to Kleckley's Sweet, and especially recommended for home use and shipment to nearby markets.

\section{LONE STAR}

A very popular sort in Louisiana where it is rather extensively cultivated by certain planters. This melon is above medium and very uniform in size, a productive bearer, and oblong in shape. The rind is mottled green and black color, somewhat like the Ratcolor. solid, crisp and very sweet in flavor. In a deep red color. solid, crisp and very sweet in flavor. In my opinion, I

Price, pkt. 5e; oz. 15e; $1 / 4$ lb. 40e; 1b. $\$ 1.25$ (prepaid).

\section{ICE CREAM, or PEERLESS}

A real fine melon for home use, notwithstanding lots of poor weather, and ripens under the most unfavorable conditions without rotting. It is not a good shipper, however, as the rind is rather thin. I have quite a large trade for this particular it in their home garden. The fruit is oval in shape, skin bright it in their home garden. The fruit is oval in shape, skin bright thin, flesh bright scarlet. solid, crisp and exceedingly sweet. You don't want to overlook this sort in making up your collection to plant this spring. Order a few ounces, or possibly a pound of this splendid sort. The illustration on the side here is an actual

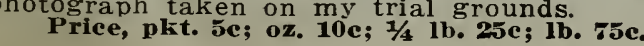

\section{Note Carefully the Photographs}

Actual photographs of the principal melons $I$ handle. Every one of these illustrations are reproduced from actual bona fide photographs, either furnished me by the grower of the seed, or taken from $\mathrm{my}$ own trial grounds where $\mathrm{I}$ test several hundred varieties every sear. There is nothing exaggerated about these pictures. Just clean cut photos, showing the nice, clean, regular lines of the melons produced from the seed I sell rou. I live in the land where the watermelon thrives. I am near the source of production. I am where the watermelon reaches the zenith of perfection. I know what good melons are. All summer I eat them, because $I$ like them, and $\mathrm{my}$ whole family are the same about them. I don't think anything is better than a nice, ripe juics, sweet melon. What do sou think about it? Agree with me? Thanks:

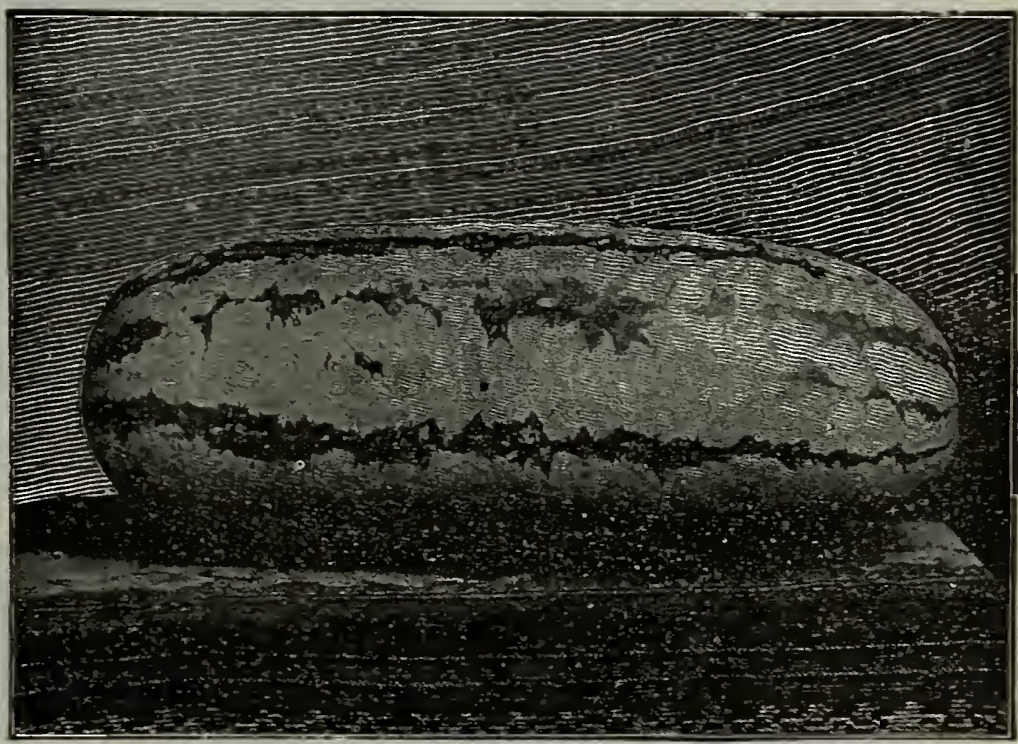

\section{BRANCH'S GENUINE RATTLESNAKE}

\section{The King of Watermelons}

This melon surpasses all other varieties in qualty and is a splendid shipper. It has netted goo returns in glutted markets when other varieties would not bring freight charges. In quality and flavor this melon is unsurpassed. Has a thin, but tough rind, making it a good shipper Flesh deep red, very sweet and delicious. This strain has been kept pure for more than forty years seed, and of whom we bought our stock.

seed and of whom we bought our stock. 1,500 acres where only this variety is cultivated. So-called Rattlesnake seeds are sold at lower prices than ours, but it is false economy to buy such seed, and money, time and labor saved by genuine Rattlesnake Melon Seed to be found in the United States. Price, pkt. 5c; oz. 10c; $1 / 4$ lb. 30c; 1b. 90e; 10 lbs. \$S.00, postpaid.

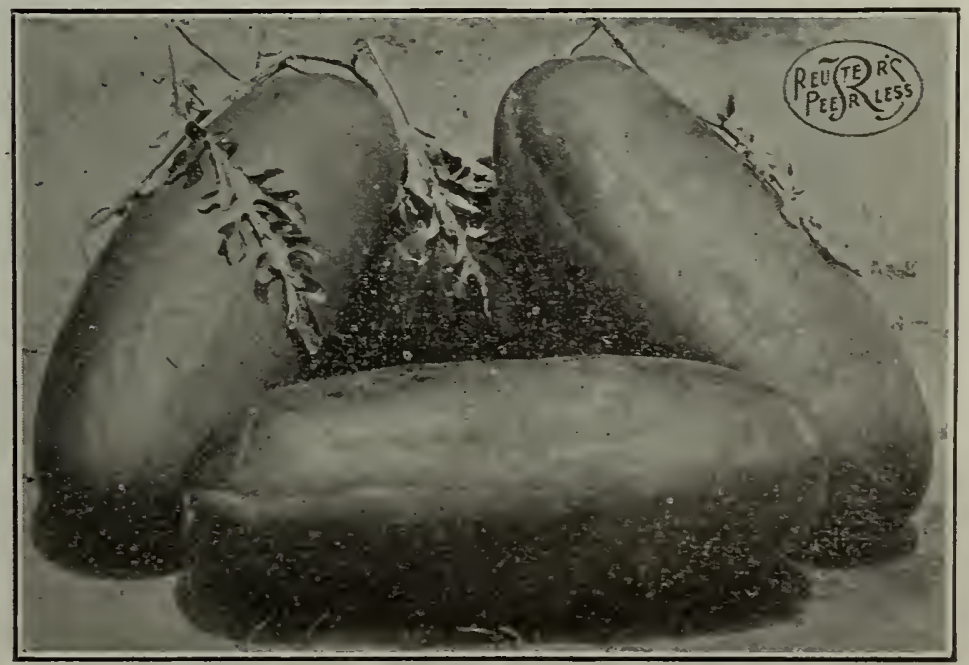

Ice Cream Watermelon, Good for Your Home Garden 


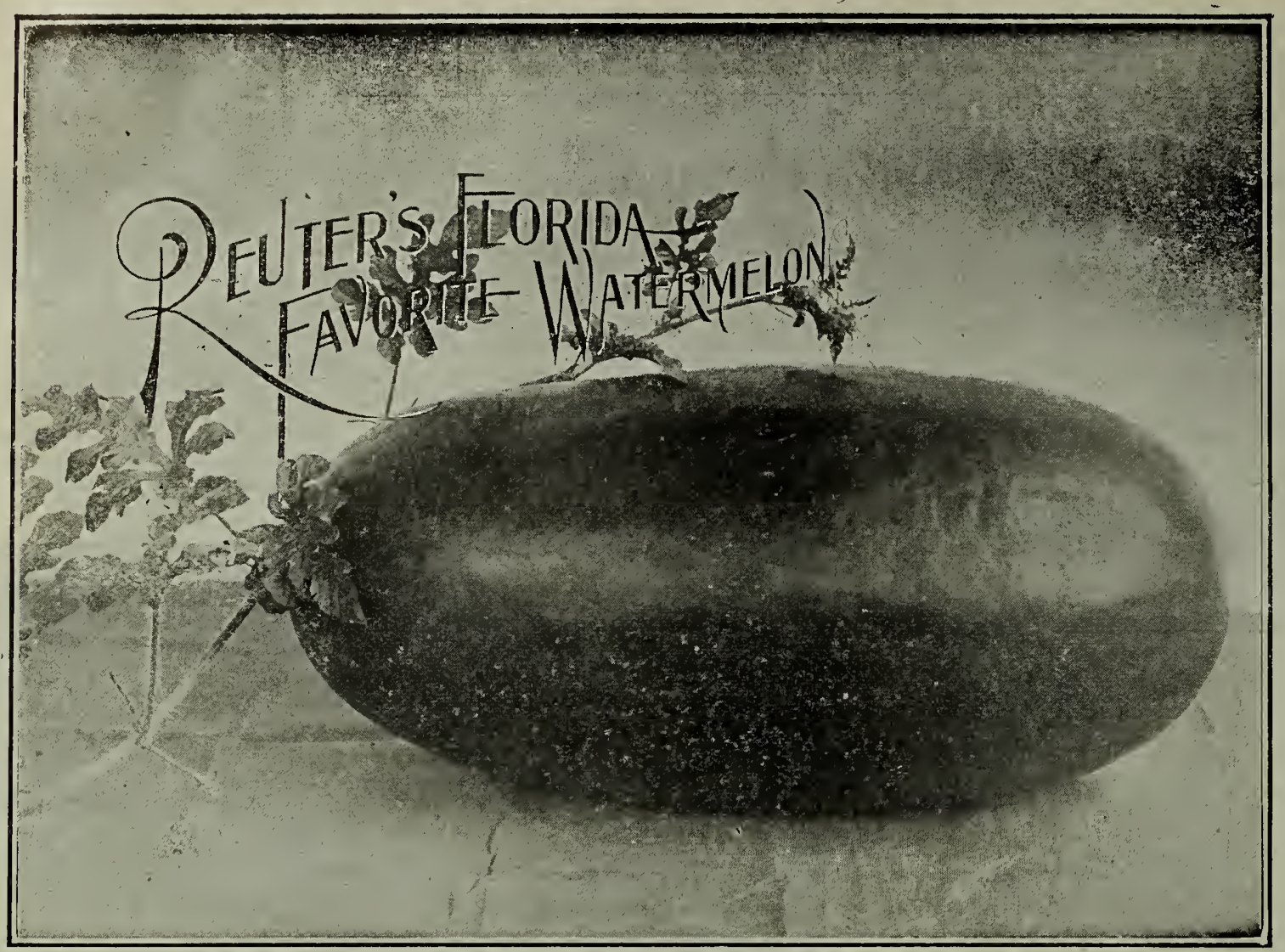

\section{$W A T E R=$ MELONS}

\section{QUALITY FIRST}

Write for Prices on Large Quantities

\section{FLORIDA FAVORITE}

Grown in Florida

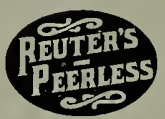

A superior

strain by care. ful selection. Oblong shape, and of medium size. Striped light and dark green; flesh, bright crimson. A few days later than the earliest sorts. The demand for our highly bred seed from every section of the South is remarkable, and our contract order with our rellable grower amounts to more than than one thousand pounds.

Price, pkt. 5e; oz, 10e: $1 / 4$ lb. 20c; 1b. 60c; 10 lbs. \$5.00.

\section{REUTER'S WATERMELON COLLECTIONS}

\section{REUTER،S TWENTY=FIVE CENT COLLECTION}

For 25e I will mail to you postpaid one ounce cach of my hest melons. I have Halbert Honey. Watson, Rattlesnake, ani Kleckley Sweet in this collection.

\section{REUTER'S FIFTY CENT COLLECTION}

For 50c I will mail to you postuaid, one ounce egeh of the following melons: Kleckley Sweet, Rubber Rind, Rattlesnake, Watson, Alabama sweet, Florida Favorite, and Ice Cream. This is a grand collection.

\section{REUTER'S DOLLAR COLLECTION}

For the nominal sum mentioned above, $I$ will mail you postpaid one-fourth pound each of Branch's Rattlesnake, Tom Watson, Florida Favorite, Rubber Rind, Kleckley Sweet, and Ice Cream. Yon cannot get more quality for the same money anywhere. Pin a dollar bill to the order sheet and mail it to me to-day. This collection will produce an acre of prizewinnins melons that you will be proud of. Anylhow it deserves a trial.

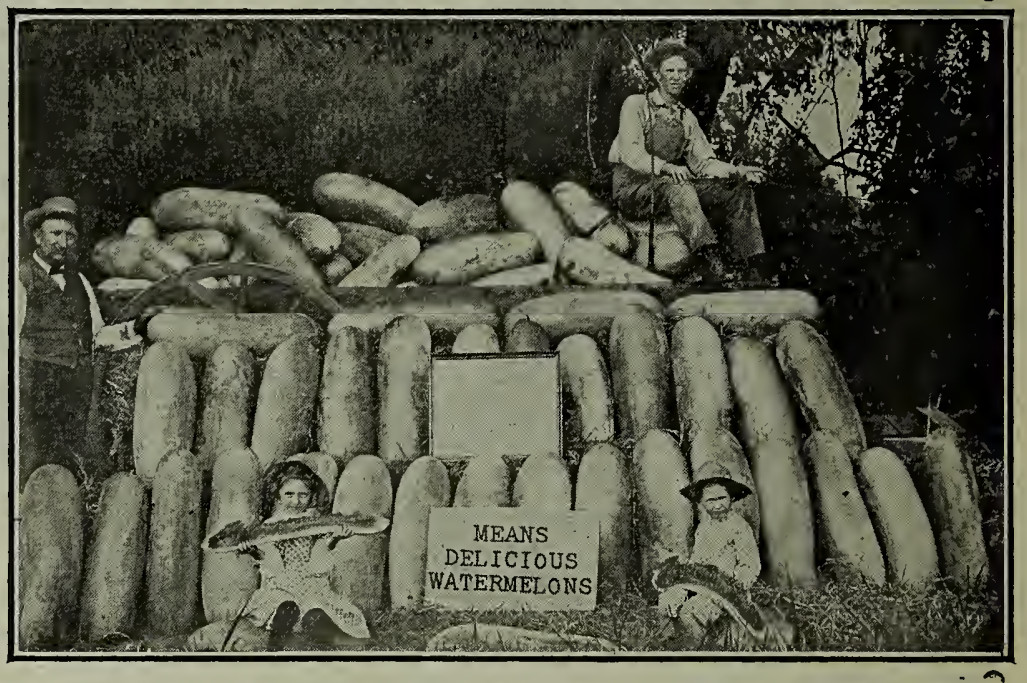

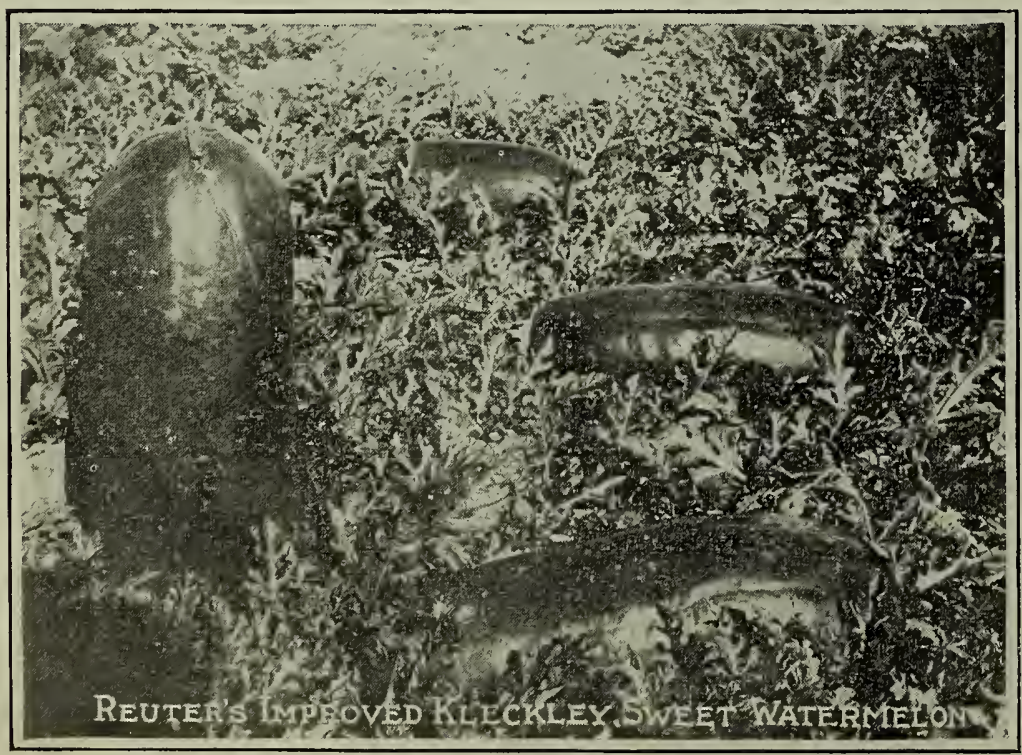

Mr. Means and a Few of His Watermelons and Kids

\section{REUTER'S IMPROVED KLECKLEY SWEET}

Rubber Rind Kleckley (Rocky Ford Strain)

A straln that is listed by some seedmen as the Hard Shelled Kleckey Sweet. The melon is oblong. ends square, color dark green, flesh deep red, stringless, solid and very sweet, with but few white seeds set firmly near the rind. The rind is not thick, but the skin is so hard and tough that it resists rough handling and stands shipment well.

Price. pkt. 5c; ox. 10c; 1/4 lb. 30c; lb. \$1.00; 10 lbs. $\$ 9.00$ (prepaid).

\section{MEANS' DELICIOUS (Grown by Means)}

a waraed meaal at the St. Louis World's Fair on quality. The melon is oblong, specimens measuring thirty-six inches from stem to blossom. Color is light green, with dark green netting enveloping the entire melon. The meat is of rich crimgon, solid, crisp. delicious and melting. Contains but few seeds that are cream colored. The rind is thin, but very tough, thus making it an excelient shipper. Vines are very prolific, and for an all around good melon, we don't know of one that will beat it. A great money maker for all melon growers. Our seed is grown expressly for us by the originator.

Price, pkt. 5c; oz. 10c; $1 / 4$ lb. 40c; lb. \$1.50; 10 lbs. $\$ 14.00$ (prepaid). 
The Cream of the Crop. Critical Selection

\section{REUTER'S GENUINE}

\section{LOUISIANA, OR}

RED CREOI E

A distinct variety that has been cultivated in this section for many years. It is the most important sort planted in this section, and shipped from here to all the Northern markets. Skin is brownish red; flesh very solid and fine grained. and rather strong flavored. Extremely productive and the best shipper and keeper of all varieties. It is the greatest Onion for the Southern grower and is rapidly becoming more popular throughout the principal onion-growing sections Matures a little later than the Bermuda seed. Our stock grown expressly for us under special most critical.

Price, pkt. 10c; oz. 40e; $1 / 4$ llb. \$1.25; 1l). \$4.00.

\section{ONION SEED}

4

Pedigree Tested Onion Seeds Mean Profitable Crops
AUSTRALIAN BROWN

This splendid extra early sort has (n) ing to its remarkable leeping qualities. It is of rouhdish corm, color of skin is an amber brown, flesh is white and firm, of mild flavor. The seed should be sown in the south will produce fine bulbs in the

Price, oz. 15c; $1 / 4$ Ib. 40c; 1 b. $\$ 1.50 ; 10$ los. \$14.00.

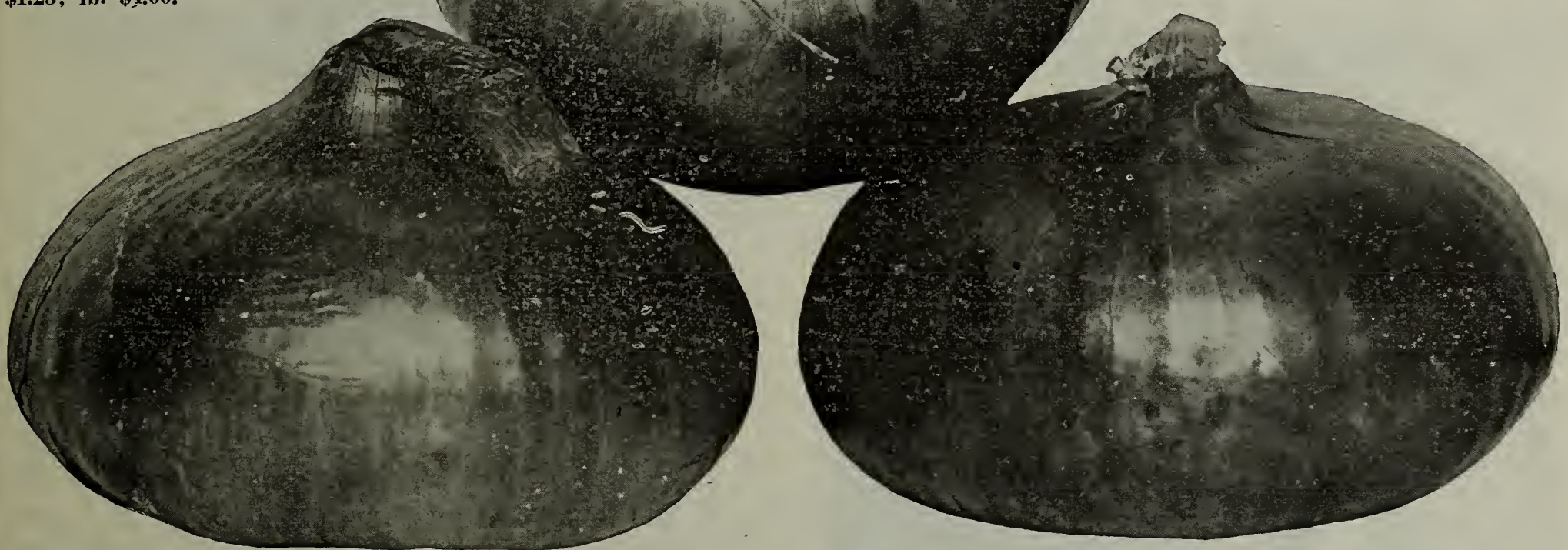

NOTE-A few of the bulbs from which our Red Creole Onion Seed is grown.

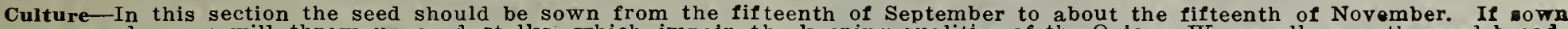

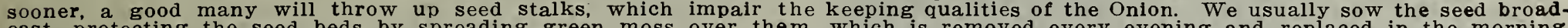

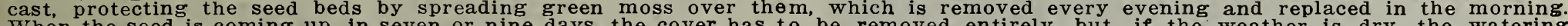

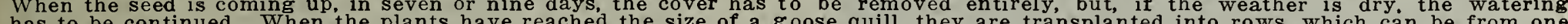

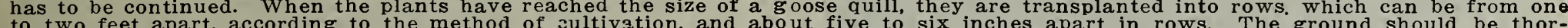

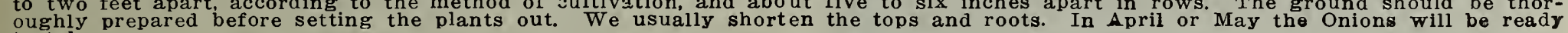
oughly prepa
to take up.

\section{GIANT YELLOW PRIZE-TAKER-American Grown}

The finest and largest of the Yellow Globe varieties. Flesh is pure white, fine grained. of mild delicate flavor. The outside skin is rich yellowish brown. It does not keep as well as other varieties we recommend.

Price. 0z. 20e; $1 / 4$ Ib. 60e; 1b. \$2.00; 10 lbs. \$18.00.

\section{LARGE RED WETHERSFIELD}

\section{YELLOW GLOBE DANVERS}

A very popular onion in many of the large markets of this ocuntry. and cultivated extensively for market purposes. A heavy cropper and good keeper. Skin. silvery yellow; flesh white, com. Price. ox. 20c; 1/4 1b. 50e; 1b. \$1.75; 10 lbs. \$16.00.

This is the standard variety of the flat Red Onion. It is rather popular in many parts of Southwest Texas, and we have sold large quantities of our seed in that state last season. Color is deep purplish red, flesh white. moderately grained and very firm. Yields enormous amount per acre. Best variety for poor or dry soils.

Price, oz. 15c; 1/4 lb. 40c; lb. \$1.50; 10 lbs. \$14.00.

\section{REUTER'S HIGH=GRADE ONION SETS}

\section{BERMUDA ONION SETS-GROWN FROM TENERIFFE SEED}

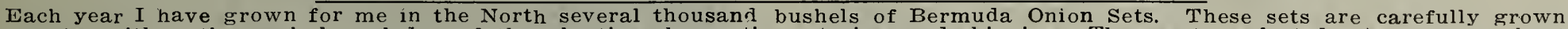

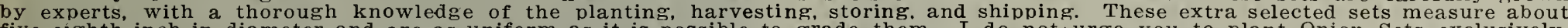

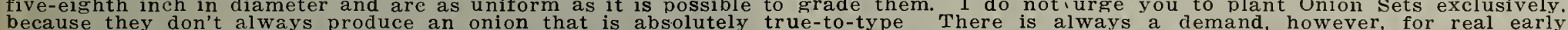

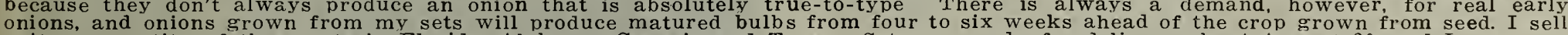

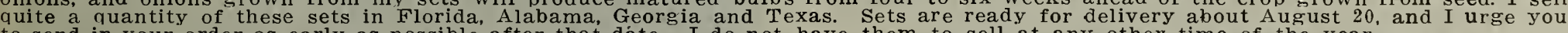

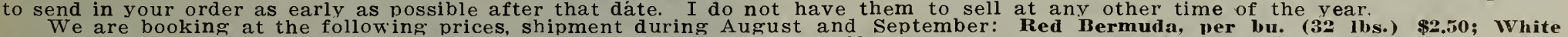
Bermuda, per bu. (32 lbs.) \$2.50; Crystal White Wax, per bu. (32 lbs.) \$3.50; Red Creole, per bu. (32 1bs.) \$3.00.

\section{SHALLOTS (White)}

A small-sized onion which grows in clumps. It is grown very extensively in Louisiana, and large quantities are shipped to the Northern markets during the winter. In the fall or early spring the bulbs are six inches in the rows. They grow and multiply very rapidly, the spring, when the tops are dry, they are taken up, thoroughly

Price, qt. 15c; gal. 40c; bu. (32 lbs.) $\$ 2.00$; 5 bu. at $\$ 1.75$ per bu.

\section{WESTERN ONION SETS}

We buy our Onion Sets from the best growers in the country, and receive the best graded stock and finest keeping sets.

Write for special prices when a quantity is required. Samples on request.

Red, per bu.

White, per bu.

White Pearls, per bu 


\section{GENUNE BERMUDA ONON SEDD GROWN AND SELECTED BY \\ T.M.RIII) Port Orotava, Tenerifie EXPRESSLY FOR \\ CilRIS.REUIIR.NewOrLeANS.LA.AGeNt}

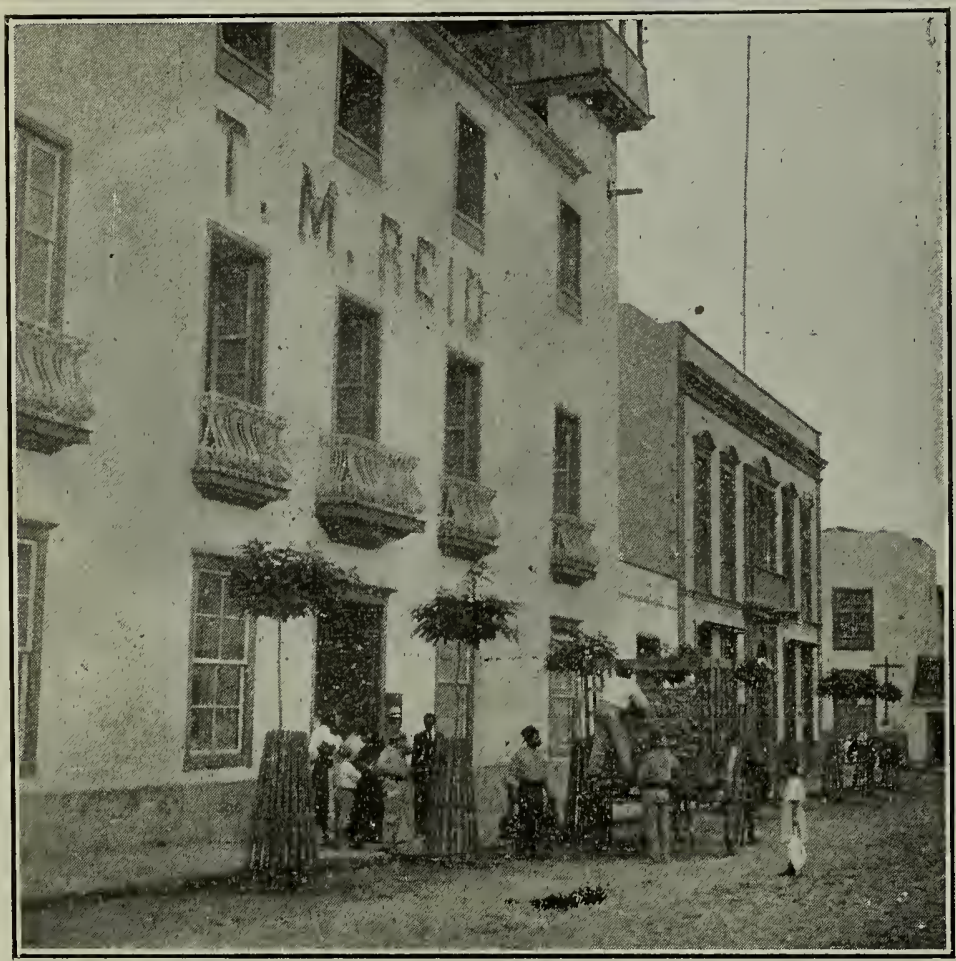

Receiving Onions at Principal Warehouse and Offices of T. M. Reid, Port Orotava, Teneriffe. (My Grower)

\section{A SHORT CROP THIS YEAR!}

will be a short crop this year owing to the disastrous losses of the past year, and thousands of pounds of seed are now lying in the express office in Texas refused by the growers. In addition to this, nearly every seedsman in the United States that handles this seed to any extent, is retaining large surpluses, having practically no demand or outlet for same. They all bough heav, expecting the usual in the past years. I firmly believe the huge profits in on plant every acre devoted to onions in Texas next year. This It is absolutely of no value whatsoever to the grower. The germination will be poor next year, the mill be weak and the chances of producing a good crop of onions from such seed is entirely out of the question. DO YOU WANT TO RISK PLANTING SUCH SEED?

Can you afford to plant your valuable ground with this kind of seed? Can you afford to spend time, money, energy, fertithat it is essential to plant pure, fresh, clean, new seed-seed that is virile, throbbing with germination and health, seed that What will these dealers and growers do with this old seed next year? Will they be strictly honorable and destroy the seed, or will they mix it up with their new seed and attempt might attempt to sell it just the way it is. Then again, they back to the Islands, to be held until the next planting time.

\section{WHAT I THINK OF THE BERMUDA ONION INDUSTRY!}

The past year was a most unprofitable and unsatisfactory one for the growers of Bermuda Onions in Texas, and thousands of acres failed to yield a single dollar of profit to the growers. The grower, the dealer, and the receiver all lost big money. concelvable method for selling the onions was used, thou sands of dollars werions to the consumers, but the results were not at all satisfactory, and hundreds of the growers and dealers The past year was also a most unusual one, as the onion acreage throughout the entire country was enormous, and the yield was more than could be consumed by our hundred million people. Everyone planted onions last year. All through the crops were neglected and ignored; discretion and good judgment were thrown to the winds; both the ignorant and the wise sowed onion seed, apparently believing that people would discontinue eating everything but onions. the cold storages beame filled with these onions Fvery operator and dealer in the United States and Canada became afraid of this vegetable. rested, and when they rushed their thousands of carloads of Bermuda Onions upon these already glutted markets that were overloaded with old onions, prices declined below the cost of production, and the returns to the growers were often in postage stamps on carload lots.

to every grower of Onions in Texas. It served a good purpose to many, however, and will tend to strengthen this grand industry in Texas, and put the growing of these luscious onions on a more profitable basis from now on. This one disastrous year. will teach the rower that it pays to carefully grow their onions, sowing the best seed, selecting only large marketable onions, packing them n standard onion crates, and shipping them in good condition. Onions of mixed colors, poorly graded, are not wanted on any market, and are not noticed at all when there is an ample supply and the demand is limited. States, and carefully compiled reports from all over the United States, and the acreage this year is tremendously decreased. I knew this would occur, but I made sure, by writing not less accurate and authentic data. and the information contained in all of them invariably is the.same-a short crop of onions everywhere.

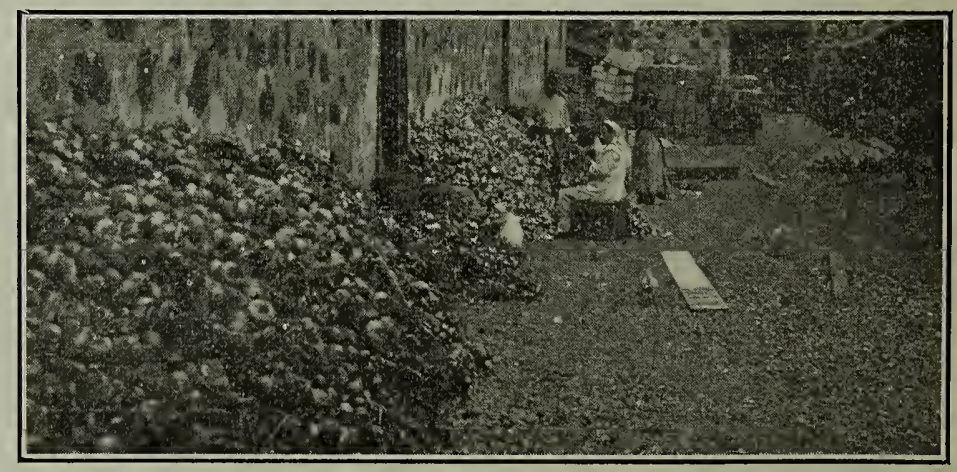

Sorting Bermuda Onions for Our 1914 Seed-Selection Means Quality

Use the Special Onion Order Sheet

In Back of this Book 
A Few of My Crystal Wax Onions-Notice the Uniform= ity in Size and Color.

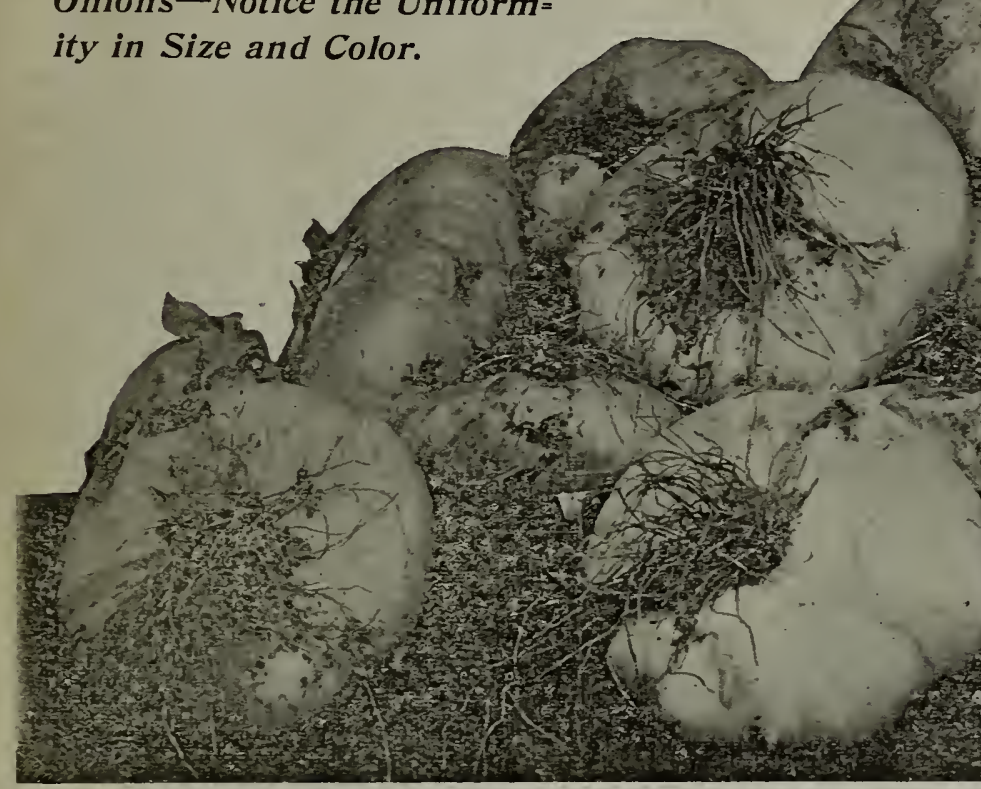

Reid's Bermuda Onion Seed is the Standard of Comparison for for all others. I sell it exclu= sively.

\section{YOU MUST PLANT GOOD SEEDS TO PRODUCE A GOOD CROP!}

Don't be deceived into buying Bermuda Onion Seed claimed to be just as good as Reid's. There is nore as good as the Onion Seed grown by this thoroughly reliable and trustworthy grower. Many seedsmen shout and claim that their seed is the best, but
everyone doesn't tell the truth. When you plant Reid's Genuine Bermuda Onion Seed. you are planting the best seed the Teneriffe everyone doesn't tell the truth. When you plant Reid's Genuine Bermuda Onion Seed. you are planting the best seed the Teneriffe
Islands produce. Mr. Reid is an actual grower-not a speculator. He is an actual producer of the seed, not a parasite that derives his ill-gotten gains from the profits made off seed bought from ignorant and dishonest petty farmers on the Islands. These kind of growers know practically nothing about onion seed, and this kind of seed will nerer produce a crop in this countri. Feid's unscrupulous dealers in the South.

I sell Reid's Bermuda Onion Seed to nearly every big grower in Texas. I sell this seed to the men who know what is the best. want honest delivery-the kind we always make.

\section{SEND ME YOUR ORDER NOW!}

I sell more Bermuda Onion Seed in Texas than any other seed house in America. This is not an idle boast

order now. Don't delay, because the demand next year will be tremendous, and the speculators will jump their prices sky high, always seeking big profits out of poor seed. Send me your order by return mail. Estimate what you intend to plant next
year NOW. Don't be misled into placing your order with someone claiming to have seed just as good as REID'S. Don't believe it, year NOW. Don't be misled into placing your order with someone claiming to have seed just as good as REID'S. Don't believe it,
as Reid's Onion Seed will produce a crop when all others fail. Fill out the order blank in the back of this book and mail it to me to-day. Don't put it off until too late.

\section{IT IS THE SEED THAT ALWAYS COUNTS!}

The backbone of the Bermuda Onion industry in Texas is Reid's Bermuda Onion Seed. Brownsville, and other sections is being produced from Reid's Genuine Bermuda Onion Seed. Brownsville, and other sections is being produced from Reid's Genuine Bermuda Onion Seed. Every grower whose living depends
on his crop plants Reid's Bermuda Onion Seed. He knows better than to risk planting any other kind. He cannot afford to risk
his crop with mongrel seed. It is a dollar-and-cent proposition with him all the time.

\section{ABOUT SEALED CANS}

Some seedsmen claim to reclean their seed upon arrival. They break the cans and shin to the growers in their own sacks. This gives these seedsmen the opportunity to mix their old seed with the new. Do you want your seed from such dealers? Can
you honestly afford to practice such false economy? My seed is all carefully recleaned before it leaves the Islands. Mr. Read devotes you honestly afford to practice such false economy? My seed is all carefully recleaned before it leaves the Islands. Mr. Read devotes
every bit of his time and energy to the production of pure reliable onion seed, and has all the modern machinery to carefully reclean seed. It is unnecessary for anyone to clean the seed here.

\section{FUTURE PROSPECTS OF BERMUDA ONIONS}

The growing of Bermuda Onions in Texas is not on the wane. It is false when you hear anyone telling you that the growing of these onions is a thing of the past. They don't know what they are talking about. They are not at all in touch
with the industry, and merely talk to be saying something. For many years the growers in Texas netted from $\$ 300.00$ to $\$ 900.00$ with the industry, and merely talk to be saying something. For many years the gromers in Texas netted from $\$ 300.00$ to $\$ 900.00$
per acre profit on these onions. I have more faith in the. Bermuda Onion Industry in Texas than ever before. I believe in
Onions. I am talking onions and urging the growers to plant more onions than ever. It is the Money Crop. It is the wealth of Onions. I am talking onions and urging the growers to plant more onion
Southwest Texas. It means the further development of a great industry.

\section{MY FINAL WORDS}

If you want to be sure of your crop, if you want to discontinue worrying about the seed you are going to plant, if you want to evade the ungrounded claims made by unscrupulous seedsmen that their seed is the best, you want to put your order in my hands. I planted old onion seed once and could have kicked myself for lutely worthless. I know this from personal pretical ex have nothing to lose and everything to gain by placing your order with me now.

All seed packed in sealed tin-lined cans, containing your order with me now. are put up in my own bags under my own seal. Order to-day.

\section{WHITE OR YELLOW BERMUDA ONION}

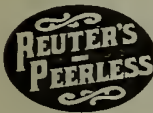

This is the leading variety that is so extensively planted by the growers in Texas, Florida and other Southern States. While known by the growers of as it is a light straw-colored onion. When you order, as it is a light straw-colored onion. When you order, Bermuda as mentioned here is not a true white onion and produces an onion that is somewhat yellow in color. It is. however. the standard variety in all the principal onion growing sections. You can make no mistake when you plant this variety. It is Price, pkt. 5e; oz, 20c; 1/4 lb. 60c; lb. \$2.00.

\section{RED BERMUDA}

Largely grown in Louisiana, but not a favorite in Texas. It is identical in size, shape, and mildness with my White (Yellow) Bermuda, and keeps better, considerable extent for bunch purposes. Arown to a per and highly recommended for home use.

Price, pkt. 5e; oz. 25e; $1 / 4$ lb. 60e; 1 . $\$ \mathbf{2 . 0 0}$
Use the special order sheet on page $\mathbf{7 6 .}$

\section{GENUINE CRYSTAL WHITE WAX}

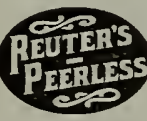

The most profitable variety of the Bermudas. It is. without a doubt, the finest onion in the world. quality. These onions usually command from twentyvariety of Bermudas, and when all markets are glutted with onions. the Wax will sell at good prices. It is the idea salad onion and is a great favorite with the most critical trade plant this variety. The seed supply is usually short, and the price is always high, but I have urged Mr. Reid to plant more largely of this variety tlian all others so that I can supply my large by disease. If you are going to plant more than five pounds next year, let me book your order now. Price, pkt. Je; oz. 30c; $1 / 4$ lb. \$1.00; 1 b. $\$ 3.00$. year, see Order Sheet in back of Catalogue. 


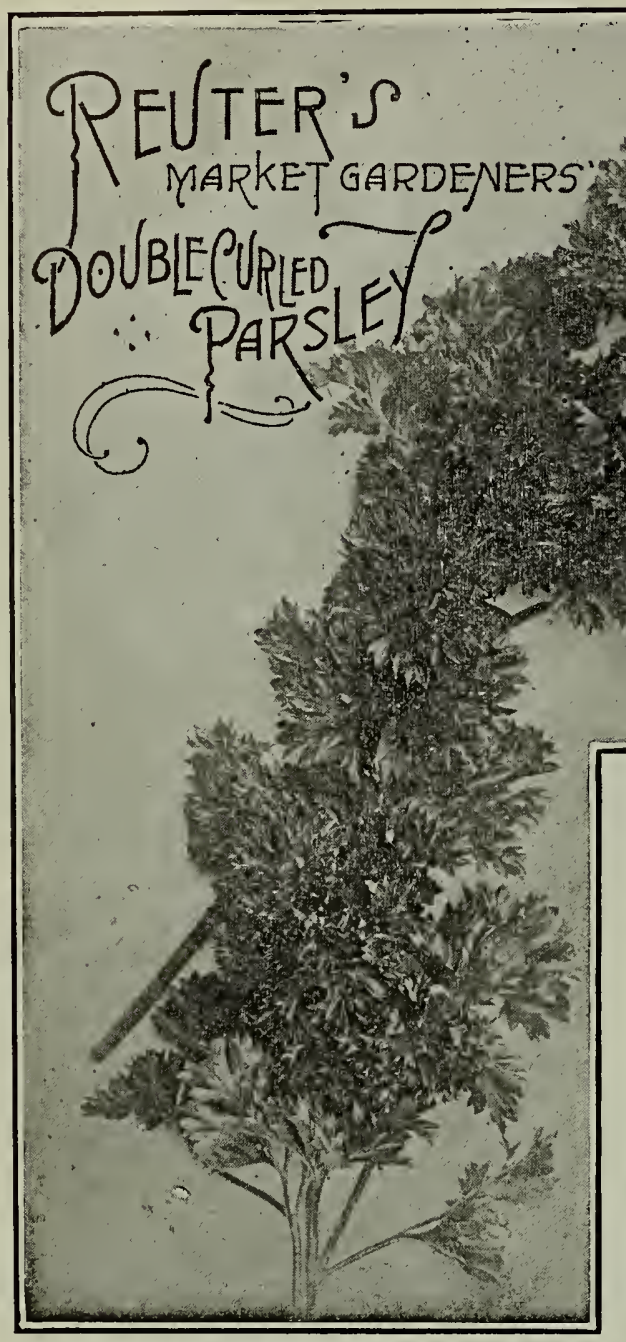

LARGE SUGAR, OR HOLLOW CROWN erov.
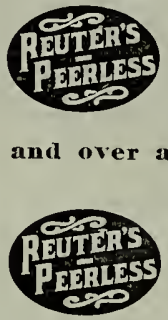
Ilos. \$65.00.

\begin{abstract}
Culture-Succeeds best on deep, rich, sandy soil, but will make good roots on any soil which is deep, mellow and moderately rich. Fresh manure is apt to make the roots coarse and ill-shaped. Sow in drills eighteen inches apart. Cover the seed one-half inch deep; thin out to five inches apart in rows when plants are large enough. Sow from sepJanuary to March for summer crops.
\end{abstract}

\section{PARSLEY}

Our European-Grown Parsley Seed is far superior to the ordinary California Grown Seed, as it is much stronger in germination, the growth more vigorous and hardy. It is grown from transplanted and selected roots only. The California grown Seed cannot be depended upon to always produce a

Culture-Sow in the fall from August to November, and in the spring from January to May. It is generally sown broadcast. Parsley seed germinates very slowly, taking two to four weeks to come up; hence, if planted early, no time thould be lost by delaying.

REUTER'S MARKET GARDENERS EXTRA DOUBLE CURLED

fitable sort for market and the best for shipping. A very vig. orous grower. The leaves are large, beauti-

fully curled, and very dark green in color. Resists heat and cold better than most varieties. and over at 55e ver ib.

\section{PLAIN OR SINGLE LEAVED}

Grown extensively by the local market gar deners. This is the hardiest variety in cultivation and is planted nearly every month in the year by the gardener's here. The leaves are large any other sorts.

These prices do not include postage. If to go by mail, add $8 \mathrm{c}$ per pound.

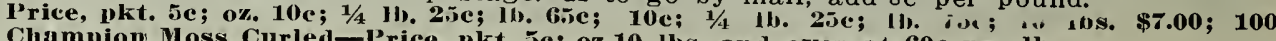

\section{PARSNIPS}

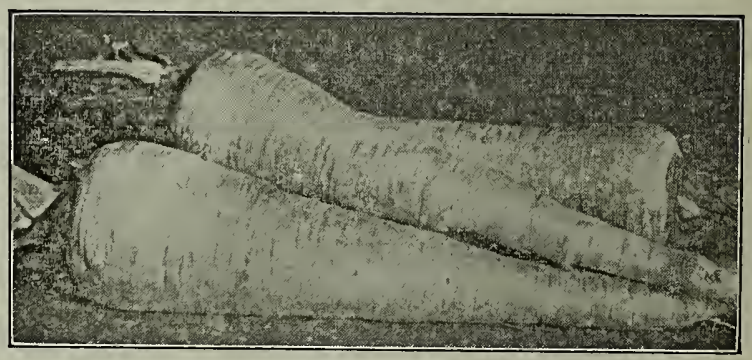

This is the best variety in cultivation. Roots long, or unlform growth, smooth. tender ard sugary.

Price. 0z. 10c; $1 / 4$ lb. 20c; lb. 50c; 5 lbs. \$2.00.

\section{PUMPKINS \\ Plant One Ounce to 25 Hills. Best Sorts for Stock Feeding and Table Use.}

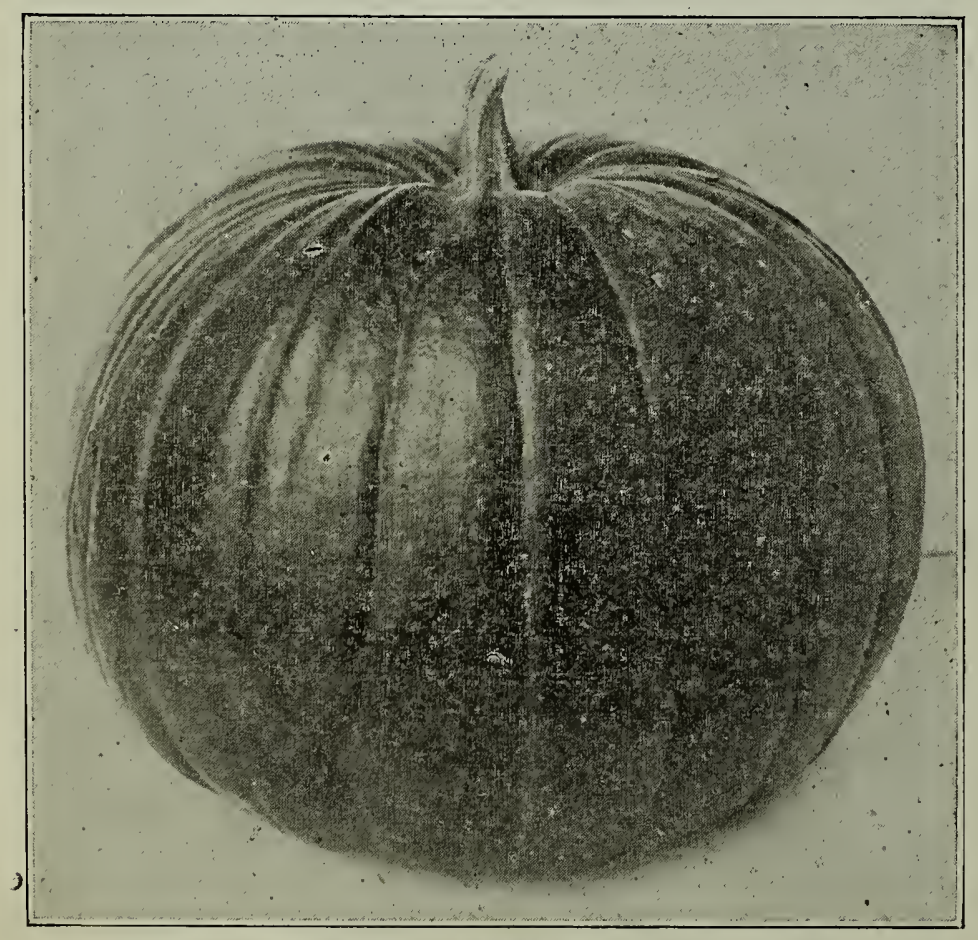

REUTER'S MAMMOTH KING
Culture-Pumpkins are not s'o particular in regard to soll as Melons or Cucumbers. They should be planted in hills ten to twelve feet apart and cultivated the same as Melons and Cucumbers. Avold planting too near other vines.

\section{REUTER'S MAMMOTH KING}

Sometimes called Jumbo. Do you really want a great big pumpkin? Plant my Mammoth King. It is surely a grand big variety, often measuring two feet in diameter and weight two or three pounds. It is a prize winning sort, and the kind you orange color, the flesi is thick, bright yellow and fine grained,

Price, pkt. ic: оz. 1йе; 1/4 1b. 40e; 1). \$1.25.

REUTER'S GREEN STRIPED CASHAW-SELECTED STOCK

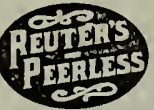
xtent for the New Urleans market Flesh light yeliow, very thick and fine grained, and exceedingly sweet. Very productive and a splendid keeper.

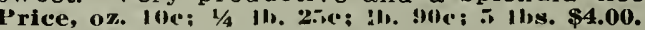

\section{LARGE CHEESE, OR FIELD}

A large round flattened punipkill. Very productive. Skin buff color; flesh yellow. The most popular for fleld or market Price, oz 10e; $1 / 4$ lh. 20c; Ih. 50c; 5 Ihs. \$2.00.

\section{MAMMOTH TOURS}

This variety is fanious lul tite size of the Pumpkins it produces, which frequently weigh one hundred and fifty pounds.

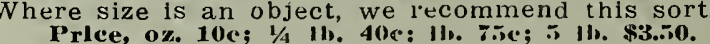

\section{MAMMOTH FIELD, OR BIG TOM}

This is one of the lidgent, must umfurm gluwing and productIve varieties known The vines are strung, vigurous and wonderfully productive. The fruits average fifteen to twenty inches in diameter. skin and flesh are of deep rich, orange color of excellent flavor for pies, etc. Cooking soft and tender. Very rood for canning and stock-feeding.

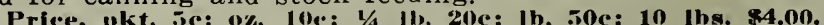

\section{SWEET, OR SUGAR PUMPKIN-Best for Making Pies}

It is sniall, being about tell litenes in didileter. li llas deep orange yellow skin and fine grained flesh. It is prolific and in every way desirable. The average weight is about five pounds. Pkt., se; oz. 10e; $1 / 4$ lb. 20e; lb. 60c. 


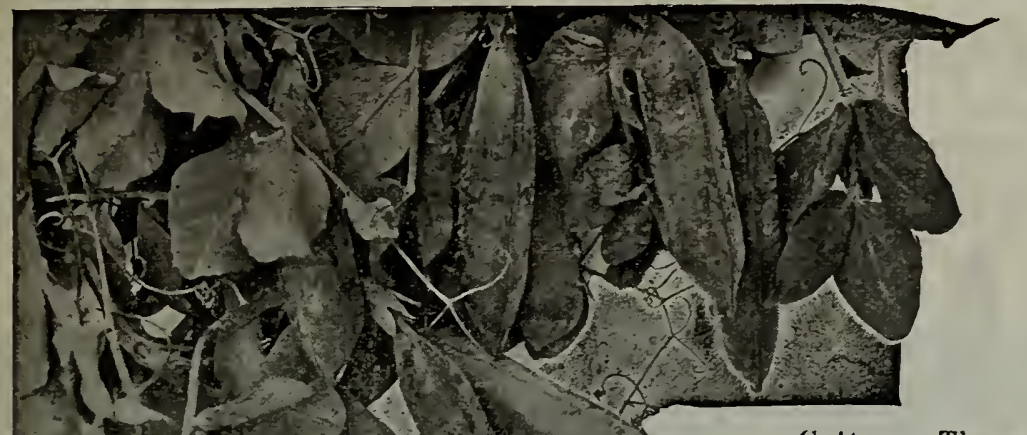

Culture-The ground should be manured the previous year, as fresh manure will produce a rank growth of vine and they will make only a small and uneven crop. at the same time a poor quality of peas. Late Peas, such as Telephone, Black Eye Marrowfat, and Large White Marrowfat. can be successfully grown in a moderately heavy soll; as, if sown in too rich ground, they will not bear much of a October and during January. February and March. The Marrowfats we plant in November. December and January for a late crop, as they will stand more cold, also bearing longer than the early sorts.

\section{SEED PEAS}

All of our Seed Peas are grown for us in the far North from the finest stocks, which are bred up by the of this famous vegetable for seed purposes.

Prices do not include postage. If to go by mail, add $8 \mathrm{c}$ per pint and $15 \mathrm{c}$ per quart to these prices.

\section{REUTER'S PEERLESS EXTRA EARLY PEAS}

Pedigree Stock-Unsurpassed. Earliest, Most Productive and Most Profitable Variety in the World

They are much hardier, more productive, and withstand greater changes of weather than any other variety. They are the largest podded Extra Early, and are entirely free from runners.

This variety is a round-seeded pea that will grow and mature quicker than any other sort in cultivation. The vines average about $2 \frac{1}{2}$ feet high. just short enough to bear a You crop. Our strain is

Price, pkt. 5e; pt. 15e; qt. 30e; gal. \$1.00; peck \$1.75; bu. \$6.50.

\section{EARLY WASHINGTON-Ready for Picking in 30 Days}

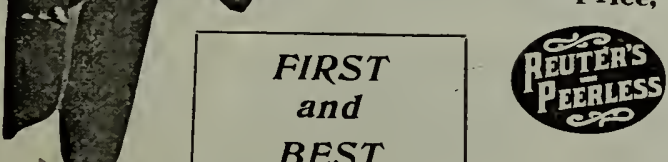

second tarly varlety matur...b abuut ten days taler trian our Peerless Extra Early. Very pruductlve and hardy; pods are somewhat smaller than the Extra Early. A favorite with the market gardeners in New Orleans for genpkt. 5c; pt. 15c; qt. 30c; gal. \$1.00; peck \$1.75; hu. \$6.50.

Price, pkt. 5e; pt.
ST-A Good Strain

REUTER'S FIRST AND BEST-A OOOd Sirain This is one uf the finest grades of Extra Earlles, and continued selection. Exceptionally pure and true to name. The pods are not yuite as large nor the vines quite as tall as Reuter's Peerless Extra Early. ALASKA, the Earliest of AII

The earliest blue variety in cultivation. Pods of medium size, but well filled; height about thirty inches. Very uniform in growth. The dark green color of its pods makes it a most desirable shipping variety, and it is a splendid long-distance shipper, as it retains its color a long time. Being hardy, the seed can be planted as early in spring as ground can be worked. Our strain is remarkably

pure, grown and bred by our experienced seed growers. IMPROVED STRATAOEM (Wrinkled)

This famous variety cannot be recommended too highly, and has become one of our most celebrated varieties. The vines ar vigorous, seed covered with immense pods many measure 5 inches in length. It is dwarf growing, but $2 \frac{1}{2}$ feet high. Peas are wrinkled, sweet, and of delicious flavor.

Price, pkt. Te: pt. 20c; qt. 30c; gal. \$1.00; peck \$1.90; bu. $\$ 7.50$. REUTER'S IMPROVED TELEPHONE

The best main crop tall peas without exception. A marvelous variety, producing pods of prodigious size and well filled with mammoth peas of exquisite flavor. Growth five feet.
Price, pkt. Jc; pt. 20c; qt. 30c; gal. \$1.00; peck \$1.9.0; bu. \$7.50.

\section{CHAMPION OF ENGLAND}

The best tall-growing late variety. Vines vigorous, growing

Price, pkt. ic: pt. 206: qt. 3110: zal. \$1.011: peck \$1.90; bu. \$7.50. GRADUS, OR PROSPERITY (Wrinkled)

The earliest, largest podded and most popular of the wrinkled varieties. Vines are vigorous and healthy, growing two to thre inches high. Pods are extra long, filled with large deep green

Price, pkt. 5c; pt. 25c; qt. 40c; gal. \$1.50; peck $\$ 2.75 ;$ bu. $\$ 9.00$. AMERICAN WONDER (Wrinkled)

Vigorous productive vines, with a luxuriant foliage, and producing the leaves on one side of the stock, growing from nine to ten inches high. On account of its dwarf habit of growth it i very desirable for private garden use. Pods are light colored

Price, pkt. 5e; pt. 20e: qt. 30e: cal. \$1.00: peck \$1.90; bu. \$7.50. $B L A C K=E Y E$ MARROWFAT
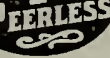

Very popular with the gardeners in this section. A strong grower and very productive. Height about four to five feet.
pkt. 5e; pt. 15e: qt. 25c; gal. 7tie; peck \$1.40; bu. \$5.00. MELTING SUGAR

They should be cooked and eaten pods and all, the same as Wax Beans. Grows five to six feet high; very productive; producing large, broad pods which are of the finest flavor and exceedPrice, Pkt. 10c; pt. 25e; qt. 40c; gal. $\$ 1.50$; peck $\$ 2.50$; bu. $\$ 9.00$.

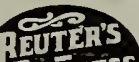

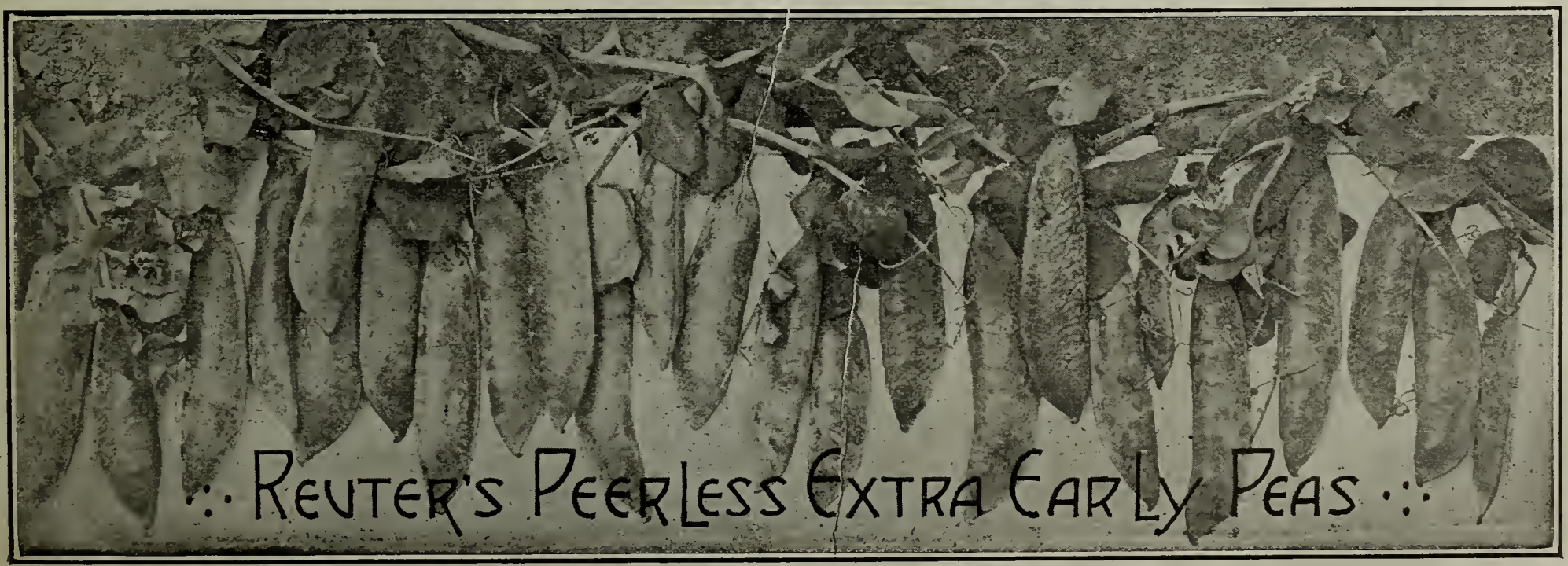


Culture-Peppers are mostly used for seasoning meat and vegetable dishes; also for making chow-chows and chili sauce. The culture is about the same as Eggplant, and the plants need as much heat to perfect them. Sow seed in hot beds in December and row. Cultivate and keep free from weeds. Sow in June for a fall shipping crop.

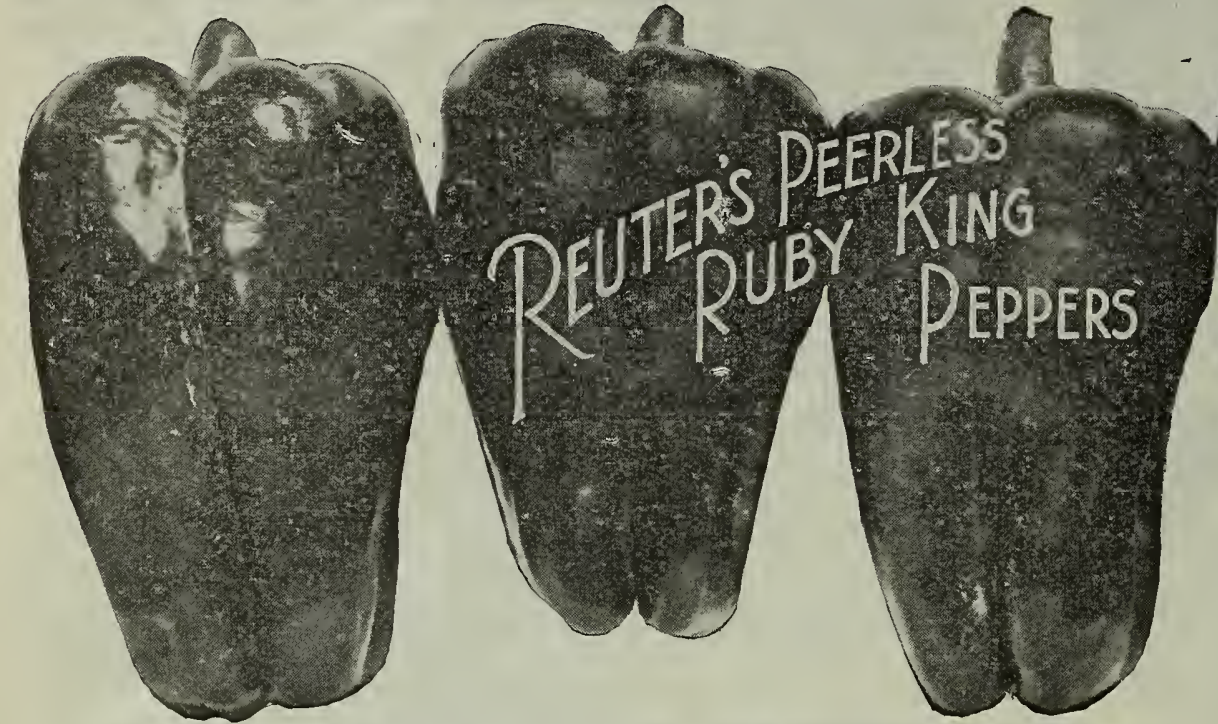

REUTEK S PEERLESS RUBY KING-Selected Stock

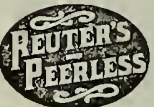

fin. Our stock runs remarkably uniform an true to name. Our grower's have devoted careful at lention to the selection of our SPECIAL stock, and
hundreds of truckers in Louisiana. Texas, Mississippi hundreds of truckers in Louisiana, Texas, Mississippi King Pepper they have ever seen. Last year we sold several hundred pounds and were unable to fill all orders. This season growth, and very productive. The fruits are very often four to in flavol: REUTER'S SWEET SPANISH MONSTROUS

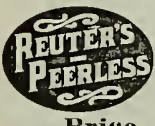
account of its earliness and productiveness. Grow

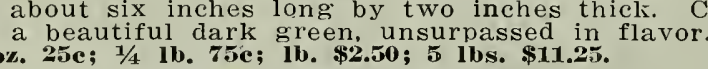

\section{REUTER'S CHINESE GIANT}

This is the largest variety known, monstrous in size and beautiful in appearance. They grow four or five inches broad at mild and as sweet as an apple. Color green, changing to a glossy scarlet when ripe.

\section{REUTER'S BIRD'S EYE}

Small as the name implies. Very fine in flavor. Can be used

either fresh or dried. $1 / 1$ lb. \$1.25; 1b. \$5.00.
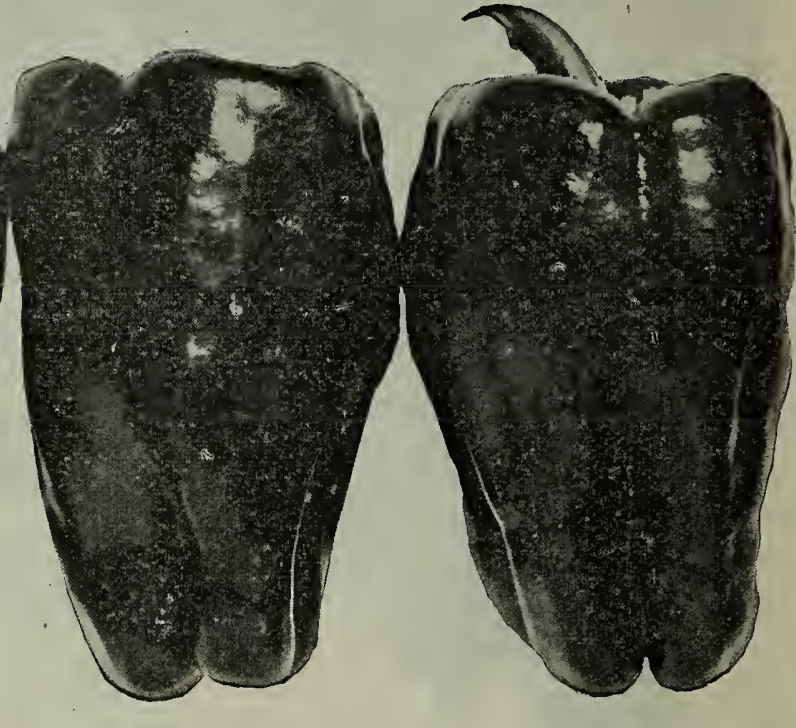

REUTER'S RUBY GIANT

If $I^{\prime}$ were asked the best pepper to grow for profit, I would say plant Ruby Giant. It is a great improvement over my Ruby King, but retains all the good qualities of the former, but is much larger in size. My seed stock is extra fine, as is usual with all of my seed. There is lots of money in growing early peppers. I grow them every year on my farm, and last year they netted the praise from all over the country about Ruby Giant is a great inducement for me to try out this strain, which I think vill eventually supersede the original variety. It is a new

variety-a cross between the Chinese Giant and Rub
the size of the former and shape of the latter retained.
Price, pkt. 5e; oz. 20c; $\mathbf{1} / \mathbf{1}$ lb. 70c; 1b. $\$ 2.50$.

\section{REUTER'S GENUINE TABASCO}

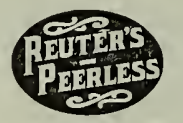

This is the variety from which is made the wellknown Tabasco Sauce. which has a national reputation for flavoring oysters, soup, meat, etc. The small bright red peppers are extremely hot and fiery in flavor. Bush three feet high.

\section{REUTER'S LONG RED CAYENNE}

well-known medium early variety, having a slender twisted and pointed pod about four inches long. Color deep green, when fruit is young, bright red when ripe. Extremely strong and pungent flesh. A favorite with many of the gardeners in the South,
and extensively cultivated in some sections for market purposes.
Pkt. 5e; oz. 20c; 1/4 lb. 60c; lb. \$2.00.

\section{PEPPER PLANTS}

We can offer strong plants of the Spanish Monstrous and Ruby King varieties. grown from our own selected stock seeds. These plants are ready in February and March.

\section{Reuter's Superior Southern Grown Mustard Seed}

Colturo-Mustard 1 a grown extensively in the South. and is sown broadcast during the fall, winter and spring. Our seed is strtcty southern grown. and is far superior and quite distinct from the Northern and European variety.

\section{REUTER'S PEERLESS SOUTHERN CURLED}

Standard varlety ralsed by the New Orleans gardeners. The leaves, which are beautifully curled. often measure fourteen inche

price. oz. 5e: $1 / 4$ H.. 1.ic; lb. 40e; 10 lhs. \$3.st.

\section{CHINESE BROAD-LEA VED}

This is a European variety with light green very large leaves. It has not the same taste as the Peerless Southern Curled, but will stand longer before going to seed.

Price, oz. 5e; $1 / 4$ lb. 15e; $1 \mathrm{~b}$. 40c; 10 lbs. \$3.50.
This is a highly esteemed vegetable throughout the entire der, to which it imparts an aromatic flavor; they are also stewed and served up with butter. Also prepared as a salad. Sow the seed in the spring:, after the ground has become warm, in drills seed in the spring, after the ground has become warm, in drills
three feet apart. Thin out after the plants are well up to ten WHITE VELVET

An entirely distinct variety; the pods are long, round and smooth. Plant is of tall growth. An abundant bearer; superior Price, pkt. 5e; oz. 10e; $1 / 4$ lb. 50e; 10 lbs. \$4.00.

\section{REUTER'S FRENCH MARKET DWARF PROLIFIC}

The finest shipping variety in existence.

the Thliest shipping variety in existence. are light are light green, medium size, nearly lound in shape, der longer than any other and cannot be excelled for shipping: Our seed is the finest reselected market pardener's stock, and is grown to meet the requirements of the most critical truckers. Prices on large quanities on application.

Price, pkt. 5e; oz. 10e; 1/4 lb. 20e; 1b. 50e; 10 lbs. \$4.00. 
I have confined myself to supplying the growers in New Orleans with Seed Potatoes for thirty-five years, and never had a complaint. Ninety per cent of the truckers in this section rely on my seed for their annual Futatu ivus. Whelı 1 uftel Hallt Cubılers and Triumphs, you will be getting what you are paying for. I only handle those varieties that are especially adapted to our climate and soil. We suggest Triumphs, Irish Cobblers, and White Stars. These sorts are the best for shipping to Northern markets.

The prices mentioned are based on values existing at the date of going to press with this catalogue. We would, therefore, suggest that you write us for special prices when ready to buy. Correspondence solicited.

Culture-The potato requires a rich sandy loam. The best fertilizers are thoroughly decomposed stable manure, cotton seed meal, or raw bone meal. Always select good size and well formed potatoes for spring planting. cut each tuber to two or three eyes to each piece; plant in drills about three feet apart in order to cultivate them properly. Potatoes are planted here from the middle of December to the latter part of March. However, the most reliable time for a general crop is to plant the latter part of January to the end of February.

They are also grown successfully in the South for fall crop. The tubers should be planted during August and September. They should not be cut if planted at this time of the year: if cut. the potatoes are ant to rot, therefore all the small potatoes or cullings should be used from the spring crop for seed stock.

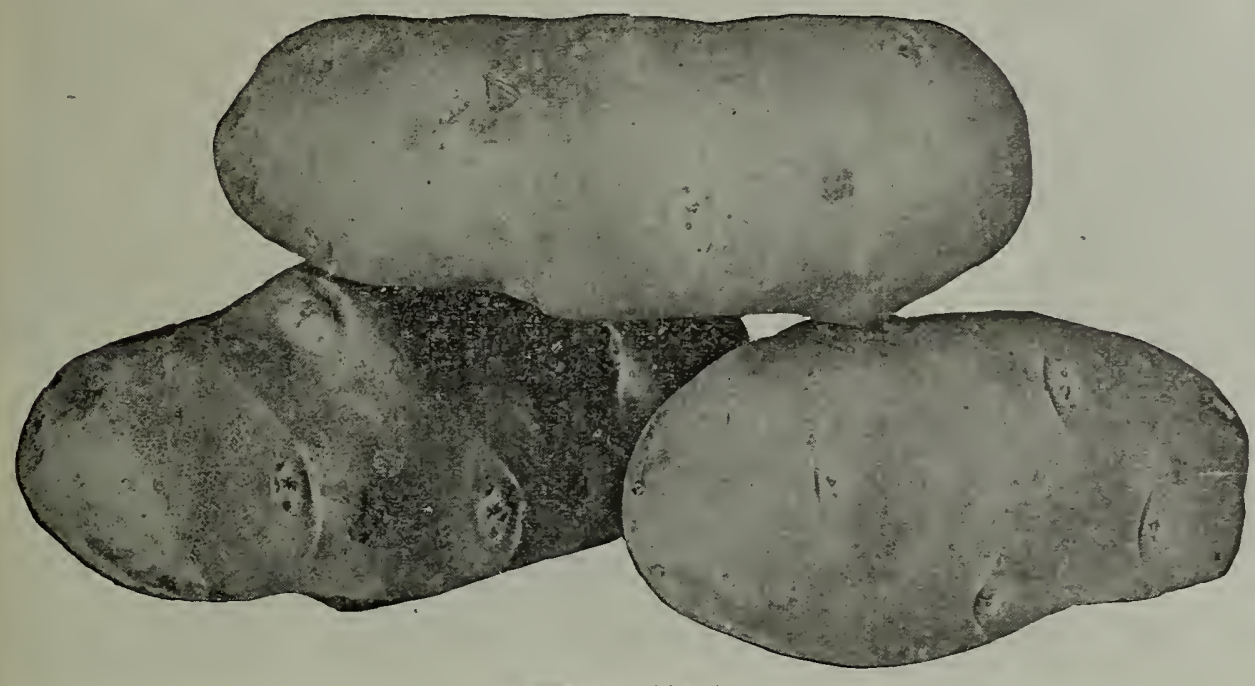

Reuter's White Star

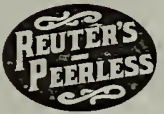

A new and very fine early variety that has attained immense popularity. It is a most excellent extra early sort. The tubers are oval to round shape, skin is clean and smooth; flesh is pure white and of the finest quality. They grow to a marketable size more uniformly than any potato we know of. The vines are very vigorous and hardy; short and upright in growth, so that the hills may be only a short distance apart. Does remarkably well in the South.

Price, peck 75e; bu. \$2.00; per sack $(150 \mathrm{lbs}$. net), \$4.75; 5 sacks at $\$ 4.50$ per sack.

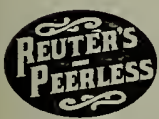

\section{REUTER'S WHITE STAR-Main Crop}

A medium early variety of exceptionally fine quality and appearance. Large, oblong, uniform-sized tubers. Vines are strong, of dark green color, and very

We consider it the heaviest cropping main crop white potato.
It is the best variety of late potato ever introduced. For growing It is the best variety of late potato ever introduced. For growing for mal.

Price, peck 60c; bu. \$1.75; per bbl. (180 lbs, net) \$4.75; 5 bbls. at $\$ 4.50$ per bbl.

\section{EARLY ROSE}

The standard variety for general use. Oval in shape. skin light pink, uniform in size, and very productive.

Peck ( 60c; bu. \$1.75; bbl. (180 Ibs. net) $\$ 5.00 ; 5$ bbls. at $\$ 4.75$ per bbl.

\section{BLISS EARLY RED TRIUMPH}

Earlier than the Rose. A grand early market and main crop sort. The favorite early potato in this section. It is an extremely early, round reddish thin-skin potato, eyes slightly depressed and of medium size. Its great beauty, productiveness, and superb quality, makes it a most profitable market variety.

Jur seed is grown in Maine, carefully selected for seed purposes. We can always challenge a comparison of quality.

Price, peck 75e; bu. \$1.75; per sack (150 lbs. net) \$4.25; 5

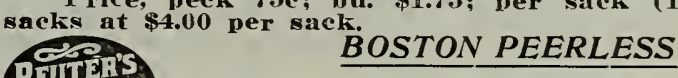

A popular late variety. Tubers are oblong to round in form, skin dull white. slightly russeted, very shallow eyes near surface. A good keeper and a heavy cropper. Price, peck
$\$ 4.50$ per bbl.

\section{Write for Prices}

\section{SWEET POTATOES}

\section{The Best Sorts}

Next to corn, the sweet potato is the most vital food crop in our Southern lands. Plant the potatoes early in the spring in prepared ridges, and cut the vines from the potato when large enough and plant them out; another method is to start the potatoes in a bed prepared expressly for that purpose, and slip off the sprouts as they come up and set these out. The latter method the soil should be thoroughly pulverized, the ridges should be 3 to 5 feet apart and the plants 14 inches apart in the row. Cultivate sufficiently to keep the surface soil loose and free from weeds. and the vines will soon cover the ground, after which no valtivation is necessary. After the plants come up and begin to make vines freely, pieces of the vines are removed and used as cuttings. taking root and growing the same as plants grown from the seed. Dig the potatoes before a heavy frost occurs; a produce this amount of slips. The principal varieties are:

PUMPKIN YAM-Excellent in quality, and productiveness. Skin and flesh yellow and sweet. Best for home use.

Price, peck 75e; bu. $\$ 2.00 ;$ bbl. $\$ 5.00$.
SOUTHERN QUEEN-Very similar to the former, but smoother, the tubers having no veins or very few.

Price, peck 60e; bu. $\$ 1.75$; bbl. $\$ 4.00$.
CALIFORNIA YAM-Earlies variety: very productive, yielding as many as three hundred barrels per acre on alluvial land. dry and mealy Price, peck soc; bn. \$1.50; bbl. \$4.00. Prices fluctuate. "Trite for market prices.

\section{My Service Bureau is Free \\ A Money Crop}

This vegetable is raised to an enormous extent in Louisiana. It is a staple product in many of the lower parishes, and is raised largely for shipment to New Orleans and Northern markets. Very popular with the foreign population. and is used for flavoring stews, soups, roasts, etc. Grows splendidly in Louisiana, and is largely cultivated, notwithstanding the fact that large quantities are imported from Italy and Spain.

In the spring they are ta October and November in drills, two or three feet apart, about six inches in the drill, and one inch deep.

the spring they are taken up and plaited together in a string by the tops.
Garlic Bulbs, 15 cents per pound. Prices for larger quantities on application. 


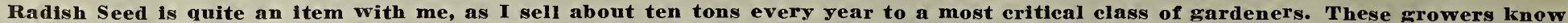

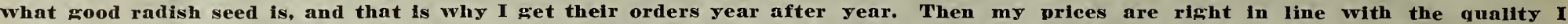

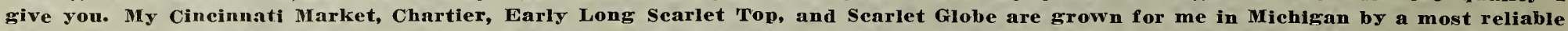

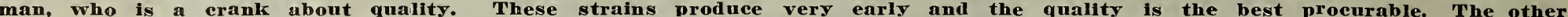

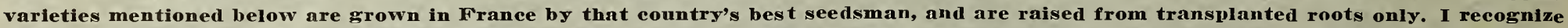

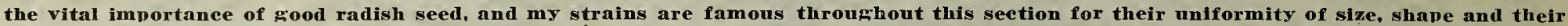
bright attractive color. Pay me a littre more, but you set much better seed, which means a more profitable crop.

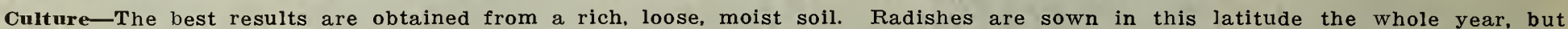

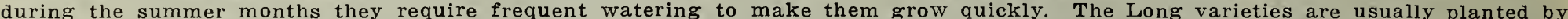

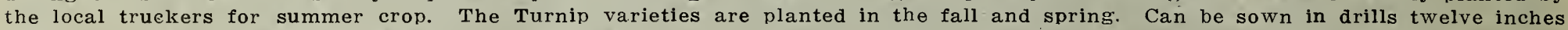
apart. Our gardeners usually sow them broadcast.

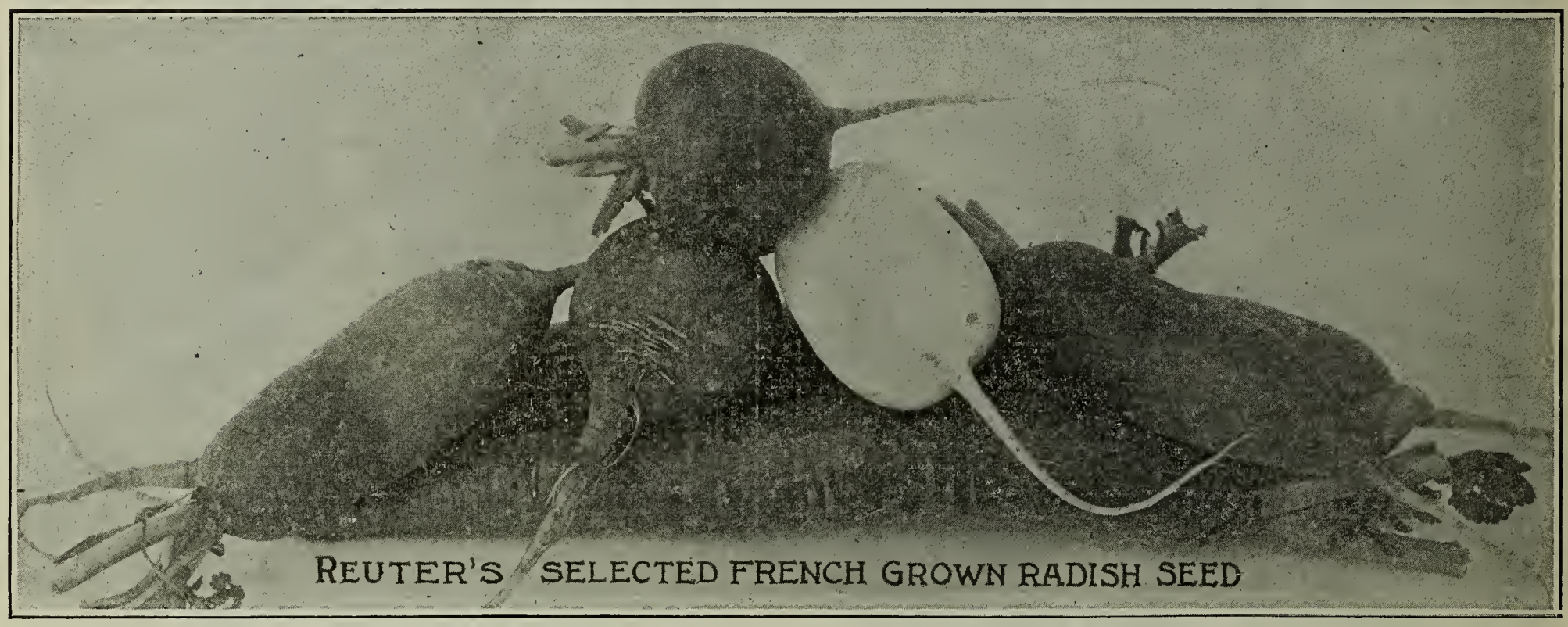

\section{REUTER'S EARLY SCARLET TURNIP, WHITE TIPPED}

The most profitable market gardeners' variety. We sell tons of this seed to the most critical growers in this section, and our stock cannot be surpassed. The truckers in New Orleans have nothing but the highest praise to say about our strain. Medium in size, very uniform and round in shape, bright scarlet in color, The scarlet is unusually deep, and affords a very distinct and pleasing contrast with the large clear white tip.

French Grown Seed, oz. 5c; $1 / 4$ lb. 15e; ib. 40e; 10 lbs. $\$ 3.50$.

Michigan Grown Seed. oz. 5e; 1 b. 30es 10 lbs. 82.50; 25 lbs. and over at 20, der lb.

\section{REUTER'S LONG BRIGHTEST SCARLET}

The finest long bright scarlet Radish in cultivation. Matures in twenty-five days from planting. Many of the growers in New Orleans plant this variety exclusively for their early local market
Price, oz. 5e; 1/4 lb. 15e; 1b. 40e; 10 lbs. \$3.50.

REUTER'S HALF $=L O N G$ DEEP SCARLET

Roots half long, with a somewhat tapering point Deep rich red color; flesh is pure white, crisp and

Price, oz. 5e; 1/4 lb. 15e; lb. 40e; 10 lbs. \$3.50.

\section{WHITE SUMMER STRASSBURG}

A large showy half long variety. Can be sown throughout the summer, as it resists the heat remarkably well.

Price, oz. 10c; 1/4 1b. 20c; 1b. 45e.

\section{REUTER'S FRENCH BREAKFAST}

A very popular French variety of quick growth very mild and tender; of an oval form; scarlet, tipped with white A splendid sort for market or garden

Price, oz. 5c; 1/4 Ib. 15e; 1b. 40c; 10 lbs. \$3.50.

\section{REUTER'S EARLY LONG WHITE VIENNA}

Beautiful in shape; skin and flesh pure white. Crisp, britle, and rapid grower.

Price, oz. 5e; $1 / 4$ lb. 15e; lb. 40e; 10 lbs. $\$ 3.50$

If you are in the market for large quantities, write for wholesale prices.

\section{LONG BLACK SPANISH}

Grows from five to eight inches long. Skin black, flesh white and firm. The best winter sort for home use.

Price. oz. 5e; 1/4 Ib. 15e; lb. 40e; 10 Ibs. \$3.50.

\section{IMPROVED SCARLET GLOBE RADISH}

Fine for market. Extremely quick growing, and of very good quality.

Price, oz. 5c; $1 / 4$ lb. 15e; lb. 40c; 10 lbs. \$3.50.

\section{REUTER'S CINCINNATI MARKET-SELECTED}

A highly selected strain for Market Gardeners.

This superior Radish was bred up by the Glass Gardeners near Cincinnati; and no finer long Radishes go into any market. It is the standard market Radish in a number of Southern trucking sections, and is, without a doubt, the most profitable long varlety in cultivation. Skin is scarlet colored, very thin, the flesh crisp, brittle and of delightful flavor.

We are proud of our superior seed, and have sold large quantities in Long Beach, Gulfport, and other trucking centers our strain is far superior to the ordinary kind sold by Northern Seedsmen.

Price, oz. 5e; 1/4. 1b. 15c; 1b. 35c; 10 lbs. at 30c; 25 lbs. at $25 \mathrm{c}$ per Ib.; 100 lbs. at 20c per ib.

\section{REUTER'S IMPROVED CHARTIER.}

A distinct and exceedingly attractive sort; a clear rose colored long radish, shading into pure waxy white at the tips. Grows to a large size very fast. One of the very best long radishes for general outdoor planting. and is extremely popular in many of the leading trucking sections of Louisiana, Mississipp and Alabama. We sell thousands of pounds of selected American Grown seed annually.

Price, oz. 5e; $1 / 4$ Ib. 15e; 1b. 30e; 10 lbs. 25e; 100 Ibs. or more at $22 \mathrm{c}$ pound.

\section{IMPROVED SCARLET GLOBE RADISH.}

Fine for market. Extremely quick growing, and of very good quality. (American Grown Seed.)

Price, oz. 5c; $1 / 4$ Ib. 15e; ib, 40c; 10 Ibs. \$3.50; 100 lbs. or more at 22c per pound.

\section{NEW ICICLE}

An entirely distinct, long, slender, pure white radish. It is the earliest and finest of the long white types. Ready for use in twenty-five days. A very lucrative market variety.

Price, pkt. 5e; oz. 10e; $1 / 4$ lb. 20e; lb. 50c; 10 lbs. $\$ 4.00$.

\section{CHINESE ROSE}

A bright rose colored radish with firm flesh, crisp, tender, and quite pungent. A very good winter sort.

Price, pkt. 5e; oz. 10e; $1 / 4$ lb, 20e; Ib. 50e. 


\section{SPINACH}

Flanders is the Best Variety for the South

Our Holland=Grown Spinach is far superior to the ordinary American=Grown and cheaper im= ported seed. We import our seed direct from those favored sections of the country where they produce the highest grade Spinach and you will find our seed both stronger in vitality and purity, larger and more vigorous in growth, and much hardier. Special prices for larger quantities than quoted.

Culture-Spinach succeeds well in any ordinary soil. Sow during the fall from September until the end of March, either broadcast or in drills, one foot apart. If the fall is dry and hot, it is useless to sow it. as the srow

\section{REUTER'S BROAD=LEAVED FLANDERS}

A very hardy and vigorous sort, proDitus ducing large thick leaves, nearly round, and Pajicass slightly crimped in the center, and of bright seed to the local truckers.

Price, oz. 5e; $1 / 4$ b. 10e; 1b. 25e; 100 1b. \$20.00.

\section{BLOOMSDALE CURLED SAVOY}

Often called Norfolk Savoy. A very popular sort

and extensively cultivated in the South. finest flavor. Upright growth. \$1.5.00.

De Quincy, La., Sept. 12th, 1913.

Having had but one year's experience in the use of your seeds, I can't give you a lengthy testimonial, but please say that they surpassed any seeds I have ever planted, being quicker to germinate, hardier in growth, success,

A. R. WOLF.

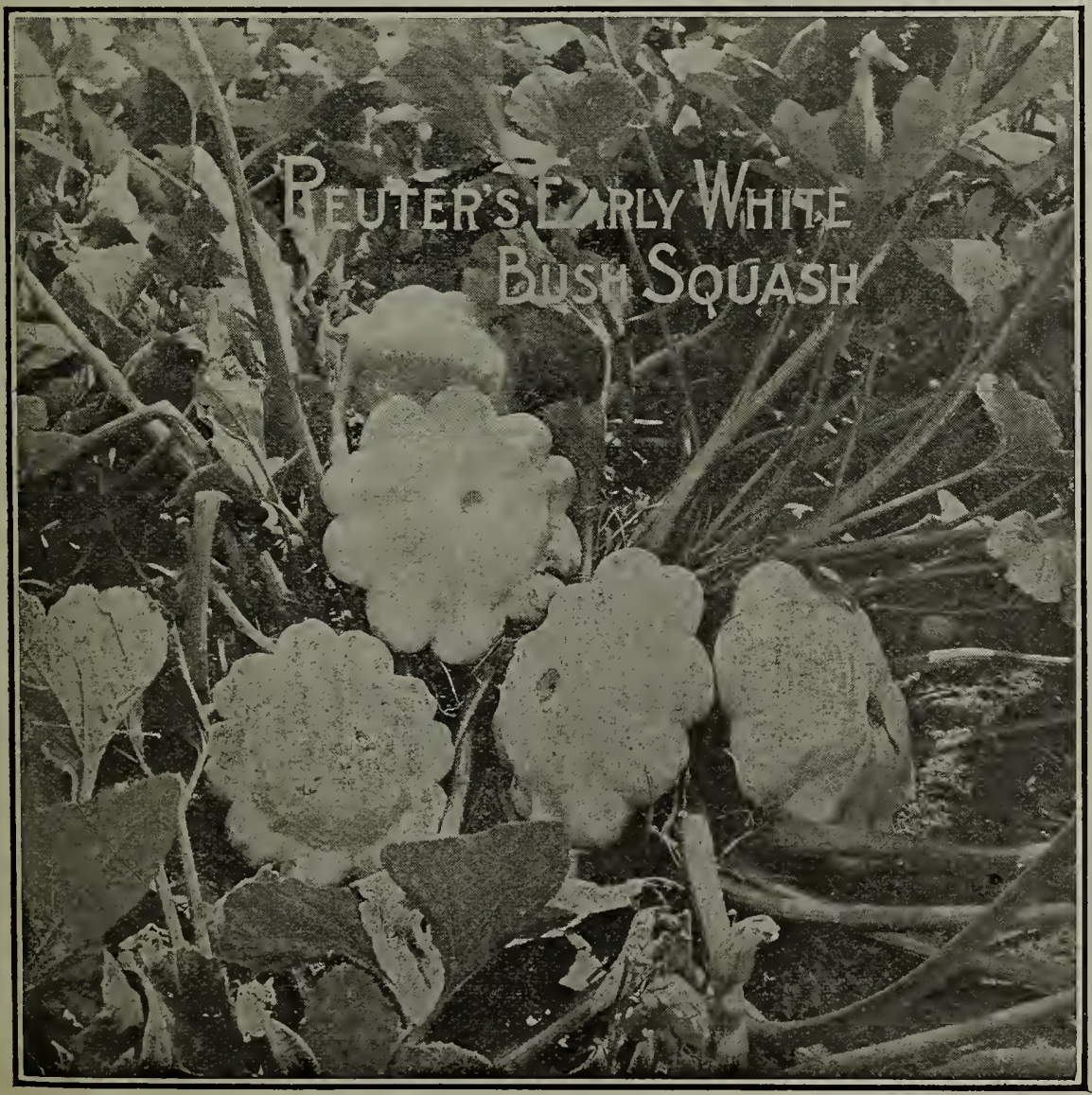

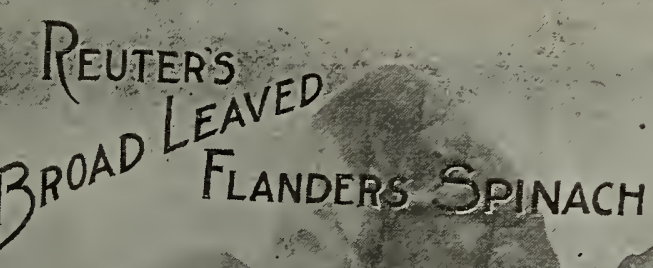

ond

\section{SQUASH}

Culture-Sow during March in hills three to four feet apart Plant six to eight seeds to each hill, thinning out to three to four plants whe For first or early crop, the seeds are planted in boxes the beginning of February, but it is best to wait
until the ground gets warmer and danger of frost is over.

REUTER'S EARLY WHITE BUSH, or PATTY PAN

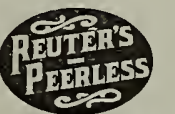
The standard early variety for mar ket gardeners, and has no superior. It is of dwarf growth, quite hardy and very productive. Color, creamy white. Our seedgrower, and we have a very fine selected strain. Our growers in New Orleans planted more than five hundred pounds 'of this stock last year. \$4.50.

\section{REUTER'S GIANT SUMMER CROOKNECK}

It is the finest crookneck for early market. The fruits quickly reach a desirable size for market. It is of golden yellow color, covered with warty excrescences, and measures from one and a half to two feet in length, \$5.00.

Price, pkt. 5e; oz. 10e; 1/4 lb. 20e; 1b. 60e; 10 lbs.

\section{TRUE HUBBARD}

This variety cannot be excelled for winter use. Flesh bright orange yellow, fine grained, very dry, sweet and richly flavored. Excellent keeper.

\section{MAMMOTH CHILI}

Grows to mammoth size. In fact, it is the largest of all squashes. often attaining a weight of two nun dred pounds without losing its fine shape and good quality. Flesh very thick, color rich yellow, fine

Price, pkt. 5c: oz. 10c; $1 / 4$ lb. 30c; 1 b. $\$ 1.00$. BOSTON MARROW

Favorite winter Squash of the Eastern States. Oval form, skin thin, when ripe bright orange, flesh rich salmon yellow. Fine flavor.

Prlee, pkt. 5e; oz. 10e; $1 / 4$ lb. 20e; lb. 60e. 
SUPERIOR NORTHERN GROWN SEED

\section{TOMATOES}

My Seed is grown expressly for me by seed growers who grow for seed only. do not use Canning Factory Seed.
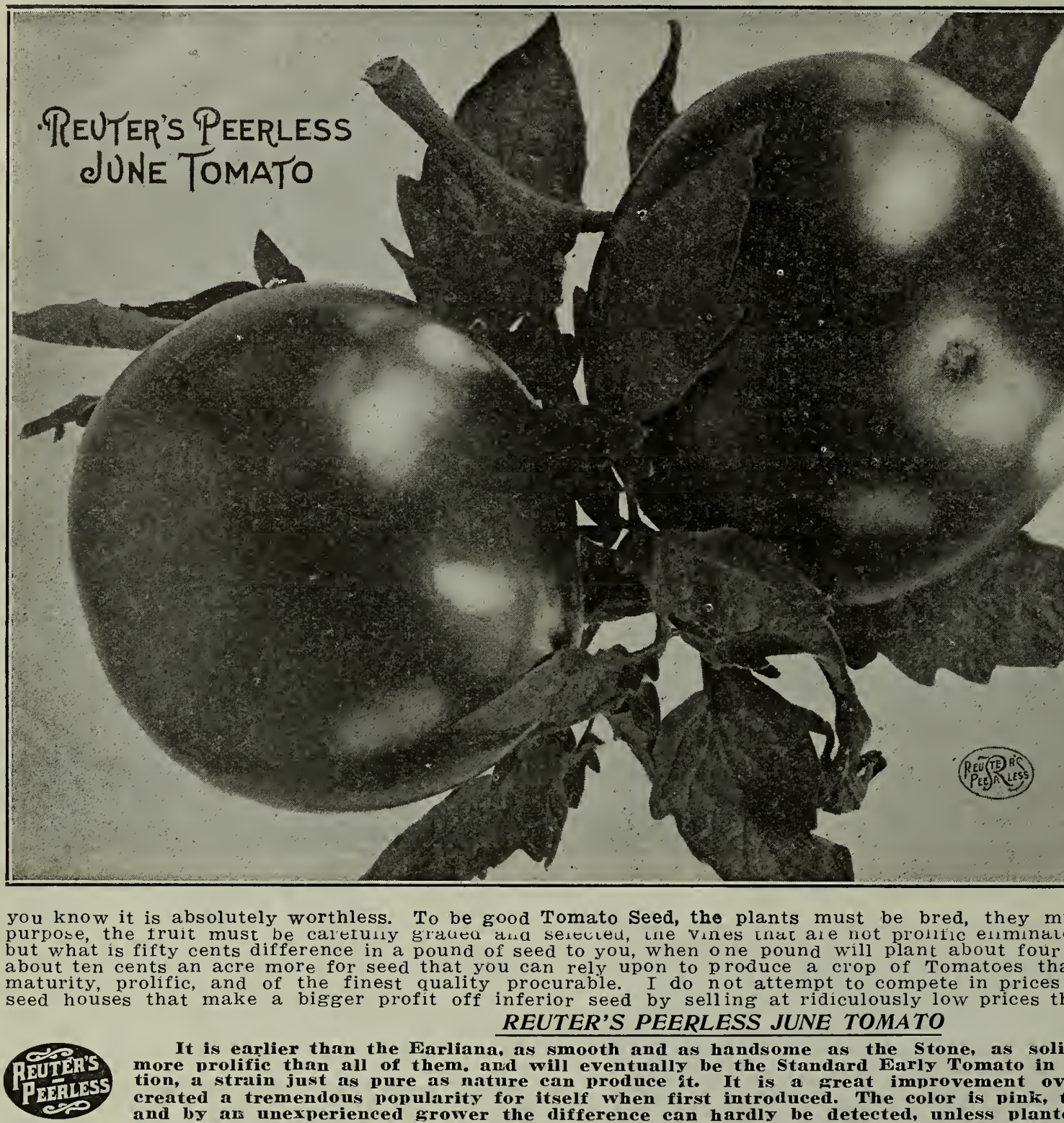

O YOU PLANT GOOD TOMATO SEED?

Two years ago I was on a train going to Chimen Convention and irough accident beaine accuainted with ne of the leading canountry $\mathrm{He}$ was not ware of the fact that was in the seed busiess, but by casually Tring to a nice field the railroad stations. he became interested mmediately, and adss. He was a very nteresting talker. and curing the course of the conversation mentioned to me the name of one of our leading seedsmen. firm known from one coast to the other. Who Is BUYING HIS REYou my surprise when this was told to me. I could not for the moment realize how a firm with so much money and so much reputation should degrade itself by stooping to buy such trashtomer's for good seed. Later in the season I bought a packet of toes this firm handled, and the result was as I expected. None true-totvpe, inferior quality, poor germination, and the grandest mixture I have ever seen. This is criminal to sell a good.

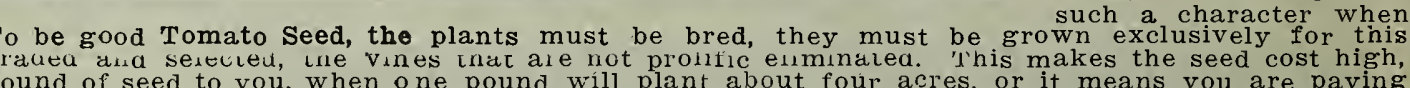

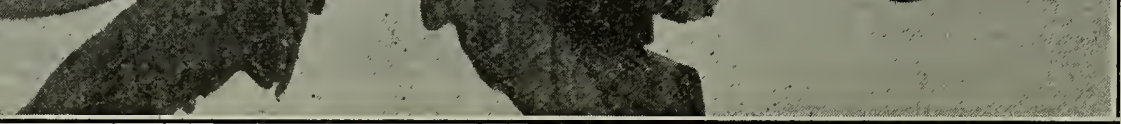
but what is fifty cents difference in a pound of seed to you, when o ne pound will plant about four acres, or it means you are paying
about ten cents an acre more for seed that you can rely upon to produce a crop of Tomatoes that will be uniform in growth and
maturity, prolific, and of the finest quality procurable. I do not attempt to compete in prices with cheap Northern and Southern maturity, prolific, and of the finest quality procurable. I do not attempt to compete in prices with cheap Northern and Southern REUTER'S PEERLESS JUNE TOMATO

It is earlier than the Earliana, as smooth and as handsome as the Stone, as solid and seedless as tlie Ponderosa, more prolific than all of them. and will eventually be the Standard Early Tomato in this country. of my own introduction, a strain just as pure as nature can produce it. It is a great improvement over the Famous June Pink which created a tremendous popularity for itself when first introduced. The color is pink, the growth resembles the Earliana, and by aw nnexperienced grower the difference can hardly be detected, unless planted side by side, when this variety and by aw unexperienced grower the difference can hardiy be detected, unless planted side by side, when this variety

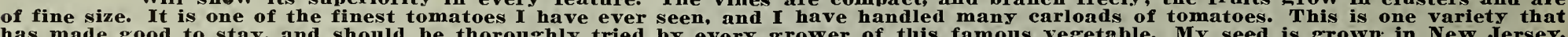

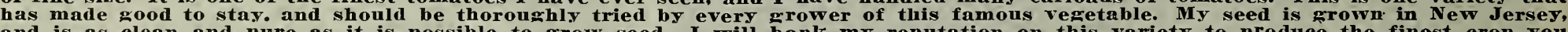

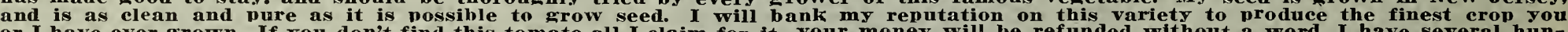
or I have ever grown. If you don't find this tomato all I claim for it, yo

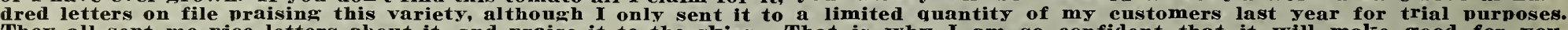

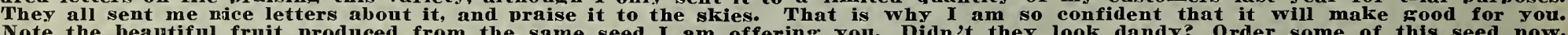

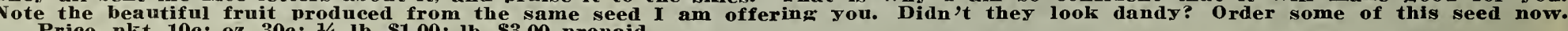

\section{REUTER'S SELECTED SPARK'S EARLIANA}

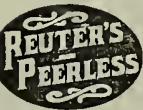
It is, without doubt. The earliest large smooth red Tomato in cultivation uniform in size and shape. Color is deep scarlet. On diness and productiveness, combined with extreme earliness, it is of great value to the market oardener. Our strain is most careprice, akt. 5c: earliness, trueness to type. and productiveness.

\section{REUTER'S REDFIELD BEAUTY}

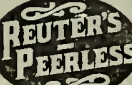

I suggest that you try my strain of this well orate on its description for I think for me to elabwell known in the South for me to speak of its Reuter's 'Redfield Beauty is a grand tomato for the Southern Trucker, and is making good in Louisiana. Florida, grow in clusters of three to five fruit. and is as regular in ing attribute, being a glossy red, the kind to make tomatoes sell at sight, and make you long for a good tomato salad when you until picked A good shipper, less liable to rot in transit than Price, plkt. 5e; oz. 30c; $1 / 4$ lb. 90e; $1 b . \$ 3.00$ (prepaid).

\section{EUTER'S IMPROV NEW S " E-Selected}

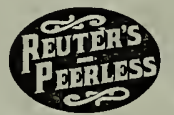

My strain is far superior to the famous Stone in solidity, productiveness and richness of color. A great favorite with all market gardeners, and is size, bright scarlet in color, smooth and exceedingly solid and firm fleshed. Quality is unexcelled. Ripens evenly to the stem without a crack. Vines are vigorous and productive.

\section{REUTER'S PEERLESS RED ROCK}

The Tomato with a pedigree. A variety that has made good all over this whole country. Fol shipping, canning, or home use, it is the ideal sort, as tomatoes. It requires about one hundred days to mature properly. The color is the thing that counts. It is solid and absolutely free from excess of water, which often proves detrimental in some of the best sorts. It is a tremendous producer, and one of the finest shipping tomatoes 1 know of. acrenty-five to thirty tons of fruit have been grown on a single of the finest and most showy tomatoes I handle Has a very strong vigorous vine, thus protecting its fruit from the excessive sun heat so effective on Tomatoes in the South. My grower has improved this particular strain to such an extent that I really believe it is far superior to the original Red Rock, which was introduced to the trade a few years ago.

Price, pkt. 5e; oz. 30c; $1 / 4$ 1b. $\$ 1.00 ; 1 b . \$ 3.00$ (prepaid). 


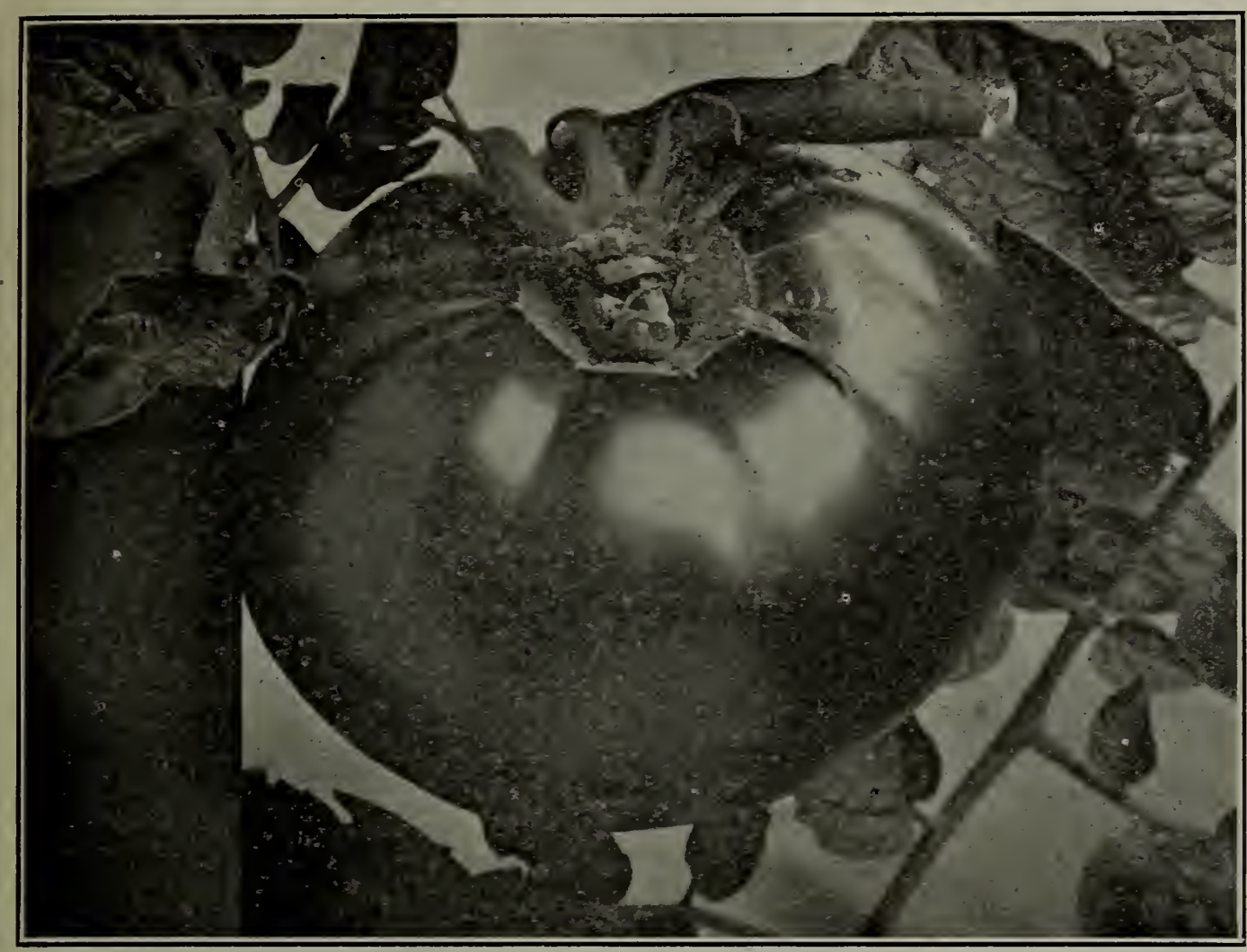

REUTER'S BUNAY BEST-Early

Note the Illustration. Looks mighty good, don't it?

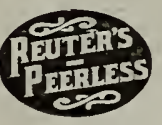

A Tomato that has the endorsements of nearly iment Station in this country. This is a most meritorious sort, and deserves the careful consideration of every practical trucker who is growing the crop. Even though you are thoroughly satisfied with the variety you are now growing, order an ounce or worth the few cents you expend, and may prove a valuable investment for tures that make it an ideal tomato for our southern clime. It produces an its fruit from the heat of our semitropical suns. It is about ten days earlier than our Early Jewel, and almost as early as our Famous Earliana and June Tomato. It is indeed a most vigorous grower, enormously prolific. scarlet red. It will ripen evenly to the stem end with cracking. It is absolutely immune from most tomato slightly fattened at the stem end, out thicker through than most other tomatoes in its class.

It is an all-around good early tomato. The seed I offer is the best pro-

Price, pkt. 10c; oz. 30c; 1/4 1b. 35c; 1b. $\$ 3.00$ prepaid.

\section{LIVINGSTON'S BEAUTY}

One of the most popular varieties and highly commended to all growers. Fruits large, uniform in color, with a slight purple tinge. Vines are vigorous

and heavy bearers.

\section{REUTER'S PURPLE ACME}

Medium size, round, smooth, solid and prolific. Purplish pink in color. Fruits are produced in clusters of four or five.
It bears shipping well and is considered a very fine standard
variety:

Price, pkt. 5c; oz. 20c; 1/4 1b. 60c; lb \$2.00.

\section{IMPROVED PONDEROSA}

A great big tomato that has won for itself first place among many of the most critical growers of this luscious vegetable. The the heaviest, and in addition to these two splendid features, it the heaviest, and in addition to these two splendid features, it immense size, and makes a splendid slicing variety, having few seeds.

If you are looking for something that is really a novelty, and at the same time a valuable variety, plant the Ponderosa.

\section{LIVINGSTON'S GLOBE \\ Reuter's Special Strain}

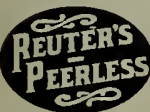

A new variety of exceptional merit, which is being extensively cultivated by the large Tomato growers in the South. In shape this variety is distinct from all others, bearing a beautiful globe. In time of ripening, it belongs among the first earproductive and a good keeper, excelling all other sorts in this

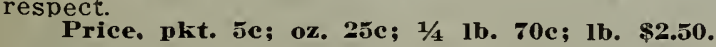

\section{EARLY DETROIT SELECTED}

The lariest and best of the early purplish toma-

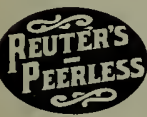
toes. A splendid shipper. Within the past fer years ite in many sections, and we have hundreds of testiite in many sections, and we have hundreds of testiing our selection. Its uniformity and size of fruit, freedom from cracking and from tendency to blight, make it a smooth, nearly globe shaped, firm and of excellent quality Our strain is absolutely pure.

Pkt. 5c; oz. 25c; 1/4 1b. Soc; 1b. \$3.00.

\section{LIVINGSTON'S CORELESS}

A very large, uniformly globe shaped, bright scarlet, main crop or late Tomato. Fruit is very solid, almost entirely free from green core and with little or no depressinn at stem end, making it very desirable for slicing, canning and shipping.

Price, pkt. 5c; ox. 30c; 1/4 1b. \$1.00; 1b. \$3.00.

\section{NEW DWARF STONE}

The largest Dwarf variety ever introduced. Vines are dwarf, but vigorous and very prolific. Coior is bright scarlet, perfect in shape, very solid and of the finest quality.
Price, pkt. 5c; oz. 25c; 1/4 lb. 70c; lb. \$2.25.

\section{TOMATO PLANTS}

We have ready about February carefully grown Tomato

plants of the following varieties: Stone, Beauty and Earliana.
Price. \$6.00 for one thousand.

\section{CHALK'S EARLY JEWEL}

The largest, smoothest and finest flavored extra early Tomato ever introduced. About a week or ten days later than our special strain of Spark's Earliana. The fruits are large and smoother. The vines grow very compactly, are immensely pro-

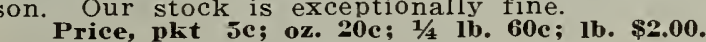

\section{REUTER'S SELECTED TROPHY}

A large late Tomato, unsurpassed in rich, deep crimson-scarlet tarcellent quality. Tines largerous and exceptionally productive. Fruits very solid, smooth and of uniform compares favorably with any in smoothness and regularity of compares favorably with any in smoothness and re

Price, pkt. 5c; oz. 20c; $1 / 4$ ib. 60c; 1b. \$2.00.

REUTER'S HOME GARDEN TOMATO COLLECTION, 25c.

$I$ will select 7 of my best strains of Tomatoes and mail them to you, postpaid, for twenty=five cents.

\section{DO YOU MAKE MONEY GROWING TOMATOES?}

It cost you just as much to grow scrub tomatoes from poor seed, as it is to grow the finest crop in your community with my thoroughbred seed. A whole lot depends upon the quality of the seed you plant. More than you think. I have devoted special attention to the growing of tomatoes for seed purposes, and enthusiastic about their beauty, their uniform growth, and other splendid features. Like all other seeds that I have gromn for me, either I or one of my boys go North each summer and inspect these crops and are sure that the seed is the kind that I can sell you without hesitation. Good seeds are the foundation of good crops, and the few cents you pay more for quality is for never question price when buying Tomato or any other seed. You must take my word for it when I tell you that my Tomato Seed is just as pure and reliable as can be. The crop will PROVE to you just howall an item, that it should be overlooked. Always remember the quality, the kind I give you, the kind that will grow the finest Tomatoes you have ever seen. Whether you grow a small patch in your back yard garden, or grow one hundred acres for profit, give me your order. 
Grown from Transplanted Roots

\section{TURNIP SEED}

The World's

Best Turnips

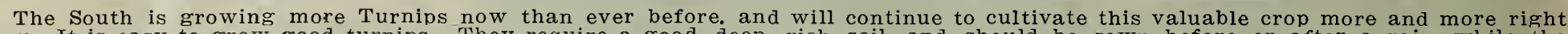

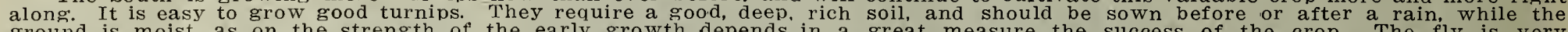

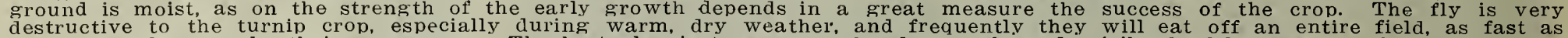

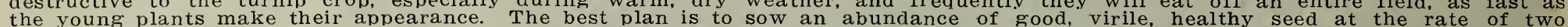

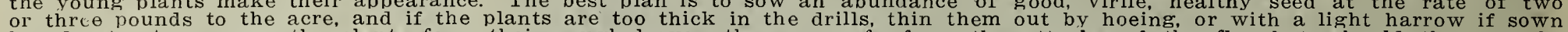

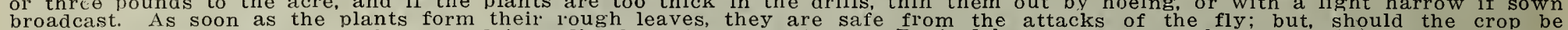

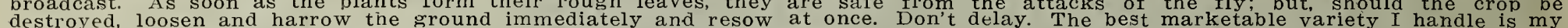

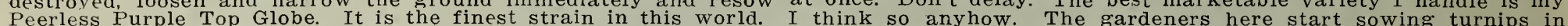

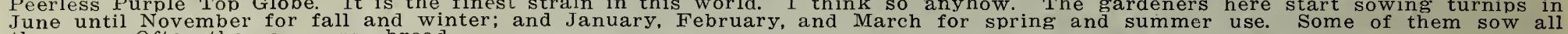
the year. Often they are sown broadcast and are not thinned out properly, resulting in poorly shaped roots. Try to avoid this if you can. Give each turnip enough room to grow. If you inches apart is sufficient. Thin the plants out to stand six inches, and as the plants grow, ridge up to them, otherwise they will form no bulbs. I handle about thirty thousand Every pound of seed is grown for $m e$ ica. When you buy and begin to compare prices, remember the REUTER be fairly compared with the stocks offered cheaper by most seedsmen. My turnip seed will always grow and produce good bulbs. The seed is always absolutely unmixed.

\section{REUTER'S PEERLESS PURPLE TOP WHITE GLOBE}

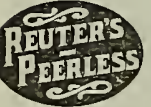

A large, rapid growing turnip with globular shaped roots. Flesh is pure white, of finest quality and excellent flavor

The crown is purplish red and the remaining portion clear white. A heavy cropper and finc market sort. Our seed is grown expressly for us in Pennsylvania and the utmost care of the best roots and keeping our strain true to shape. Last year we sold more than 4,000 pounds of this special stock to the New Orleans Market Gardeners. $1 / 4$ 1b. 15e; 1b. 40c; 10 lbs. \$3.50.

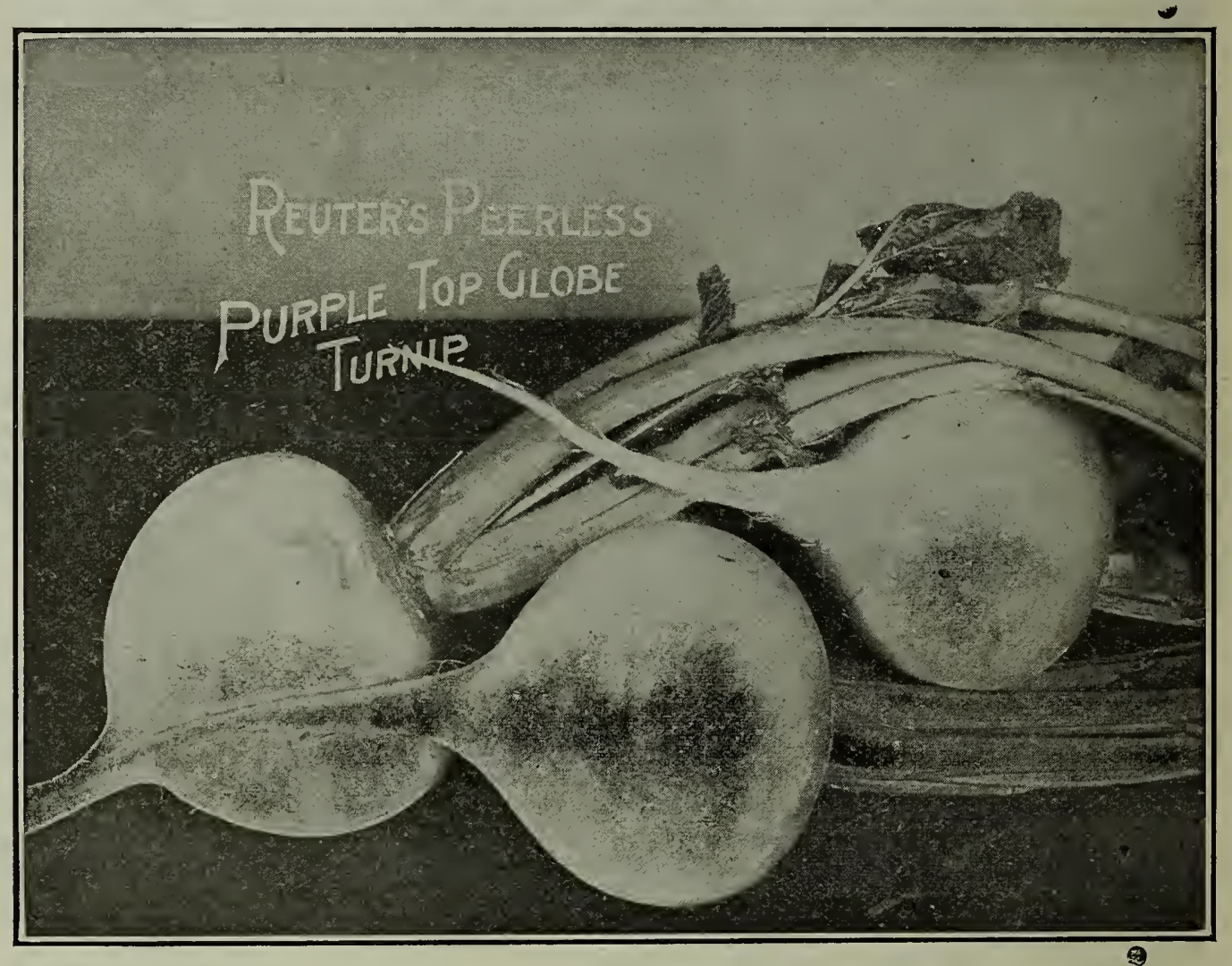

\section{EXTRA EARLY WHITE MILAN}

Very popular and desirable. Roots clear white, very smooth, flat and symmetrical. Its excellent qualities and fine appearance make it a valuable crop to grow, and it is ready for market much earlier than any other white variety.

\section{LARGE WHITE GLOBE}

A variety grown exclusively for stock feeding. Globe in shape, flesh and skin white. Tops and leaves are inclined to make a strong growth. $15 \mathrm{pr}$;b. 50e; 10 lbs. $\$ 4.00$.

\section{COWHORN OR LONG WHITE}

This variety is clear white, except a little shade of green at the tho of the root, which grows in shape similar to a cow's horn. The flesh is fine grained and well flavored, desirable both for table use and stock feeding. A rapid grower and well adapted for winter use. $1 / 3$ lb. 15e; lb. 50e; $10 \mathrm{lbs}$. $\$ 4.00$.

\section{POMERANEAN WHITE GLOBE}

One of the most productive kinds and in good, rich soil, roots will frequently grow to twelve pounds in weight. It is globe

shaped and slightly flattened; skin very white and smooth.
Price, oz. 5e; 1/4 lb. 15e; 1 . 50e; 10 lbs. \$4.00.

\section{SWEET GERMAN, or HANOVER}

Resembles the Rutabaga in growth. It is a white fleshed variety, very solid, firm and sweet. It is a good keeper and splen-

Price, oz. 5e; $1 / 4$ lb. 15e; 1 b. 40c; 10 lbs. $\$ 3.50$.

$$
\text { SOUTHERN PRIZE, or DIXIE }
$$

A variety that is extensively cultivated throughout the South for winter greens. It also produces large and beautifully-formed turnips. Very hardy and needs no protection.
Price, oz. 5e; $1 / 4$ lb. 15e; 1b. 40e; 10 lbs. \$3.50.

\section{SOUTHERN"SEVEN TOP}

Cultivated extensively in the South for tops, which are used for greens. It is very hardy and will grow all winter, but does not produce a good root, and is only recommended for the tops.

\section{EARLY WHITE FLAT DUTCH}

A most excellent early garden variety and extensively raised in the Southern States. Roots medium-sized, flat, color white, very early, sweet, and tender.

Price, oz. 5c; $1 / 4$ 1b. 15e; 1b. 40c; 10 lbs. $\$ 3.50$.

\section{WHITE EGG}

A quick growing, egg-shaped, perfectly smooth, pure white variety. Very solid, firm, fine grained flesh, of sweet, mild flavor. It grows to a good size and is excellent either as an early variety.

Price, oz. 5e; $1 / 4$ lb. 15e; lb. 50c; 10 lbs. \$4.00.

\section{EARLY PURPLE TOP (Strap Leaved)}

This variety is good for early planting. Very flat, of medium size, flesh white with a purple or dark red top; leaves few, short and of light color

\section{LARGE AMBER, or YELLOW GLOBE}

Of very large size, globular shaped, solid, yellow flesh. It keeps well, and is desirable for either table or stock feeding.

Price, oz. 5e; 1/4 lb. 15e; lb. 40c; 10 lbs. $\$ 3.50$.

\section{PLRPLE TOP YELLOW ABERDEEN}

A popular sort, with yellow flesh, very solid and tender. A good yielder and splendid for stock feeding and table use.

Price, oz. 5c; $1 / 4$ lb. 15e; $1 \mathrm{~b}$. 40c; 10 lbs. $\$ 3.50$.

\section{RUTABAGA or SWEDE, The Best Variety Ever Known REUTER'S IMPROVED AMERICAN PURPLE TOP}

This is the largest and most productive Rutabaga in cultivation. Grows to a very large size and of the finest quality. Excellent
for table use and stock feeding. It has an exceedingly short neck, is very solid of a beautiful orange or amber color. with a handsome purple top. Our strain is the result of many years' critical selection, and is famous throughout the Southern States for its great purity and excellence.; 10 lbs. $\$ 3.00$. 


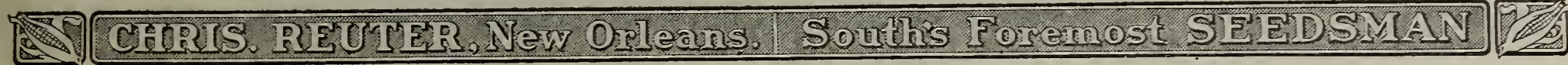

\section{VEGETABLE PLANTS AND ROOTS}

We have grown for us under special contract large quantities of VEGETABLE PLANTS AND ROOTS, and can supply the varieties listed below in their proper season. If wanted by mail, add 15c per 100 for postage on Cabbage and Cauliflower plants, and $30 \mathrm{c}$ per hundred for Eggplants, Peppers, Tomatoes and Plants. Tre advise our customers to have plants and ship only express. We pack all plants in first-class manner, and ship

strictly fresh plants, but cannot guarantee safe arriraloz. 2:; ARTICHOKE PLANTS. G

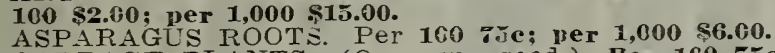

CABBAGE PLANTS. (Our own seed.) Per 160 75e; per 1,000 $\$ 4.00$.

CALLIFLOWER PLANTS. Large Algiers. Per $100 \$ \mathbf{\$ 1 . 0 0 ; ~ p e r ~}$ $1,000 \$ 5.00$

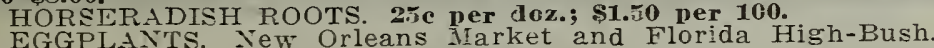

Per $10 \%$. 1 ; rer 160 sec: per $1,000 \$ 8.00$

PEPPEFS Euby King and Spanish Monstrous. Per dozen

10e; per 100 s6e; per $1,000 \$ 8.00$.

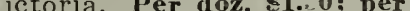

STR HWR Klondykers and Lady Thompson.

Per $100 \div 0 \mathrm{c}$; per $1.000 \$ 1.00$.

TOMATO PLANTS. Bะauty, Stone, and Earliana. Fer doz. 10c;

per 16060 ; per $1,000 \$ 6.00$

VEGETABLE PEAR. The Chayote or Mirliton belongs

the Gourd family. It makes a rapid-growing vine, with grape-like the Gourd family. It makes a rapid-growing vine, with grape-like
leaves. The fruits are used like Squash or Eggplants. It has leaves. The fruits are used like squash or Eggplants. It has only one seed. Which is enclosed in the bulo, and the whole fruit each extra.

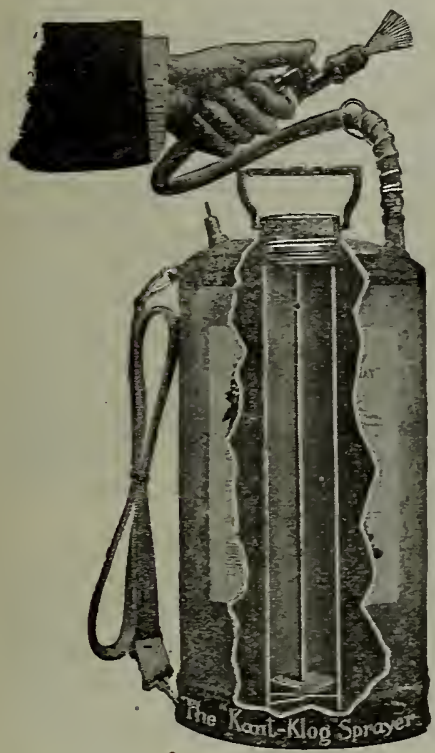

KANT KLOG NOZZLE.-The only nozzle that can be successful$1 y$ cleaned without stopping the spray or removing the nozzle from the tree. The first and only nozzle ever made which gives both treams. Sprays fruit trees, potatoes, vegetables, tobacco and cothouses, fire, disinfecting, etc. Price, with galvanzed steel body, \$5.00 with polished brass body, $\$ 7.50$. Kant Klog Nozzle only, \$1.50 each.

KNAPSACK SPRAYER. - One of the best, strongest, and most effective of all Knapsack Sprayers. The ank is made of heavy copper slightly concaved to fit the back, The pump is made entirely of brass, will not get out of order. Can be will not get out of order. Can and fungicides in the Orchard, Field and Garden, and is the cheapest knapsack sprayer made. Price $\$ 15.00$. Additional hose, $30 \mathrm{c}$ per

Write for Catalogue if interested in Sprayers or Garden Imthe Famous Planet, Jr., Garden Tools, Kant-Klog Sprayers, and other renowned garden and farm implements.

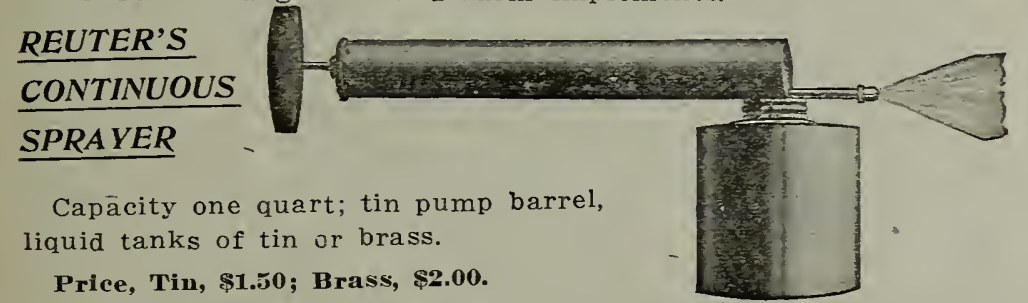

HOW TO PLANT GARDEN SEEDS
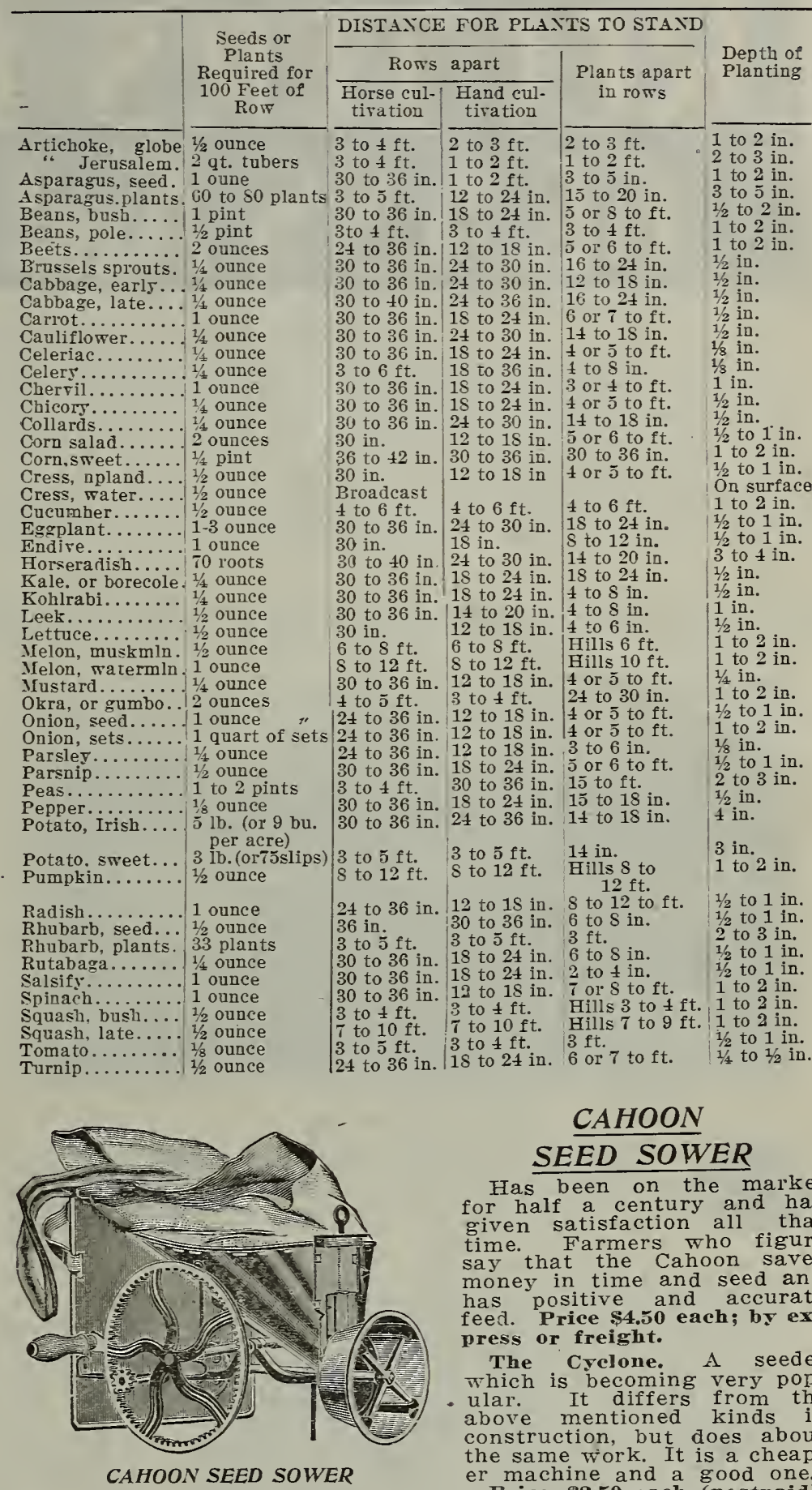

CAHOON

SEED SOWER

Has been on the market for half a century and has time. Farmers who figure money in time and seed and has positive and accurate press or freight.

The Crclone. A seeder which is becoming very pop-
ular. It differs from the above mentioned kinds in the same work. It is a cheapmachine and a good one.
Price, \$2.50 each (postpaid).

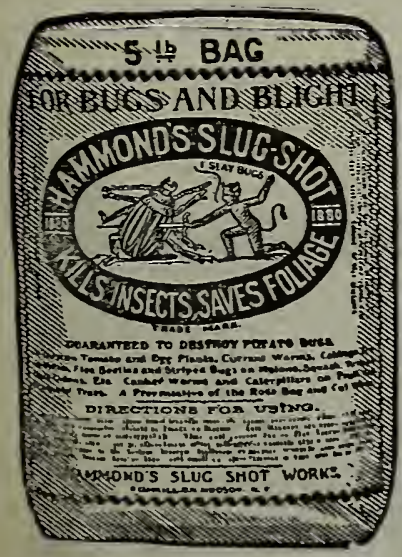

GRASSELLI'S ARSENATE OF LEAD (POWDERED)-100-1b. kegs, 34c per lb.; 50-1b. kegs, 36c per 1b.; 20-1b. kegs, 3Sc per $1 \mathrm{~b}$; 1 -1b. cans, 50c per $1 \mathrm{~b}$. GRASSELLI'S ARSENATE OF LEAD (PASTE)-100-1b. Kegs, 9e per 1b.; 50-1b.
kegs, 10e per 1b.; 20-1b. kegs, 12e per 1b.; 10-1b. kegs, 14e per 1b.; 2-1b. glass jars, 20 per lb.; 1-lb. glass jars, $25 \mathrm{c}$ per $1 \mathrm{~b}$.

GRASSELLI'S BORDEAUX MIXTURE (PASTE)-100-1b. kegs, 12e per 1b.; 50-1b. kegs, 14c per 1b.; 20-1b. kegs, 16e per lb.; 10-1b. kegs, 18e per 1b.; 2-1b. glass jars, 25e per lb.; 1-ib. gilass jars, 30e per lb. 20c. PARIS GREEN-Per 1b. క0c; 10 lbs. \$4.00; 20 1bs. \$7.00. Write for prices on larger quantities

HAMMIOND'S SLUG SHOT-A very popular, non-poisonous powder for destroy-

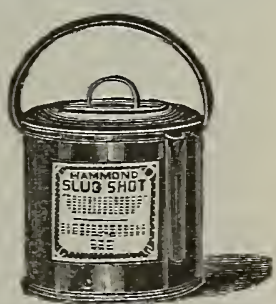

DUSTER bug insects of all kinds on Cabbage Plants, Letruce, etc. It also dest

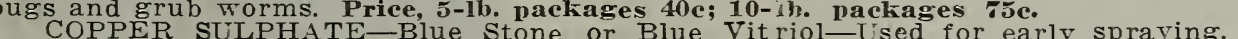
at 14e per ll.: 10 lbs. at 13 e per 1h. Write for prices on larger quantities.

KEEOSENE ENILLSION-Quart 40e; 2 quarts $5 \mathrm{c}$; gallon \$1.25. REUTER'S TOBACCO DUS'T.

The most effective and cheapest remedy we have ever found for the insects. flies, worms. ete., that are so destructive to Cabbage, Cauliflower, Cucumbers, Tomatoes, Egginants, Mrelons, etc. This is a very strong grade of tobaceo ground up into fine powder like snuff. It is also a rery good fertilizer. 2,000 $1 \mathrm{hs}$. (ton) $\$ 32.00$. Write for prices on carload lots.

DIRT BANDS. In order to get an early crop of Egoplants, Cucumbers, etc., these boxes should be used. They are 4 inches square and 4 inches deep, without bottoms. Price, 40c per $100 ; \$ 2.00$ per 1,000 . Tacks for Dirt Bands, 30e per lb. R1.80.

DUSTERS FOR HAMMOND SLUG SHOT. Price, gallon size 60c; $1 / 2$ gallon size 50c. 


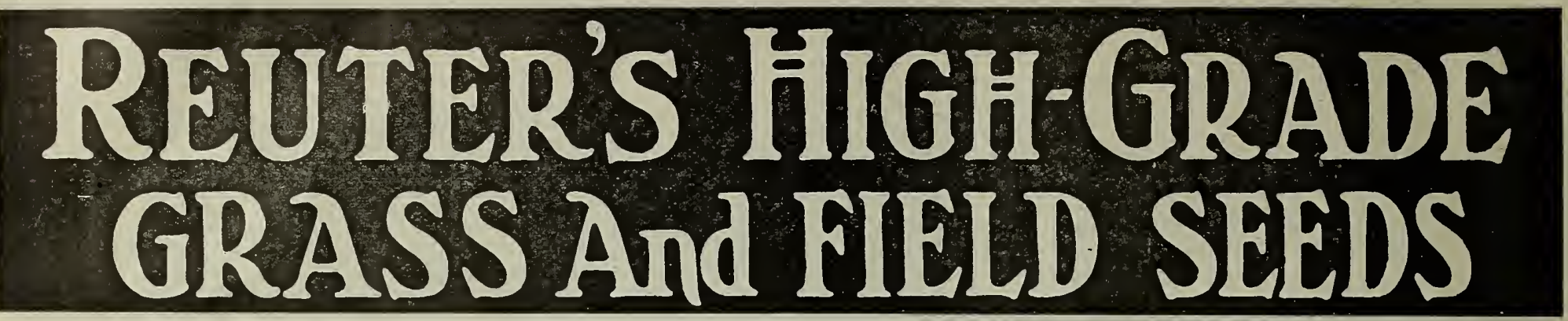

WE HANDLE ONLY ONE GRADE OF GRASS AND CLOVER SEEDS.

The best grade and to compete in price with irresponsible seedsmen who quote low prices with little or no regard for quality. The tendency is to to compete in price with irresponsible seedsmen who quote low prices with little or no regard for quality. The tendency is The stocks we offer are grown expressly for the best trade and can be absolutely relied upon in every particular. Our first and.
only consideration is quality, and then we figure our prices. We are confident that it is impossible to obtain better grass and clover seed than ours at any price. to the time, labor and expense of preparing the land for seeding, and then sowing worthless seed which will not germinate, or if contain a large percentage of noxious weed seed, which often prove detrimental to the land, and may require many years to eradi-

\section{LESPEDEZA, or JAPAN CLOVER}

I grow and have grown for me under my, personal supervision more than 10,000 bushels of extra cleaned, fresh, sound Lespedeza. Absolutely free from Johnson Grass. Offer only heavyweight "pan" seed, not uncleaned threshed scrub seedl

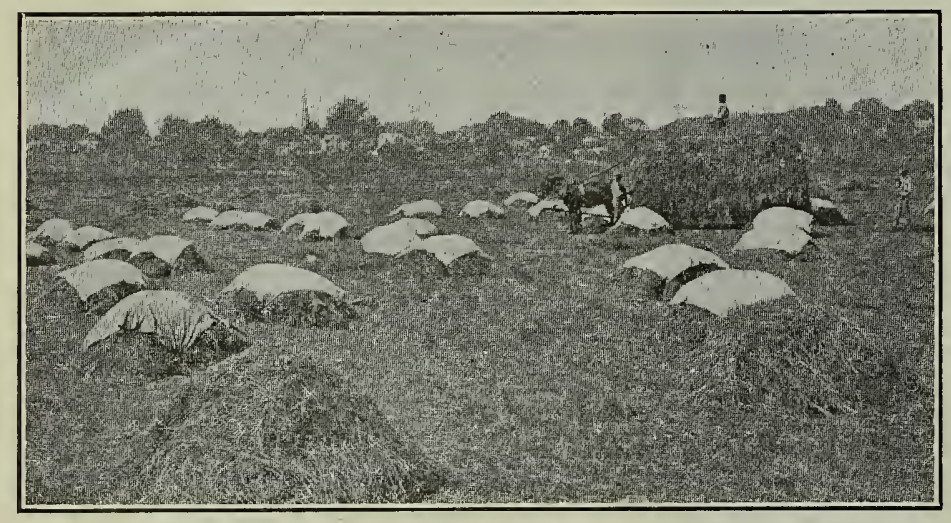

Curlng Lespedeza Hay

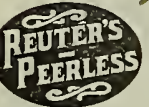

legume. A Southern Seed. Grows anywhere; is tenacious in any soll; lasts always; well known in the South. We recommend sowing a bushel to an
acre, broadcast. as soon as all danger of frost is past, about February or March, or it may be sown
in the fall. For pasture it is necessary only to scarify the surface of the ground with a disk harrow, and it will often grow well without any previous preparation of the soil. Old December and January before the seed is much sprouted.

It endures heat and drouth without injury, and stock eat it though on rich soils it becomes of upright growth, furnishing an abundance of hay and pasture. It is also a great plant for enriching solls, as it will grow on the poorest of soils, and great value for pasture comes largely from the fact that it comes late in the summer after other clovers and grasses are dried out. by frost. There is no question now but that Japan Clover is one the country are beginning to realize its value in building up old, worn-out soils. While it is a soil builder and renovator, its value finest quality of hay. When the soil becomes so poor as to refuse the quickest way to reclaim such soils is to grow Soy Beans and As stated, Japan Clover, unlike all other Clovers, seems not to have any choice of soils. It grows luxuriantly on wet, sour
soils, on sandy soils, on poor clay soils, on rich lime soils, and found growing in poor clay gutters.
Japan Clover and Bermuda grown together makes a fine pasture for our hot summers, resisting the hot dry weather and giving good grazing. when and where all other clovers and recleaned, perfectly cured and sound. Price, per lb. 20c; 10 lbs. $\$ 1.75$; pex bu. \$1.25; 100 lbs. \$16.00.

\section{YOU SHOULD PLANT LESPEDEZA}

In many parts of the South the farmers are on the verge of financial ruin-wrought by the boll-weevil, soil exhaustion, high money rates, and being forced to go West and North for their the one-crop farmer is beginning to look the facts straight in the face and realize that someThe farmers in the South cannot continue to farm the way they have been for the past twenty-five years. The big brutal
facts of to-day, in so far as farming is concerned, are that we are in a period of transition from the old, ruinous, single-crop system of farming to a better and more profitable system of diversification and stock raising. Many of us have not as yet realized that such a change is apparent but it is inevitable and must come. We must practice better methods of cultivation, raise several tion and scientific cropping grow plenty of grasses and clover tion and scientific cropping. grow plenty of grasses and clover crops, plenty or Corn, Oats, Barley. Wheat. Lespedeza, etc. The future of the South is in your hands. Will it be a barren field with an occasional crop of Cane, Cotton, Rice? No. It will be one of many silos, many big barns. plenty of cattle, hogs, cornfields, lespedeza, oats, good meadows and pastures. This change will not come all at once, but gradually we will arrive at the point when we must evade planting one crop, and practice intensified farming and live-stock raising. This will be the foundation of the wealth of the South, and will mean the upbuilding of a bigger, better, and more productive land, where the farmer other crowded Northern and Western States.

\section{MORE COWS $=$ MORE HOGS $=$ MORE SHEEP $==$ MORE HAY}

We have a natural live stock country. Our winters are usually very mild, our summers not affected by intense heat We can grow crops twelve months in the year, have pasture continuously. Our cattle will never want for feed. We will never have to buy corn or hay or oats to fill the bins. Our farms will produce all our cattle can consume and more. Our soils are rich or can be made

\section{PLANT LESPEDEZA=IT IS THE WEALTH PRODUCER OF THE SOUTH}

I have talked Lespedeza to nearly every farmer in my vicinity. But I never tire of pointing out its good features. It is THE clover for the South. Don't be misled. You cannot get anything ing than Lespedeza to plant in the spring. It is rapidly gainIt is popularity on merits, not being boosted and the price of seed inflated ties have been explointed to the farmers in this country. It is a safe, dependable crop. It can be relied upon to produce results. It will succeed when all other grasses and clovers fail. It will It will succeed when all other grasses and clovers fail. It will or drouth. It is a vigorous grower and is inclined to be of low or drouth. It is a vigorous grower and is inclined to be of low grow uprioht It will enrich the soil enrich your pocket enrich the community in which you live soll, enrich your pocket, enrich hard times. You will stop the drain upon your savings when you plant one bushel to the acre this spring, either upon your best or poorest land. It will yield from two to three tons of hay to the acre. It only requires re-seeding about once every three years. It has made good in every sense of the word, and I hope

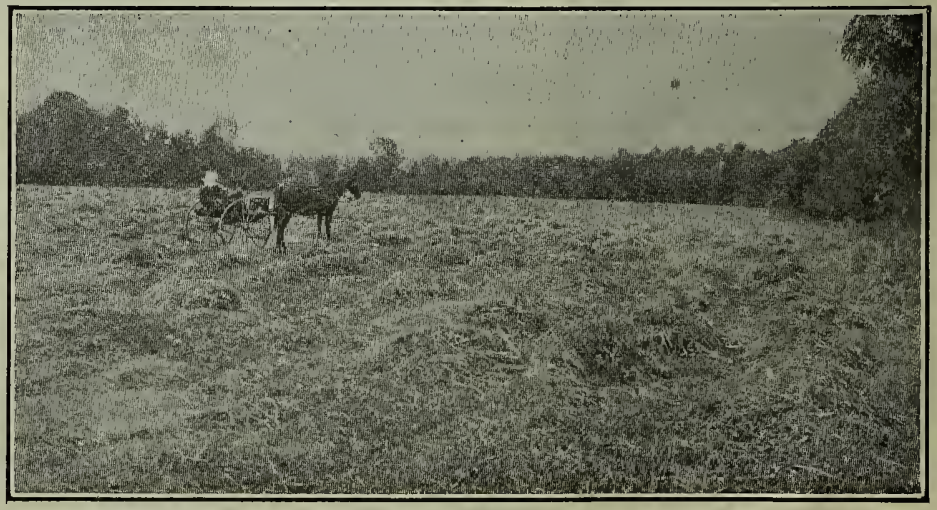


to live until I can see every farm in the South growing Lespedeza The hay is valuable and is eagerly sought by the best dealers in is greater than the supply. It is worth this year about twentyfive dollars per ton. Just think of it! Let us get ogether and endeavor to upbuild this grand

Sow one bushel to the acre, broadcast as soon as all danger of frost is over (February or March with us). You will then be started on the road to prosperity. I don't believe you know what Lespedeza means to the South. It is the surest crop I know of. It is profitable, easy to grow, does not cost much to sow an acre, is a great soil renovator, of great value as fertilizer, improving our poor lands and making our rich lands better. when you plant Lespedeza.

Cattle eat it greedily. Its high feeding value value. which approaches alfalfa, and its ability to thrive under all sorts of conditions. and thus to furnish pasturage in the summer and fall till killed by frosts are its strong features. It will stand any kind of grazing.

It reseeds itself so readily that it is rarely necessary to som it on pasture lands. This, however. is often desirable in a new pasture or in an old pasture where, for any reason. the plant does not occur. It occasionally happens that the Lespedeza seeds sprout unusually early, owing to favorable weather, and the plants are killed by late frosts. Such pastures may be reseeded simply by scattering the seed over the top of the sod, but with better results after scratching with a harrow. New pastures should be seeded early in the spring. preferably in February in our State, and later Northward. Seedings up to the middle of April in Louisiana have given satisfactory results. An excellent stand is frequently secured simply by spreading the manure from from one pasture to another when the seeds are ripe. Sometimes hay with ripe seeds is scattered over the high points of pastures in which Lespedeza is desired, the wind and rains spreading the seeds over much of the fields. The seed will live in the soil for at least one year. so that fairly good

\section{HOW AND WHEN TO PLANT LESPEDEZA}

Sow one bushel to the acre just as soon as all danger of frost is over, usually February or March with us in Louisiana. Sow it broadcast on growing grain. If sown on sod. I recommend first scarifying the land well with a disk harrow in order to give the seed a good seed bed. Old Lespedeza pastures may February before the seed is much sprouted.

\section{SOILS BEST SUITED TO LESPEDEZA}

The best crops are secured on good soils that have a considerable percent of fine silt. However, the plant will thrive on almost any kind of land. It likes a soil that affords plenty of moisture, but with good surface drainage. It does remarkably Well on the poorest kind of soils and continually improves these soils,

Bloat in animals from grazing on Lespedeza is unknown. The stems and leaves are succulent ilke Clover. Again, the growth comes on slowly in the spring. and the animals graze never known ill effects to follow. Like other clovers. however,

\section{LESPEDEZA, OR JAPAN CLOVER}

By W. R. Dodson, Dean and Director L. S. U. Experiment Station

Lespedeza is rapidly gaining headway as a commercial hay in the cotton producing states. It is gaining popularity on its merits, as there is no organization actively pushing its claims upon the hay consumer. The efforts that are being made to introduce it into new territory are not well organized and there is very little advertising being done. Where a good quality of Lespedeza has been the writer the writer goes, been pronounced an exceptionally good hay. Stock become fond it; there is is increasing in popularity with the producer because of the readiness with which it may be cured into good hay, the ease with which it can be perpetuated on the soil. and because it enriches the soil on which it

There are other good reasons why it commends itself to the producer. As the consuming public becomes better acquainted with its merits the price is bound to advance very materially. The chemical analyses show it to be of per cent of digestible nutrients than contained in any of the grass hays, like Timothy, which is so popular on the Southern market. Thile it is a clover plant, the stems are very slender, With many branches, so that it carries a high
per cent of leaves to stems. Good hay will carry from 40 to 50 per cent of the total weight in leaves and the fibrous stems are so fine that they are
entirely consumed by horses or cattie. Like the other clovers. it runs high in protein, being pronounced superior to any of the grass hays. If we adopt the usual rule of reducing the food elements to the pound basis for comparison, one hundred pounds of Timothy would carry sixty-six pounds of valauble food material, exclusive of the fiber, while one hundred pounds of Lespedeza would carry eighty-one pounds of valuable food material, exclusive of the fiber, An animal consuming one hundred pounds of Timothy would, according to average experiments, digest from this hundred pounds, thirty-nine pounds. or pounds, or the equivalent thereof, from one hundred pounds of Lespedeza. The Lespedeza, therefore, would contain about 38 per cent more digestible units than Timothy.

Comparing Timothy and Lespedeza as to their content of the four most would be were to sell at $\$ 16.20$ a ton, Timothy on the present market $\$ 16.20$ to ton. As a matter of fact. when Lespedeza brings a ton. Thent market, $\$ 16.20$ a ton, Timothy would ordinarily bring $\$ 20$ to $\$ 25$ acquainted with the merits of Lespedeza.

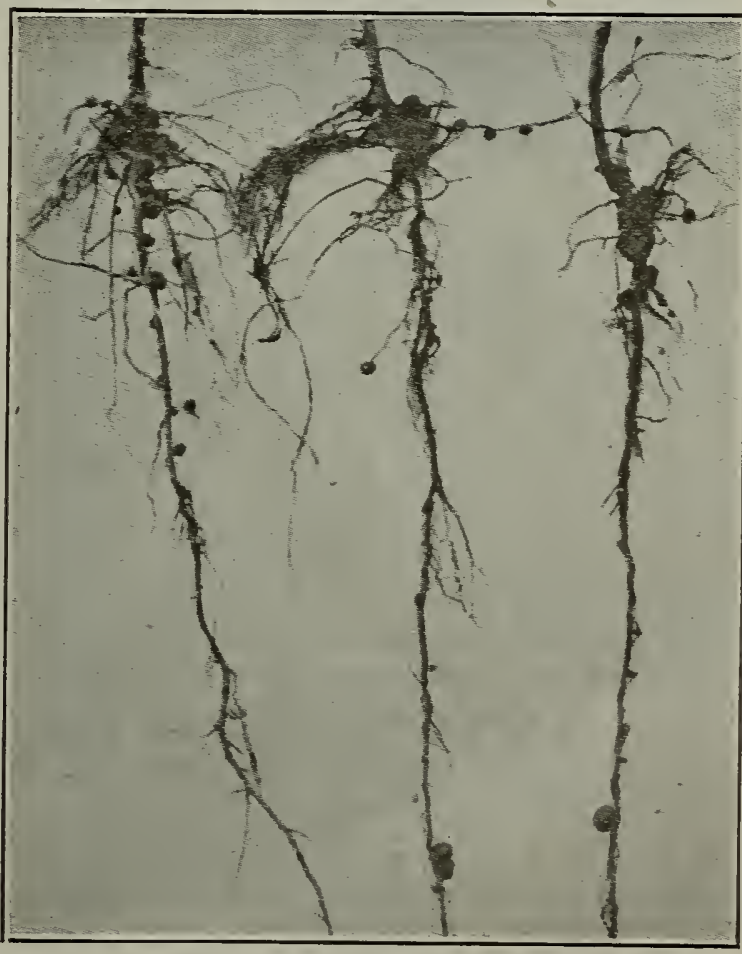

Lespedeza Roots Showing Tubercles 
Samples Will Be Gladly Furnished

\section{ALFALFA, or LUCERNE (Medicago Sativa)}

The King of all hay crops. A perennial, and where once set $:$ becomes established. With proper management, it will continue to grom and give remarkable returns for years. It has done more io develop this country than all the other riches of the land. Its use as a forage crop increases every ycar, and the crops of hay which it produces are adding immensely to the wealth of the country. produces heavy crops continuously for many years, and will pay more net profit than any other crop that can be produced with an equal outlay of money and labor.

Alfalfa will thrive on almost any soil but a wet one. It is the dry land forage plant. Its drouth and heat-resisting qualities
due to the tremendous development of jts roots. These have known to reach the almost impossible depth of 100 feet. These roots tap the water supply beyond the reach of other plants, and alfalfa will remain green when other plants dry up. The plant does not spread from the roots, but from the crown above the ground.

When the plants first appear above the ground they presen tiny appearance and make rather a feeble growth until the roots get
a good hold on the subsoil. Altitude does not seem to affect the growth wren other conditions are favorablc, for it thrives from sea

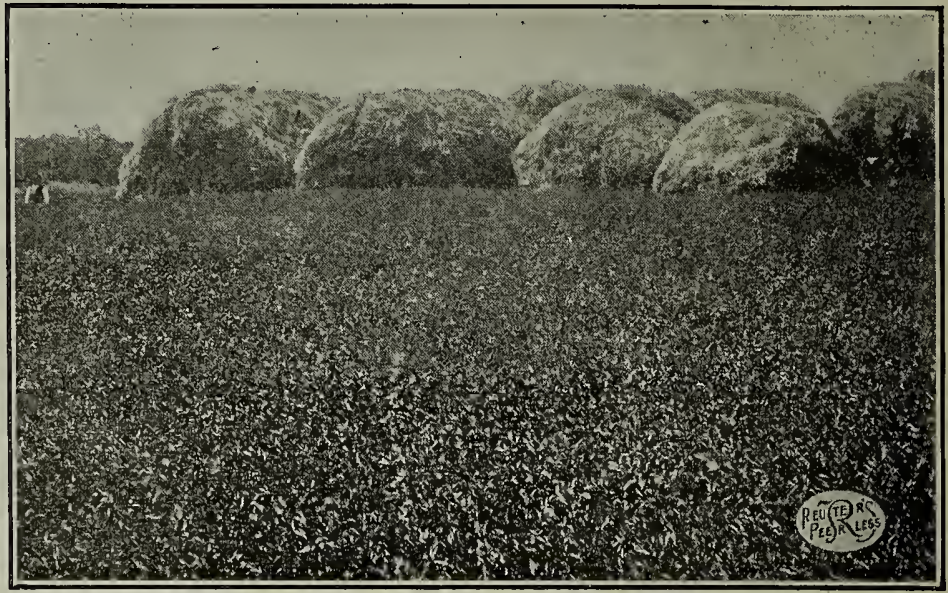

ALFALFA

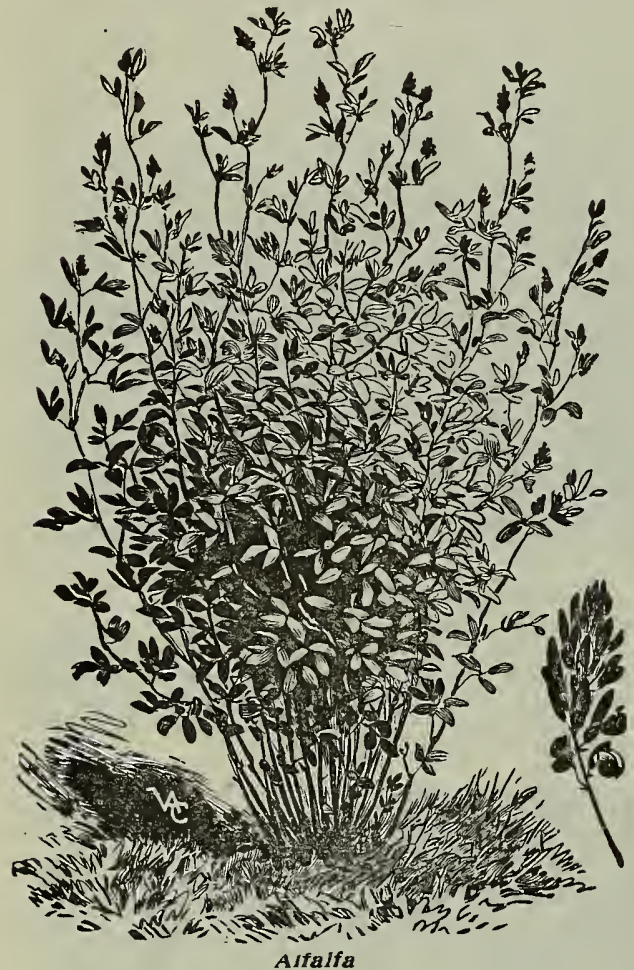

level up to 8,000 feet above the sea. Alfalfa will stand almost any amount of surface drouth, butthere must be underground water, a damp but porous soil, which the roots may reach. is after the rains have put the ground in condition and there is still time for a good sturdy growth before cold weather sets in. Fall months are the best to sow Alfalfa in the South, although it is planted almost the year round. The best time for fall seeding is after the rains have put the ground in good condition, and there is still time for a good sturdy growth before cold weather sets in. Well-established strong rooted Alfalfa will withstand the more vigorous climatic conditions, but very young plants may be seriously injured by a slight frost or killed by a severe freeze.

Tho soil should be made exceedingly firm before attempting to sow Alfalfa. Great care must be taken so as to plow and prepare the soils so as to prevent both washing from heavy rains, and to have the land so that no water will stand or remain for any time on the seed or young plants. Soils that have become. worn out, or exhausted by constant cultivation of crops must be fully reclaimed and a sufficient amount of plant food restored. In many Southern States, where the soil is well worn out by the continued cultivation of Cotton, such soils should have at least two crops of cow or stock peas grown on them before attempting to grow Alfalfa. Hence, it is important to have the soil thoroughly prepared, so as to secure a perfect stand at once, while the young plants are slow in their first or early growth; yet, When once they

(n) ber are the best months to sow in this State. There is, however, one difficulty, which is that it frequentIy happens in the South that the weather is dry in the fall and there is not enough moisture to cause the seeds to germinate. When this is the case, the next best time to sow will be in the spring commencing in February and ending in April. Sow twenty-five to thirty pounds of our New Re-cleaned Alfalfa Seed to the acre. The best seeder for sowing the seed is the wheelbarrow seeder, which distributes the seed evenly over tho surface.

Alfalfa should be cut when in full bloom and after the first year; cuttings may be made at intervals, according to the growth of the plant. As many as six cuttings have been made in one season. When curing the hay do not let it get wet, and do not handle which constitute the most valuable part of the hay. Don't be deceived by cheap prices on poor imported seed. Buy our high-grade Western Grown Seed. It is the best in the
world. Price, per lb. 30c; per bu. \$12.00; per 100 lbs. $\$ 18.00$.

RED CLOVER (Trifolium Pratense)

This variety of clover is more commonly known in this country than any other. It has been grown over a wide range of the United States from our earliest history of agriculture, and in recent years has invaded our Southern states with very good
results. It is grown alone for both hay and pasture, and in combination with other clovers and grasses. Fifteen to twenty pounds of seed will sow an acre. In my climate it is usually
sown in the fall and early spring. It is then either pasture or
cut for hay the following summer, then plowed up in the fall. cut for hay the following summer, then plowed up in the fall. the plant food had become exhausted then attempt to grow clover, by sowing on wheat or other grains in the fall, the results of soils, but does best on good, well-drained clay loam, in which lime is a prominent constituent.

Price, 1b. 30c; 10 lbs. $\$ 2.50 ;$ bu. (60 llos.) $\$ 12.00 ; 100$ lbs. $\$ 18.00$.

\section{WHITE DUTCH (Trifolium Repens}

This is a small, hardy, perennial spreading Clover. While it makes fine pasture, yet it is of to small growth to permit of its making hay. It is frequently sown with other clovers and grasses where a fine pasture is wanted. For mixing with lawn grass inches high and is hardy under all conditions. When sown alone use twelve to fifteen pounds per acre, but when sown with Price, per lb. 50c; per bu. $\$ 22.50$; per 100 lbs. $\$ \$ 35.00$
.

Price fluctuates; current quotations on request.

\section{ALSYKE CLOVER (Trifolium Hybridum)}

Comes from the little province of Alsike in Sweden. One of the hardiest varieties known. Under ordinary conditions it grows from one to two feet high. Very valuable for pasturage and soiling. When grown alone the treatment for Alsyke is the same as Red Clover. and the hay is similarly cured. It is one of
the best varieties to mix with Timothy. It will withstand almost any a mount of freezing, also a very good resister of drouth and wet alike. It is unequaled for growing on wet, marshy soils where no other variety of clovers will grow. Sow $10 \mathrm{lbs}$. to the Frice, per 1b. 35e; per bu. \$14.00; per 100 lbs. $\$ 22.00$.

\section{MAMMOTH, or SAPLING CLOVER (Trifolium Medium)}

Also called Pea.Vine or English Clover. Similar to Crimson Clover, ut of ranker growth and blossoms three weeks later. It will grow on many soils, where the small Red would prove a failure. It will grow on poor clay soils, on sandy soils, in the Cony words. and will grow farther south than will the June or under for soil improvement, the Mammoth is by far the best variety as it not only roots much deeper, making a wonderful root development, but its tap root acts as a sub-soiler. thus putting more organic matter in the soil than can be had from the June or many other clovers. $\$ 18.00$.

Price, per lb. 30c; 10 lbs. $\$ 2.50$; per bu. $\$ 12.00$; per 100 lbs.

Prices fluctuate; current quotations on request. 


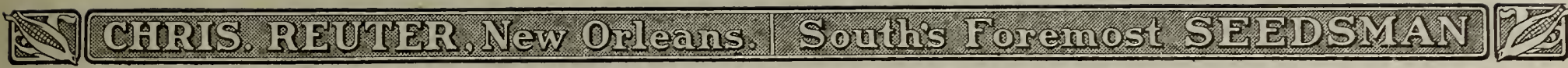

\section{Use My Free}

Service Bureau

BEST CLOVERS

Pay a Little More

And Get Quality

\section{SWEET CLOVER (Melilotus Alba)}

Can be planted in the fall and spring with good results in Texas, Louisiana, Alabama, Georgia, Mississippi and other Southern States. On the black prairie soils of Alabama and Mississippi spring seeding is the universal practice. Further North, fall seedings are popular. A good preparation of the land for seeding is to grow a crop of cow peas or soy beans during the previous summer. Before planting cow peas the ground should be plowed as deep as possible an water will stand, and so that a mowing machine can be run over it easily. As soon as the crop of cow peas and beans is gathered the ground should be disked and plowed very shallow adn then the ground should be dise is fine and mellow, after which the seed is sowed at the rate of twenty-five to thirty pounds to the acre and covered by rolling or light harrowing. Deep plowing just before seeding is never good practice, as it leaves the subsoil in such a loose condition that the plants are more easily thrown out of the ground by winter freezes and suffer more seriously in summer drouths. Heavy seedings are necessary in the South. One can not a few dollars in seed. As mentioned before, Sweet Clover resembles Alfalfa in appearance, habits of growth, and food content or nutritive value, which, together with their similarity in origin and history, as well as having on the roots the same species of nitrogengathering bacteria, would almost lead one to believe that Sweet one time the same parental species.

Sweet Clover is very hardy, makes a rank growth of stems, leaves and roots, but is not persistent, as it may be killed easily by mowing when in bloom. If allowed to mature, it will reseed itself abundantly, even when pastured, and continue like a perenIt thrives in a variety of soils, growing well in almost pure sand in silt, loam, and hard, rocky and decidedly poor clay soils devoid of humus. It also grows on hills, bottom lands, in well-drained and in wet soils, and in alkaline and non-alkaline soils. It adapts and in wet soils, and in alkaline and non-alkaline solls. It adapts and hard freezes of our Northern States and has been planted successfully in Canada. It does remarkably well in the South where Western plains where the drouth at times is severe. The long, deep taproot enables it to obtain moisture in times of drouth and pretaproot enables it to obtain moisture in times of

of three to four feet though a single plant growing by itself will have tri-foliate and three-lobed leaves, resembling Alfalfa. The second yave it tendency to branch out more. It bears a heavy growth of es up from the roots early in the spring, stooling out still heavier foliage of a rich green color, and attains a height of throws out a number of long lateral branches, and the main stems shoot up to a height of six to ten feet, and is from a quarter to a half-insh thick at the ground. The early yart of July, the plant reaches full bloom, has lost many of its leaves. and assumes Dods, and are borne on slender racemes three to four inches lon:

Horses, Cattle, Sheep, Hogs, and Poultry all feed upon and relish sweet Clover as they do Alfalfa, and it is found by analysis to contain about the same food elements. The high percentage of fat it contains makes it an ideal forage for milk production and for fattening animals.

The second season it yields about three cuttings of one to two tons each. One cutting can only be obtained the first season.
If your ground is poor plant Sweet Clover. It will grow on a ny land. Resembles Lespedeza in this. respect, also in its resistance of drouth. 10 lbs. \$2.25; bu. \$12.00; 100 1bs. \$18.00. (Both hulled and unhulled seed. Specify when ordering.)

\section{BURR CLOVER (Medicago Maculata)}

A clover that has won itself favor with the leading farmers in Alabama, Georgia, Texas, Louisiana, and Mississippi. The demand the past year has been tremendous, and I was not able to fill my orders. It is an annual, producing a plant of rather creeping instead of upright growth. It makes both hay and pasture, and its greatset value is as a winter and early spring pasture. Its growth
is very good, even on the poorest kind of land. It can be planted with perfect safety, as it can be easily eradicated. It is a leguminous crop, gathering nitrogen from the air and, after furnishing winter grazing, leaves the soil in better condition for succeeding crops.

Burr Cloyer Seed is produced in small prickly pods wound up spirally into a ball. The Southern Grown Seed is always sold and the Southern Grown Seed will produce a crop more hardy than require inoculation, whereas the California Hulled Seed does,

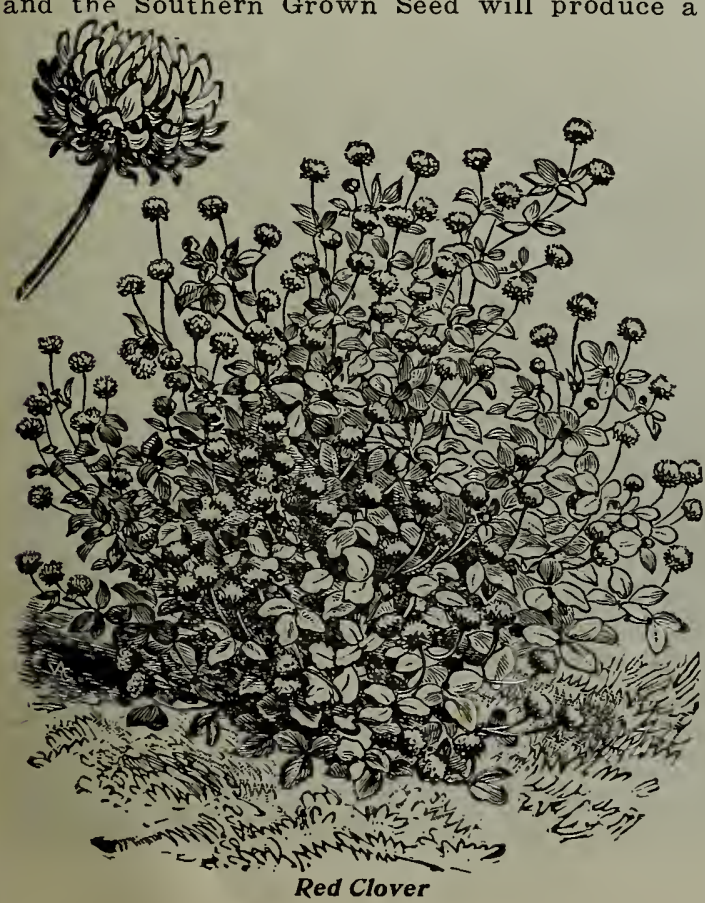
acre, and about fifteen pounds of the cleaned seed. I can supply you with both plant the Hulled Seed, don't fail to order some Farmogerm to inoculate. It is not necessary to inoculate the Unhulled Seed, as the lurrs carry the nitrogen bacteria. Sow in the fall or spring. It is a good plan to sow it on Bermuda sod in septemclover will grow right with the Bermuda, so that the combination will furnish excellent pasture both winter and summer. The clover in the winter and the Bermuda in the summer. Once established, it reseeds itself, and improves in Srowth and appearance each, succeeding year. I am entirely sold out of the

shipment then at the following prices:
Price, lb. 20c; bu. (10 lbs.) $\$ 2.00 ; 1001 b$ s. $\$ 18.00$ $\$ 18.00$.

Callfornia Recleaned Seed, $1 \mathrm{~b}$. 30c; $10 \mathrm{lbs}$. \$2.50; bu. (60 lbs.) $\$ 12.00 ; 100$ lbs.

\section{CRIMSON CLOVER (Trifolium Incarnatum)}

This is a variety of clover that has attracted a great deal of attention in the cotton region for the past few years, but the position which it will finally hold is still uncertain. It does remarkably well in Louisiana, Mississippi, and other ofthern States. It $\mathbf{s}$ an annual which begins its growth with the autumn rains, On favorable soils it reseeds itself, even though the ground be plowed and used in Crimson Clover. Its value is tremendous, being the best early forage and soilimproving crop I know of. Plant during August, September, October, and November at the rate of fifteen to twenty pounds to the acre. It is very desirable to results. It thrives best on just after a good rain as otherwise a poor patch often results. It thrives best on loose, sandy soils, and does not make a satisfactory
growth on stiff or wet, or poorly drained clays. It does well on poor lands, and in
this respect is better than Red Clover, adding mcre fertility to the soil than any other Clover. It is very valuable to grow with other crops, and is often combined Sowing may be made in both corn and cotton fields. It is not hardy for more than one failures are doubtless to be attributed to a lack of the proper bacteria.

Price, 1b. 20c; 10 lbs. \$1.75; bu. \$6.00; 100 1bs. \$9.00. 


\section{TWO VALUABLE NEW AND DISTINCT GRASSES}

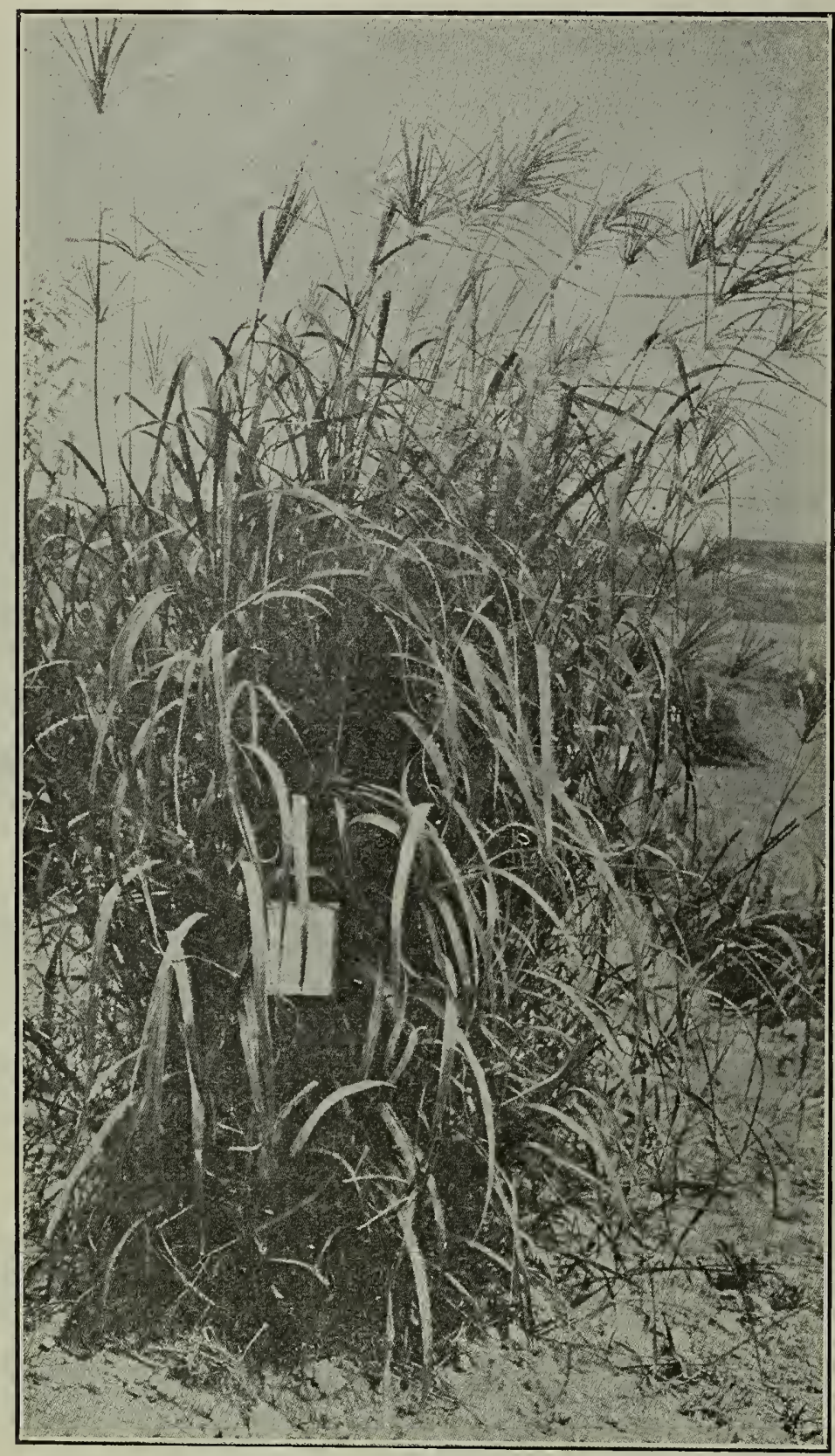

RH DFS GRASS

\section{SUDAN GRASS}

Sudan Grass not only grows luxuriantly in the South, but it has proved to be a very profitable and successful forage crop. Like Rhodes, it was also introduced from Africa, where apparently they are native, and, while there is no positive proof that this is the case, the evidence is quite convincing, as they do not seem to be found growing naturally in any other part of the world. It will make three to four cuttings each year and when cut before the seed gets ripe it makes a fine hay and is liked by all stock. It is easily cured and easily handled as hay and is very drouth resistant. It is an annual. It is unquestion ably better adapted to the South than any other section of this country. It has been grown in Texas within the past few years very successfully and the reports are very optimistic well when mixed with cow peas and soy beans. It should be planted in the spring. at the end of February. or the end of March for best results, but can be planted most any time in the growing months. It should be planted in rows twenty to twenty four inches apart. The best tool for planting on a small scale is a garden drill with which it can be done very accurately. Three to five pounds of seed will plant an acre. It can also be sown broadcast when it will take about seven to ten pounds. It will yield as much tonnage, however, when planted in rows, as it can then be cultivated, and it responds to cultivation as well as do other plants, for it is given plenty of room to stool. It is far ahead of sorghums, having more feeding value, can be cured in less than half the time, is much easier to handle and bale,

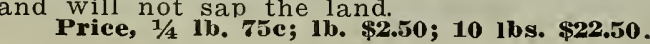

\section{RHODES GRASS}

Rhodes Grass is a native of Central and South Africa where it is regarded as one of the best species for pastures on dry soil. It is a perennial, growing from three to four feet high, with large numbers of very long, narrow and tender leaves, and with rather a few branching seed spikes or slender branching stems. It is a species that does not spread by underground root-stocks, but produces running branches which root at the joints or nodes, thereby producing new plants. The runners are not so abundant when the grass is growing thickly, and therefore does not materially interfere with the machinery at the time of harvesting the hay crop. To be a vely valuable hay grass a variety must possess certain important characteristics. It must be aggressive, or at least able to maintain itself for a considerable length of time against weeds and other enemies; it must furnish a profitable yield; it must be palatable and nutritiqus, and possess a good color and general appearance, either loose or in the bale, when cured; and it must have reasonably good seed habits. Rhodes Grass has all of these qualities and besides it seems to be able to grow on poor soil and is fairly drouth resistant. Its inability to stand cold weather will limit its acreage to the Southern States, as the climatic conditions in our Northern territories do not agree with it.

When grown from seeds its growth is commonly erect the first season, but when grown from roots, or the second season when grown from seed, it makes runner-like branches from 2 to 4 feet long. which root at the joints and so cover the ground quite rapidly.

It is propagated by both seeds and roots, as above described. I think it advisable that you sow the seed, planting during the spring at the rate of 10 pounds to the acre. Sow about cornplanting time, when the weather is not too severe Have a soil that has a fine mellow surface, and then give a light harrowing. As the seed is produced only in small quantities and as it continues to be developed and matured through the entire season, scarce. The seed is planted in Louisiana and other Southern States from February until June with excellent results. While the principal value of Rhodes Grass is for grazing, it is also used hay ging two to three cuttınos of about one ton each to the acre, and the hay is of excellent quality. It bears severe drouth and moderate frost without injury, but is easily killed by plowing late in the season. Thus it is not a pest, but a most Welcome acquisition to my big list of high-grade grasses. Six first made in May, the second in July, and the third in September. At the present market price of hay in the South, it can be easily seen that such vields are very profitable.

Price, 1/4 1b. 40e; 1b. \$1.25; 10 1bs. \$10.00.

Order early as the supply is limited.

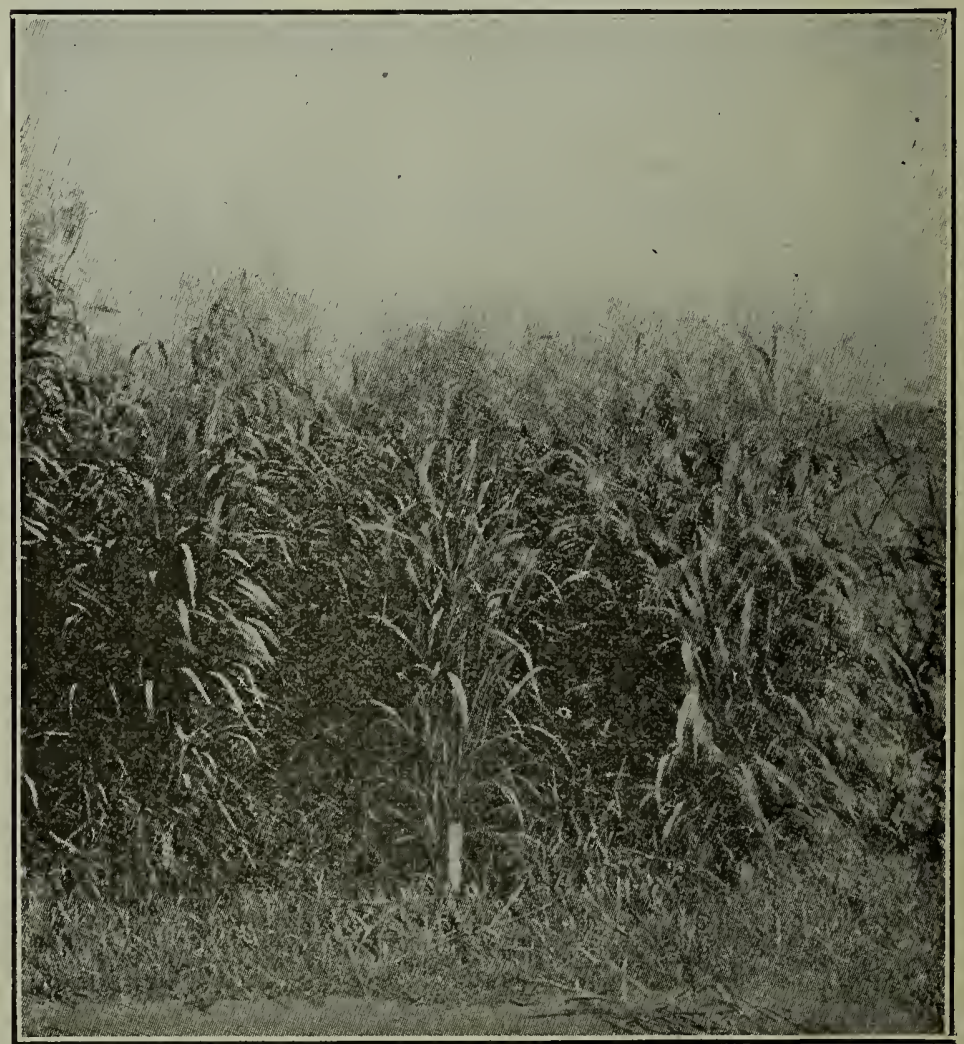




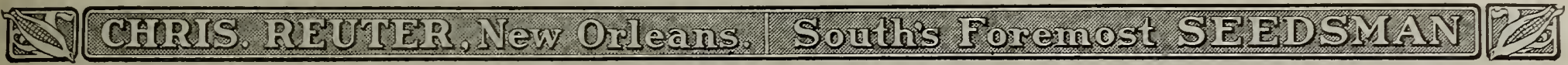

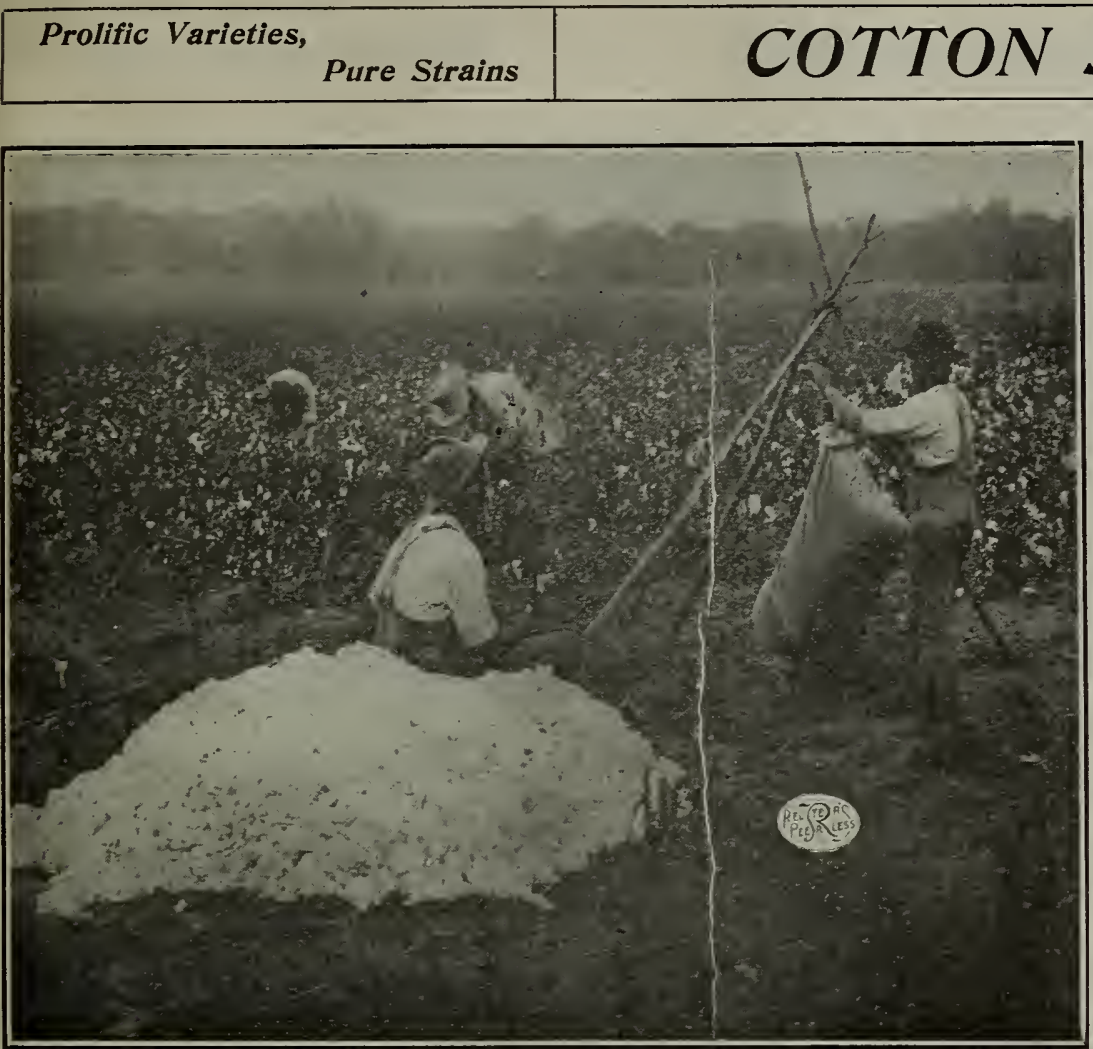

Picking Hawkins' Extra?Early=Prolific Cotton=

Write for prices carload lots

F. O. B. my Growers' Stations

You've heard a lot about cotton seed and about varieties that can withstand the boll-weevil and evade every other known disease. You, no doubt, have read seed catalogues and publications; they say lots more than truth about the cottonseed industry. I am not going to write up twenty-five pages on cotton seed in an endeavor to put you all up in the air about the kind you ought to plant, but I'mention a few good standard sorts that are trustworthy, and absolutely dependable. I don't grow any cotton seed. I don't claim to have several thousand acres in cotton but I have grown for me in North Carolina the finest types procurable. Seed from this state is always earlier to mature in our climate, and it has been proved that the early varieties are the kind that evade the bollweevil. Furthermore, I don't claim to know all about cotton. No man or collection of men to-day can truthfully say that they are familiar with every detail of the cotton If you are interested in large quantities, write me for quotations F.O.B. your point, or F.O.B. grower's station. I uotation Pequest Sheet at once, and let me figure with Qun. Then, send me your order. I know the price won't best.

\section{REUTER'S RE=IMPROVED EARLY KING COTTON SEED}

Get ahead of the boll-weevil this year and plant this variety. Don't think that it is impossible to grow cotton infested with this pesky little insect are now producing lots of good cotton. - lit under contract by the best and only expert cotton breeder of this variety in North Carolina-the country where it to the highest standard of perfection for more than forty to the

I really consider myself fortunate to be able to contract for all the sears. this breeder can supply, having sufficient proof of the quality and merit of this seed as the very best producing variety under all favorable and unfavorable conditions. It is, without a doubt, the most effective resisting boll-weevil variety I know of, and in fact a resister of all insects, bad stands and shedding.

RE-IMPROVED-Double limbed and bolled, the last and best results ever obtained from scientific cotton breeding after so many years of careful cotton breeding, producing marvelous results and yields.

It grows, fruits, and matures in almost lightning rapidity-takes on fruit sufficient in thirty days' fruiting time to make a bale of cotton, and has produced 1560 pounds. of lint cotton in a season on one acre. If you are discouraged about planting cotton. change your seed, and sow this stock. My seed is grown
Carolina Seed. You cannot buy better seed anywhere.

Price, peck 75c; bu. \$2.00; sack (3 1-3 bu.) \$5.00; ton \$90.00. Write for prices on carload lots F.O.B. New Orleans or shipping station.

\section{SIMPKINS' PROLIFIC COTTON}

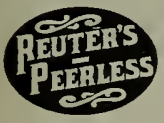

\section{The Boll-Weevil Deceiver. Strictly North} Carolina Seed. Eighty days from planting to boll. This Cotton has become well known throughout the South, and an exte!nded description is unnecessary. Don't put faith in the get-rich-quick seedsmen. Stick to the old reliable sorts that have proved to be reliable and trustworthy. Every year there are hundreds of new sorts pussed to the front 等 acknowledged to be the hardiest, most uniform in maturity and earliest of all varieties, with the possible exception of my Re-Improved Early King. Simpkins has produced as much as three bales to the acre, averaging 40 per cent lint, and in tests made at the Arkansas Experime

Price, per bu. \$1.75; in 5 bu. lots and over, \$1.50 per bu,

Write for carload prices F.O.B. New Orleans, your sta: tion, or North Carolina shipping point.

\section{HA WKINS' EXTRA EARLY PROLIFIC}

My seed comes direct from the originator, Mr. Hawkins, in Georgia. Why plant scrub seed when you can take the best cotton in the world, such as Hawkins' Extra Farly Prolific seed at a small cost per acre and can more than double system and make more in farming by planting this wonderful cotton. This is the earliest, most prolific, easiest picked, and most superior lint, and finest staple; tall grower, picked, and most superior lint, and finest staple; tall grower, near the surface, branching; two short limbs, together all the way up to the top, all literally covered with bolls; light foliage; large boll, small seed, light gray or dark green, yielding 38 to 40 per cent lint; opens well, growing much taller than other varieties, giving every advantage over other varieties in yield per acre. On the short fruiting limbs of the Hawkins Cotton, near the bottom and the middle of the stalks. will be found growing two bolls or ten bolls can be covered with the span of the hand on the same limb, and is called by many cotton growers a DOUBLE-JOINTED COTTON, and is well adapted to all kinds of soil. With judicious mantring, quick and rapid culture up to fruiting time, cotton will grow three bales to ceived the first prize at the Georgia State Fair. Every sack of this seed bears the brand of the originatur, and none is genuine without. Your order is shipped direct from his station. Mr. Hawkins is the originator and grower. Write for prices on large quantities.

Price, peck 60e; bu. $\$ 1.75 ; 5 \mathrm{bu}$. or more at $\$ 1.60$ per bu.

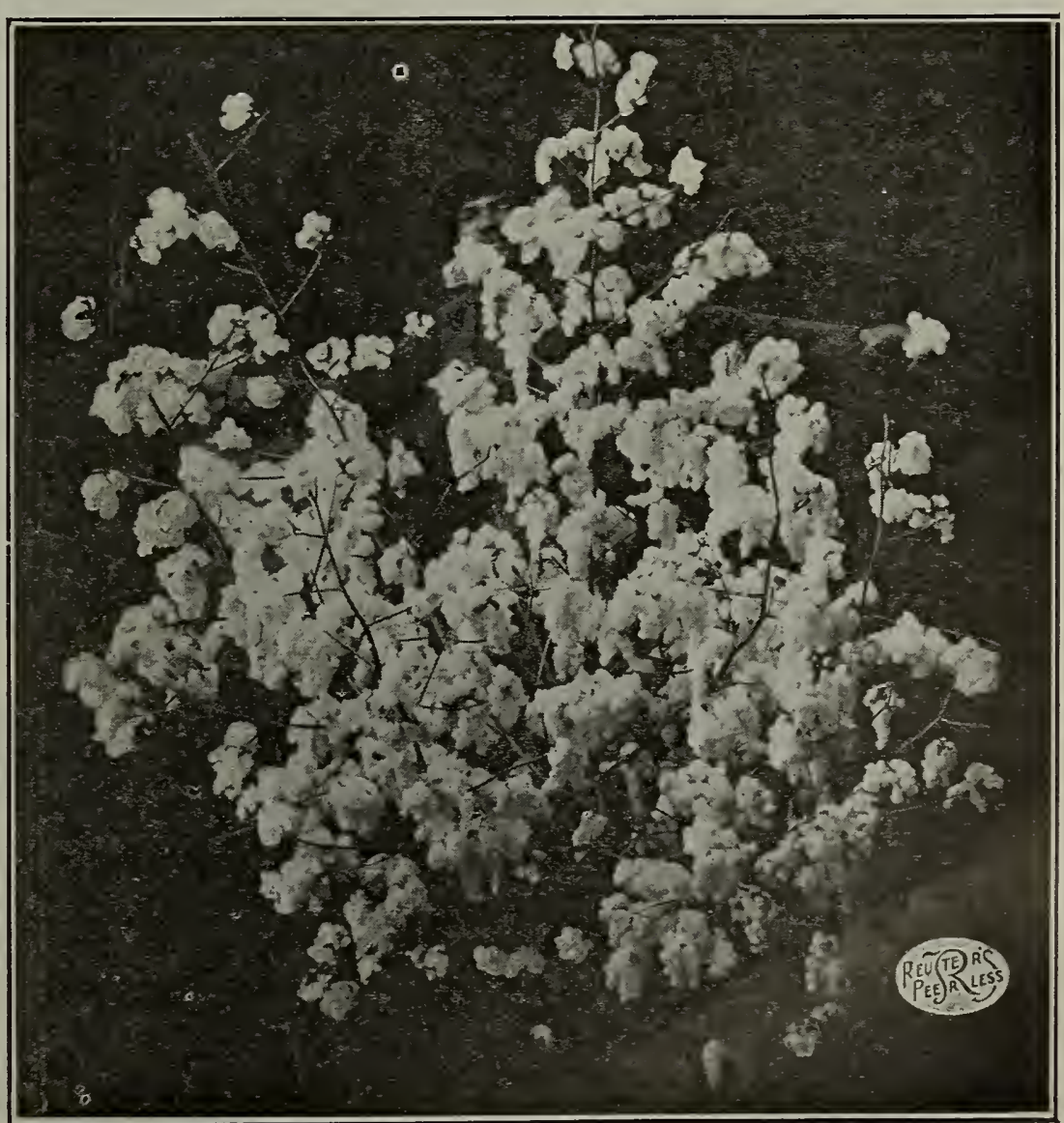

SIMPKIN'S PROLIFIC COTTON 


\section{MITCHELL'S RE=IMPROVED EARLY KING COTTON}

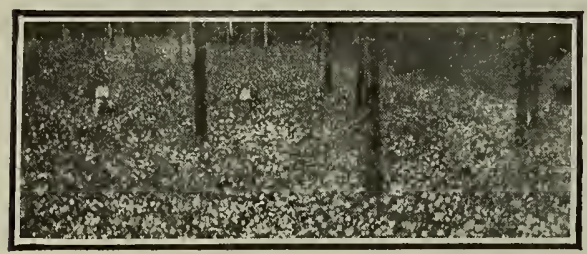

\section{BALES FROM 80 ACRES}

875 Pounds of lint cotton from best acre was the yield of field shown here, crop planted in boll-weevil territory. Mitchell's Re-Improved Early King Cotton Seed planted in this crop. Mitchell's Re-Improved Early King Cotton Seed (North Carolina grown and Improved) Defies Insects, Boll-Weevil, Frost! It successfully combats pests and unfavorable seasons. It has the greatest known power of earliness, proflicacy, large yield of lint. It laughs at frost and whips the boll-weevil and all other acre in the first thirty days of fruiting time. Under favorable conditions it has produced $\mathbf{1 , 6 4 0}$ pounds of lint cotton on one acre. Under the most favorable conditions proved Early King Cotton Seed is broad double limbed, double bolled, and a mass of squares, and some to spare, matures first bloom in 60 days, full grown bolls in 90 days, first picking in 120 days. The early maturing variety has solved the boll-weevil problem. Mitchell's Cotton, planted in June, 1912, on overflow land actually showed open bolls 90 days from date. Think of this marvelous record.

No more danger from Boll-Weevil, Mitehell's Re-Improved Early King Cotton seed too early and too prolific for them. Small boll, short staple, very early, very prolific-"the safe, sure, sane" variety for

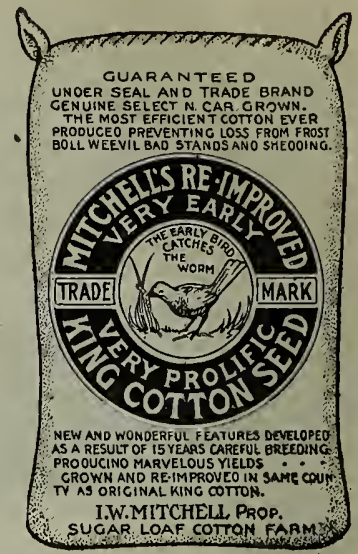
boll-weevil territory.

\section{NOW, MR. COTTON GROWER!}

Cotton can be made successfully and profitably with Mitchell's Re-Improved Early King Seed-this "in spite of the boll weevil"-but let me urge you "to live at home," have your ow n spring and fall vegetable garden, raise your own corn, "oats, hay, and other feedsturfs-make your own meal and meat-raise a surplus of cattle and hogs to sell to local butchers or forcotton crop, thereby making yourself independent of the Cott on Bears. When your cotton is ready for market, if you are not satisfied with the then ruling quotation, then you are independent. Haul your cotton home, or store same in some public warehouse; take your receipt to your local bank and borrow, if necessary. three-quarters of the value of your cotton. This general independent holding movement will certainly "bull the market." You then can sell when the price of the staple advances of your idea of value.

EVERY SACK OF MITCHELLS RE-IMPROVED EARLY KING COTTON SEED WILL BE PUT UP IN SACKS (3 1-3 bUShEls, 100 lbS.) BRANDED WITH MITCHELL'S SPECIAL TRADE MARK. Every package sealed as a guarantee to you that they are genuine Mitchell's Re-Improved Seed, grown under his personal care and supervision. See that every sack has this TRADE RE-IMPROVED EARLY KING COTTON SEED.

\section{THE SUPPLY IS LIMITED!}

I urge you to place your order with me as early as possible, as the indications point to a short crop in North Carolina grown Mitchell's Re-Improved Early King Cotton Seed this season.

It is the earliest, most prolific, most perfect bred, and has largest yield of lint cctton on record in the Cotton Belt. It has held the record as the best boll-weevil dodger cotton yet ever produced and will so long as time lasts, on account of the advantage it has in earliness and prolificacy and its long continuance breeding and selection for improvement. For more than forty years it has, year by year, been bred up to the very highest standard of perfection and my grower has installed the most improved machinery known to science to gin this cotton and produce the highest quality of seed free of dirt, trash, and faulty seed. REMHMBER and a prolific boll maker cannot produce a paving crop in boll-weevil districts, because the only practical and ertain way to fight the boll-weevil is to plant a hardy, prolific and quick maturing strain and rush it through to picking before many generations of bollweevil have had time to come forth. Such a Cotton is MITCHELL'S RE-IMPROVED EARLY KING COTTON. IT MAKES A GOOD
CROP OF ICOTTON IN SPITE OF ALL THE BOLL WEEVILS.

Write for prices on large quantities F.O.B. your station, or my grower's shipping point.

Price, bu. $\$ 1.75 ; 5$ bu. or more at $\$ 1.50$ per hu.; $\$ 90.00$ per ton.

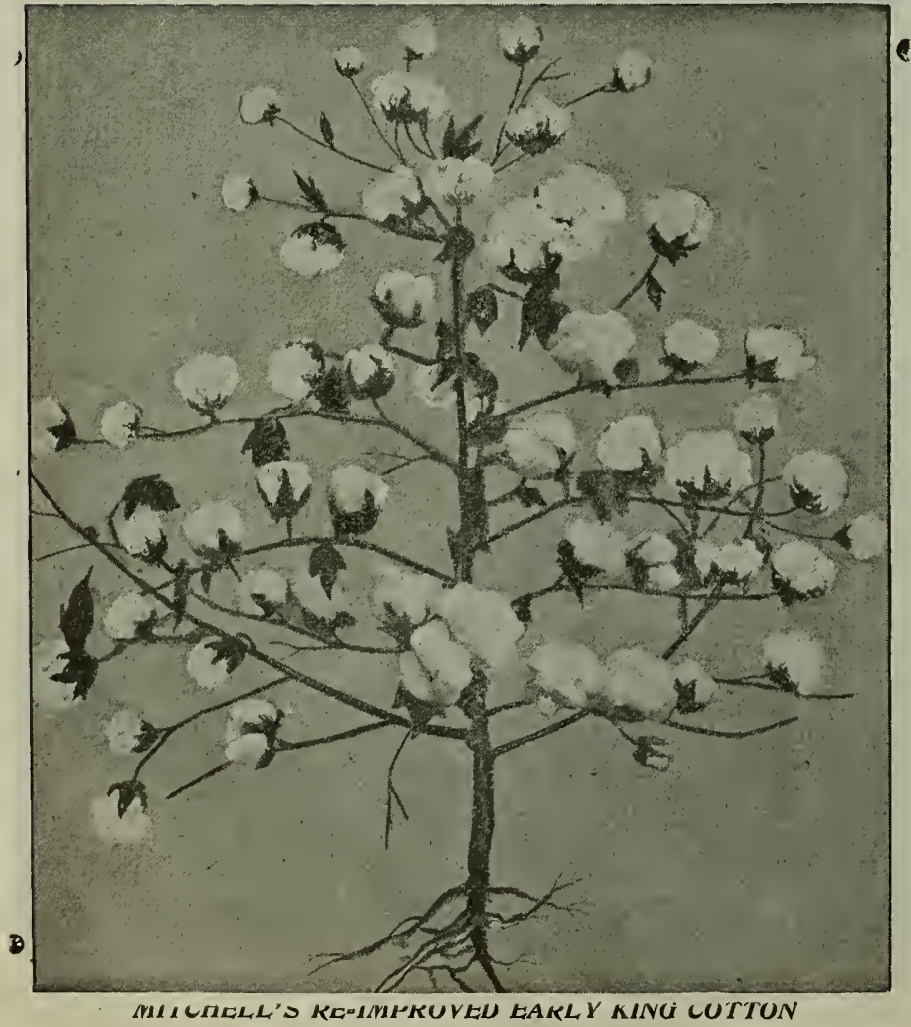

\section{CLEVELAND BIG BOLL PROLIFIC}

Since its introduction this cotton has been very generally grown throughout the Cotton States, and has unquestionably put itself in first place with many or our most progressive cotton planters. It has large bolls
and good fiber, which measure often from 1 inch to
1 1-16 inches. Very early in maturity, about forty per $11-16$ inches. 'Very early in maturity, about forty per cent lint; carries less foliage than most other varieties. It does remarkalily, well in Louisiana, Mississippi, and other southern States. It is practically free from anthracnose, suffering less than most big bolls. The stalks are branching in growth, with five or six primary limbs; the first limbs are long and begin near the ground, an essential feature in early cotton. 1,350 pounds per acre has been gath

Price, peck 60c; bu. $\$ 1.75$; 5 bu. or more at $\$ 1.60$ per bu.

Write for prices on large quantities, either F.O.B. your station or F.O.B. my grower's shipping point.

\section{MEBANE TRIUMPH BIG BOLL}

Does very well in the boll-weevil countries, and is
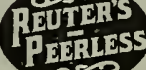

(1)

seed is

Price, peck 60e; bu. $\$ 1.75 ;$ bu. or more at $\$ 1.60$ per bu.

Write for prices on larger quantities F.O.B. your station or F.O.B my grower's shipping point.

\section{SEA ISLAND COTTON}

Extra long staple; line $1 \frac{5}{8}$ to 2 inches. Seed black and lintless. Plant one-half bushel to the acre in rows-5 feet rows, 3 feet drill. This famous Cotton is well known all over the coast countries. Tall bush; yield about 30 pounds lint for 100 ibs. seed. This lint usually brings about three times as much as the short staple.

Price, peck $\$ 1.00$; bu. $\$ 3.25$ (40 lbs.). 


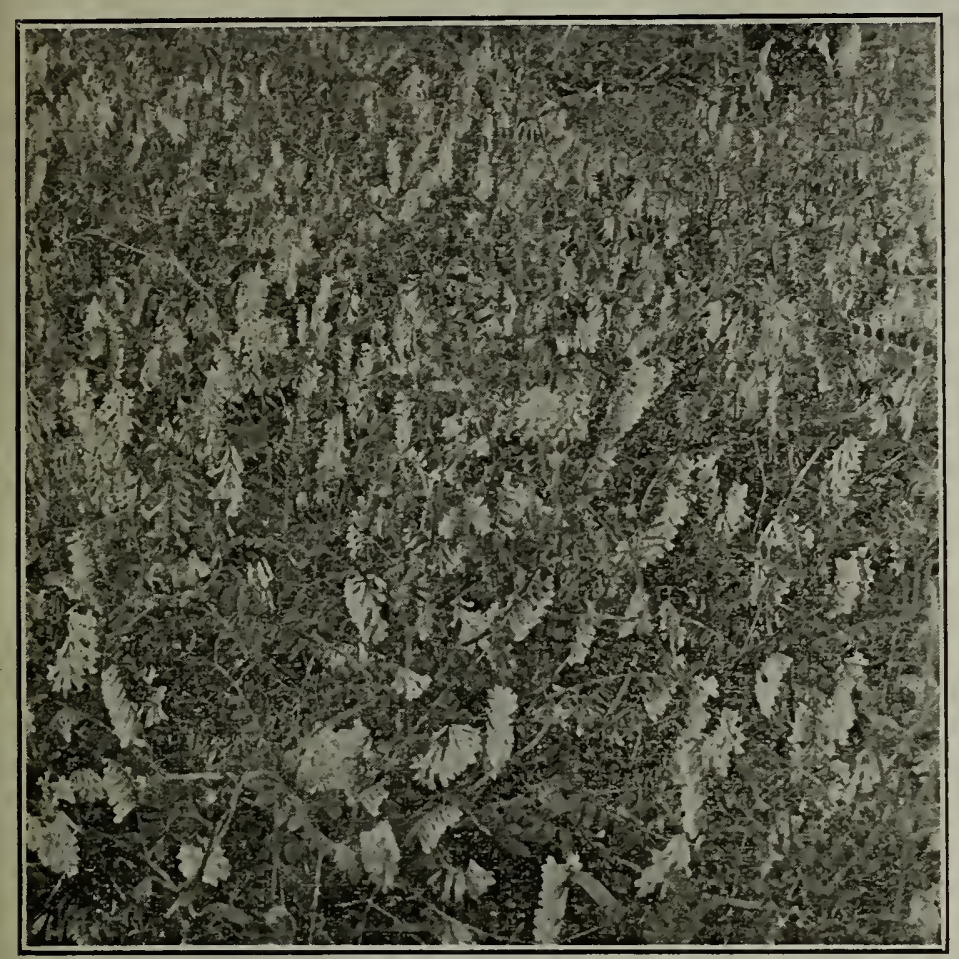

HAIRV, or WINTER VETCH (Vicia Villosa)

Makes one of the largest yielding and most nutritious ha
crops. peas in its nitrogen gathering properties.

it certainly deserves more attention than has been given to it during the past few years. Last year the demand was tremendous, owing to the favorable results obtained and the praise South. Recent tests on my own farms convince me that a planter makes no mistake in selecting this valuable forage crop, and eventually
the North.

Don't be afraid to sow plenty of Hairy Vetch. No matter if you have never grown it before, sow a few acres in it this of your ground this coming planting time in this thoroughly tried out and proved soil-improving crop. It has proved to proClover, Burr Clover. Vetch is high in protein content, is a good hay, pasture and valuable soiling crop. and its more general and remove much of the existing necessity for buying hay from the North. Vetch as a cover crop cannot be excelled Like all legumes, it improves the land by adding nitrogen and organic matter to the soil. As it grows through the winter and spring and may be harvested in time to plant corn cow peas and sometimes cotton on the same land, it should be used in building up impoverished soils and in maintaining the productivity of the up impoverished soils and in maintaining the productivity of the time, when this is needed for the cow pea crop, except possibly at the harvest time of the cow pea hay. fact that, like other legumes, it is able to use the free nitrogen of the air through the aid of bacteria which live in the ondules on roots. When plowed under, the plants decay quickly. A ton the roots and stubble, including the nodules, contain approxiAugust, September and October. The earlier the start the better for winter grazing. It has been sown as late as December in Louisiana with excellent results. if the etch gets well started and is inoculated, there is little danger from any hot or dry weather firmly rooted before cold weather sets in. Late fall-planted Vetch sometimes suffers from dry weather in the spring much more than the earlier fall-planted and better rooted Vetch. Use one bushel to the acre when sown alone in drills, and about one and Vetch with Wheat, Rye, or Oats, use only about thirty pounds. The yield of forage varies from ten to fifteen tons per acre, equal Price, lb. 20c; 10 lbs. \$1.75; bu. (60 lbs.) $\$ 7.50 ; 100$ 1s. \$14.00.
to three to four tons of dry hay. On land that has never gro

\section{GIANT BEGGAR WEED}

This is a valuable forage plant and a wonderful restorer of the land, far more valuable as a fertilizer than either Peas or Clover, and superior to either for forage in many sections of the South. Once established it comes up annually without any further attention. It interferes with no crop you may want to plant, be ing easily kept under by cultivation, and it can be totally eradicated from the soil by two years' successive pasturing. This fea ture, too, adds to its great value for some very valuable forage plants, such as Johnson Grass, Bermuda, etc., become the worst of pests when you wish to devote the land on which they are established to the cultivation of other crops. This plant is a rank feeder-with deep feeding roots-and brings up from the subsoil the dormant fertilizing elements deposited there for years, and leaves them on the surface. If your ground is too poor to grow anything worth while, sow Beggar weed. For forage it is equal to any good hay plant, although not sufficiently bulky for use alone in filling a silo. Its greatest value, however, is as ish it and make rapid gains in flesh while pasturing on it worn-out horses and mules when turned into beggar weed pastures will get sleek and fat without further attention. You make no mistake when you plant a few acres in Giant Beggar Weed. The seeds are light and small. Sow about ten pounds broadcast on land in the same manner as you would Oats, and plow under in like manner. Plant in June. It grows four to eight feet high, very erect. Yields from one to two tons to the acre.

Price, 1b. 80c; 10 lbs. \$7.00; 100 lbs. \$65.00.

\section{OREGON, or SPRING VETCH (Vicia Sativa)}

One of our best leguminous soil enriching crops. Planted both in fall or spring. Is very much like the Hairy Vetch in growth and habit, and is used for the same purpose. It is not quite as hardy as the other sort. It grows three to five feet; and in the early spring is turned under. We usually sow two busliels to the cre.

Price, 1b: 15e; 10 1bs. $\$ 1.00 ;$ bu. $\$ 4.00 ; 100$ lbs. $\$ 8.00$.

\section{BUCKWHEAT}

A desirable and profitable crop for spring sowing. It is easily grown, makes a splendid flower food for bees, and a large yield of grain. It is prized as a poultry feed, being regarded as to hogs and other stock. It is also an excellent fertilizer and soil improver. Should be turned under like Cow Peas. Plant one bushel to the acre.

Japanese. This variety yields very largely and is earlier than the common sorts. Grain large. Plants a

Price, 1b. 10c; 10 lbs. 75e; bu. $\$ 2.25 ; 100$ lbs. $\$ 4.00$ MAMMOTH RUSSIAN SUNFLOWER

Produces enormous heads, measuring 15 to 20 inches in diameter. Seeds are highly valued by farmers and poultry breeders who have tried it as an excellent and cheap food for fowls. For poultry it is the best egg producing grain known. It can be raised cheaper than corn. and is destined to be an article of great piece of ground during the early spring up to the middle of July.

Price, 1b. 10c: 10 1bs. 90e; 100 lbs. 87.50 .

\section{LET'S NOT SAY GOODBYE!}

These lines are intended as a personal message to you if you are one of my friends wlio plant my seeds. First, I wish you personally to accept my sincere thanks for your past patronage and other favors you have shown me. Second, permit me to extend you my earnest and best wishes for a good, big, healthy, profitable crop this spring-the kind that will help pile up your bank account.

The Seed business is done on confidence. Almost every kind of seed I sell is based on confidence. You must have some way of being morally certain that I am giving you a dollar's worth of seed for every dollar you send me. You must take my word for it. though, before you even knew what kind of seed I sell you. You must believe in me all the time. You cannot help yourself. It is planter have confidence in the man who sells him his seeds. You cannot afford to plant the seed yourself one year in order to see if planter have confidence in the man who sells him his seeds.

My guarantee is squarely back of every package of seed I sell. I will not knowingly sell you any seed otherwise than what I tell you. My customers are my friends and my seeds are trustworthy, because I keep them reliable, as $I$ know what they are from the time they are planted for the seed until they produce the seed which I sell to you.

When you buy from me you have the confidence that you are protected by my knowledge and my guarantee. You have faith in my seeds because you know that more than 50,000 critical Southern Gardeners plant them year in and year out. believe in me. I want you to know that I am telling you the truth. I want you to realize that while $I$ am trying to malse a living selling you dependable seeds, that $I$ want your friendship and confidence plus all the time.

My last words are, use my Free Service Bureau. My constant effort is to please.and benefit you. You are my friend; so write me often, whether you order or not. 


\section{FORAGE CROPS BEST FOR THE SOUTH}

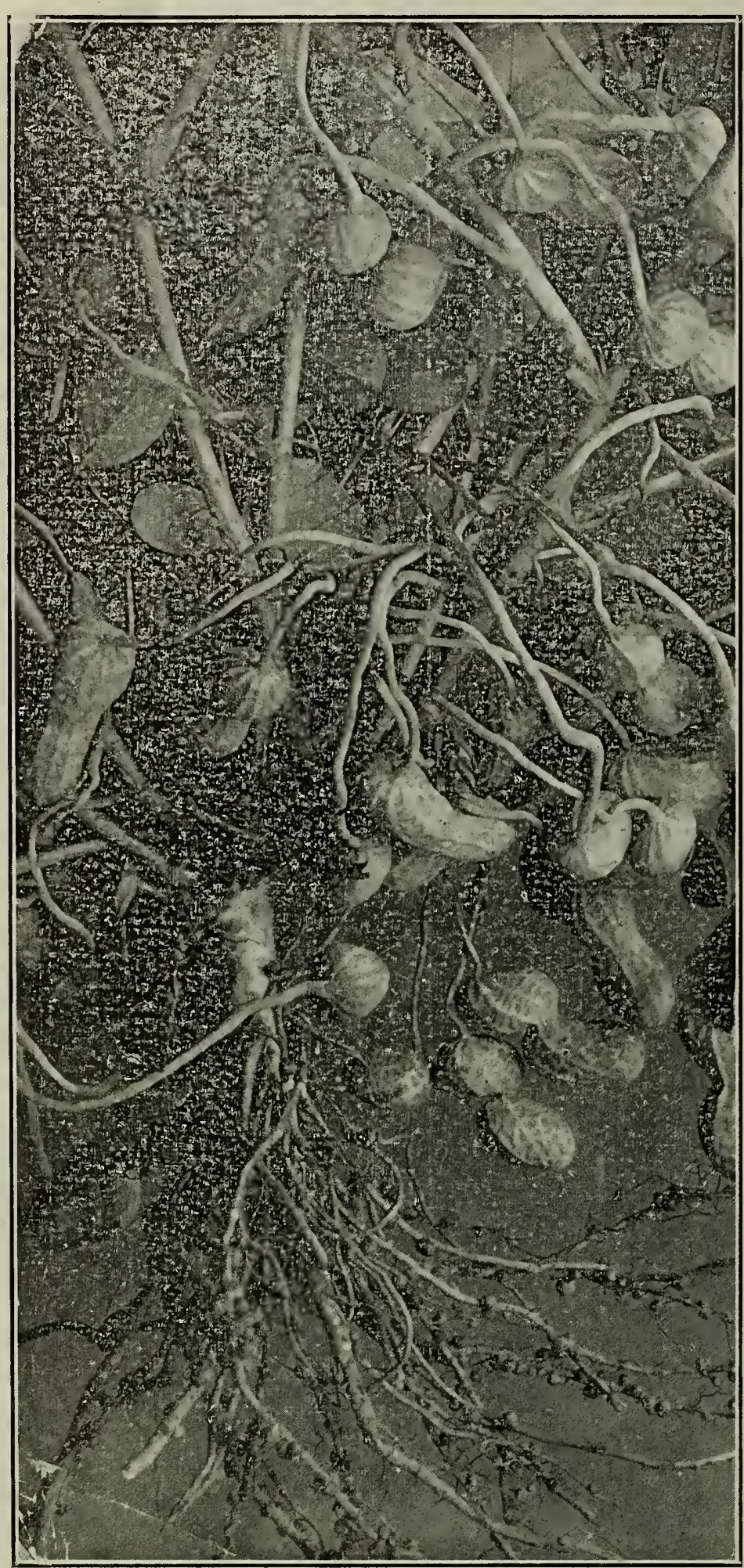

SPANISH PEANUTS

DWARF ESSEX RAPE

Is much like the Irutabaga in appearance, although the root resembles that of the Cabbage. It really belongs to the Cabbage family of plants, and will produce good crops in any soil suitable for Turnips, Cabbage, Wheat, Corn, etc. Should be sown broadcast. at the rate of twenty pounds per acre. A common practice the grain is harvested the Rape will grow and afford fine pasture for poultry, sheep, hogs, and cattle. Rape will endure quite severe cold weather, and make a good pasture after frost has kiled ordinary pasture grass. The fields are ready for grazing splendid tee ws after seeding. On account of its quick growth, be largely used in this section and throughout the South, and considering the small expense of seeding and its satisfactory yield, there is no farm which should be without it.

Price, 1b. 15e; 10 lbs. \$1.00; 50 lbs. \$4.50; 100 lbs. \$8.00.

\section{PEANUTS}

The Peanut is worthy of more general cultivation throughout the South, especially in the boll-weevil district, where it will in many cases be found more profitable than cotton. The reanut is a soil builder and renovator. If included in the crop rotation and ploperly handled, pealluts are not exhaustive of soil fertility. The tops of the peanuts make fille hay, relished by all stock, while the roots furnish rich foud fur both mall and stock. Our best soll, as this indicates lime, which is essential for this plant. They yield fiorty to one hundred bushels to the acre, according to how well the crop is managed. Peanuts should be shelled before planting but can also be planted in the hull 16 to 18 inches apart. They should be planted from March until June, in rows about $2 \frac{1 / 2}{2}$ or 3 feet apart, dropping the nuts 8 to 10 inches apart, one in a hill. Cover one or two inches. Cultivate three or four times with a cultivator, so as to loosen the earth and keep down the weeds. When they mature, pull them up, turning the roots to the sun. In bright weather they will be cured sufficiently in twenty-four hours. It requires two bushels in hull to plant an acre.

\section{WHITE MAMMOTH PEANUT}

This variety grows to an enormous size and does extremely well in the The pods measure on an average of $2 \frac{1}{4}$ inches in length and $1 \frac{1 / 4}{4}$ inches in diainetel. Thick shelled and deeply ridged. The kernels are of light color, $1 \frac{1 / 8}{\text { inches long and one-half inch in diam- }}$ eter. Although of wonderful size, its productiveness is still more of peanuts to one kernel planted. making it the most prolific and largest peanut known.

Price, gul. \$1.00; peck \$1.75; bu. \$6.00.

\section{SPANISH PEANUT}

In addition to their value for growing for the nuts, these are very largely used in the South as a forage and fattening crop for hogs and other stock. They are early to mature, very productive, and in the far south, where they can be planted during crop being planted early in July, the tops making a hay crop and the nuts a grain crop. They grow more compact than the Virginia Peanuts making it possible to grow them closer, makbusliels of marketable Peanuts and variety frequently yields sixty lbs. to the bushel.

l'rice, peck 60e; bushel $\$ 2.00$.

\section{VIROINIA BUNCH}

A very profitable variety, plant rather dwarf, stems upright. follage l'd ther light, pods clustered about the base of plant. usually two, sometimes three, seeds in a pod; pod bright and clean, color standard variety for roasting. They furnish excellent forage.

Price, weck 60e; hu. \$2.00.

\section{TENNESSEE RED (28 lbs. to the bushel)}

Small-podded variety; similar to Spanish, except that the pods are lunger, sometinies containing five to six peas crowded together; leas dull red ill color. This variety is well adapted to stock and quality of the peas.

Price, sal. 50c; peck 75e; bu. \$2.25.

\section{CHUFAS=EARTH ALMONDS}

A species of ground nut forming an abundance of small tubers A species but near the surface Grown in many sections for feeding to hoos fol which purpose they are hichly recommended. After the crop is grown hoos may be turned into the field thus saving the labor of harvesting and feeding required by most crops

They do best on light, sandy soil, or richer soil that does not contain much clay except a subsoil. They should be placed in drills two to three feet apart, dropping three to five Chufas in a hill 15 to 20 inches apart. Cover to a depth of about two inches. They should be kept clean and the soil stirred occasionally. Level tubers mature in September and can remain in the ground until needed. Oue peck will plant an acre.

Price, 1l. 25c; peck $\$ 1.50 ;$ bu. $\$ 5.00 ;$ (44 lbs. to the bushel).

\section{TEOSINTE}

This hardy, strong-growing plant has proven its great value soiling crop. Yields enormous quantities of excellent forages. The plant grows 10 to 15 feet high. Louisiana Experiment Station reports a yield of fifty tons. The cultivation is the same as Sorghum though it will require much less seed for planting. One seed makes 30 to 50 stalks or stools. Seeds only in extreme South. Both stalks and leaves contain a rich, sweet sap, making them of highly nutritious quality. The forage is rich and tender and is greedily eaten by horses, cattle and sheep. Sow during green fodder Teosinte may be cut three or four times during the season, but then it should not be allowed to grow any taller than three to four feet. In cutting it is advisable to cut clean to the ground, as this will insure a
high. Two pounds per acre.

Price, oz. 10e; ll. 75e: 10 lhs. \$6.00. 


\section{REUIERSSIRESAIIECTED SORGHUMS}

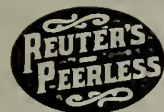

\section{SOUTHERN FORAGE CROPS-Selected}

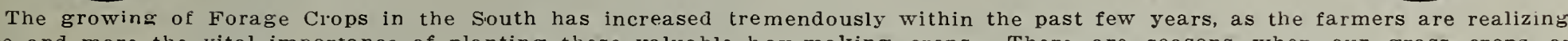

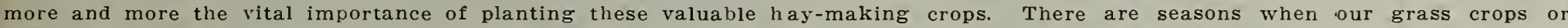

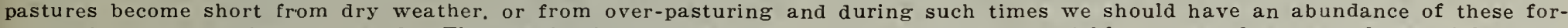

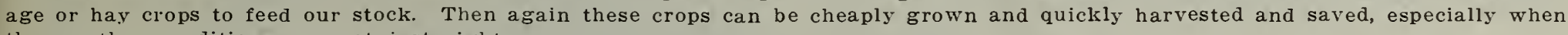
the weather conditions are not just right.

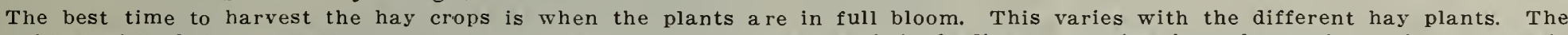

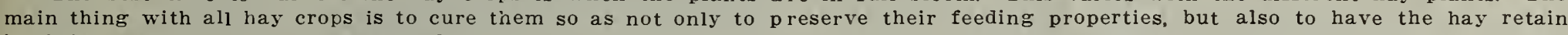
its bright, green color and sweet odor.

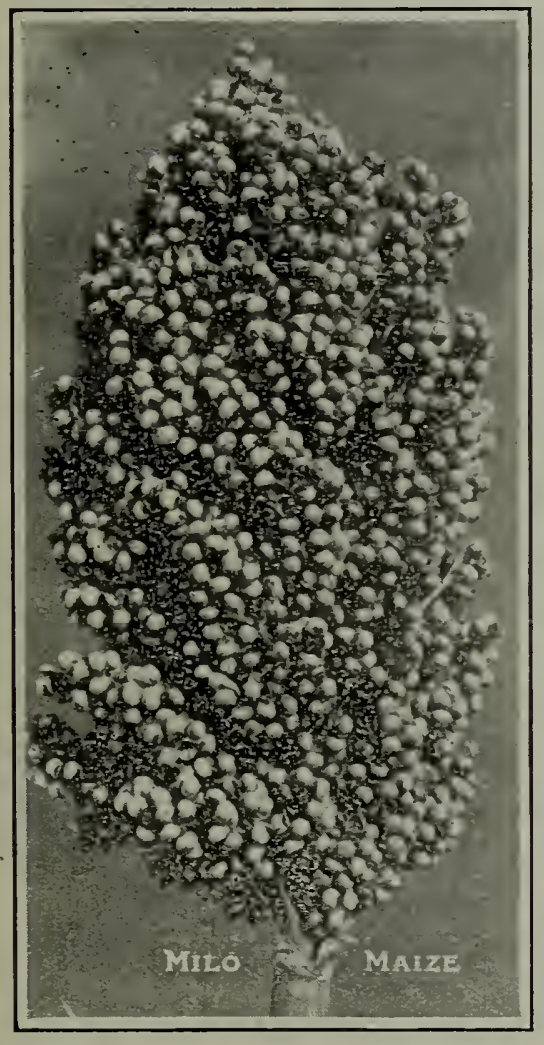

\section{RED KAFFIR}

This variety grows taller than the White; the stalks are more slender, but more juicy and very leafy. The heads grow long and slender and measure from twelve to and brittle. It does well on poor land and yields well. It ripens a little earlier than the White variety and yields much heavier even on this soil.

Price, 1b. 15e; 25 lbs. \$1.25; hu. \$2.25; 100 lbs. \$4.25.

\section{GENUINE DWARF MILO MAIZE}

Grows only about four feet high and makes a small stalk as compared with the old type of Milo Maize. The stalks are short, but large and stand up remarkably well The heads are large, so are the seeds. Earlier than the Kaffir Corn and Standard Milo Maize. The yield is flom 60 to 100 bushels to the acre. It is a straight-necket variety, which is a valuable feature in gathering, feeding and cutting the heads. It will stand greater drouth than any other sorghum, and for that reason is admirably adapted to dry farming. Should be extensively grown, in fact, every farmer should plant a of April until August 1st. Every animal on the farm, from the hen to the horse, will eat and fatten on the seed. Sow $101 \mathrm{bs}$. to the acre.

\section{YELLOW MILO MAIZE}

Growth is tall, 9 to 12 feet, stooling from the ground like White Milo Maize, but not so much. It sends out shoots also from the joints. Seed heads grow to a great size, often weighing three-fourths of a pound, sometimes a full pound, after ripening. On account of its branching habits this grain should be planted in rows four to five apart.

Price, 1b. 15e; 25 lbs. \$1.25; bu. \$2.25; 100 lbs. \$4.25.

\section{JERUSALEM CORN (White Durra)}

This is very similar in every respect to the Dwarf White Milo Maize and has the same drouth resisting habits. It is considered by some the greatest drouth resister of nearly all the other Sorghums is round. Grows five feet high, makes one large head on main shoot and several smaller ones on side shoots. The leaf development is about equal to the Kaffir Corn. Everything considered. it is regarded as one of the most profitable plants for dry-land falming. From five to six pounds of seed will sow an acre.

Price, 1b. 15e; 25 lbs. \$2.00; bu. \$3.50; 100 lbs. \$6.50.

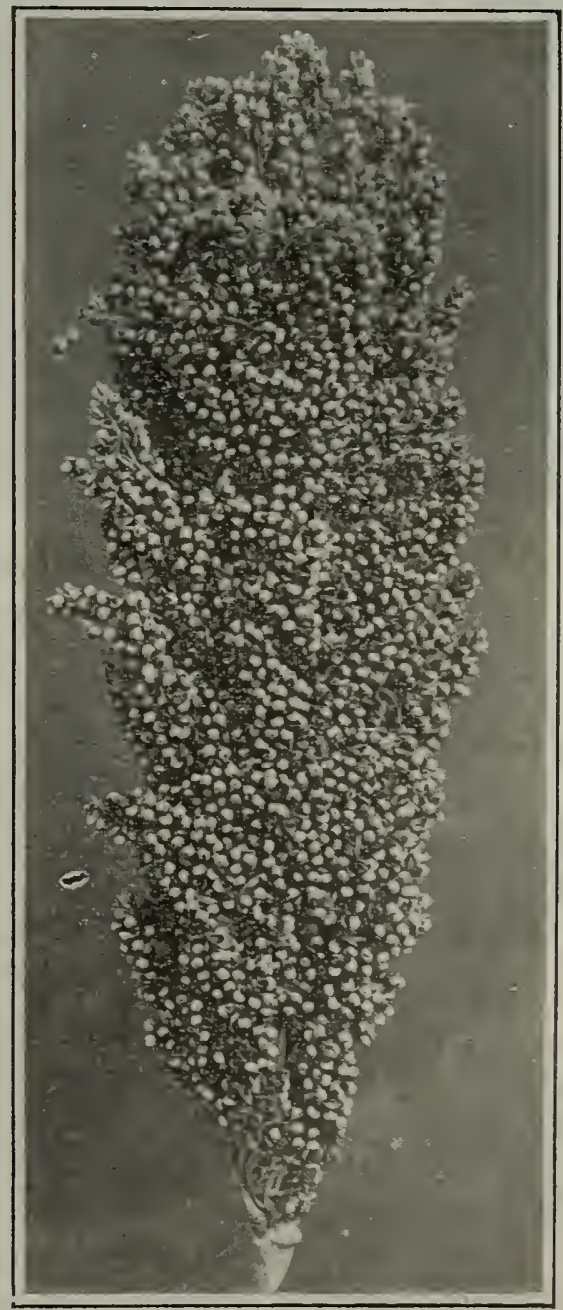

White Kaffir Corn 


\section{EGYPTIAN WHEAT (Shallu) Non=Saccharine}

It is a variety of Sorghum that is wonderfully prolific and should be planted the same way, either for grain or hay. It grow's remarkably well, with little moisture. The great value is in the seed, which is most excellent for food for the poultry, and in fact all stock on the farm: Fifty to one hundred bushels of seed may be grown to an acre. It should be thrashed as wheat or other grain. It would prove far more valuable to grind the seed for all stock except poultry. As it contains 80 per cent of the feeding value of our common corn as a food for stock, it can be made far more valuable as a stock food on many farms than our common corn. Even if the farmer does not want to grow it for the farm stock, he should plant a sufficient acreage for making an ample supply for all the poultry on the farm. It is planted once and then cut the same sorghum or Milo Maize. If it is used six to eight feet high. Plant it from January until July. In drills, use two pounds to the acre; when sowing broadcast, one and Price, lb. 15e; 10 lbs. $\$ 1.00 ; 25$ lbs. \$2.25; bu. \$4.00; 100 lbs. $\$ 7.50$.

\section{FETERITA Non-Sacharine}

A new variety of the Durra group recently introduced rrom British Egyptian Soudan. It produces stalks of medium slze, bearing ten to twelve leaves and a large upright head, well filled with pure white or bluish white seeds. The grain is larger bushels to the acre was reported this past season. The increased yield and the earliness of this variety will bring it to the front rapidly.

Price, 1b. 20c; 10 lbs. \$1.00; 25 lbs. \$2.25; bu. \$4.00; 100 lbs. \$7.50.

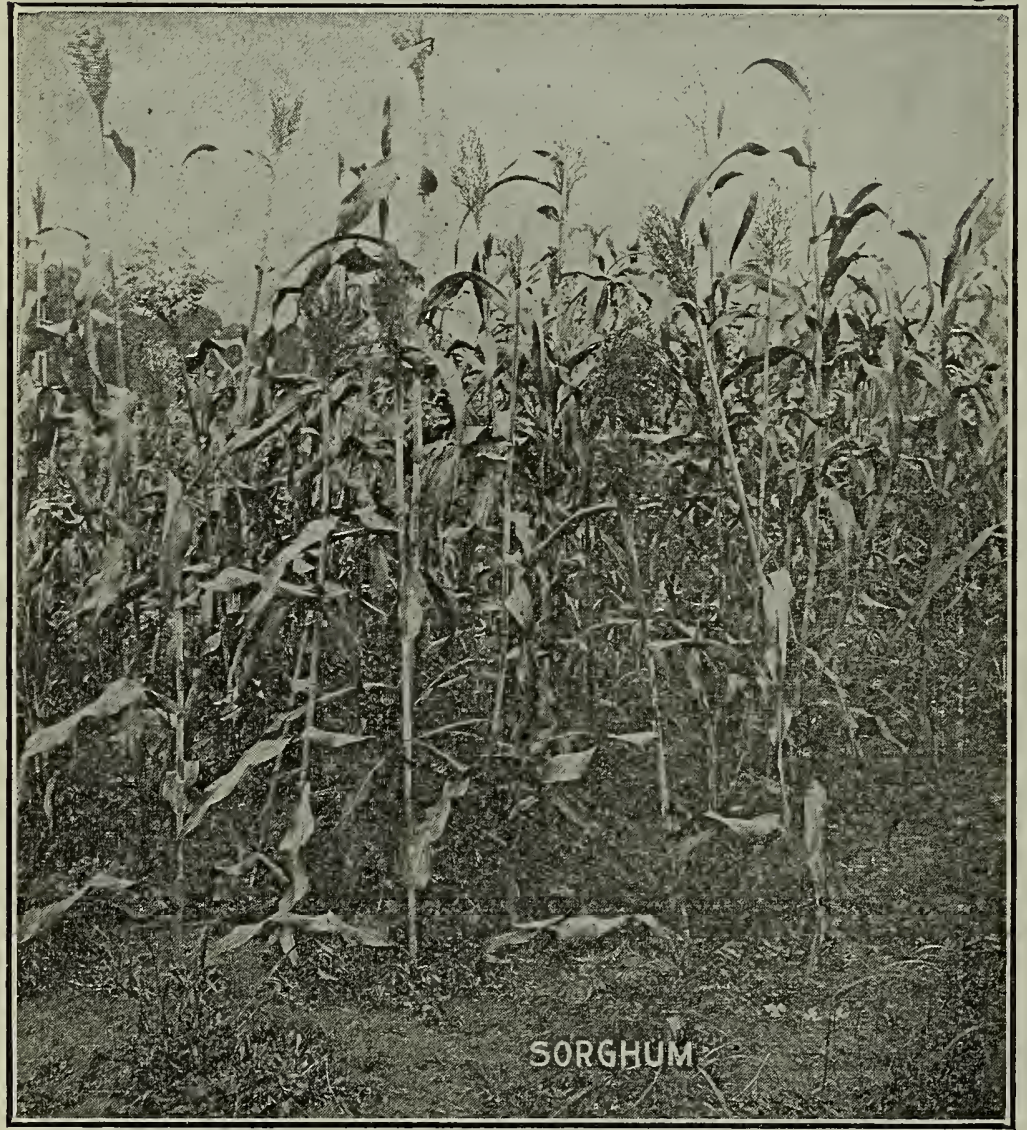

TEXAS-SEEDED RIBBON CANE

This is a comparatively new variety of the Saccharine Sorghums. A very strong and tall growing variety, noted for the immense quantities of finest syrup which it produces. It strong, leafy stalks make excellent forage. Plant in rows three and one-half feet apart, eight to ten lbs. to the acre.

Price, 1b. 15c; 10 lbs. \$1.00; 25 1bs. \$2.20; bu. \$4.25; 100 lbs. $\$ 8.00$.

\section{RED TOP, or SUMAC CANE}

This has proven to be a very valuable variety. Seed is smaller than that of either the Amber or Orange. Produces an immense quantity of fodder. Very sweet and of the best for hay.

Price, lb. 15e; 10 lbs. \$1.00; 25 lbs. \$2.00; bu. \$3.50; 100 lbs. \$6.00.

\section{BROOM CORN}

There are many farmers who make this a most profitable crop. One acre will produce 500 hundredweight of brush and nearly 40 bushels of seed. It is a very good crop for dry land farming. The straw sells as high as $\$ 200.00$ per ton. It has very little value for feed, as neither the stalks, blades or seed are good to feed any kind of stock. Broom Corn may be planted prevent it getting mixed with feed crops. From 4 to 8 qts. of seed plant an acre.

\section{IMPROVED EVERGREEN}

Grows about 8 to 10 feet high, stands up well and is entirely free from crooked brush. The fiber is long and fine.

Price, lb. 15e; 1 lbs. \$1.00; bu. \$3.00; 100 lbs. \$5.50.

\section{SACCHARINE SORGHUMS-SUGAR CANE}

The value of Sugar Cane as a hay crop is yearly becoming better known and appreciated by thousands of farmers in the South. The Saccharine Sorghums are supcrior to others for fodder, and produce the best green food that can be grown for feeding horses, cows, etc. The Sorghum plant is a strong rapid grower and a greedy feeder, so that it succeeds best on a deep, rich, moist soil. Stable manure is an excellent fertilizer. The best time to plant this crop for forage is from about March until the last of July. The seed can be planted in drills from two to three feet apart and the crop cultivated, or they may be sown broadcast. Use about one-half bushel to the acre where sowed in drills, and use 100 to $150 \mathrm{lbs}$. to the acre where sown broadcast. Two cuttings can always be made and sometimes three or more.

All our Cane Seed is recleaned by the best machinery. We do not purchase cheap farm stock full of broken grains and very dirty. Pay a little more and get the best. Prices on Cane Seed fluctuate. Write for prices, stating quantity desired.

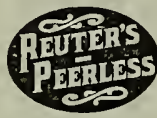

\section{JAPANESE HONEY SORGHUM}

Known in somc sections as Japanese Seeded Ribbon Cane, and sold under that name by various seedsmen. It makes an unsually large stock, sometimes as large in diameter as Ribbon Cane and much taller. Matures in 120-125 days. It sends up from two to four stalks which reach a height of eleven to fourteen feet. The seeds are plump, slightly larger than Sumac, and when hulls are removed seed appear to be of dull reddish brown color, and after threshing, are almost totally enclosed in a bluntly-pointed glistening red glume; heads long and medium loose. Yields as much as four to five hundred gallons of the very best syrup to the acre. The syrup is lighter in color and milder in taste than that of the Sumac, Orange, or Amber. $\$ 7.00$.

Price, 1b. 15e; 10 lbs. \$1.00; 25 lbs. \$2.00; bu. \$3.75; 100 lbs.

\section{EARLY ORANGE}

With taller and heavier stalks than the Early Amber. It is not as early as the above variety, but a great producer. It is considered better for syrup making.

Price, lb. 15e; 10 lbs. 75e; 25 lbs. \$1.50; bu. \$2.75; 100 lbs. \$4.75. REU RFR'S PFDITREE EARIV A MBER

The leading and most popular variety. It is the earliest sort, and makes the finest hay, green or cured, which is relished by all stock. No farmer can make a mistake by selecting this variety, either for hay, pasture or syrup.

Price, lb. 15e; 10 lbs. $75 c ; 25$ lbs. \$1.50; bu. $\$ 2.75 ; 100$ lbs. \$5.00. REUTER'S SUGAR DRIP SORGHUM

This is an entirely new variety that is creating quite a furore in the South, and is largely planted for syrup purposes. I believe that it belongs at the very top of sorghums when grown for this purpose, and should be more extensively cultivated than it is. It is not a difficult matter to make sorghum syrup, so plant a few acres this year, and you will find ready sale for it in your local market, or even the larger cities are now asking stools and stalks. Plant it in rows about four feet and about one foot apart. Grows 12 to 15 feet high. In some sections of the South it is known as Georgia Cane. The demand for the seed has usually been greater than the supply, so I suggest that you place your order early, so as to avoid disappointment. My seed is Southern Grown, and selected by a careful grower in Georgia who has been orowing this stock a few years. $\$ 3.00$.
Price, 1b. 15e; 10 lbs. $\$ 1.00 ; 25$ lbs. $\$ 2.00 ;$ bu. $\$ 3.75 ; 100$ lbs. 


\begin{tabular}{|c|c|c|}
\hline WRITE FOR MARKET & MICES AND SAMPLES & $\begin{array}{c}\text { Our Seed is carefully recleaned. } \\
\text { Price includes bags. }\end{array}$ \\
\hline
\end{tabular}

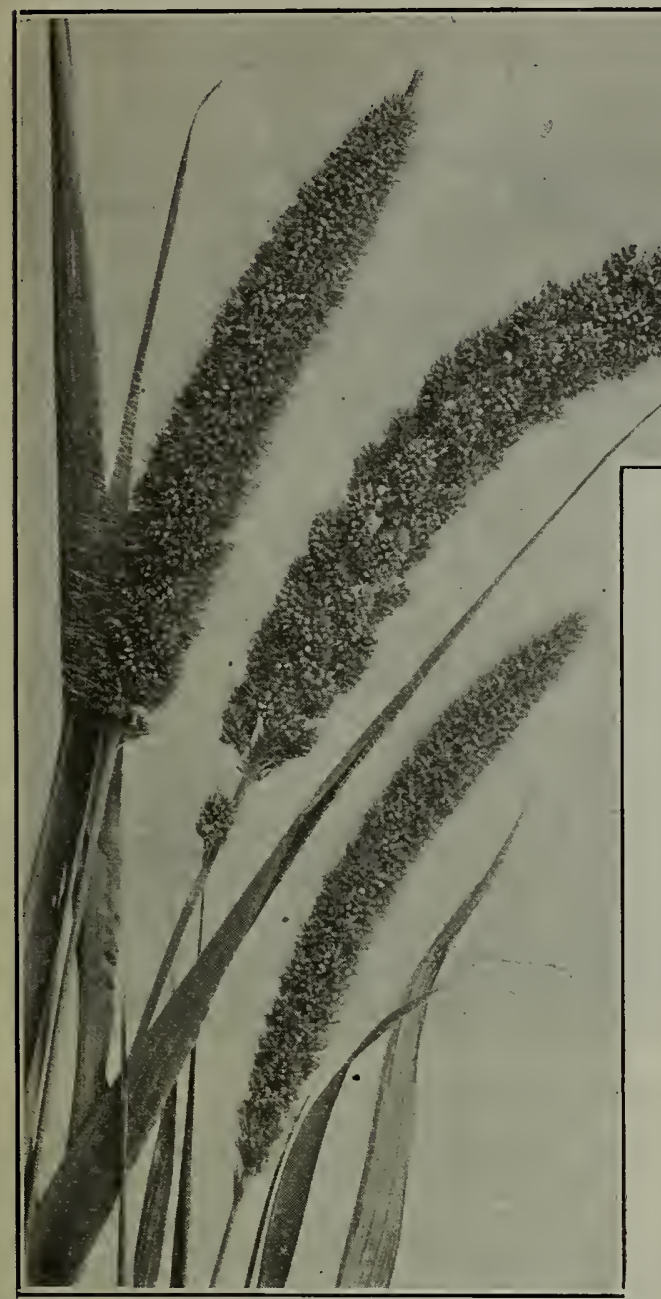

REUTER'S BIG GERMAN MILLET

PEARL, or CATTAIL MILLET

Immensely productive. Twenty-five tons per acre. It is an annual plant having long, broad foliage, and if allowed to develop fully will attain a height of from 10 to 12 feet, and bear numerous heads from 19 to 20 inches in length, and one inch in diameter, completely covered with thousands of seeds, much relished by poultry. It is a rapid grower. throwing out from one plant to numerous suckers, and if cut as soon as it reach

It may be sown in drills or broadcast, though the better plan is to sow in drills three or four feet apart, and cultivate. Tn be fed as a forage crop, it should be cut and fed when green. It is practically worthless for hay.

Price, 1b. 20c; 10 lbs. \$1.50; bu. \$6.00; 100 lbs. \$11.50.

\section{HUNGARIAN MILLET}

For good, low grounds on rich snil, this makes even a more valuable crop than German Millet. It is of fine growth and vakes excellent hay. It has numerous succulent leaves, which makes excellent hay. It has numerous succulent leaves, which furnish an abundance of green fodder, taken by all kinds of let resembles it very closely and is frequently found mixed with Hungarian.

Price, ib. 10c; 10 lbs. 60c: bu. \$2.50; 100 lbs. \$4.50.

$$
\text { SIBERIAN MILLET }
$$

This is a splendid variety of Millets, which is rather new to the South, having been recently introduced to us from Russia. It is the earliest millet we know of. Should be sown rather early and continue sowing at intervals any time during the season when it will produce an abundance of green foliage as well as making a very fine crop of hay. This Millet has been successfully grown in Louisiana, Texas, and other 'Southern States, and is truly a meritorious variety. Many growers claim it is superior to the German Millet, but I doubt it very much. It is, however, much earlier than my Big German.

Price, 1b. 15e; 10 lbs. 75e; bu. \$2.50; 100 1bs. \$4.50.

\section{REUTER'S SEED POTATOES}

In order to secure the best possible yields, combined with the best quality, there is no crop that a change in seed is so essential as in seed Potatoes. Don't plant scrub-stock and grow a small stock of poor potatoes, which are hardly marketable at any price. There is a world of difference between our highly selected Northern Grown Seed and the ordinary commercial grade of so-called seed potatoes sold by produce mer-

Millet is used principally as a hay and forage crop. It certainly deserves more extensive cultivation. Makes superior hay and is a fine soilling crop for dairy cows, young stock and sheep. Yields heavily and is highly nutritious. It is easily cured and its rapid growth makes it especially valuable as a catch crop. To grow Millet for hay it should be sown broadcast at the rate of one bushel to the acre. Millets are of rapid growth so consume large quantities cf plant food, as well as requiring a great amount of moisture. Deep, rich soils, clay soils, are the best suited for Millet. The soil should be broken deeply and the seed bed made fine before sowing. The best time to plant Millet is from April to July. Millet should always be harvested for hay before the seed becomes ripe. In fact, after the seed ripens the hay is of little value. The best time to cut is when the seed is in the milk. It is easily cured, requiring only one or two days' sun to put it in condition. Two crops can be grown on the same land.

\section{REUTER'S BIG GERMAN MILLET \\ Tennessee Grown Seed} rect development. My seed is cultivated in drills expressly for this purpose. This no other varieties are grown near this sort, and isolation is absolutely essential in this my stock, but this seed becomes more or less hybridized with Common Millet, Hungarian Goutail and often gives very disappointing results. Be sure to buy strictiy man Millet has been in cultivation since 1870. Quite a long time ago, isn't 作 came from originally. In nine times out of ten, you will discover that yield is necessarily lessened, and renders the hay of less value, because common West.

\section{MANITOBA HOG MILLET}

Grows from three to six feet tall. Produces large heads and larger seed than any other Millet. Seeds are large and contain a high percentage of oil. The seeds have a higher feeding value per pound than our common corn. This plant always produces a heavy head of seed. The seeds furnish the best of all foods for all poultry. It has produced as high as seventy-five bushels of seed per acre. One great feature of this Millet is that the seed
ripens before the straw, so that it may be cut and bound as ripens before the straw, so that it may be cut and bound as while the seed may be housed and be fed separately as grain. while the seed may be housed and be fed separately as grain.
This plant is an annual, and like other Millets must be planted each season. By beginning to sow with early corn planting and keep up sowing first of every month up to september ist, we can have fine green forage for our stock all the summer.

Price, 1b. 15c; 10 lbs. 75e; bu. $\$ 3.00 ; 100$ lbs. \$5.50.

\section{JAPANESE MILLET-BILLION DOLLAR GRASS}

This is one of the best plants ever introduced into this country. It grows from one to six feet tall, according to the soil. From one-half to three-fourths bushel per acre will usually anFrom one-half to three-fourths bushel per acre will usually answer. It may be sown in drills or broadcast. It may be cut when
in full bloom, or from then to the dough state of the seed for hay, or it may be cut and bound when the seeds are ripe, the same as or it may be cut and bound when the seeds are ripe, the same as Theat. The seeds furnish excellent feed for poultry and hogs. grown together on good soil they will produce from four to ten tons of hay per acre. Usually in a favorable season, the stubble of both millet and peas will start
second crop from the one seeding.

Price, lb. 15e; 10 1bs. \$1.00; bu. \$3.50; 100 lbs. \$6.50.

\section{WRITE FOR DELIVERED PRICES}

The prices on all Millets, Clovers, Soy Beans, Velvet Beans etc., are constantly changing. If you intend to buy a large quantity of anything I handle, write me for prices delivered your station. Use the Quotation Request Sheet in the back of this cata-
logue. Don't be afraid to ask questions. I have a big force of help in my office to do nothing else but serve you. If you want to know the probable cost of anything delivered your station, or if you want to know if any of these crops are adaptable to your section, write me freely.

ghums, Lespedeza, etc., are unexcelled. I am not merely telling you this to get your order, but get my samples before ordering. 


\section{LOUISIANA RED RUST PROOF OATS POSITIVELY RUST RESISTANT FREE FROM JOHNSON GRASS}

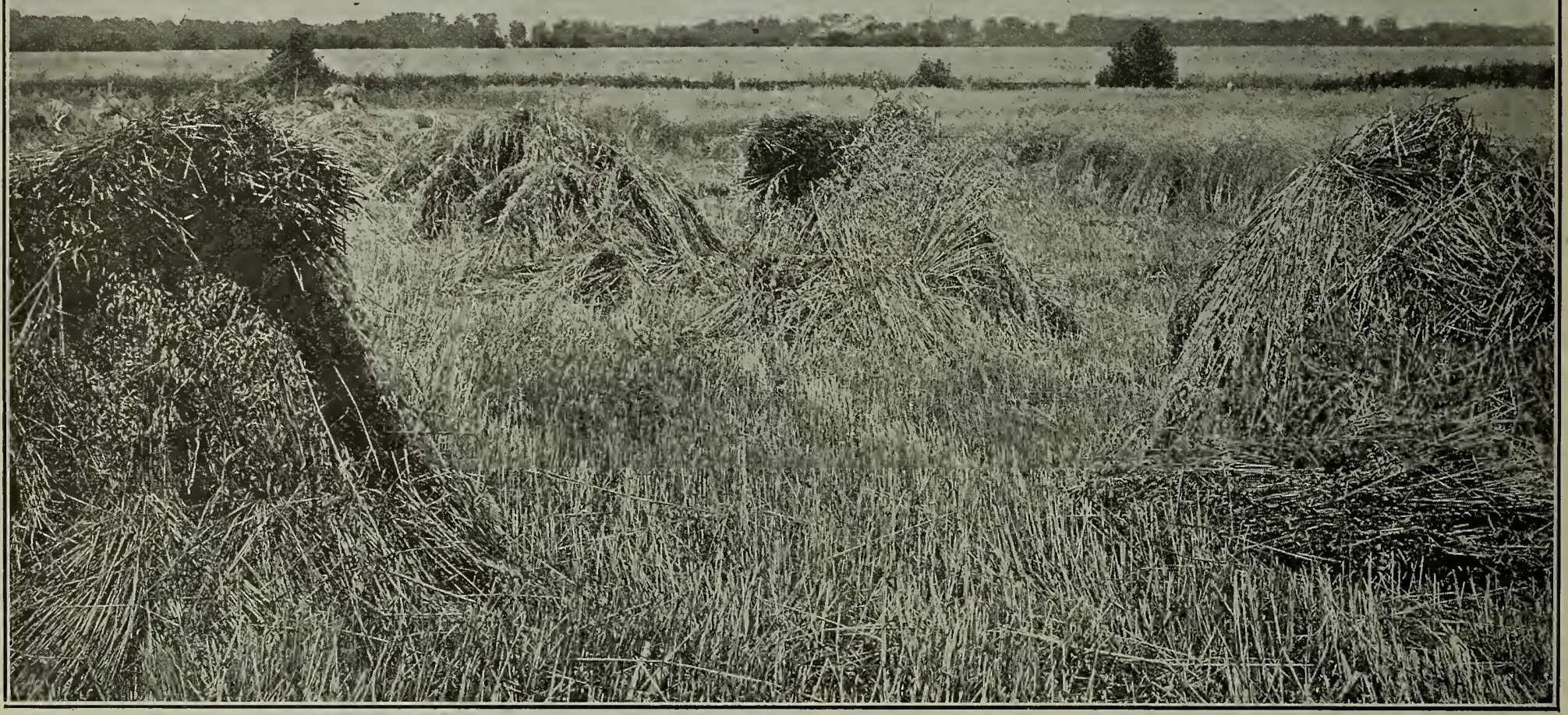

\section{WHY YOU SHOULD PLANT LOUISIANA GROWN RED RUST PROOF SEED OATS!}

Oats are Oats to many of our best growers. They don't realize the tremendous difference between quality and grades, and when they are ready to sow Oats they go right ahead and buy from anybody anywhere. For many years the growers in Louisiana were
planting Red Rust Proof Oats grown in Texas. Not a single seed house in this State endeavored to push Louisiana Seed Oats. I talked personaly with several of the dealers, and they advised me that they can't make a profit selling high-grade re-selected Louisiana Oat Seed. Just think of it! They all advised me the same way, saying that they can buy all the Rust Proof Oats they want out of Texas at forty and fifty cents per bushel, and often this price is F.O.B. New Orleans or other cities in the State. They argued that the planter was not looking for extra fine oat seed. As long as they grew and produced something that resembled imported from Texas, mixed with Johnson Grass, and they rust like the devil. You want to steer clear of these dealers. You simply of the ord put your land, which is indeed valuable to you, into scrub seed. It may cost you a fortune trying to eradicate some other reliable grower in Louisiana, be sure that the stock has been grown in Louisiana for several years, is thoroughly acclimated, and free from Johnson Grass.

READ WHAT THE LOUISIANA EXPERIMENT STATION THINKS OF LOUISIANA GROWN SEED OATS!

"Louisiana-Grown seed Oats should be secured by all means. Texas Grown Seeds are very apt to contain Johnson Grass Seed, and frequently oats sold as Texas Rust Proof Oats are only partly resistant to rust." foregoing statement, which is included in Bulletin No. 124, which will be sent to your address absolutely free if you write the Experiment Station at Baton Rouge, La. Every year there are thousands of acres planted in Oats in the South and the results are exaggerated claims of seedsmen pouring forth lots of hot-air about hundred bushel yields. Don't you believe it. I have had my Oats planted alongside of some of these "Hot-Air Oats," as I call them; the results have always been as expected. Last year the same time and both cultivated the els to the acre, whereas mine yielded more than fifty on the very same land, planted at forty cents per bushel, whereas my own Oats were sold for $\$ 1.00$ per bushel, and I had not near enough to go around. There is strength in Louisiana Red Rust Proof Seed Oats, there is yield, there is every essential to make it the grandest oat in the world. toan truthfully say that Louisiana Grown seed Oats will out-yield any other oats on the market, no matter who may offer them ful sight. It would make you feel good to get in those fields and see the remarkably even height and practically every head having the same number of developed grains on it. I BELIEVE IN OATS!

I believe that the day will come in the near future when every farmer in the South will grow Oats. The big sugar planters It means the are already realizing the imporat more profits. crop, and putting hundreds of acres in this one great big grain crop. planted extensively, wealth abounds.

We are in the greatest live stock country you ever saw. We have many natural advantages that should force us to put some animals on our farms. The policy of the cotton grower to plant nothing but cotton, the sugar planter to grow nothing but sugar is must plant more than one crop if we expect to continue farming. Plant more Oats, more Wheat, more Barley, more other good, sound, sensible crops that will pro
speak too highly for their merits.

Fruit Growers Attention!

This is the hardiest known variety of the Citrus family. Green bark and numerous stout branches armed with strong. sharp thorns. Very valuable as a stock for citrus trees of different kinds. White, fargrant flowers for hedge for defensive as well as ornamental purposes. Fruit, golden yellow, as large as a walnut. It is deciduous, grows well in the open ground. It has become of great importance as a stock for citrus trees of all kinds. Varieties budded on it are made hardier because of its dormant and It has been claimed that it dwarfs the trees budded upon it, but the tests of years in our test groves at Bohemia, La., have not proven to be so, except in the case of a few varieties. tain plenty of moisture or to which water can be applied by irrigation. It should not be planted on high, dry, sandy land lacking moisture. On such soils it is a failure.

Seed, one-quarter 1b. 25e; lb. 90c; 10 lbs. \$8.50. 


\section{PLANT GOOD ACCLIMATED SEED OATS ONLY}

MY LOUISIANA GROWN SEED OATS WILL OUT= YIELD ALL OTHER VARIETIES!

Possibly you don't believe it, but no doubt you will be willing to let me prove it to you this coming fall. Don't wait until the planting season is upon you to figure from whom you are going to get your seed oats. Make up your mind as soon as you can, Oats are the best. They will make good on your farm, the same way they have made good on thousands of other farms and planway they have made good on thousands of other fater Oat. It is the Oat that has revolutionized the growing of Oats in Louisiana, and within a year or so Louisiana Seed Oats will be in big demand and within a year or south. They have made good, not once, but everywhere in the South. Tear more attention is being devoted hundreds of times. Every year more attentivation of Oats. Eventually the South grow more to the cultivation of ats. Ev of the United States, and why not? Oats than any other section of the H Oats you will double your yield. It will make Oats your most profitable crop. It will mean are continually asked to pay.

\section{MY FIELD SELECTION OF SEED}

In addition to having my Seed Oats all thoroughly cleaned and recleaned, fanned and graded by the most modern machinery, had are thrashed together and are kept for my seed. By conand are thrashed together and are kept for my seed. By constantly developing my seed stocks in this way, I am able to offer you a pedigree variety that is absolutely trued Anything that is inferior is discarded; my type is kept yielding. Anything that is inferior is discarded; my type is kept pure all the time. I am all the tim individual plants. There is no by testing strains developed from individual plant

smut, rust, or Johnson Grass in my are the finest that you have ever grown. They simply can't be beat when it comes to yield or quality. When anyone talks about quality, my Oats are put at the top. As stated before, all of my Oats are re-cleaned when they leave my New Orleans warehouses. Threshing machines don't take out the weed seed and the light non-productive grains. Our machines here do that kind of work. If you want to plant TER'S LOUISIANA RED RUST-PROOF.

I would like to take you through my warehouse, and just show you how careful we are about cleaning and grading Oats. Then you would realize why 1 am forced to ask you a lew cents ferior, so-called seed Oats. You would be surprised to see the amount of trash iavable.

Farm conditions in the South can be greatly improved by the use of a greater variety of crops and definite systems of crop rotation and by keeping a number of animals on the farm. A rational crop rotation in the South is one which occupies land practically the entire year. protecting the soil from washing during the winter by the use of a growing crop, such as Crimson Clover, Vetch, Oats, etc. If you increase the number of animals on your farm, it will be es.

\section{WHEN TO PLANT!}

Sow your oats in September, October and November at the rate of about two bushels to the acre, possibly a little more. They are usually sown broadcast by farmers in the South, but this method is not to be recommended. The "Open Furrow Method of Planting" is absolutely the best in my estimation. When sown broadcast and harrowed in. much of the seed is left near the
surface, even in well-prepared ground, so that many of the plants are shallow rooted and are killed by heaving or cold. A better method, where broadcast seeding is essential, is to sow the seed on clean ground which has been disked, covering it should then be left rather rough, as the uneven surface furnishes some protection for the plants. The use of a grain drill more uniform stand and more even germination and growth than broadcast seeding. Drilling. also requires less seed and the plants are less liable to be killed by cold. Drill at least three inches deep on well prepared land, leaving the drill furrows as open as possible, and don't harrow after drilling. This leaves the seed in the bottom of shallow furrows, which is a measure to protect in the bottom of shallow furrows, . Which is a measure to protect seeding oats and other small grains in the South has become seeding oats and other small grains in the south has become
extremely popular, and has proved to be worthy of more general
use. By this method the seed is sown in drills 16 to 24 inches apart. In a four-year test at the Alabama Experiment Station the open-furrow method of seeding was compared with broadcast seeding. The average yield for the broadcast plants was 24.2 bushels to the acre, while plats drilled in deep furrows yielded 27.4 bushels. Drilled plats in which the furrows were filled
after seeding averaged 26.7 bushels. This station recommends after seeding averaged 26.7 bushels. This station recommends the open-furrow method on well-drained lands; on wet or very level land water may stand in the furrows long enough to injure the crop. The "Open Furrow System" is as follows: The ground is thoroughly broken and harrowed during September or October. plow point to open the furrow into which are drilled the seed and fertilizer together in any quantity desired. Oats planted in the fall invariably yield more than oats planted in the spring, but they are to some extent sown in the spring by some of my customers. Remember that thirty acres of Oats planted in the fall will give you a carload of feed by June 1st, and five carloads of Lespedeza hay four months afterwards, provided ycu plant part of February or early March.

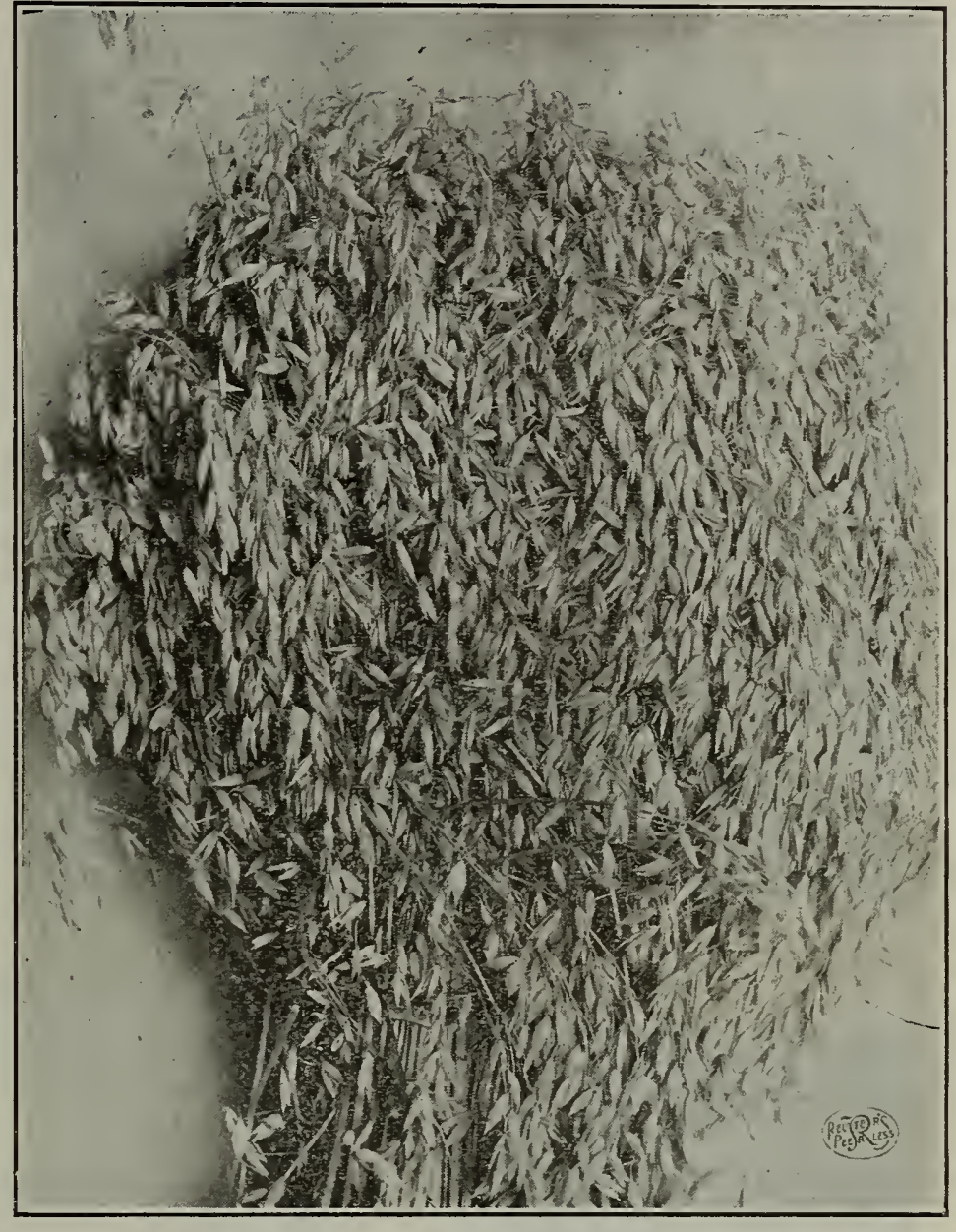

Sheaf of Our Louisi na Grown Oats=-Superior to All

\section{PRICES OF REUTER'S LOUISIANA RED RUST=PROOF OATS}

Good Louisiana Grown Seed is always the best and is dependbought for little or nothing from any grain dealer in your town. You simply can't afford to risk sowing trash. Pay just a little seed is absolutely re-cleaned, fresh, sound, and free from Johnson Grass.

Price. peck 50c; bu. $\$ 1.25 ; 10$ bu. $\$ 10.00 ; 100$ bu. $\$ 90.00$. station.

amples gladly furnished. Let me quote you F.O.B.

\section{WINTER TURF OATS}

Valuable for winter grazing and grain throughout the South Its turfing and stooling qualities are remarkable, even when thinly sown soon spreads and covers the ground. Sow $1 \frac{1 / 2}{2}$ to 2 bushels to the acre.
Price, bu. $\$ 1.25$.

\section{It Pays to Plant the Best Varieties of Seed Corn!}

To use our thoroughbred, inherited seed corn will cost you but 35 to 50 cents per acre, freight charges included. It is,
therefore, evident that if it produces but one bushel more per acre than old run out sorts, it will more than pay the expense of the seed. And if you get 20,30 or 40 bushels increased yield per acre, there is more profit in it for the money invested, ten In confirmation of this, we wish to again quote Prof. P. G. Holden, of the Iowa State Experiment Station, of Ames, Iowa, who says: "I took seed corn from the corn planter boxes of one hunlege, and planted in the trial fields of the Agricultural College. Some made only 20 bushels per acre, while other lots yielded almost 100 bushels. This wide difference was all in the seed. The land and methods being identical. The expense of growing was the same. The best seed and varieties produced fully four times as much corn, of better quality, than did the other lots 


\section{FOUR VALUABLE GRAINS TO SOW IN THE SPRING AND FALL}

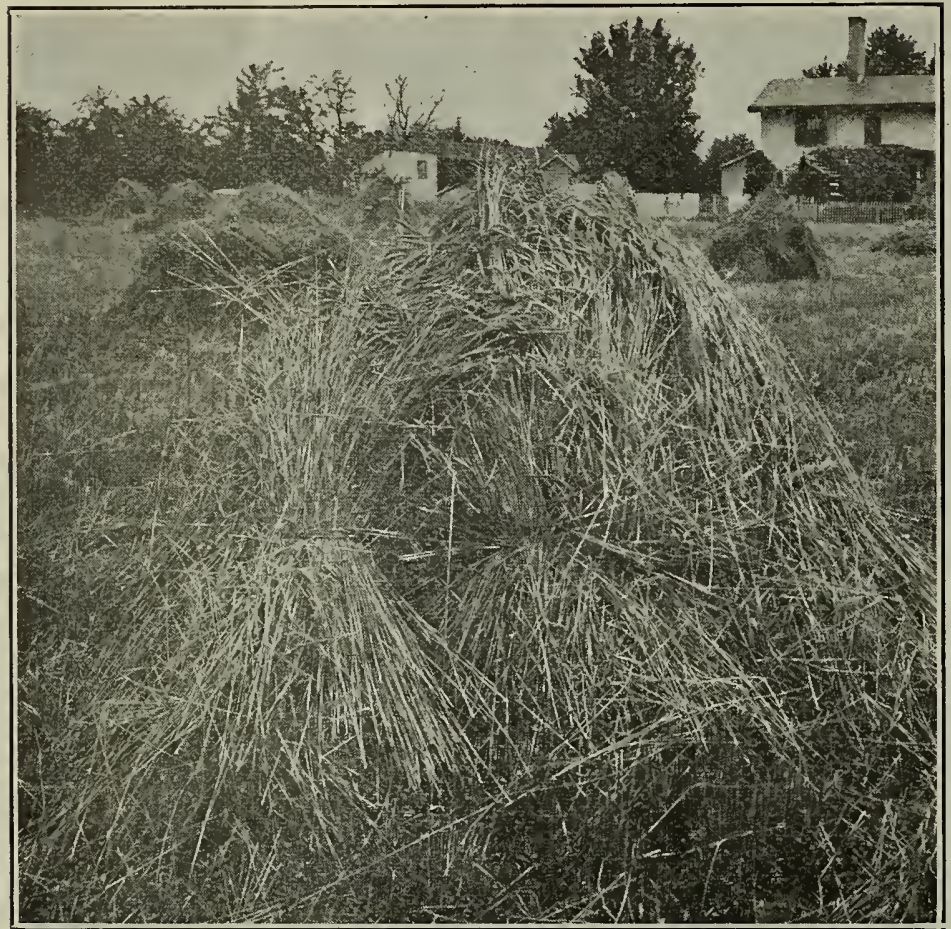

RYE

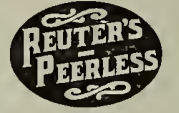

\section{REUTER'S SOUTHERN WINTER RYE}

When I say that you should plant more Rye, I don't urge you in an endeavor to sell my seed, but I realize that you ought to plant more of this valuable grain crop. "The sowing of Winter Rye in the fall and early spring in the South is becoming more popular every year as a winter and spring crop for grazing and cutting for green forage. Rye is extremely hardy, and will grow on the poorest kind of land. It makes the finest kind of winter and spring pasturage, and if sowed early can be grazed until late fall. If cut when in bloom, or before fully headed out, it makes a fair quality of hay, and when used for grain, the straw is excellent for bedding purposes.

It is not truly a soil-improving crop, but makes a great deal of humus, and when turned under on the land, will greatly help impoverished lands. Where I live it is sown from the middle of August until November, and then again in hte early spring. The main planting time is in the fall, however, as it is more valuable when sown early.

It is a very hardy plant, withstanding all kinds of very cold weather without serious injury. The ground should be well prepared before you sow; plant early, thus giving the young plants plenty of time to get a good stand. Sowed both broadcast and in drills. The seed should be covered no more than two inches. Sow at the rate of one and one-half to two bushels to the acre. The planters in Louisiana usually mix Rye with their Oats. It makes an excellent combination. If you sow a few acres in Rye in the fall, you can depend upon it to furnish you excellent grazing during the winter and spring. This is its principal value in the South, though the value of a Rye crop as a winter cover crop on the land should also be taken into consideration.

It makes about ten tons of green feed to the acre in five Don't you think it worth cultivation?

Price, 11. loc; peck 60c; bu. \$1.75. Write for quantity prices when you are about to plant. The market varies from time to time, and I sugrest that you use my Quotation Request sheet before

\section{SOUTHERN GROWN SEED WHEAT}

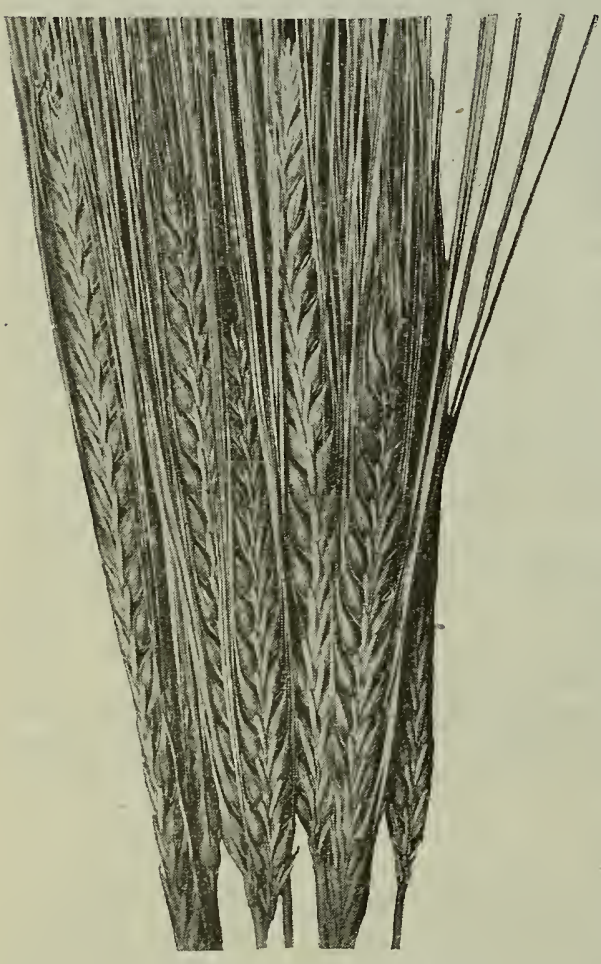

I handle both the Beardless, or Smooth Head variety, and the Bearded, or Long Wheat will give you a better yield, but it the Beardless, or Smooth Head variety, and the Bearded, or Long Berry variety. I think that the Smooth Wheat will give you a better yield; but it does not stand unfavorable weather conditions as good as the other, and then again, the grains are more liable to shatter than on the Bearded sort. Wheat is usually sown in my section during september, October, November and December, and then in the early spring. The seed will not germinate well during warm weather, and if sown too early wheat is liable to get infested with insects. Wheat requires a good soil for its perfect development. Rich clays and heavy loams that are well drained give the biggest yields. Plow your ground early if you intend to plant wheat. The best yields are obtained from early plowing, followed at intervals by harrowing, thus preventing the growth of weeds. It is both drilled and sown broadcast. The amount of seed usually sown upon an acre is

\section{GEORGIA RED WONDER}

that is immensely popular throughout the South, and is without a doubt the finest you can grow. It has a good stiff straw and stands up well. Large flinty grains, and taking it altogether, is one of the best varieties I know of. My seed is grown in Georgia by a reliable farmer, the seed is therefore thoroughly acclimated, and will always grow a satisfactory crop. Being a hardy, vigorous sort, it can be planted almost

Price. 1b. 15e; peck 75e; bu. \$2.25.

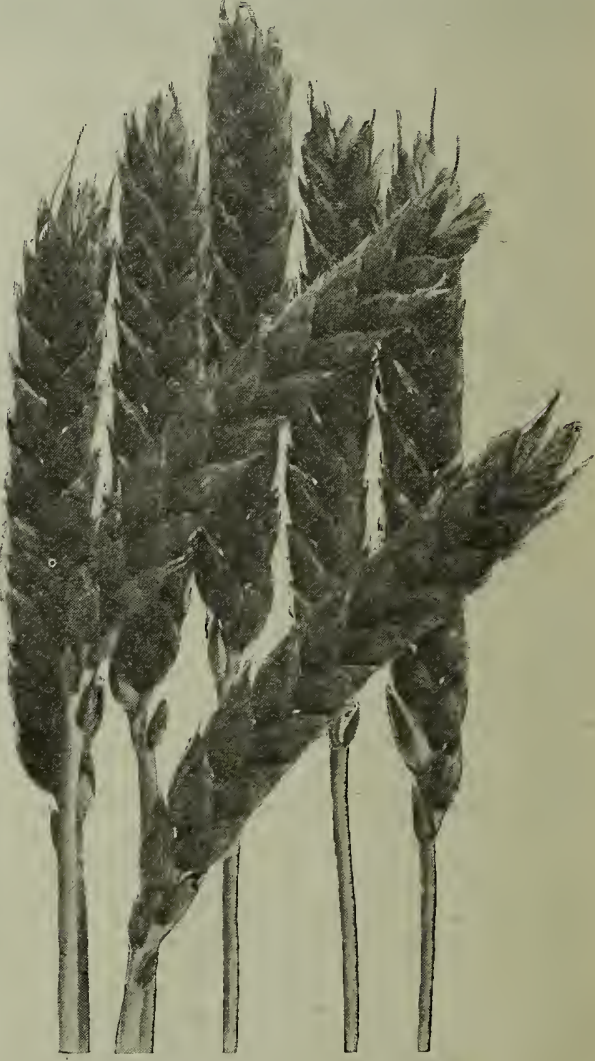

GEORGIA RED WONDER WHEAT

\section{BLUE STEM}

This is an old variety that is popular in many sections of the South. It is a very fine early beardless sort, excellent for both grain and grazing. peck 65c; bu. \$2.25. Prices change.

\section{SOUTHERN GROWN BARLEY SEED}

It is sown by us in the fall, during the months of September, October, November and sometiems in December, ley stocis out more and really makes better fall, winter and sprino grazing than either Rye or Wheat. Cut for hay it cures splendidly and is superior in nutritive and feeding qualities than Timothy hay. Sow at the rate of one and one-half to two bushels to the acre broadcast. My seed is Southern Grown. I handle only the Bearded Variety.
A very valuable new orain from Russia. It grows tall like Rye and matures early like Barley, and each year, when tested by the side of each, it has yielded twice as much per acre as Oats, and three bushels to one of Barley, and it is much better feed for stock than either. It yields forty to sixty bushels per acre, and from four to six tons of straw hay. Tough and hardy, it stands the drouth better than any other grain, making it a sure crop. It is a grain to sow tor profit. Prepare your land as you would for these crops, and sow at the rate of two busliels, or eighty pounds, per acre. Sow very early in the spring or fall, and do not let it stand until it gets ripe before cutting, as any grain that yields well

Price, 1b. 10c; bu. $\$ 2.00$. 


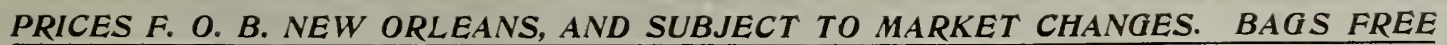

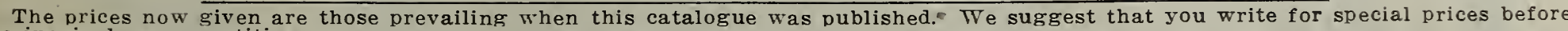
ordering in large quantities.

The varieties listed below are selected expressly for the South. They are absolutely high-grade stocks,
refully tested for germination and purity before being sold. Samples cheerfully mailed free on request.

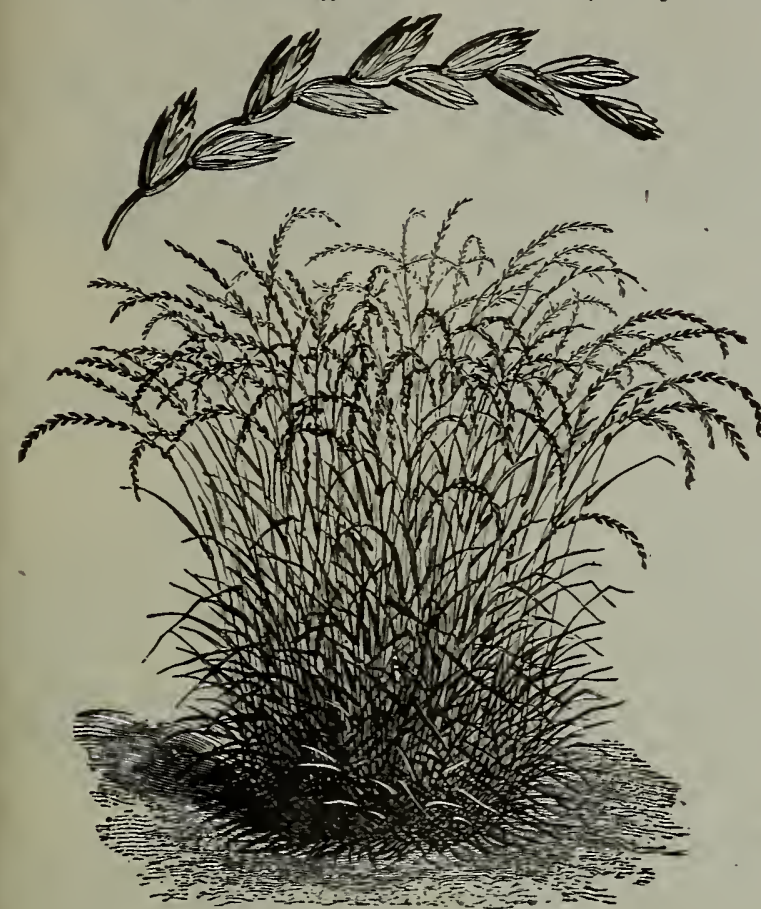

Reuter's Eaglish Rye Grass

\section{ENGLISH RYE (Lolium Perenne)}

This is a very valuable variety for permanent pasture. also for lawn purposes. It succeeds well on many soils, and is well adapted to the various solls and conditions of the South. It is worthy of all the praise given. It will cover the ground sooner and make a better sward in a few weeks after planting than most other grasses. and withstands drouth to a remarkable degree. It is used extensively for lawns The Bermuda being easily affected by frost, becomes red and rusty looking, while the English Rye during the winter presents a beautiful appearance, being a vivid green, and as the Bermuda during April and May makes its appearance. it overgrows the English Rye, causing the latter to decay and act as a fert September to March at the rate of three bushels to the acre. Our new crop is carefully recleaned and may be depended upon.

\section{Price, per lb. 15c; 10 lbs. \$1.00; bu. \$1.75.}

\section{RESCUE GRASS Bromus Unioloides)}

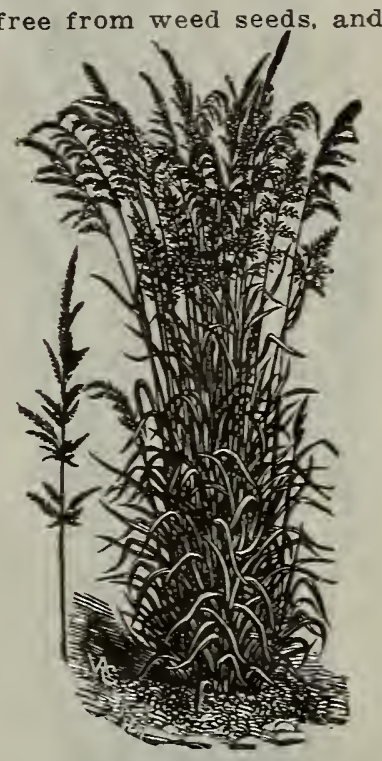

Tall Meadow Oat Grass

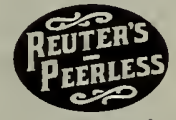

Finest grass for winter pasture in the South. It succeeds vest on rich, loamy soll. Sow during August and September and will dry and unfavorable season it may be worth but little before isebruary and March. (Sow $11 / 2$ to 2 bu. to the acre.) This grass is an annual and will die after producing seed. If prevented from seeding will last several years. During the summer it dries up of that the use of

\section{Price, per ib. 20c; per bu. 8200 ; per 100 1b. $812 . \mathrm{m}$. \\ TALL MEADOW OAT GRASS (Avena Elatior)}

This hardy perennial grass is coming into more general use in many sections of the South, and is well adapted to places where long, severe drouths exist, as its roots descend deeply into the soil. While it will grow on any good, rich soil. yet it is well
fitted for sandy or gravelly soils, particularly lowlands. May be sown in March or April, and mowed the same season. We suggest that you sow in the fall and winter. It yields heavier. Grows about three to four feet in height and produces an abundance of fine blades from the ground to the top. Also used for lawn purposes, where it retains a beautiful green color.

Price, per lb. 30c; per bu. \$3.00; per 100 lbs. \$20.00.

bushels per acre. It grows from two to five feet high, with broad leaves. While it is not so choice of soils, growing as it does on uplands and lowlands both, yet it, like other grasses, suited for it. Price. per 1b. 25c; per. bu. \$2.75; per 100 lbs. $\$ 15.00$

\section{KENTUCKY BLUE GRASS (Poa Pratensis)}

This grass has always been regarded as the standard pasture grass of America. It has no superior as a pasture grass. It forms a compact sod which will stand trampling unusually well. It is an admirable drouth resistant and is unsurpassed for fall and winter pasture. In combination with White Clover it forms the finest and smoothest lawns. For this purpose from 50 to 60 pounds of White Clver should be sowll per acre. If sown for pasture, two bushels are sufficient. It grows slowly from one to two feet tall, with many long, narrow root leaves. May be sown from September to April, preferably during February and March. The importance of a thorough preparation of the soil cannot be too strongly impressed, as satisfactory
results carnot be expected if it is done carelessly. The seedbed should be firm and compact be expected if it is done

Price. lb. 25c: per hu. \$3.00: 100 lhs. \$16.00.

\section{BERMUDA GRASS (Cynodon Dactylon)}

Bermuda is a Soutnern Grass. It delights in sunshine and warmth. It is extensively cultivated in this section of the country for lawns. It is a small, creeping, hardy perenninl, which thrives on nearly all our soils, even growing on many of our poorer, thin sandy soils, though like other grasses it gives better results on richer soils. The upright flower stems vary in height from a few inches to two feet. according to the richness of the soil. The leaves. which are short and numerous, grow near the base of the plant. Bermuda Grass is very valuable for pasture, as well as for hay crop. Grows vigorously during the hot summer months when other grasses are parched and dead. On good soll it will make splendid hay, furnishing two or more cuttings and frequently yielding four tons to the acre. It is very difficult to eradicate when once well established.

One of the chief reasons that this grass has nct been more extensively introduced is the fact that it has been the practice of propagating it from roots, as it does not mature from seed in this country. However, it is just as easy to get a good stand by growing the seed. The seed should be planted in the spring. Seed requires 60 to 90 days to germinate. The ground should be well prepared with a good firm seedbed, as the seed is small and is seeded broadcast at the raet of ten pounds per acre. Do not cover more than half an inch. The seeding should not be done too early, as the seed will not germinate if sown before the weather and ground have beeame warm.

Price. ner 1h. \$1.00; 10 lhs. \$9.00; 100 lhs. \$80.00. 


\section{REUTER'S EXTRA CLEANED GRASS SEEDS}

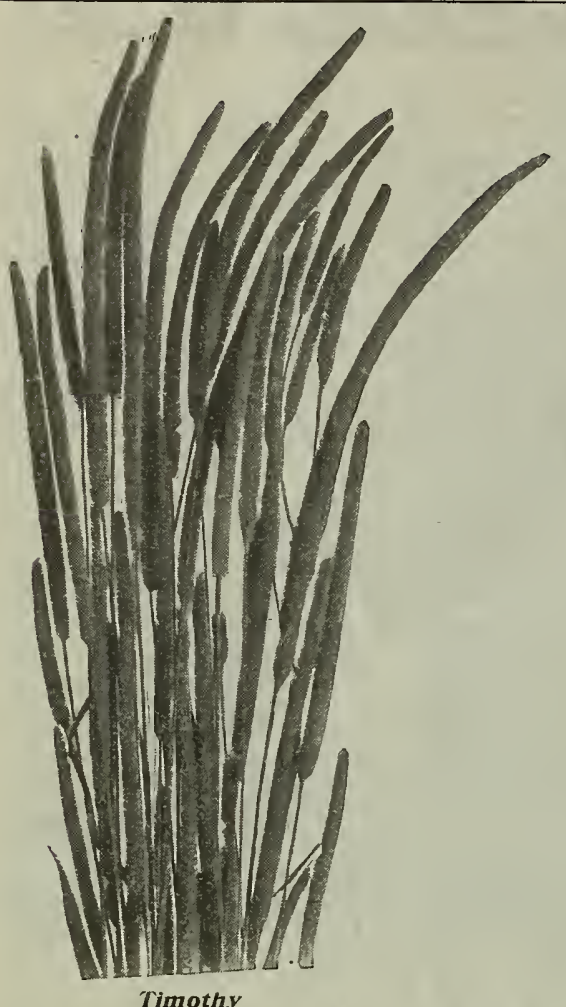

Price f.o.b. New Orleans and subject to market changes. Bags free. TIMOTHY (Phleum Pratense)

Timothy has long been recognized as the standard hay grass of this country. It is grown over a very large part of the United States. It is a perennial grass, growing from two to
four feet tall. It succeeds best in the rich, heavy clay soils. Timothy and gether make excellent hay. When sown alone one-fourth bushel of good seed should be sown per acre.

Cimothy is pre-eminently a hay crop and will not stand heavy pasturing; and, except unscarcely a variety of natural or tame grass that is more more than five or six years. There is in rcely a variety of natural or tame grass that is more generally cultivated than this. If cut in season it makes a most splendid nutritious hay, while for pasture it cannot be recommended,

Timothy should not be allowed to become over or dead ripe before cutting as the hay would become woody and lose much of its feeding value. The best time to cut Timothy for hay is when the heads are in bloom. Growing in stools. it does not form a very compact sod, and because of the shallow

Price, per lb. 20c; 10 lbs. \$1.25; bu (45 lbs.) \$3.50; 100 lbs. \$7.00.

\section{PASPALUM DILATATUM}

Sow eight to ten pounds to the acre. Has given splendid results in the South. It is an deal grass for dairy farmers, as it produces enormous quantities of fresh, green, juicy feed during the hottest weather; 1t also keeps green during the winter. The seed may be sown at any time during the fall or early spring. Germinates slowly and requires from three to four Price, per 1b. 60e; 10 lbs. \$5.00; 50 lbs. \$20.00.

\section{RED TOP, OR HERD'S GRASS (Agrostis Vulgaris)}

Ripens the same time as the Mammoth Red or Sapling Clover and Timothy and makes hay of the finest quality if sown with these. It is almost equal to Timothy for hay and superior to it for pasture. Thrives in solls too wet for Timothy. It is one of the best grasses for Spring and fall sowing. It makes a fair yield of palatable and nutritious hay and is especially to twenty days, and is more persistent and productive than other grasses under like conditions Excellent for lawn mixtures. Sow 2 bushels to the acre in September, October, Februtions. Mach. If with Timothy for hay from 6 to $10 \mathrm{lbs}$. if with other grasses for pasture, 3 to 5 lbs. A common idea regarding Red Top his been that it was only suitable for wet lands.
sut this is a mistake. It will grow on any kinl of soll.

Price, per lb. 30c; per bu. (14 lhs.) \$4.00; per 100 lbs. $\$ 30.00$.

JOHNSON GRASS (Sorghum Halapense)

A perennial grass with long, cane-like roots. It belongs to the Sorghum family of plants and so is better adapted for hay than pasture, though where well managed it furnishes fine pasture as well as hay. It thrives best on our heavy, black, lime soils, and while such soils seem to suit it best, yet it will grow almost as well on our rich clay solls. as well as

sandy soils. Grows from three to four feet high. cannot be excelled. It will give three cuttings annually and make at least three to five tons per acre. The hay is course and not attractive in appearance, but stock of all kinds eat it greedily, tender. Once planted it cannot be eradicated.

Price, per lb. 20e; 10 lbs. \$15.(K): per bu. \$3.3.5; ner 100 liss. $\$ 12$. BROMUS INERMUS, or HUNGARIAN BROME GRASS

This is a rapid growing perennial grass of recent introduction into this country. It withstands the severest droughts as well as our coldest winters, growing equally well over a large range of country. It may be sown alone or with other grasses and may be sown in the Fall or Spring, preferably during February and March. The roots form a very thick sod, crowding out weeds and other plants. It grows 3 to 4 feet high,
furnishing an abundance of splendid hay and a quick aftergrowth, which affords fine grazing. Plant 40 lbs. of seed to the acre. A bushel contains $14 \mathrm{lbs}$.

Price, per 1b. 30c; per bu. $\$ 3.00$; per 100 ibs. $\$ 20.00$.

\section{COLORADO GRASS (Panicum TeXanum)}

This grass is quite common in many sections of Texas, where it has proved invaluable for both pasture and hay. It has been introduced into sections of Oklahoma, or bottom lands throughout the Gulf States. grows to a height of from 3 to 5 feet, stems are small and leaves broad. Under favorable conditions it will crowd out other grasses and weeds, but it is very easily killed by cultivation. It is grown quite largely in some parts of Louisiana. preferring low damp soils, and will make two to three cuttings in a season. 10 lbs. $\$ 2.00 ; 100$ lbs. \$17.00.

\section{PARA GRASS-Panicum Molle}

This grass is making a wonderful record in many sections of the Southern States. It has been lately introduced into the country from South America, and its field of usefulness seems to be confined to sections below the frost line. It has been known to grow 40 feet long in one season, and four cuttings have given 18 tons of hay per the new growth being ready to cut by June and will furnish good cutting every six weeks from that time until the end of the season, although it should not be cut after Winter protection to the roots. Plant time to produce a crop of leaves to serve as a is June 15 th to August 1 st. Price of roots, $\$ 1.00$ per 100; $\$ 8.00$ per 1,000 .

\section{ITALIAN RYE (Lolium Italicum)}

A splendid variety. coming to full maturity the first season. Should be sown in during the Fall. Winter and early a dense, matter turf, which gives excellent grazing during the Fall. Winter and early Spring. It is particularly adapted for permanent yield three or four successive cuttings of most hay.ilent hay. It grows well on any soil, but is especially adapted to rich of most excellent hay. It grows well on any overflow than many other grasses. October. Three bushels sow an acre. It is be. sown during August, September and It should be cut when in bloom for hay. We strongly advise sowing this variety in mixture with other grasses and for hay. We strongly advise sowing this variety in merease the yield of the first cutting of as it comes in early and will very largely common clover successfully. When sown in this wav we recommend seeding 10 to 15 pounds of Italian Rye with ten or twelve pounds of Crimson Clover to the acre

Price, per lh. 15c; 10 lbs. $\$ 1.00$; ner hn. $\$ 1.75 ;$ per $100 \mathrm{lbs}$. \$7.00.

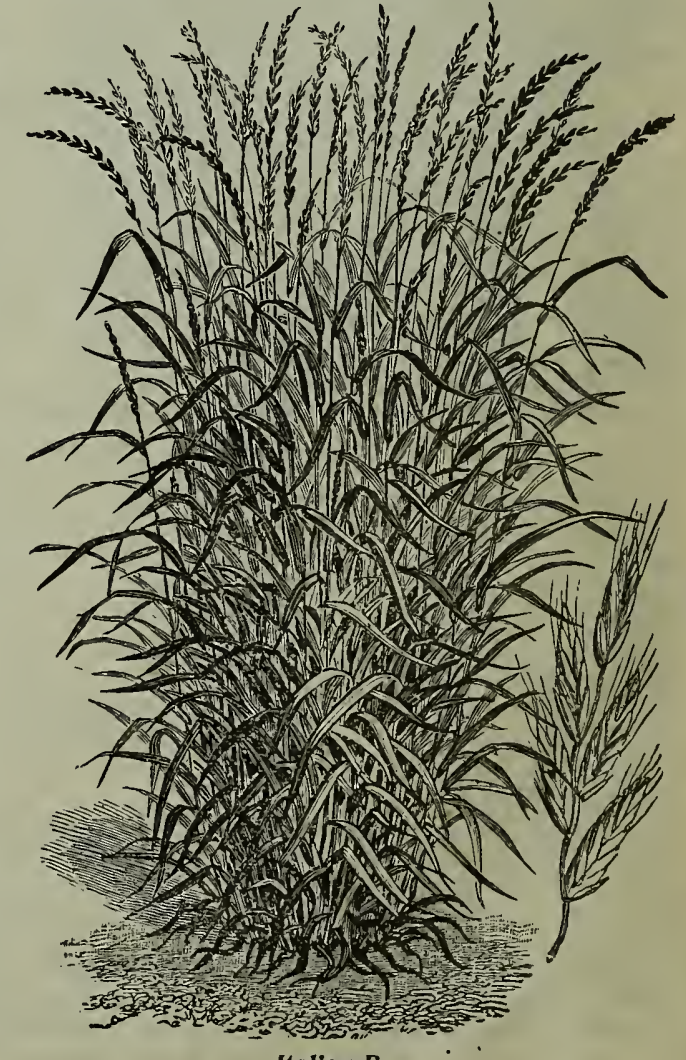

Italian Rye 
The King of Forage Crops

\section{Soy or Soja Beans}

Samples and Prices

on Request

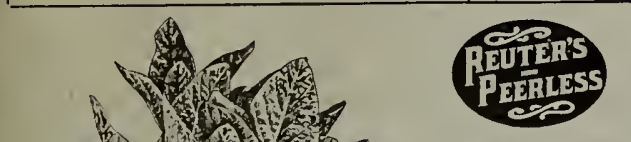

Before $I$ go ahead and tell you all about Soy Beans and how

Louisiana, Texas, and other southern states, I want te my seed, which is grown expressly for the past year has been tremendous. A stock is clean and mighty good, and is not to be all acquainted with this valuable cause I believe in Soy Beans. and have talked about their merits to every farmer in the state with whom I have come in contact. My seed is good, clean, thoroughly dried and cured. Fifty bushels to the acre was the average yield on the farm last year. This sounds mighty good. don't it? a splendid soil-improver and a great producer of nutritious feed. There is no crop so easily grown that can be used to such a good advantage as the Soy Bean. It will thrive in any kind $n f$ soil Extreniely hardy. resisting drouth, and enduring more water than corn. There is no raw vegetable product known which contains such a high percentage of protein and fat in such a highly digestible form. In enriches the ground in whick it is planted by the free nitrogen gathered from the air, and which is deposited in the ground by the roots, leaving it in ideal condition and rich in nitrogen $\mathrm{f}_{\mathrm{r}} \mathrm{the}$ next crop. Fodder is relished in either dry or green state by all kinds of cattle. Excellent to coma well-balanced ration in one crop. and I am advised that it is unnecessary to feed corn, ${ }^{\circ}$ cottnnseed meal or any oil feeds whatever when feeding Soy Beans. never seen a crop that cleans land better than these wonderful nitrogen gatherers. It is almost impossible for any weeds to thrive where a crop of Soy Beans is grown, and for effectively eradicating Soys It is not in the least affected by drouth or hot weather Resists these two elements, and withstands continued rains to a very great extent. In recent tests in Louisiana, the Soy Bean stood the excessively moist conditions better than the cowpea.

exculture-The land should be prepared as for cowpeas, and the seed planted in drills at a sufficient distance to permit one or two cultivations. One bushel of seed will plant two or three acres. the amount depending on the distance between the rows. The planting should be shallow, never more than two inches, or many of the seeds will decay. ro oculation with soil from an old soy bean field is not usually necessary in the South. Rabbits are exnear woods. If wanted for hay the crop should be cut when the upper leaves begin to turn yellow but if wanted for seed the gathering should be delayed until nearly all the leaves have fallen. The hay is easily cured and is fully as nutritious as that from Cow Peas. The yield is usually large, often ex

ceeding forty bushels per acre. It is also sown broadca

SOY BEAN

Beans may follow a crop of Rye or Barley. Sowing thickly will prevent the stalk from growing too coarse.
them to be cut and turned to better advantage.

\section{REUTER'S MAMMOTH YELLOW SOY BEANS}

Grown in Louisiana Under My Own Personal Supervision

The largest growing and most popular of all Soy Beans, and is the one kind that is so extensively cultivated in the South. 1 do not advise y nu to plant any other. This sort does very States. Grows three to five feet high. The pods ar short covered with hair and contain from one to four beans. It is a tender annual, and should not be planted until all danger of frost is past and the weather is warm and dry. While it is a dry land plant and will or on on the poorest soils, yet will produce better if planted on good soils. The time required to reach maturity varies from one hundred to one hundred and twenty davs

pressly for us under contract while our stock is grown expressly for us under contract. yet the local market influences for special prices if vou will require a laroe quantity. Anyhow, if you don't write me about the price, and send me your order. I will bill you at the market price the day I ship. Isn't that fair? bushel.

Price, fal. 60c; peck 85e; bushel $\$ 2.50 ; 10$ bushels $\$ 2.40$ per

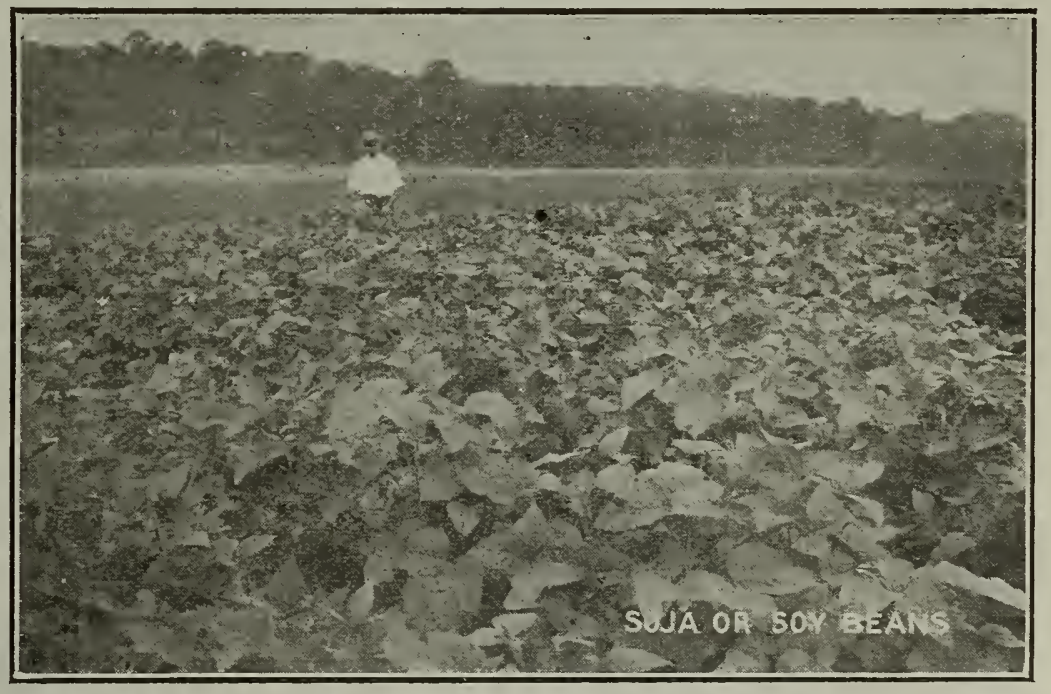

VELVET BEANS

Better Buy Your Seed

From Me This Year and Avoid Disappointment
Beware of Velvet Bean Seed!

If in doubt, send your Seed to the State Laboratory for testing

VELVET BEANS

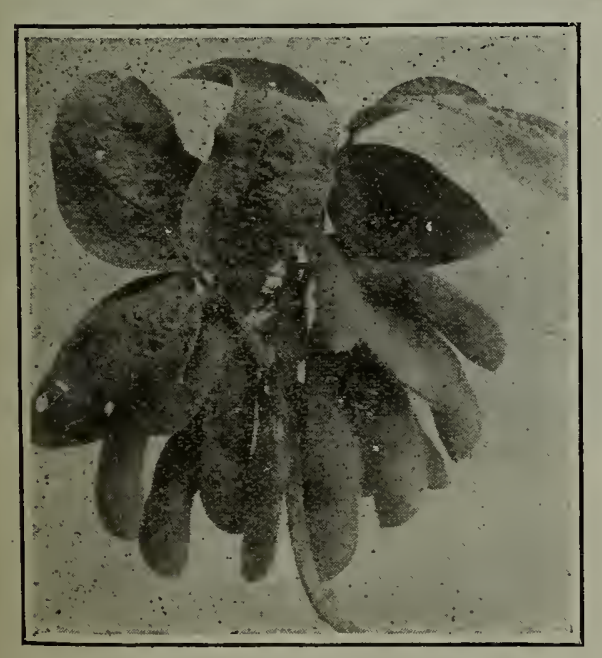

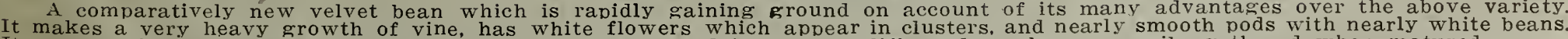

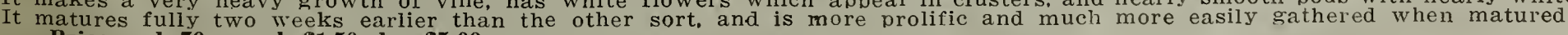

Price, ral. 70c; peek \$1.50: bu. \$5 00.
The velvet bean is the most rank growing annual legume cultivated for forage and is one of the best plants for the production of feed and as a restorative crop in rotation. vines are so long and tangled that it is difficult to cut and cure, though when cut early and well cured the hay is of excellent qualit. It makes an immense amount of fall and winter grazing, produces seed abundantly and following crop. In this respect, it is far superior about a peck to a peck and a quarter to plant an acre. and one bushel will sow three to four acres very easily.

It is principally used for winter grazing, and for that purpose it is one of the best crops that can be grown. Grazing usually begins at about the time of the first frost. and may be continued through the winter, as both vines and beans remain in an eatable conand again when they become slightly softened in late winter, so that all are consumed before the ground is ploughed in the spring. Dairvmen find that it oives the greatest stimulus to milk production when grazed in the fall, while beef growers value it more highly for winter grazing. Hogs usually find plenty of grow fifty feet long and set great clusters of pods, which are soft and hairy like velvet. Should be planted from March until May at the rate of one peck per acre. The plant will not grow until the soil and weather both become warm. Plant in rows four be sown broadcast and plowed in. They soon make rapid growth and completely cover the ground with a thick mass of leaves.

\section{BROWN FLORIDA. or SPECKLE VELVET BEANS}

The variety that is so generally grown in the South. Makes a very strong growth. Price. gal. 70c; peck \$1.25; bu. \$4.50.

\section{FAMOUS LYON VELVET BEAN}




\section{GREAT SOIL}

IMPROVER

\section{COW PEAS}

WRITE FOR

MARKET PRICES

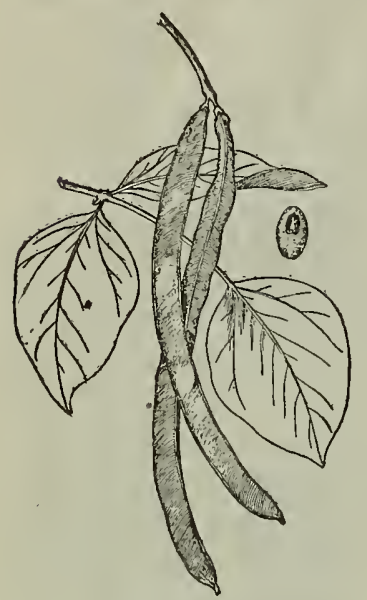

THE CLAY

It is safe to say that no one thing can add more to the agricultural wealth of the South than the more extensive growing of the Cow Pea. This will supply the Southern markets with much of their hay, whicl
is now shipped in from the North and West. It will tend to increase the production of live stock, which is
very essential in securing the maximum returns of any system of agriculture; and it will go far toward very essential in securing the maximum returns of any system of agriculture; and it will go far toward that the Cow Pea is essential to successful agriculture and more Cow Peas are planted every year by the farmers in the South. It is the greatest plant for all the Southern States, for grain, hay, and to be used as a soil renovator. The Cow Pea is a wonderful gatherer of nitrogen, and as a means of adding humus to the soil is easily the superior of any nitrogen gathering legume. It is the staple forage crop for corn at the last plowing, when it will make a good crop of hay, and at the same time furnish plant food for the soil. mination, as seed more than one year old is likely to be very low in vitality. It is practically certain

Good Cow Pea hay is fully as valuable for feed, pound for pound, as Red Clover Hay, and very nearly qual in value to Alfalfa, or to wheat bran. The principal value of this hay lies in its high percentage of digestible protein, which is nearly four times that of Timothy Hay. One reason why Cow Peas are not more extensively used as a hay crop is the difficulty often experienced.in curing the large growth of suc. with it in mixture, it is not a difficult matter to make good Cow Pea Hay unless the weather is decidedly unfavorable. The Cow Pea is a tender annual, easily affected by frost and wet weather, so should not be planted until all danger of frost is past and the weather becomes warm and the soil dry Can be sown in drills from two to three feet apart and cultivated. However, it is generally more profitable to sow broadcast about two or three bushels to the acre. When grown for hay, they are usually sown in our secripe. At this stage none of the best hay varieties have dropped their leaves. The readiness with which the hay can be cured depends largely upon the maturity of the vine and the conditions of the weather; hence the advisability of having the harvesting done when the season is most likely to be dry.

fufficient PEAS IN MIXTURES.-Cow peas are frequently sown with Corn. When grown the farmer secures a crop of Corn, is an excellent plant to grow with Corn for ensilage, and is being quite extensively used for this purpose in the South, where silos are becoming popular. When planted in the cornfield it is usually at the last cultivation of that crop. The quantity of seed used to the acre ranges from a half a bushel or less to two bushels, depending largely on whether the planting is broadcast or in used to the acre ranges from a half a bushel or less to two bushels, depending largely on whether the planting is broadcast or in rows close to the corn. The best results I have obtained are by the use of about three pecks of seed and planting near the rows of corn, preferably with a corn, cotton, or other planter, immediately after the last plowing of the corn. In the sugar cane districts tice and is becoming general. The work is very satisfactorily done with a strong wooden-toothed rake, which pulls the vines and leaves them in small bunches for curing. The harvesting is also done with a mower to some extent.

Cow Peas are also planted with other crops successfully. It is planted with sorghum, kaffir corn, soy beans, etc. Very favorable reports have come in from my customers who have planted with soy beans, as they are strong enough to assist very materially hay of this mixture is an exceedingly lich one, as the composition of both plants is ligh in protein. Seeding should be at the rate of a bushel of Soy Beans and a half bushel of Cow Peas on an acre.

Millets are often grown in mixtures with Cow Peas. You must sow a quick growing variety of Cow Peas in this mixture. er use the late rank growing sorts with Millet. Sow three pecks of Millet and the same quantity of Cow Peas to the acre.

The feeding value of Cow Pea hay has long bees recognized, and it is so extensively known, that it is unnecessary for me to

There are at least fifty varieties of Cow Peas, but only a few of the very best of these are extensively cultivated in my section. Some are trailing. while others are half-runners, and others are of the bunch variety. Some are early, others late.

\section{THE CLAY-Best Variety for the South}

It is the most popular pea in the South. The plants are vigorous, usually seeding sparingly. Tall, erect, large green leaves. Pods are large and yellowish, seeds kidney shaped, medium size, cream color; medium to late in ripening.

\section{WHIPPOORWILL}

A favorite early bunch-growing variety. Seed is reddish brown speckled. A great favorite on account of its early ma-

Price, gal 50c; peck 75c; bu. \$2.50.

\section{UNKNOWN, or WONDERFUL}

A very vigorous orower. It is the largest growing and The seed is large in size and of a very light clay color.

\section{NEW ERA}

is not inclined

Price, gal. 60c: peck $850 ;$ bu. $\$ 3.00$.

\section{LARGE BLACK $=E Y E$}

This is a laroc late vining variety. The vines grow very

large; also good for table use. Matures in six to eight weeks.

Price, gal. 60c; peck s5e; bu. \$\$.00.

\section{WHITE SUGAR CROWDER}

Grows upright, bushy and under ordinary conditions needs pining varieties Every farmer should plant th

\section{RED RIPPER}

Vigorous, half-trailing large green leaves, and stems. valuable variety and excellent to grow in Corn. The seed is dark red. Matures late.

\section{MIXED}

Large quantities of peas are mixed through handling, and will not grade as straight varieties. Just as good for forage purposes and make fine pasture, as they mature at different times. Usually sell for less than the others.

Price, gal. 40c; peck 60e; bu. \$2.00.

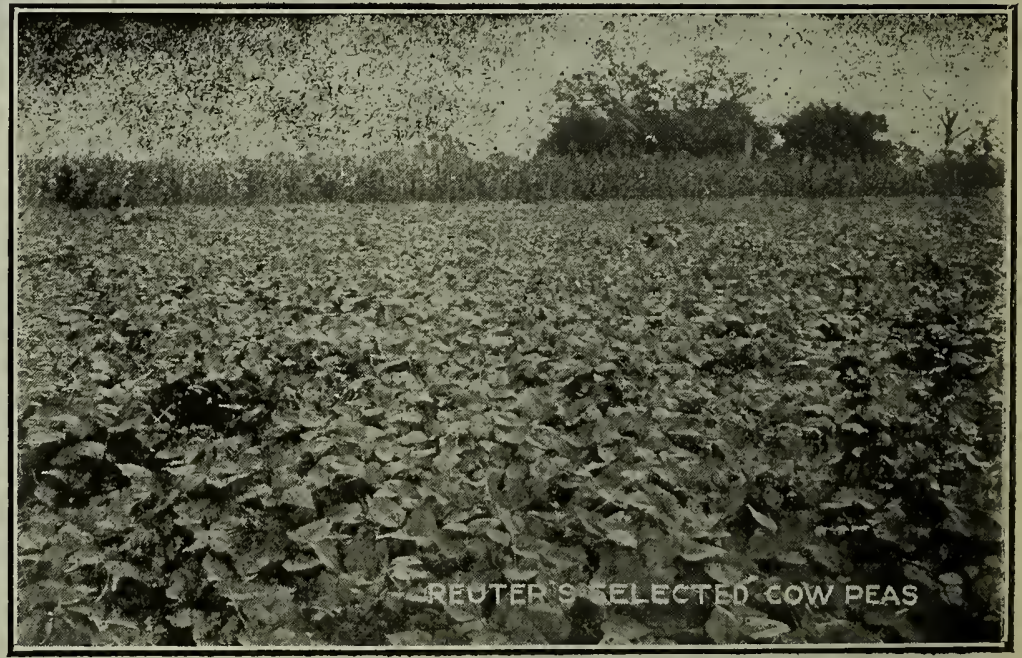

\section{CANADA FIELD PEAS}

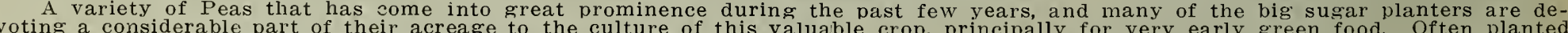

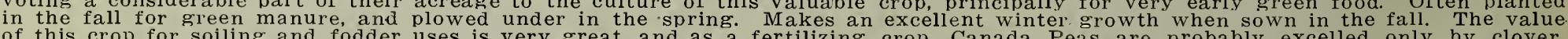

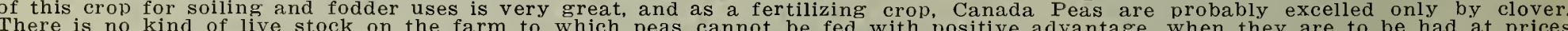

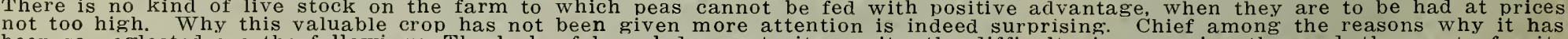

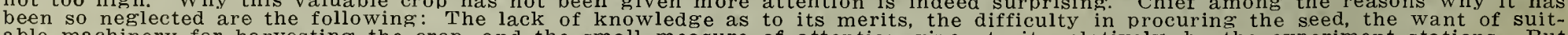

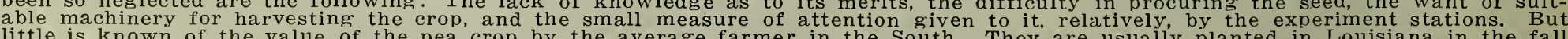

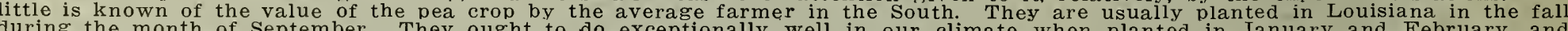

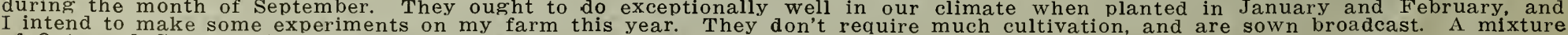
of Oats and Canada Field Peas is not bad if the land is rich enough.

Price, gal. 60e; peck \$1.00; bu. \$3.50. 


\section{Monthly Table for Sowing Grass, Field and Vegetable Seeds}

WHAT TO PLANT AND WHEN TO PLANT FOR EACH MONTH IN THE YEAR.

The directions given here are for the latitude of New Orleans-the great vegetable-growing scction of America.

If applied north

of here tie time oi planting will be later, while persons in a more southern latitude should start sowing earlier.

To attain success in growing vegetables it is absolutely essential that only Pure and Reliable Seeds be sown. REUTER'S PEERLESS VEGETABLE SEEDS are the STANDARD among the leading Market Gardeners in New Orleans, and are unexcelled for their great purity and fine quaitity.

\section{JANUARY.}

Sow Beets, Carrots, Spinach, Radishes, Mustard, Turnips, Leeks. Sow Lettuce, Endive, Cabbage, Broccoli, Kohlrabi, Large Algiers, Early Snowball, and Dry Weather Cauliflower. As the weather is rather unstable during this month, it is advisable to sow in a frame and protect the young plants during the severe
cold weather. and set them out the latter part of February, or beginning of Alarci.

Chervil, Soup Celery, and Parsley should be sown. Sow Eggplants. Peppers, Tomatoes, and Cucumbers in hot beds. Herb leading varieties.

Plant Peas of ali kinds for spring crop, such as Black Eye Marrowfat. Large White Marrowlat, Telephone, Stratagem, Champion of England, etc. The Extra Early varieties, such as Reuter's etc.. do better if planted the latter part of this month.

Irish Potatoes should also be planted this month. Note our ist of standard varieties. Divide and tran

Cabbage plants sown in November. tion are the Red and White Bermuda, Crystal White Wax, Red and White Creole, Australian Brown. White Queen. etc. Now is the right time to sow Onion Seeds for sets. Sow Cucumbers in the right time to sow Onion Seeds for sets. Sow Cucumbers in or when danger nf frost is over.

Plant Red Rust Proof Oats, Speltz, Seed Rye, Barley, Wheat, Spring and Hairy Vetch, Alfalfa, all kinds of Clover. (Note our select list.) Buckwheat, Dwarf Essex Rape, Kentucky Blue, Red
Top, Rescue, Johnson, Tall Meadow Oat, Meadow Fescue, Orchard Grass, Timothy, all varieties of Millet, etc.

\section{FEERUARY.}

Sow Beets. Carrots, Radishes, Mustard, Spinach. Parsnips, Leeks. Turnips, Swiss Chard, and Kohlrabi.

Sow Lettuce, Cabbage, Cauliflower, Chervil, Soup Celery, Pars. ley. and Endive. Shallots can be taken up, divided and set out. All varieties of Peas can be planted now. Potatoes for general all the leading varieties. Plant Asparagus seed and roots.

Begin to plant Bush Beans as soon as the weathes permits. Cucumbers. Melons, and Squash can be planted in the open ground, but must be protected with boxes. Continue to plant Eggplants, Corn can be planted.

In the Field, plant Alfalfa, Dwart Essex Rape, Hairy and Spring Vetch. and all kinds of Grass and Clover Seeds that are planted in January. Sorghum can also be planted this month. Mangel Wurzels and Sugar Beets should be sown for stock food. Don't fail to plant Lespedeza Clover this month. It is the best famous Seed Corn.

\section{MARCE}

Sow Beets, Carrots. Radishes, Lettuce, Spinach, Mustard, Swiss hard, Leek, Soup. Celery, Parsley, Chervil and Endive. Plant Bush and Pole Beans of all kinds. but for Lima Beans would advise waiting until the end of the month, as they rot easily when the ground is not warm enough or too wet. Sow squash, Cucumin the open ground and sow the seed for a later crop. Plant all varieties of Peas. Plant Potatoes and Corn

Sow Sorghums. Kaffir Corn, Dhouro, Milo Maize. Teosinte, Broom Corn (we are agents for Ratekin's Famous Seed Corn), Alfalfa. Lespedeza or Japan Clover, and other well-known varieAlfalfa, Lespedeza or Japan Clover, and other well-known varie-
ties. Plant Cow Peas, Velvet Beans, Soy Beans, Canada Field ties. Plant Cow Peas, relvet Beans, Soy Beans, Canada Field usually the quality is lower than the price.
us

\section{APRIL.}

Sow Beets, Carrots, Parsley, Mustard, Radishes, Chervil, Soup Celery, Lettuce, Endive. Escarol, Melons, Okra, Squash, Tomatoes 作 Beans. Pumpkins can also be planted now. Sow Kohlrabi in Towards the latter part of the month, sow Late Italian Giant Caiflo the latter part of the month, sow Late Italian Giant and should, therefore, be planted early. Plant Tomatoes and Corn, With Grass and Field Seeds, continue to plant as in March, putting in a good forage crop when the ground is idle.

$$
\text { MAX }
$$

Sow Corn, Melons, Cucumbers, Squash, Eggplants, Tomatoes, Peppers. Okra, Pumpkins, Bush and Pole Beans, Radishes, and Early Market, 'Large Salamander, Royal Summer Cabbage, etc. During the hot weather. Lettuce requires a great deal of water, and it will, if neglected, soon become hard and tasteless. Celery for bleaehing may be sown this month, but requires plenty of water. Sow Large Algiers and Early Italian Giant Cauliflower. June, Squaw Corn and White Wonder if planted this month will make a fine crop of roasting ears.

Sorghums, Millet, Cow Peas, Soy and Velvet Beans, Field and Broom Corn can also be planted

\section{JUNE,} Plant Farly Mohawk, Yellow Six Weeks, Bush Beans, and
Southern Prolifie and Router's White Creaseback Pole Beans. Sow
Melons, Squash. Cusumbers, Okra, Endire, Pumpkins, and Mexican June Squaw and White Wonder Corn. Large Algiers and may still be sown this month, and towara the end of can be sown. Sow Celery for bleaching, summer varieties of Lettuce and Radishes, Purple Top and White Flat Dutch Turnips,
and Mustard. Sow Tomatoes, Eggplants, and Peppers for a fall crop. Cabbage may also be sown in this month for winter crops. The Flat Dutch and Drumhead varieties seem to do the best it anted this month.

Plant Cow Peas, Canada Field Peas, Soy and Velvet Beans, Sorghums, and all varieties of Field Seed Corn can be planted.
Remember that we are agents for Ratekin's Famous Seed Corns. JULY.

Get a copy of my fall price list. It will help you to select Sow Cucumbers, Tomatoes, Large Algiers and Early Italian Giant Cauliflower, Endive, Lettuce, Turnips, Radishes, Leets, IIustard. Parsley; Celery for bleaching and Soup Cel

sown. Plant Pole, Bush, and Lima Beans, Mexi

the ravages of the insects, we recom

Plant Field Corn. Try our White Wonder. A grand sort for late planting. Continue to plant Cow and Ca
Velvet Beans. Soy Beans, Millet. Sorghums, etc.

\section{AUGUST,}

This is the priacipal month for the market gardeners in thie South as they are all now busy sowing and planting all kinds of Vegetables.

Sow Beets, Carrots, Half Long French and Long Brightest Scarlet Radishes, Parsley, Chervil, Lettuce, Endive, Kohirabi, Mustard, Swiss Chard, all kinds of Turnips, all varieties of Cabbages Celery, and other varieties of Celery. Sow Large Algiers and Early Italian Giant Cauliflower. Sow Tomatoes for late crop. Plant Bush Beans, Early Washington, Blue Beauty, Early Alaska, First \& Best, Reuter's Peerless Extra Early. Black Eye, and Large be planted early this moth for winter crop. Mexican June, Squaw and White Worder Corn can still be planted. During this month Shallots and Onion Sets can be set out.

Plant Cow Peas, Field Peas, SEPTEMBER.

Plant Bush Beans and all early varieties of Peas. Sow Radishes, Beets, Carrots, Parsley. Mustard, Chervil, Swiss Chard, Endive, Leeks, Kohlrabi, all varieties of Celery. Lettuce, Turnips, Cabbages of all kinds, also Salsify. Parsnips and Celeriac.

Red and White Creole, Red and White Bermuda, Crystal White Wax are the best sorts for the South. Set out Celery Cabbage and Caulifiower Plants. Sow Spinach if the weather is not too warm and dry. Continue to plant Potato
crop. Set out Shallots and Onion Sets.

Plow under your Cow Peas and prepare your land to plant Seed Rye, Barley, Wheat, Oats, Speltz, Hairy and Spring Vetch Buckwheat, all varieties of Clover (except Japan Clover), Dwar Rescue, Timothy, etc. Wow Canada Field Peas this month for a winter cover crop. Possibly you might continue to plant Milwinter cover crop. Possibly you might continue to plant Mil-
lets, Giant Beggar Weed. Try our two new Grasses-Sudan and Rhodes. Both are wonderful prod

Sow Cabbage; we are proud of our list of standard tested rarieties. Sow Onion Seeds of all kinds, also Spinach, Cauliflower, Parsley, Chervi, Ǩohirabi. Lettice, Radishes. Endive, Soup Celery, Celeriac. Parsnips, Brussels Sprouts. Late varieties of Peas can
be planted. Divide and transplant Shallots. Set out Artichoke plants.

Plant Rye. Barley, Wheat. Louisiana Rust Proof Oats, Speltz, Sow Red Top, Kentucky Blue, Timothy, Rescue Grass, and all other varieties mentioned during Septemicr. Note our carefully other varieties mentioned during Sept

\section{NOVEMBER.}

Sow Spinach. Radishes, Beets, Carrots, Turnips, Lettuce, Leeks, Endive, Escarol. Mustard, Kohlrabi, Parsley, Salsify, Parsnips and ing bage. Plant Black wye anth prepare the hotbeds for Cucumbers. Comtinue to set out Artichoke plants.

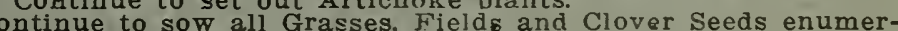
ated for October.

\section{DECEMBER.}

Sow Spinach. Radishes, Carrots Beets, Endive, Lettuce, Leeks, Turnips. Mustard. Sow Cabbage, Cauliflower and Kohlrabi in a frame for a late spring crop. Sow Peppers, Tomatoes, Cucumbers, Eggplants in hotbeds for early plants. Set out Artichoke plants. Dwarf Essex Rape, all kinds of Grass Seeds, Rye, Wheat, Berley, Speltz and Oats. 


\section{Tables Showing the Quantity of Seed Usually Sown Upon an Acre}

The following estimates apply strictly for REUTER'E SEEDS-seeds that are fresh, pure, fuil of vitality and ready to grow when planted. Seeds offered at cheaper prices than mine are usually old and of poor germination, requiring considerably more to plant the same acreage. It's economy to plant Reuter's Seeds. More than 50,000 critical Southern Market Gardeners tell you the very same thing.

\section{VEGETABLE SEEDS}

\section{Quantity}

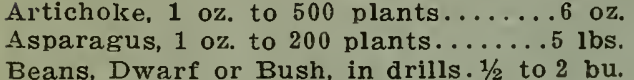

Artichoke, $1 \mathrm{oz}$. to 500 plants.......
Asparagus, $1 \mathrm{oz}$. to 200 plants......
Beans, Dwarf or Bush, in drills. $1 / 2$ to $2 \mathrm{bu}$.

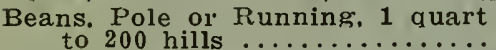

$1 / 2 \mathrm{bu}$.

Beets. Garden, $1 \mathrm{oz}$. to 100 feet of $10 \mathrm{lbs}$. Beets. Mangel. 1 to oz. to $150 . \ldots \ldots 6 \mathrm{lbs}$. Broccoli, 1 oz. to 3,000 plants......... Brussel Sprouts, $1 \mathrm{oz}$, to 3,000 plants $5 \mathrm{oz}$. Carrot. 1 oz. to 100 feet of drili....4 lbs. Caulifiower. 1 oz, to 3,000 plants....5 oz. Cellery, 1 oz. to 10,000 plants.......4.
Quantity
per acre.

Corn. Sweet, 1 quart to 50 hills....10 qts. Cress. $1 \mathrm{oz}$. to 150 feet of drill.....8 $\mathrm{lbs}$. Cucumber, 1 oz, to 100 hills $\ldots \ldots .2$ lbs. Engivant, 1 oz. to 2.000 plants. $\ldots \ldots 4$ oz. Garlic, bulbs, $1 \mathrm{lb}$, to 10 feet of drill $.2 \mathrm{bu}$. Garlic. bulbs, 1 lb. to 10 feet of drill.$_{1 \%}^{2}$ bu. Gourds, 1 oz. to 25 hills.........2 Kale. 1 oz. to 3,000 plants.........2 Leek, 1 oz. to 200 feet of drill. . . 44 lbs. Lettuce, 1 oz, to 200 feet of drill.2 to $4 \mathrm{lbs}$. Melons, Water, 1 oz. to 25 hills...... Okra, 1 oz to 50 feet of drill......10 lbs. Onion Seed, for Sets $\ldots \ldots \ldots \ldots . . . . .30$ lbs. Onion Sets. 1 quart to 20 feet of drili. 8 bu. Peas, Garden, 1 quart to 100 feet of

Quantity Pepper, 1 oz to 1500 plants ......... Parsley, $1 \mathrm{oz}$ to 200 feet of driil...... Parsnips, $1 \mathrm{oz}$. to 250 feet of drill...5 $\mathrm{lhs}$. Potatoes (Irish) average........10-14 Bu,

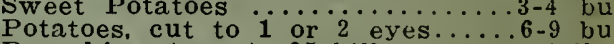
Pumpkins, 1 oz. to 25 hills........ Radish, 1 oz. to 100 feet of drill..... iv lbs Rhubarb, 1 oz. to 500 plants

Salsify, 1 oz. to 150 feet of dirill...... Squash, Dwarf, $1 \mathrm{oz}$. to 40 hills...... 3 lbs Squash, Running Varieties. $1 \mathrm{oz}$. to $10 \mathrm{lb}$

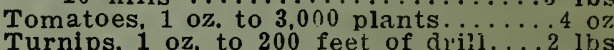

\section{GRASS AND FIELD SEEDS}

Quantity per acre

Barley

Buckwheat

Corn, (for silage)

Corn, Pop

Corn, Sugar

Clover. Alfalfa (broadcast)

Alfalfa (drilled) (a.....

Clover. Alsyke (on Wheat or

Rye) ......................

Clover. Crimson (on Vetch or

Rye) $\ldots$ (Huiled)
Clover, Burr

Clover, Burr (Unliulled)

Clover, Maminoth or Sapling

Clover, Mammoth (on Timothy) Clover, Red (alone) ….... $15-20$ lbs. Clover, White Dutch ..........12-15 lbs. Clover, Melilotus or Sweet..15 to $20 \mathrm{lbs}$. Clover, Japan (Lespedeza)

Clover, Japan
(on Oats in spring)

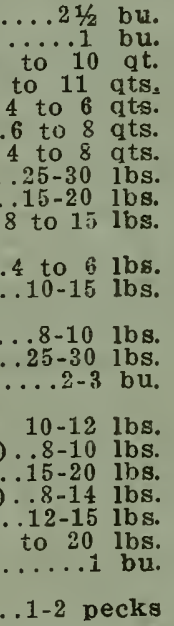

\section{Quantity}

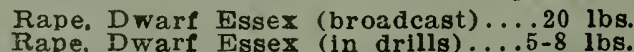
Grass, Bermuda ................. Grass, English Bluo ................. Grass, Para Grass, Kentucky Blue $\ldots \ldots \ldots \ldots \ldots \ldots .2$ bu Grass, English Rye $\ldots \ldots \ldots \ldots \ldots \ldots, 3$ bu Grass, Italian Rye $\ldots \ldots \ldots \ldots \ldots \ldots \ldots, 3$, bu

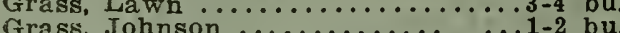
Grass, Johnson.$\ldots \ldots \ldots \ldots \ldots \ldots \ldots \ldots \ldots \ldots \ldots$ Grass, Orchard $\ldots \ldots \ldots \ldots \ldots \ldots \ldots \ldots, \ldots, 2$ bu Grass, Red Top . . . . . . . . . . Grass, Rescue $\ldots \ldots \ldots \ldots \ldots \ldots 2$ bu $\ldots \ldots \ldots \ldots \ldots 2$ bu Grass, Timothy .............15-25 lbs. Grass, Hungarian or Broom ....15-20 lbs Guinea Grass ............. Root Cuttings

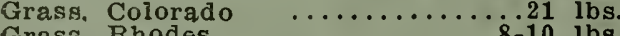
Grass, Rhodes (a................ Grass, Sudan (alone) $\ldots \ldots \ldots \ldots \ldots 30$ lbs. Grass, Sudan (on Cow Peas) .....20 lbs Kaffir Corn (in drills) $\ldots \ldots \ldots \ldots .1 / 2$ bu Kaffir Corn (broadcast) $\ldots \ldots \ldots \% \%_{1 / 1}$ bu. Hemp (in drills $\ldots \ldots \ldots \ldots \ldots \ldots \ldots \ldots \ldots \ldots \ldots$ 1/2 bu Hemp (broadcast) $\ldots \ldots \ldots \ldots \ldots \ldots 1 / 4$ bu Millet, Japanese $\ldots \ldots \ldots \ldots \ldots \ldots \ldots 25.30$ lbs.
Quantíty per acre.

Millet, Pearl $\ldots \ldots \ldots \ldots \ldots \ldots \ldots \ldots \ldots \ldots$ 10-12 lbs. Millet, Hungarian ........... Mowlet, Manitoba $\operatorname{Hog} \ldots \ldots \ldots \ldots \ldots{ }^{8 / 4-1}$ bu. Cow Peas (in drili, with corn).... Cow Peas (for seed .... $\ldots \ldots 2-3$ pecks Oats (alone)

. Peanuts. in hull $\ldots \ldots \ldots \ldots \ldots \ldots \ldots \ldots \ldots \ldots \ldots \ldots, 2$ bu.

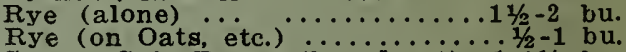
Soy or Soja Beans (broadcast)..1-11/2 bu. Soy of Soja Beans (in drills) ....2-3 pecks Sorghum (forage, broadcast) ...11/2-2 bu. Sorghum (for seed or syrup) .....5-8 lbs. Sorghum (for silage or solling.

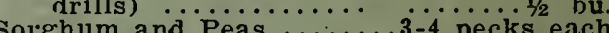

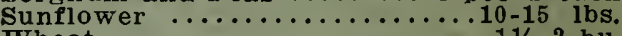

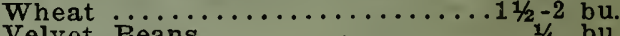

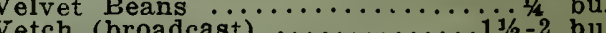
(n) Vetch (on small grain) $\ldots \ldots \ldots \ldots \ldots \ldots$ in bu

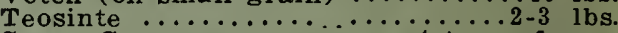

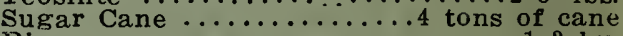

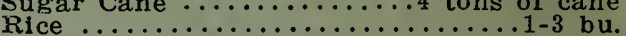

\section{STANDARD WEIGHTS OF VARIOUS SEEDS Per Bushel}

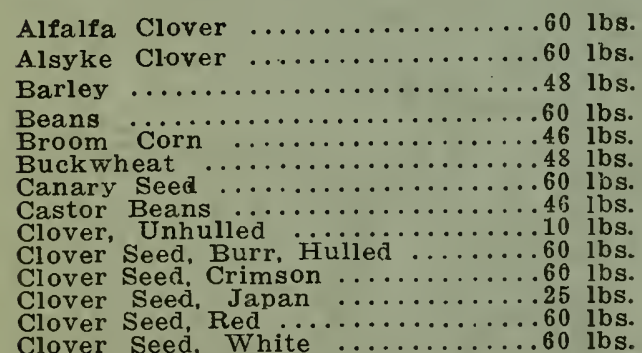
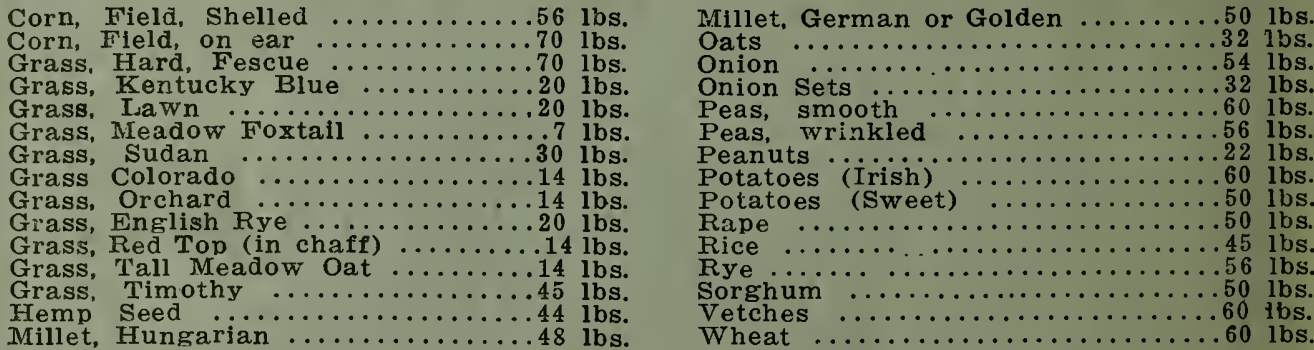

\section{DIRECTIONS FOR MAKING A HOT=BED}

Owing to the mild winters in the South, hotbeds are not used as extensively as in the North, except to raise such tender plants as Peppers, Eggplants and Tomatoes. There is little forcing of Vegetables done here, with the exception of Cucumbers and Lettuce and, if we do not have frosts, the latter does better in the open ground than under glass. It is rather simple to make a hotbed. Anyone who has the use of tools can make the wooden frame; the sashes can be obtained from any sash factory. We consider a wooden frame five to six feet wide and ten feet six inches long a very good size. It should be at least six inches higher ta the back than in the front, and covered by three sashes $3 \frac{12}{2} \times 5$ feet. The manure should not be over a month old; it should be thrown together in a heap, and, when commencing to heat, be worked over with a fork, and the long and short manure evenly mixed. In Louisiana the ground is generally low, and, to retain the heat of the manure for a long time, it is best to put the manure on top of the ground-that is, make a bank two feet wider than the frame. Keep the edges straight and the corners firm; when thrown up about eighteen inches, trample the manure down to six or eight inches, then put another layer of eighteen inches and trample down again; place thereon the frame and sash and fill in six
to kill the weeds, which may have come up; then sow; the seesd. 


\section{Order Sheet for Genuine Bermuda Onion Seeds}

CAREFULLY GROWN AND SELECTED BY

T. M. REID, PORT OROTOVA, TENERIFFE (Spain)

EXPRESSLY FOR
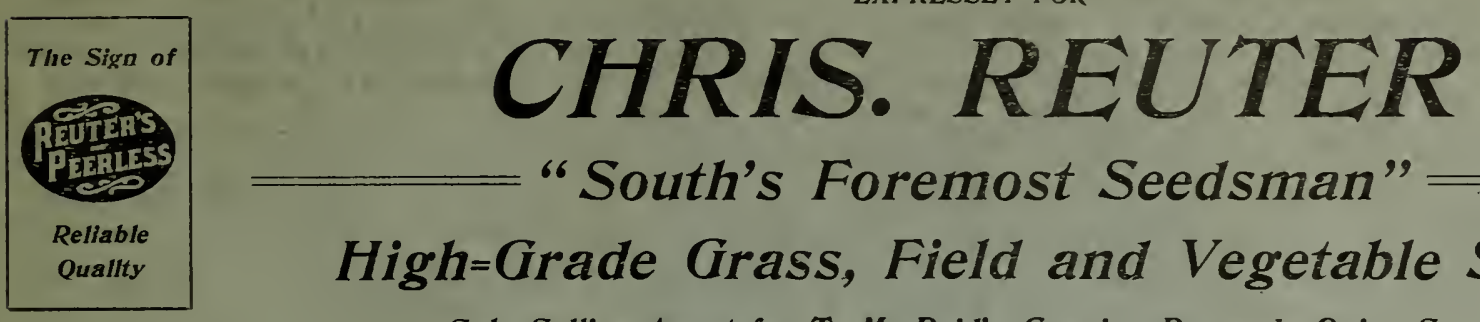

"South's Foremost Seedsman"

High=Grade Grass, Field and Vegetable Seeds

Sole Selling Agent for T. M. Reid's Genuine Bermuda Onion Seeds

Office and Store: 1136=1140 DECATUR STREET, New Orleans, La.

Please enter my order for the following quantities of T. M. REID'S GENUINE BERMUDA ONION SEED, delivery to be made after harvest of the present growing crop-August=September, 1914.

$\begin{array}{lll}\text { Ibs. WHITE (YELLOW) BERMUDA } & \text { at } \$ & \text { per } 1 \text { b. } \$ \\ \text { Ibs. CRYSTAL WHITE WAX } & \text { at } \$ & \text { per } 1 b . \$ \\ \text { Ibs. RED BERMUDA } & \text { at } \$ & \text { per } 1 b . \$\end{array}$

Prices F. O. B. New Orleans - Freight and Duty Paid

ABOUT DELIVERY - With a NORMAL Onion Seed Crop I can MAKE FULL DELIVERY to my customers, as I do not book orders for more than 75 per cent of the quantity under contract with Mr. Reid.

ABOUT QUALITY - All of my Onion Seed is grown by T. M. Reid, Port Orotova, Teneriffe, or he is having it grown under his own personal supervision, thus decreasing tremendousiy the chances of getting mixed inferior Seeds of poor germination. My Seed is pure and unmixed as to type and color. it is the finest that money, labor and brains can produce.

ABOUT PAYMENT - One=quarter cash to be paid on May ist, salarce upon arrival of Seed. Growers and dealers of established credit, draft at 8 days sight from date of shipment.

\section{Range of Prices on Reid's Genuine Bermuda Onion Seed. \\ Seed Deïivery Next August and September.}

1 ship in ORIGINAL TIN-LINED SEALED CANS containing 25, 50, 100 and 200 jbs. each. All orders for less than 25 lbs. are put 'up in bags under my own seal. You get quality, notbing but quality, all the time. No mixture,

no adulteration, nothing but strictiy pure, fresh, sound, ciean Seed.

WHITE BERMUDA.

5 lbs. and over, per $16 . \$ 2.00$

10 lbs. and over, per $1 b .1 .90$

$25 \mathrm{Ibs}$. and over, per $1 \mathrm{~b} . \$ 1.80$

50 Ibs. and over, per ib. 1.75

$100 \mathrm{lbs}$. and over, per $1 \mathrm{~b} . \$ 1.60$

$200 \mathrm{lbs}$. and over, per $1 \mathrm{~b} . \quad 1.50$

Price of RED BERMUDA the same as the White.

CRYSTAL WHITE WAX:

5 lbs. and over, per $1 b . \$ 3.00$

$10 \mathrm{lbs}$. and over, per Ib. 2.90
$25 \mathrm{lbs}$, and over, per $\mathrm{lb} . \$ 2.80$

50 lbs. and over, per $1 b .2 .75$
$100 \mathrm{lbs}$. ańd over, per $1 \mathrm{~b} . \$ 2.60$

$200 \mathrm{lbs}$. and over, per lb. 2.50

Write for Prices on Larger Quantities.

Date

191

Shipping Instructions :

Signature

P. $O$

State

This sale is based upon the expectations of an average crop, and Chris. Reuter is not obligated for quantities in the event of unforeseen disasters to Mr. Reid's growing crops or wai ehouses.

Chris. Reuter gives no warranty, express or implied, as to the description, purity, productiveness or any other matter of any seeds or sets he sends out, and he will not be in any way responsible for the crop. 


\section{Reuter's Special Quotation Request}

CHRIS. REUTER, Seedsman, New Orleans, La.

Dear Friend - Please send to me at once your very lowest price on the list of Seeds I give below. I want you to quote me your best prices and also tell me frankly whether you believe the Seeds should be shipped by freight or express, and also tell me as near as you can what the probatle cost of delivery will be. It is understood and agreed that in requesting these quo tations I am under no obligation to order same, and that this request is entirely for my own information as to prices and cost of delivery.

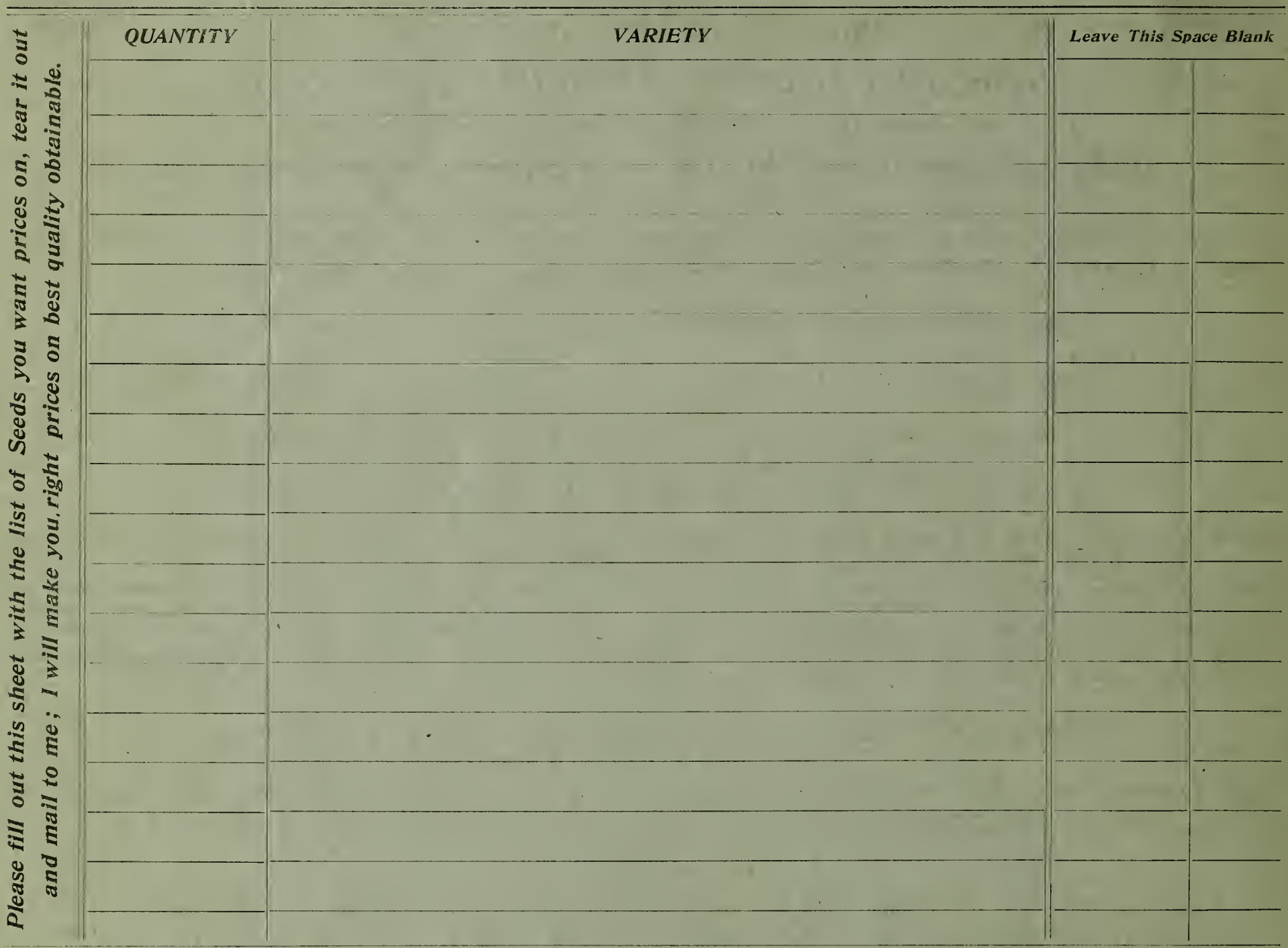

Please answer these questions. It will help ME to help YOU.

Do you grow for market or home use?

How large is your farm?

Do you raise field crops?

Do you raise live stock?

Have you a silo?
What are your principal crops?

Do you contemplate planting other crops?

If so, what?

Can my Service Bureau help you?

If so, write me FREELY.

Whether you send me an order or not, I want you to make use of my SERVICE BUREAU. If there's anything you fail to understand, don't be a bit afraid to ask me questions. I can always give you advice or directions about any special crop you are now growing or that you intend planting. I get hundreds and hundreds of letters every year from people who ask me all kinds of questions. And, don't forget that all the time I am selling Seeds that are better than you can buy elsewhere, no matter how much you pay.

Please write plainly in the blank spaces below.

\section{Your name}

P. $\boldsymbol{O}$.

County

R. F. D.
I am on the

Railroad

My Express Office is

The name of the Nearest Freight Station is 


\section{WHAT FARMOGERM IS.}

Farmogerm is a pure culture, or growth of nitrogen=fixing bacteria that have been selected and bred up to trans= form large amounts of nitrogen from the air into soluble nitrates. These bacteria are grown in a jelly, or food, in which they remain active for long periods of time, and sent out in a bottle which admits the necessary supply of pure air, yet keeps out destructive contaminations. If alfalfa can be grown on hot, sandy land of South New Jersey, why can't you grow it?

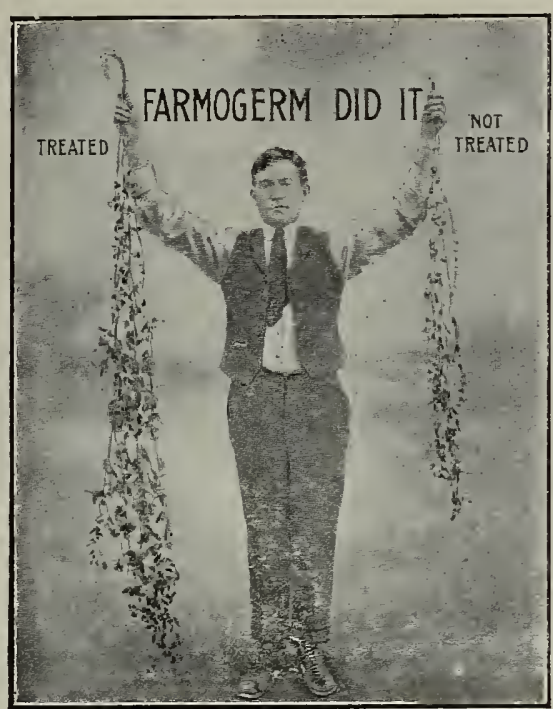

WHAT FARMOGERM WILL DO.

Unless the soil is very acid or wet, Farmogerm will:

1. Increase the yield and quality of legume crops, giving quicker growth and earlier maturity.

2. Increase the food value of legumes.

3. Make legumes grow in new localities where they cannot otherwise be grown successfully.

4. Supply nitrates to other crops growing with the inoculated legume crop.

5. Enrich the soil for future crops, thereby increasing the permanent value of the farm. Better crops-better soilless fertilizer-less labor.

\section{THE STANDARD INOCULATION}
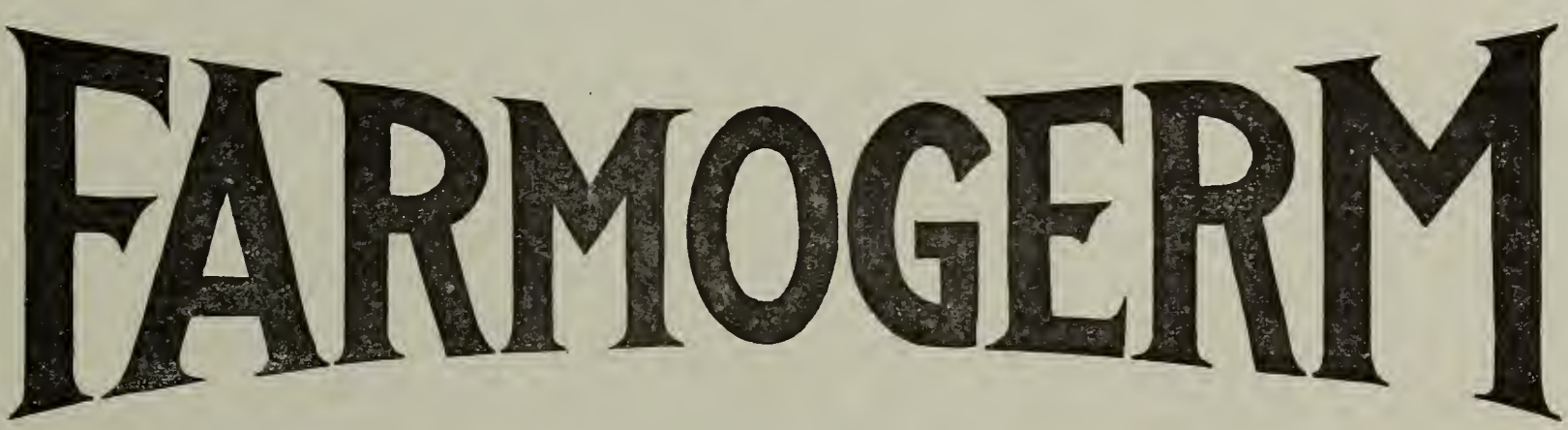

\section{HIGH BRED OXYGEN GATHERING BACTERIA}

\section{INCREASED CROPS}

are a well established certainty in all instances where inoculations are used together with proper culture methods. Not only is the crop increased in weight, but in richness. The U. S. Department of Agricul= ture, Bulletin No. 71, substantiates these statements. Why not increase your farm yields without extra labor and at practically no extra cost?

\section{FARMOGERM ON ALFALFA. LOUISIANA STATE UNIVERSITY}

College of Agriculture and Agricultural Experiment Stations.

Baton Rouge, La., Sept. 2, 1912.

Earp=Thomas Farmogerm Co.

The cultures which you sent me last year were used and gave very good results. I planted some of the Peruvian alfalfa on the station ground here, and the inoculated seed gave strong plants that lived through the Summer, while the uninoculated seed gave only weakly plants that mostly died out during the Spring mon'hs.

(Signed)

C. W. EDGERTON.

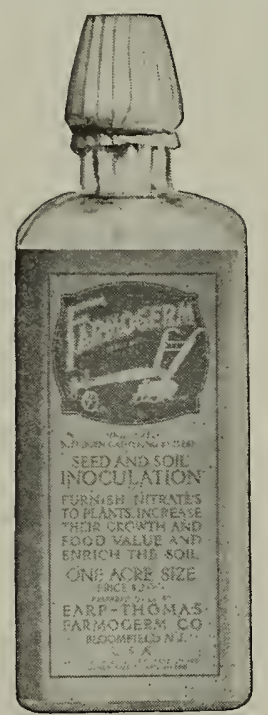

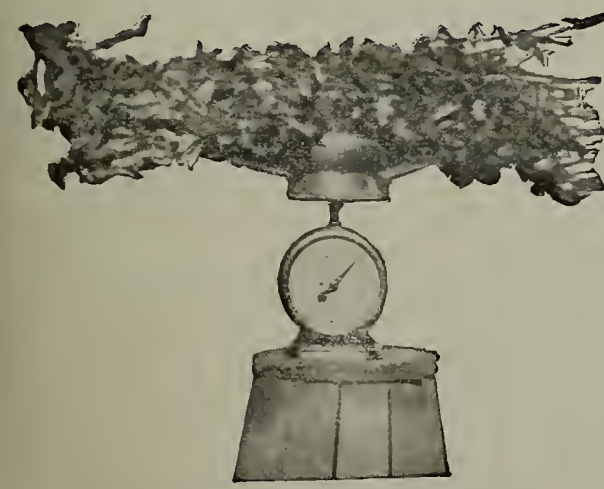

10 SOJA BEAN PLANTS NOT INOCULATED
FIELD AND GARDEN PEAS AND BEANS yisld earlier, longer and better when treated with Farmogerm. Farmogerm is endorsed by Farmers, Federal and State Agricultural Departments and Pri= vate Estates. It is delivered to you in bottles ready for use-You can inoculate the seed for ten acres in ten minntes.

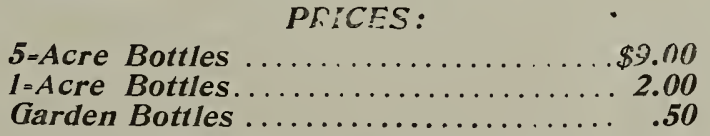

Farmogerm and Alfalfa in Maryland.

On Sept. 12, 1911, Mr. S. N. Loose, Jr., of Wash= ington county, writes as follows: In regard to results obtained by using your cultures on the Alfalfa plantea. in September of last year, I beg to say same was very satisfactory and results obtained were very favor= able.

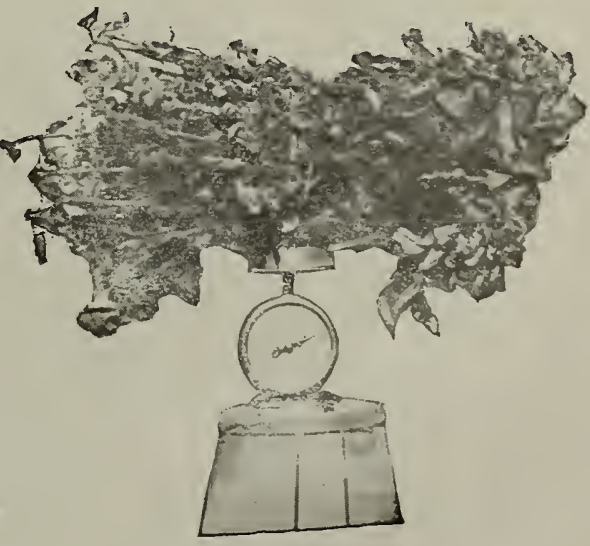

10 SOIA BEAN PLANTS INOCULATED 


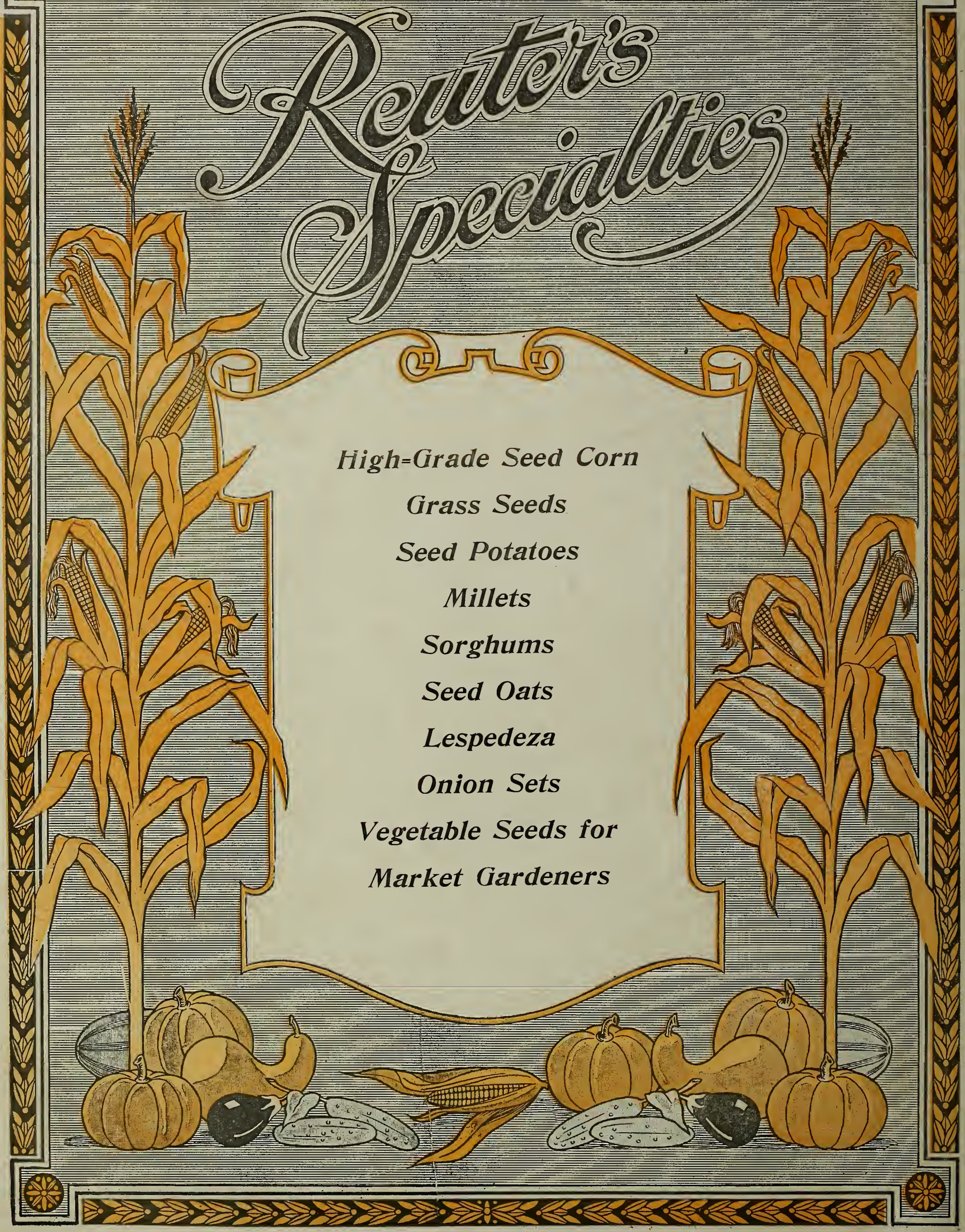

